$\mathrm{K} / \mathrm{CG}--1077 / \mathrm{V} 2$

DE93 012416

\title{
SECURITY CLASSIFICATION OF INFORMATION
}

\section{Volume 2. Principles for Classification of Information}

Arvin S. Quist

Classification Officer

Oak Ridge K-25 Site

Oak Ridge National Laboratory

April 1993

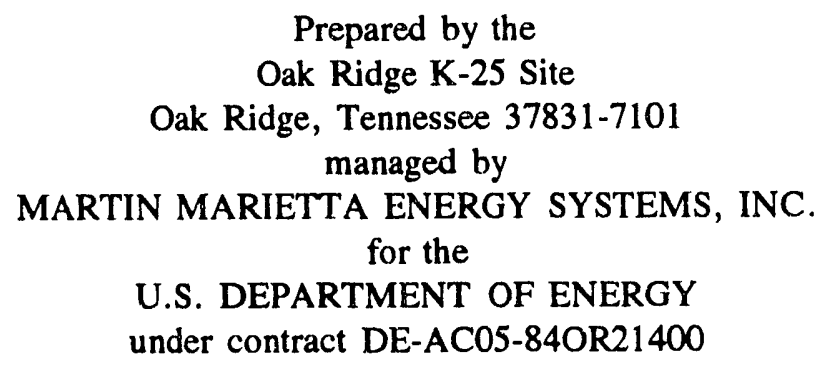




\section{CONTENTS}

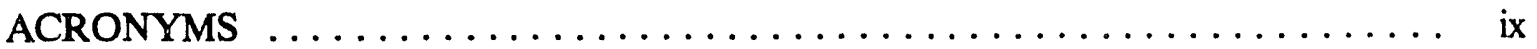

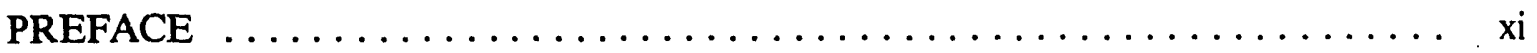

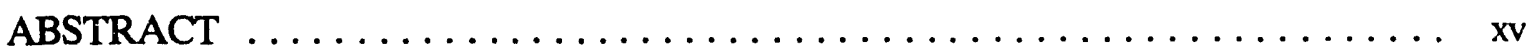

Chapter 1. INTRODUCTION $\ldots \ldots \ldots \ldots \ldots \ldots \ldots \ldots \ldots \ldots \ldots \ldots \ldots \ldots \ldots$

Chapter 2. MAJOR TYPES OF CLASSIFIED INFORMATION-

SUBJECTIVE AND OBJECTIVE SECRETS $\ldots \ldots \ldots \ldots \ldots \ldots \ldots, 5$

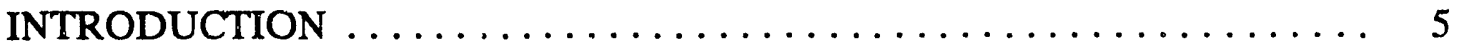

SUBJECTIVE SECRETS $\ldots \ldots \ldots \ldots \ldots \ldots \ldots \ldots \ldots \ldots \ldots \ldots \ldots, 5$

OBJECTIVE SECRETS $\ldots \ldots \ldots \ldots \ldots \ldots \ldots \ldots \ldots \ldots \ldots \ldots \ldots \ldots \ldots \ldots$

TECHNICAL INFORMATION AS AN OBJECTIVE SECRET $\ldots \ldots \ldots \ldots, 7$

SUBJECTIVE SECRETS, OBJECTIVE SECRETS, AND TRADE

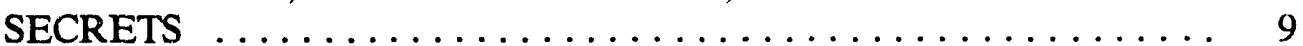

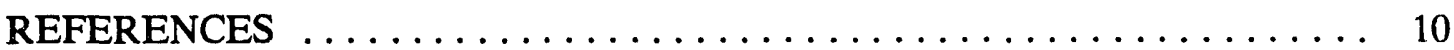

Chapter 3. CLASSIFICATION OF INFORMATION-AN OVERVIEW $\ldots \ldots \ldots, 11$

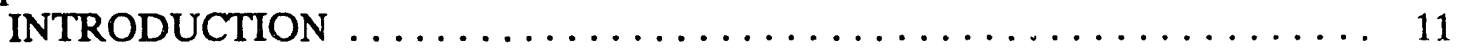

NSI, RD, FRD, AND ORIGINAL CLASSIFICATION DECISIONS . . . . . . 11

MAJOR DECISIONS IN CLASSIFYING INFORMATION $\ldots \ldots \ldots \ldots \ldots, 13$

DETERMINING WHETHER INFORMATION SHOULD BE

CLASSIFIED ............................. 13

Precisely Defining the Information to be Classified $\ldots \ldots \ldots \ldots \ldots \ldots .14$

Precisely Specifying Why the Information is Classified $\ldots \ldots \ldots \ldots \ldots .15$

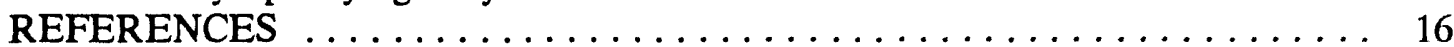

Chapter 4. CAN THE INFORMATION BE CONTROLLED

BY THE GOVERNMENT? . . . . . . . . . . . . . . . . . . . . 19

INTRODUCTION .................................. 19

DOES THE GOVERNMENT HAVE THE POWER TO CONTROL

THE INFORMATION? ......................... 19

DO ADVERSARIES ALREADY KNOW THE INFORMATION? . . . . 21

CAN ADVERSARIES READILY OBTAIN THE INFORMATION? . . . . . $\quad 24$

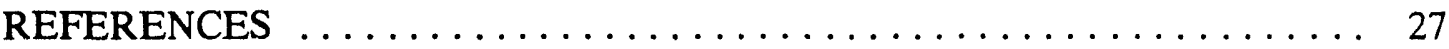

Chapter 5. INFORMATION-DISCLOSURE RISKS AND BENEFITS . . . . . . . . 29

INTRODUCTION .............................. 29

THE MEANING OF NATIONAL SECURITY AND NATIONAL

DEFENSE ............................ 30

The Meaning of National Security $\ldots \ldots \ldots \ldots \ldots \ldots \ldots \ldots \ldots \ldots, 30$

The Meaning of National Defense $\ldots \ldots \ldots \ldots \ldots \ldots \ldots \ldots \ldots, 31$ 
RISKS (COSTS) OF INFORMATION DISCLOSURE (CLASSIFICATION

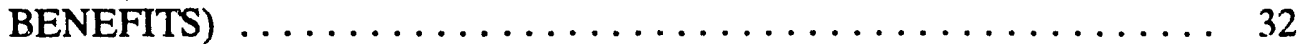

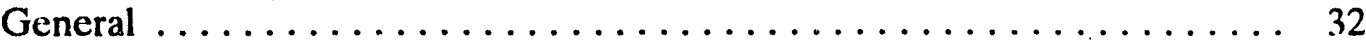

Six Criteria for Evaluating Risks of Information Disclosure $\ldots \ldots \ldots \ldots 33$

Assistance to Other Nations in Developing New Armaments . . . . . . . . 34

Assistance to Other Nations in Improving Their Armaments ........ 39

Assistance to Other Nations in Manufacturing Materials for Armaments . . . 39

Detrimental Effects on U.S. Foreign Relations . . . . . . . . . . . . . 40

Any Other National Security Impact or Significance . . . . . . . . . . . . . 40

Detrimental Effects on Classification Program Credibility . . . . . . . . . . 40

BENEFITS OF INFORMATION DISCLOSURE (COSTS OF

CLASSIFICATION) $\ldots \ldots \ldots \ldots \ldots \ldots \ldots \ldots \ldots \ldots \ldots \ldots \ldots \ldots \ldots \ldots$

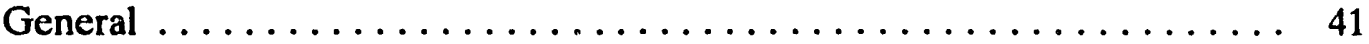

Eight Criteria for Evaluating Benefits of Information Disclosure . . . . . 41

Benefits to the Progress of the U.S. Program . . . . . . . . . . . . 42

Benefits to the U.S. Program by Eliminating Classification Costs . . . . . . 43

Benefits to General Scientific and Technological Progress ........... 45

Benefits of Technology Transfer ................... 45

Benefits to U.S. Foreign Relations . . . . . . . . . . . . . . . 45

Importance of the Information to Public Discussion and Education . . . . . 46

Any Other Significant Benefit to the United States ............ 46

Benefits to the Credibility of the Classification Program ........... 47

SUMMARY ............................. 48

REFERENCES $\ldots \ldots \ldots \ldots \ldots \ldots \ldots \ldots \ldots \ldots \ldots \ldots \ldots \ldots \ldots \ldots$

Chapter 6. BALANCING INFORMATION-DISCLOSURE RISKS

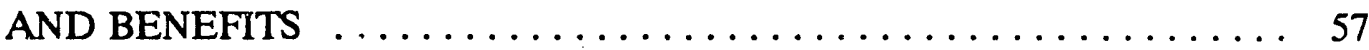

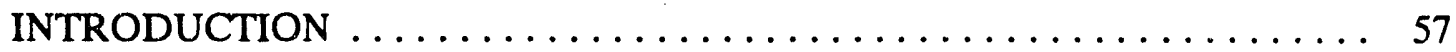

RATIONALE FOR BALANCING INFORMATION DISCLOSURE

RISKS AND BENEFITS $\ldots \ldots \ldots \ldots \ldots \ldots \ldots \ldots \ldots \ldots \ldots \ldots$

National Security Information $\ldots \ldots \ldots \ldots \ldots \ldots \ldots \ldots \ldots \ldots$

Atomic Energy Information $\ldots \ldots \ldots \ldots \ldots \ldots \ldots \ldots \ldots \ldots$

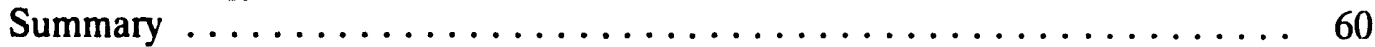

NEED FOR STANDARDS TO USE IN THE BALANCING PROCESS . . . . 61

OUR LEGAL SYSTEM'S RULES FOR WEIGHING EVIDENCE $\ldots \ldots \ldots \ldots .61$

BALANCING STANDARDS FOR DECLASSIFYING ATOMIC

ENERGY INFORMATION . . . . . . . . . . . . . . . . 64

STANDARDS FOR BALANCING INFORMATION-DISCLOSURE

RISKS AND BENEFITS $\ldots \ldots \ldots \ldots \ldots \ldots \ldots \ldots \ldots \ldots \ldots \ldots$

Proposed Standards for Balancing Information-Disclosure Risks

and Benefits ....................... 66

Presumptions in Balancing Information-Disclosure Risks and Benefits . . . 71

Weighting Factors for Information-Disclosure Risks and Benefits . . . . . . 72

Requirements for De Minimis Damage to National Security . . . . . . . . . 72

Classification of Basic Scientific Research ................ 75

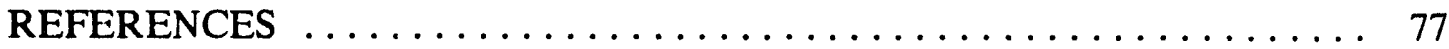


Chapter 7. CLASSIFICATION LEVELS $\ldots \ldots \ldots \ldots \ldots \ldots \ldots \ldots \ldots \ldots \ldots \ldots$

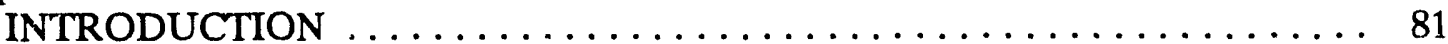

CLASSIFICATIC ${ }^{\prime}$ LEVEL DEFINITIONS AND EXAMPLES $\ldots \ldots \ldots \ldots \ldots$. 82

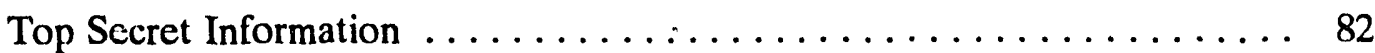

Secret Information . . . . . . . . . . . . . . . . . . . . . 84

Confidential Information $\ldots \ldots \ldots \ldots \ldots \ldots \ldots \ldots \ldots$

PRINCIPLES FOR ASSIGNING CLASSIFICATION LEVELS . . . . . . . 87

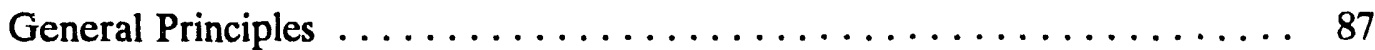

Classification Because of Effort Required to Get the Information . . . . . 89

Reasonable Doubt About Classification Level . . . . . . . . . . . . . . . . 89

CLASSIFICATION LEVELS FOR SCIENTIFIC OR TECHNICAL

INFORMATION $\ldots \ldots \ldots \ldots \ldots \ldots \ldots \ldots \ldots \ldots \ldots \ldots$

Top Secret Scientific or Technical Information . . . . . . . . . . . . . . . 89

Secret Scientific or Technical Information ................. 90

Confidential Scientific or Technical Information . . . . . . . . . . . . . 90

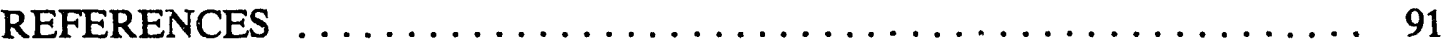

Chapter 8. CLASSIFICATION DURATION $\ldots \ldots \ldots \ldots \ldots \ldots \ldots \ldots \ldots \ldots$

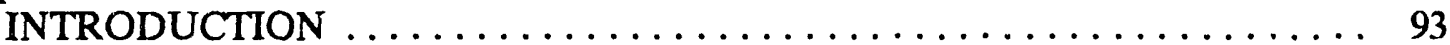

PRINCIPLES FOR DETERMINING THE DURATION OF

INFORMATION CLASSIFICATION $\ldots \ldots \ldots \ldots \ldots \ldots$

General ................................. 95

Classification Duration Defined by a Time Period ............. 97

Classification Duration Defined by an Event ............... 97

Classification Duration Based on Probability of Unauthorized

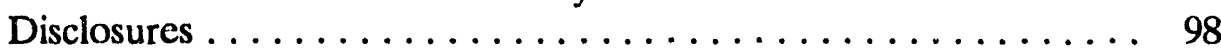

Classification Duration of Scientific or Technical Information . . . . . . . 101

REFERENCES ............................... 101

Chapter 9. CLASSIFICATION OF ASSOCIATIONS OF INFORMATION $\ldots \ldots \ldots 103$

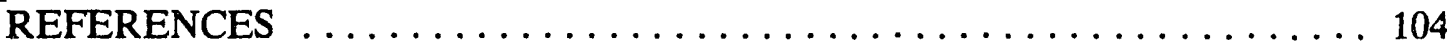

Chapter 10. CLASSIFICATION OF COMPILATIONS OF INFORMATION $\ldots \ldots 107$

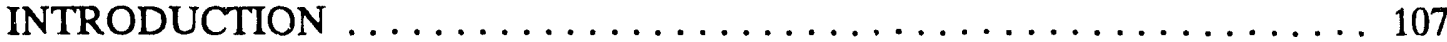

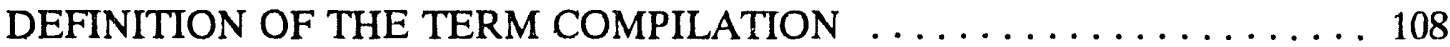

COMPILATIONS OF UNCLASSIFIED INFORMATION WITH NO

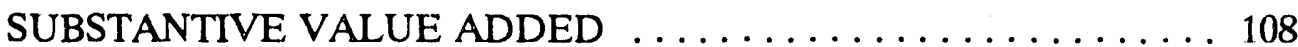

Description of Compilations with No Substantive Value Added . . . . . . . 108

Classification of Compilations with No Substantive Value Added . . . . . . . 109

COMPILATIONS OF UNCLASSIFIED INFORMATION WITH

SUBSTANTIVE VALUE ADDED $\ldots \ldots \ldots \ldots \ldots \ldots \ldots \ldots$

Description of Compilations with Substantive Value Added . . . . . . . 116

Classification of Compilations with Substantive Value Added . . . . . . . . 116

Judicial Decisions on Classification of Compilations with Value Added . . . . 116

COMPILATIONS OF UNCLASSIFIED INFORMATION REQUIRING

SUBSTANTIAL EFFORT TO COMPILE $\ldots \ldots \ldots \ldots \ldots \ldots \ldots$

CLASSIFICATION LEVEL OF COMPILATIONS OF CLASSIFIED

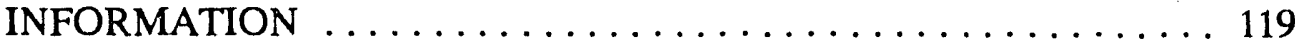




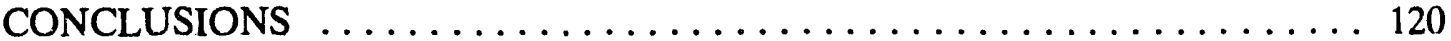

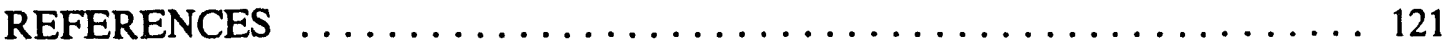

Chapter 11. DECLASSIFYING CLASSIFIED INFORMATION $\ldots \ldots \ldots \ldots \ldots 123$

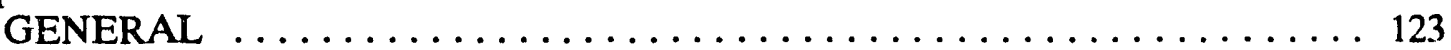

DECLASSIFICATION OF RESTRICTED DATA AND FORMERLY

RESTRICTED DATA . . . . . . . . . . . . . . . . . 123

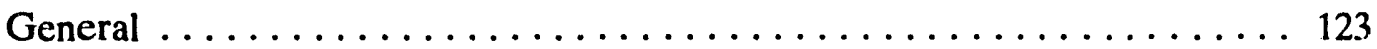

Declassification of Atomic Energy Information Under the

Manhattan Project ....................... 125

Declassification Under the Atomic Energy Act of $1946 \ldots \ldots \ldots \ldots . \ldots 128$

Declassification Under the Atomic Energy Act of $1954 \ldots \ldots \ldots \ldots . \ldots 129$

DECLASSIFICATION OF NATIONAL SECURITY INFORMATION $\ldots \ldots$.

Declassification Requirements Contained in Executive Orders . . . . . . . 135

Principles for Declassifying NSI Classified by Executive Order . . . . . . . . 137

Principles for Declassifying NSI Transclassified from RD . . . . . . . . . . . 139

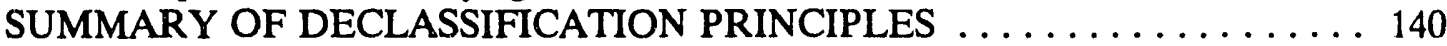

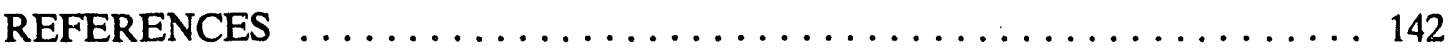

Chapter 12. DOWNGRADING CLASSIFIED INFORMATION $\ldots \ldots \ldots \ldots \ldots .145$

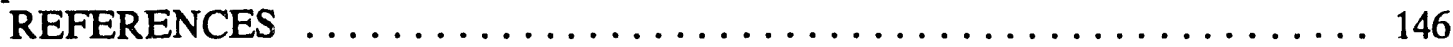

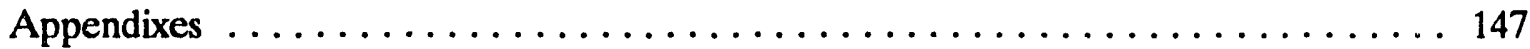

A. CLASSIFICATION OF INFORMATION PRINCIPLES AND

TRADE SECRET LAW . . . . . . . . . . . . . . . . . . . . . . 149

B. CLASSIFIABLE AREAS OF NATIONAL SECURITY INFORMATION . 167

C. CLASSIFICATION OF MILITARY OPERATIONS INFORMATION . . . . 175

D. CLASSIFICATION OF MILITARY WEAPONS INFORMATION . . . . . 179

E. CLASSIFICATION OF INTELLIGENCE INFORMATION . . . . . . . . . . . 187

F. CLASSIFICATION OF FOREIGN RELATIONS INFORMATION . . . . . . 193

G. CLASSIFICATION DURATION BASED ON THE PROBABILITY

OF UNAUTHORIZED DISCLOSURE OF THE CLASSIFIED

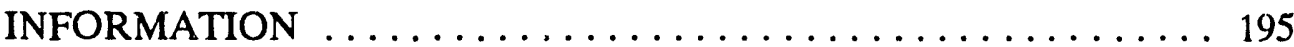


Volume 3.

CLASSIFICATION MANAGEMENT

Major topics to be discussed:

.PREPARING CLASSIFICATION GUIDES

CLASSIFICATION OF PROCUREMENT ACTIVITIES

MAKING DERIVATIVE CLASSIFICATION DECISIONS

CLASSIFICATION EDUCATION

TRAINING AUTHORIZED CLASSIFIERS

PENALTIES FOR UNAUTHORIZED DISCLOSURE OF CLASSIFIED

INFORMATION

PENALTIES FOR UNDERCLASSIFYING INFORMATION

PENALTIES FOR OVERCLASSIFYING INFORMATION

Topics of appendixes:

Classification Management in the Department of Energy

Classification Management in the Department of Defense

Classification Management in other Federal Agencies

The National Classification Management Society

Attributes of an Authorized Classifier

Volume 4.

CONTROL OF CERTAIN UNCLASSIFIED INFORMATION

Major topics to be discussed:

UNCLASSIFIED CONTROLLED NUCLEAR INFORMATION

FOIA EXEMPTIONS-OFFICIAL USE ONLY INFORMATION

EXPORT CONTROLS ON SCIENTIFIC AND TECHNICAL INFORMATION

EXPORT CONTROLS ON NUCLEAR TECHNOLOGY

OTHER UNCLASSIFIED CONTROLLED GOVERNMENT INFORMATION

INFORMATION CONTROLLED BY PRIVATE ORGANIZATIONS 


\section{ACRONYMS}

$\begin{array}{ll}\text { AEC } & \text { U.S. Atomic Energy Commission } \\ \text { AEI } & \text { atomic energy information } \\ \text { CIA } & \text { Central Intelligence Agency } \\ \text { COMSEC } & \text { communications security } \\ \text { CRD } & \text { Confidential Restricted Data } \\ \text { DoD } & \text { U.S. Department of Defense } \\ \text { DOE } & \text { U.S. Department of Energy } \\ \text { EO } & \text { Executive Order } \\ \text { FGI } & \text { foreign government information } \\ \text { FOIA } & \text { Freedom of Information Act } \\ \text { FRD } & \text { Formerly Restricted Data } \\ \text { ISOO } & \text { Information Security Oversight Office } \\ \text { MRARs } & \text { measured resource area ratings } \\ \text { NSC } & \text { National Security Council } \\ \text { NSI } & \text { National Security Information } \\ \text { NTIS } & \text { National Technical Information System } \\ \text { OADR } & \text { Originating Agency's Determination Required } \\ \text { OC } & \text { DOE Office of Classification } \\ \text { RD } & \text { Restricted Data } \\ \text { TABs } & \text { Technical Abstract Bulletins } \\ \text { U.S.S.R. } & \text { Union of Soviet Socialist Republics } \\ \text { ADC } & \text { Authorized Derivative Classifier }\end{array}$


Information is classified, that is, given a security ciassification, by the U.S. Government to identify that special information whose unauthorized disclosure could damage the national security. It is very important that classified information be correctly identified as such as soon as it comes into existence. Otherwise, the special precautions necessary to prevent its dissemination to individuals not authorized to receive it will not be implemented, one or more such individuals will probably obtain that information, and our national security will be damaged.

After it has been determined that certain information is classified and the documents or materials containing or revealing that information are appropriately marked, then security requirements to protect that information come into effect. Those subsequent security requirements, which include physical security measures, personnel investigations, and other procedures for protecting classified information while it is stored, used, and transmitted, are expensive. Accordingly, it is important to classify only information that truly requires protection against unauthorized disclosure.

Classified information can be disseminated only to those who "need to know" that information. Unnecessary classification of scientific and technical information will prevent its distribution to all scientists and engineers in the United States who could use that information. This restriction slows overall national progress in science and technology-an area upon which our national security heavily depends. Unnecessary classification also kecps the citizenry from being fully informed about matters of national significance. This restriction of information is undesirable for our nation, which has as a founding principle the right of (and necessity for) the public to be informed on governmental matters. Finally, unnecessary classification tends to decrease the actual protection for correctly classified information by lessening the credibility of (respect for) classification.

The classification of information, documents, or materials is a complex activity. It is not an exact science but requires subjective determinations (judgments) by classifiers. To reach sound classification decisions, the classifier (1) must be knowledgeable in the field in which the classification decision is made, (2) must be provided with adequate classification guidance, and (3) must understand and apply the principles of classification. A classifier generally acquires knowledge of the field in which he or she provides classification guidance (e.g., uranium enrichment technologies) by education, training, and experience. Written classification guidance is provided to a classifier in the form of classification guides. However, a classifier's knowledge of the principles of classification, and how they should be applied to reach classification decisions, is usually acquired only by self-study and on-the-job experience. There is no formal educational program for training classifiers.

A document that broadly covers the classification of information would be very helpful to classifiers in their "self-education and training" and in their preparation of classification guides. Such a document would also assist classification managers in establishing sound classification programs. To the author's knowledge, no single document, or small number of documents, provides background information on classification of information in the United 
States, describes classification principles, provides guidance in the selection and training of classifiers, presents information to aid in preparing classification guides, discusses employee classification education, and considers other important aspects of classification and of a sound classification program for an organization. This series of documents is being prepared to remedy that situation and thereby to assist classifiers in becoming better at their jobs and to help classification managers in improving their organization's classification program.

The first volume in this series, K/CG-1077/V1, Security Classification of Information, Volume 1. Introduction, History, and Adverse Impacts, issued in 1989, provides background information on classification of information in the United States. It broadly describes the need for classification, the basis for classification, and the history of classification in the United States from colonial times until World War II. Classification of information since World War II, under Executive Orders and the Atomic Energy Acts of 1946 and 1954, is discussed in some detail in Volume 1, with particular emphasis on classification of atomic energy information. Adverse impacts of classification, especially with respect to classification of scientific or technical information, are also descibed.

This present document, Volume 2, describes and discusses principles of classification, declassification, and downgrading. Future volumes will encompass the remaining topics mentioned above.

This series of documents is being written primarily from the perspective of a Department of Energy (DOE)-contractor Classification Officer. These documents will be of special interest to DOE and DOE-contractor personnel who prepare or interpret guidance for the classification of atomic energy information. However, these documents will also be useful to other U.S. Government and government-contractor employees who are concerned with information classification. The basic classification principles are the same for any government activity.

Since the main emphasis of this series of documents is on classification of information within DOE and its contractors, these documents are very much concerned with information classified as Restricted Data or Formerly Restricted Data under the Atomic Energy Act of 1954, as amended, as well as with information classified as National Security Information under Executive Order (currently Executive Order No. 12356). Further, because of the focus on DOE interests, there is considerably more discussion on the classification of scientific and technical information and material, including hardware, than on military operations information, foreign relations information, intelligence information, or other classified areas of information.

Classification in this document means security classification or classification of information based on the adverse effect that its unauthorized release would have on national security, as contrasted to classification on other bases. The qualifying term security has generally been omitted in this document, primarily for reasons of custom and convenience (one less word) but also to minimize possible confusion between the separate and distinct roles of classification and security. Security customarily means physical security. Classification personnel decide when information is classified. After that decision, and the appropriate marking of the document or other material that contains or reveals this information, security personne! become responsible for the physical protection of this information. 
The author welcomes suggestions for improvements in this document and especially solicits comments, pro or con, on the substantive aspects of the document. The author would also appreciate being made aware of additional sources of information that discuss principles of security classification of information. 


\section{ABSTRACT}

Certain governmental information must be classified for national security reasons. However, the national security benefits from classifying information are usually accompanied by significant costs, such as those due to a citizenry not fully informed on governmental activities, the extra costs of operating classified programs (e.g., research and development programs), the extra costs of procuring classified materials (e.g., weapons), and the extra expenses to our nation when advances made in classified programs cannot be utilized in unclassified programs (i.e., when a scientific or technical advance made in a classified program has to be independently discovered in an unclassified program). The goal of a classification system should be to clearly identify that information which must be protected for national security reasons and to provide adequate classification guidance so that information not needing such protection is not classified. This document was prepared to help attain that goal.

This document is the second of a planned four-volume work that comprehensively discusses the security classification of information. The main focus of Volume 2 is on the principles for classification of information. Included herein are descriptions of the two major types of information that governments classify for national security reasons (subjective and objective information), guidance to use when determining whether information under consideration for classification is controlled by the government (a necessary requirement for classification to be effective), information disclosure risks and benefits (the benefits and costs of classification), standards to use when balancing information disclosure risks and benefits, guidance for assigning classification levels (Top Secret, Secret, or Confidential) to classified information, guidance for determining how long information should be classified (classification duration), classification of associations of information, classification of compilations of information, and principles for declassifying and downgrading information. Rules or principles of certain areas of our legal system (e.g., trade secret law) are sometimes mentioned to provide added support to some of those classification principles.

This document is expected to be particularly useful to Department of Energy (DOE) and DOE-contractor personnel concerned with the security classification of information. Classification of scientific and technical information is extensively discussed because this is of major importance within DOE. However, this volume contains a significant amount of information that will be useful to classification personnel in all federal agencies because the basic classification principles are the same for any governmental activity. 


\section{Chapter 1. INTRODUCTION}

The main purpose of this document is to comprehensively develop and describe principles for the classification of information. The classification principles of interest are those principles that guide the original classification of information, as contrasted to principles for the derivative classification of documents or materials. Original classification is a determinution that information requires protection for national security reasons and that this information is not already classified under existing classification guidance. Derivative classification is a determination that a document or material contains or reveals information already classified.

Although this document focuses on principles for the original classification of information, derivative classifiers should also find its contents interesting and useful. Many derivative classifiers help prepare classification guides, which are written records of original classification decisions. Therefore, a knowledge of classification principles, and the rationale for those principles, should assist those classifiers when they help prepare classification guides.

Classification decisions, whether original or derivative, are frequently difficult to make. Objective principles are needed to help make those decisions. Although security classification of information for national defense and foreign relations reasons (national security reasons) is an ancient practice, the basic principles that guide classification decisions have never been comprehensively discussed. Existing classification principles need to be explicitly identified, explained, and compiled so that classifiers can be aware of them, can understand them, and can use them to make effective and consistent classification decisions. Additional classification principles need to be formulated because existing principles do not ensure that all matters pertinent to classification decisions are considered when those decisions are made. This document was prepared to comprehensively discuss existing principles for classification of information and to describe some proposed new principles.

Although classification of certain information by our government is necessary for national security reasons, such withholding of information from the public is to some extent at variance with our nation's fundamental principle of having a public informed about all governmental activities. Therefore, it is especially important that a system of classification-of-information principles have a solid foundation and framework so that information is classified only when necessary. To the author's knowledge, such a foundation has not yet been described. Such a foundation needs to be proposed; this document attempts to describe such a foundation.

To develop a foundation for the security classification of information, this author found it reasonable to examine some other fields of knowledge, analogous to classification of information, for rules or guidelines that might be similar to classification principles. If that other field has been long established, with rules that have survived rigorous debate and that have their roots deep in our culture, then one can be reasonably confident that those rules are soundly based. If some classification principles are similar to some of those rules, then one can be reasonably confident that those classification principles are also soundly based. 
Further, an examination of the other field of knowledge might also provide insights that would lead to new classification principles.

Trade secret law is a field of knowledge that is analogous to classification of information, especially to the classification of scientific and technical information. Trade secret law is a particularly useful field from which to draw analogies because our legal system has an especially firm foundation. Therefore, classification principles that are similar to legal principles should be very reliable.

Since analyzing trade secret law as a possible foundation for or support of classificationof-information principles is somewhat outside the main purpose of this document, that analysis has been relegated to Appendix $A$, which provides a discussion of the many similarities between trade scc:et law and classification of information and, more importantly, describes some rules of trade secret law that are analogous to certain classification of information principles. Later chapters of this document mention those trade secret law rules to provide support for existing and proposed classification principles.

This volume's comprehensive discussion of classification of information principles starts in Chapter 2 with a description of the two major broad types of classified informationsubjective secrets and objective secrets. Unfortunately, not much has been written about broad types of classified information since shortly after the end of World War II. At that time, scientists and others were concerned about the continued extensive classification of much scientific or technical information that had been generated during that war. In particular, there were intense discussions about how much and what kind of atomic energy information should continue to be classified. Chapter 2 summarizes the published knowledge on the major broad types of classified information. It is hoped that this presentation will stimulate more discussion about characteristics of the major types of classified information.

Chapter 3 presents an overview of classification of information, including a discussion of the differences between National Security Information and classified "atomic energy information." That chapter mentions the major decisions that need to be made to determine whether information should be classified and outlines the steps that need to be taken to reach those decisions.

The heart of this document is contained in Chapters 4 through 6. The primary objective of those chapters is to describe three major steps which must be carried out when deciding whether information should be classified. Those steps are (1) determining whether information under consiueration for classification is or can be controlled by the government (Chapter 4); (2) determining the risks and benefits of information disclosure (the benefits and costs of classifying information) (Chapter 5); and (3) balancing information disclosure risks and benefits to establish whether disclosure of the information could, on balance, damage the nation (Chapter 6).

Chapter 5 proposes six criteria for evaluating information disclosure risks and eight criteria for evaluating information disclosure benefits. Elements of each criterion are discussed. Chapter 6 gives an extensive rationale for incorporating a risk-benefit balancing process into classification decisions. This balancing process, which has always been an essential part of declassification decisions on atomic energy information (Restricted Data and Formerly Restricted Data), does not appear to be widely used for making classification 
decisions for National Security Information, the other category of classified information. Such balancing should be a required step in making all classification (and declassification) of information decisions. Chapter 6 also includes some proposed standards for balancing information disclosure risks and benefits. Those standards are based on atomic energy information declassification standards and on rules of our legal system for weighing evidence in civil and criminal trials.

The classification level of information (Top Secret, Secret, or Confidential) and the duration of classification of information are described in Chapters 7 and 8, respectively. The little guidance existing for determining classification levels is summarized in Chapter 7, and some new guidance is proposed. Chapter 8 , in addition to generally discussing principles for determining the duration of classification of information, also proposes that in some instances the estimated duration of classification might be based on the number of people who know the classified information. This proposal is extensively discussed in Appendix $G$. The equation derived in Appendix $G$ for estimating the probability of unauthorized disclosure of classified information might be very useful in assessing vulnerabilities in information security programs for classified projects.

Classifying information because of its association with other information is described in Chapter 9. The principles to be used in those classification decisions are relatively straightforward and are widely accepted. However, there is extensive disagreement among classifiers on whether compilations of unclassified information should sometimes be classified and whether compilations of many items of information classified at one level (e.g., Confidential) should sometimes be classified at a higher level (e.g., Secret). Chapter 10 discusses classification of compilations in detail and proposes some rules to be used in those situations.

Throughout most of this document the discussions are about classification of information. Since principles for declassifying information are quite similar to principles for classifying information, it should be understood that, in general, those discussions could equally apply to declassification of information situations. Also, principles for downgrading information (i.e., reducing its classification level) are similar to principles used to determine the classification level of classified information. The last chapters of this document discuss principles for downgrading and declassifying information.

The major classification area of interest throughout this document is on scientific or technical information, regardless of whether the classified information is Restricted Data, Formerly Restricted Data, or National Security Information. Although this is only one area of classifiable information, it is the area of most interest to the author. It is also the area of most interest to contractors to the Department of Energy and the Department of Defense. However, as a matter of general interest and to provide some insight into classification principles used for other classifiable National Security Information areas, brief discussions on the classification of those other areas are included as appendixes to this document. 


\section{Chapter 2. \\ MANOR TYPES OF CLASSIFIED INFORMATION- SUBJECTIVE AND OBJECTIVE SECRETS}

\section{INTRODUCTION}

Before starting a detailed discussion of classification principles, it is useful to describe the characteristics of the two major broad types of information that a government may want to classify-subjective and objective information. So far as the author knows, those iwo types of classified information were first described (as "operational" information and "scientific" information) in some detail by L. N. Ridenour ${ }^{1}$ in 1945 . Ridenour also mentioned a third type of information that governments classify - "technical" information. However, technical information and scientific information are considered, in this document, to be subsets of objective information.

The following two sections of this chapter describe the characteristics of subjective and objective secrets. The third section discusses why technical information is included, along with scientific information, in the category of objective secrets. The last section of this chapter discusses why trade secret law includes only objective secrets and does not encompass subjective secrets.

\section{SUBJECTIVE SECRETS}

One major type of information that a government sometimes classifies is unique to the government in the sense that the government has decided to conduct its affairs in a certain way. So long as the government effectively controls and protects the information about that decision, that information cannot be independently discovered by an adversary. Examples of unique (subjective) information are a government's specific military plans to invade another country (e.g., the time and place of the invasion) or a government's foreign policy about a particular international situation. When subjective information is originated, an adversary does not have that information. The adversary cannot independently generate that information. Subjective information, if properly controlled and protected, cannot be obtained by another country except through espionage or through unauthorized (either inadvertent or deliberate) disclosures of that information. This type of information has also been characterized as a "true secret. ${ }^{2}$ L. N. Ridenour designated this type of information as "operational" information ${ }^{3}$ (an operational secret). It is better characterized as subjective information or a subjective secret. This type of information is said to have the following characteristics: ${ }^{1}$

1. Compactness. The secret can be told in only a few words (e.g., the time and place of an invasion). This feature makes the secret easy to steal and easy to transmit.

2. Almost universally understandable (special expertise is not required to understand the secret). Therefore, anyone can steal the secret. 
3. Arbitrary. An adversary needs to steal it to obtain it. The secret cannot be independently discovered.

4. Subject to change. The secret can be changed at (nearly) the last moment. If a nation learns that an adversary has discovered the time and place of an invasion, that time and place can be changed.

5. Perishable over the short term (short-lived as a secret). When an invasion begins, the adversary learns the secret. The secret has been "made public." This also means that the secret needs to be kept for only a limited time-the stringent security measures required are not permanent.

The term "subjective information" will be used throughout this document to describe this type of information.

\section{OBJECTIVE SECRETS}

Another type of information that a government may want to classify is information which, even though discovered, developed, or controlled by that government, may be already known to or can be independently discoverable by another country. Scientific information (e.g., "scientific secrets" ${ }^{3,4}$ ) is included in this type of information. For example, the number of neutrons produced when a $U-235$ nucleus fissions, which is an important parameter that must be known when evaluating whether an atomic bomb is possible, can be discovered by competent scientists who have the proper materials and equipment. This type of information cannot be absolutely controlled. Scientific information is a fact of nature, not a secret. ${ }^{\dagger}$ Scientists in other countries can independently make the same or similar scientific discoveries through their own efforts. This type of information may also be termed "objective" information or an objective secret. The characteristics of this type of information are said to be as follows: 5

1. Diffuse. Usually there are no "magic" formulas. Lengthy reports are generally required to describe scientific information. Therefore, "scientific secrets" generally are not easy to transmit.

2. Usually understandable only by other scientists.

"A good illustration of the difference in a "true" secret (operational secret) and a "scientific" secret was given by L. N. Ridenour during his appearance before a special Senate committee on atomic energy in February 1946. He used the following examples to distinguish between those two types of secrets:

The use of the word "secret" for the results of scientific investigation or the findings of engineering is genuinely misleading. Let me illustrate what I moan. If I say, "I am thinking of a number, but I shall keep it a secret," I have used the word "secret" in it usual sense. Apart from the possibility of my telling you the number, you have no way of knowing it or finding out what it is. On the other hand, if I say, I know the critical mass of U-235 necessary to make a bomb, and I intend to keop it secret, " I am using the word secret in an ontirely different sense. I am saying to you, not that you cannot find out what I know, but that you must find th out for yourself, without my help. This may cause you to become annoyed with me, but it cannot keep you in ignorance [L. N. Ridenour, in "Atomic Energy," Hearings Before the Special Committee on Atomic Energy, United States Senate, 79th Congress, 2nd Sess., Part 5, Feb. 15, 1946, pp. 536-537. Essentially the same information appears in the following article: L. N. Ridenour, "Secrecy in Science," Bull. At. Sci., 1(6), 3 (Mar. 1, 1946)].

t"Secrets are made by men, not by nature" [L. W. Nordheim, "Fear and Information," Bull. At. Sci, 10, 342-346 (1954), p. 346]. 
3. Not arbitrary. A "fact of nature." Others can get the answer (if they ask the right question).

4. Not subject to change. Eternal. A fact of nature has only one value.

5. Can be long-lived as a secret. Others can independently discover the information, but such discovery may require much effort. Therefore, this information may be kept secret for a relatively long period of time.

The term "objective information" will be used throughout this document to describe this type of information.

\section{TECHNICAL INFORMATION AS AN OBJECTIVE SECRET}

A third type of information does not exactly fit into either the subjective (operational) or objective (scientific) categories of secrets. That third type is technical information. ${ }^{5}$ It concerns, for example, the technical design and performance of new weapons (as contrasted to the scientific basis for their design). ${ }^{1}$ Technical information has characteristics similar to scientific information in that it is diffuse and usually completely understandable only by other technical people. However, unlike scientific information, technical information is not a fact of nature. It is a method, process, technique, or device that is employed to create a product from a fact of nature. A fact of nature (scientific information) may be exploited by several methods (the details of which are technical information) to accomplish essentially the same objective. Thus, there are usually several technical solutions to the problem of how to use a fact of nature to achieve a certain result. Another difference between scientific information and technical information is that technical information is subject to change (improvements can always be made to a technical process). However, like scientific information, technical information is eternal-if the same technical procedure is always followed, then future results will be the same as those achieved in the past."

\footnotetext{
"Ridenour's 1945 article [L. N. Ridenour, "Military Security \& the Atomic Bomb," Fortune, 32, 170-223 (November 1945)] also discussed "security" of operational, scientific, and technical information, some aspacts of which are of interest to classification of these types of information. Ridenour was of the opinion that security of operational information was accomplished mainly by concealing this information (i.e., classifying and stringently protecting this information-security by concealment). However, since "scientific secrets" are facts of nature, they cannot be concealed forever from an adversary. Security by concealment was not the long-term solution. For a nation to maintain security in scientific matters (i.e., stay ahead of an adversary), Ridenour believed that "security by achievement ${ }^{n}$ was the answer. That is, he believed that scientific information should not be classified and that the United States should rely on the ability of its scientists and engineers, if they had access to all pertinent information a: could freely discuss this information with others, to keep the United States significantly ahead of its adversaries. For technical information (e.g., design of weapons), both security by concealment and security by achievement were applicable ("achievement" to get a new weapon quickly; "concealment" to ensure surprise in its first use and to reduce the application of countermeasures by an adversary).

With respect to the ability to keep secrets, Ridenour mentioned that it was to some extent easier with operational information than with technical information. Only a few people need to know operational secrets (e.g., staff planners), at least initially. However, hundreds or thousands of persons need to know technical secrets about weapons systems (e.g., the designers, manufacturers, and users of those weapons).

The "security by achievement" policy seems to have been accepted, or strongly considered for acceptance, by the Department of Defense (DoD) in 1971. A new DoD policy was to not classify scientific or technical information for technological areas in which lead time advantage was indispensable and in which the United States had a worldwide superiority. The absence of classification was expected to lead to greater interest and faster achievement of U.S. objectives, thereby maintaining U.S. superiority in that area [G. MacLain, "Updating Security Classification
} 
It was mentioned earlier in the chapter that technical information is used to exploit scientific information-that technology implements facts of nature. There are two parts to the use of technology to create a product (e.g., a weapon system). First, one has to know the technical information that can implement the scientific information. Second, one has to be capable of using that technical information; one has to have the industrial skills (know-how and hardware) and the specific materials to implement the technical information. "6ecrecy is the only way to protect scientific information. Secrecy can also protect technical information. However, other protective measures such as export controls must be used to keep an adversary from acquiring industrial skills and strategic materials. ${ }^{7}$

Although three specific types of information that a government may want to classify have been mentioned-subjective, objective, and technical-it seems that an optimum categorization would be to specify only two major types, subjective and objective, with scientific and technical information being subsets of objective information. Scientific and technical information share many characteristics with respect to classification matters, and both differ significantly from subjective (operational) information. Therefore, in this document, scientific and technical information will generally be considered, for classification purposes, as a single type of information.

In subsequent chapters, much more attention will be paid to classification of objective information (e.g., scientific or technical information) than to classification of subjective information (e.g., military operational information, foreign relations information, etc.). Scientific or technical information generally is information of a more permanent nature, is not subject to rapid change, and has lasting value, as com ared with operational information which usually is fluid, is subject to rapid change, and has transient value.

\footnotetext{
Management and its Support by DCAS Organization," J. Natl. Class. Mgmt. Soc., 7, 9-14, (1971) pp. 10-11].

"The protection of scientific and technical information can be thought of as a three-tiered process: (1) protect the scientific secret, (2) protect the technical information that exploits the scientific secret, and (3) protect the industrial skills and strategic materials that are necessary to exploit the technical information. This three-tiered process is consistent with the three classes of secrets concerning atomic energy information and the Manhattan Project that were described by General L. R. Groves in 1945 [U.S. Congress, House of Representatives, Committee on Military Affairs, "Atomic Energy," Hearings on HR 4280, An Act for the Development and Control of Atomic Energy, Oct. 9 and 18, 1945, 79th Congress, 1st Sess., 1945, Testimony of Gen. L. R. Groves at pp. 12-13]:
}

The secrets, as they are loosely termed in the public discussion, are divided properly, I think, into about three classes. One class of these secrets consists of established scientific facts which were not secret at all. . . . The second classification of secrets is the scientific developments which went beyond this, and most of those developments were not basic. They were made up of hundreds and hundreds of problems that had to be solved before this work could be done.

They involved things such as the purification of metals and the purification of other products and the handling of certain products that are not easy to handle safely. They involved all the research work, principally that which was done in many laboratories by thousands of scientists. There are other ways to do this. We hit one way. Probably there are several ways in which you can do those various items, but they require a tremendous amount of work.

This could undoubtedly be achieved by other nations if they spend the money, the labor, and the time and have the scientific organization with which to do it. In time they can, of course, do it. It is merely a case of relative speed. ...

The other class of secret, which is the biggest field, is the ingenuity and the skill of the American worker and the American management, both the top management and the junior management, and that is a secret that $I$ do not think any other nation has, and I do not think anyone is going to have it in a hurry. 


\section{SUBJECTIVE SECRETS, OBJECTIVE SECRETS, AND TRADE SECRETS}

Although there are two major types of classified information, subjective and objective secrets, trade secret law recognizes only one type of trade secrets-objective secrets (see Appendix A). Trade secrets include information about manufacturing processes, "recipes" for products (e.g., the formula for $\mathrm{Coca}-\mathrm{Cola}^{\oplus}$ ), and other objective information which could be discovered independently by another business. Many trade secrets are analogous to the scientific or technical information (especially technical information) that governments sometimes classify.

Subjective secrets are not generally protected by trade secret laws. Although a government will classify and protect the date on which it plans to invade another country (subjective information), a business cannot receive trade secret protection for the date on which it plans to introduce a new product. The Restatement of the Law of Torts definition of a trade secret specifically excludes this type of information:

[A trade secret] differs from other secret information in a business (se日 \$759) in that it is not simply information as to single or ephemeral events in the conduct of business, as, for example, the amount or other terms of a secret bid for a contract or the salary of certain employees, or the security investments made or contemplated, or the date fixed for the announcement of a new policy or for bringing out a new model or the like. ${ }^{8}$

One reason for the difference between trade secret law and classification rules with respect to the treatment of "sensitive" subjective information may be that businesses can effectively protect subjective secrets. Those subjective secrets usually need to be kept secret for only a relatively short time period-they relate to "single or ephemeral events" - and need to be known only by a few people. Businesses can usually keep this subjective information a secret by their own intensive information protection efforts. In contrast, the trade secrets of a business usually must be kept secret for a relatively long time period-the production processes to which they relate are used for many years-and those trade secrets eventually become known to many persons. Because trade secrets usually must be kept secret for many years and those secrets berome known to many persons, those trade secrets are more vulnerable to theft. Also, there is generally a greater economic incentive for thievery of those objective secrets, as compared with that of subjective secrets." Therefore, objective secrets need the extra protection afforded by trade secret law so that businesses depending on those trade secrets are not harmed by unscrupulous competitors who steal those secrets. Trade secret law remedies this thievery by issuing injunctions that prohibit the thief from using the trade secret or by awarding monetary damages to the injured business.

The matter of monetary damages suggests another reason why trade secret law protects objective secrets but not subjective secrets. The time and effort required to develop a trade secret can be reasonably easily quantified in monetary terms, as can its current economic (market) value. Therefore, it is relatively easy to quantify monetary damages in trade secret litigation. In contrast, it is generally relatively hard to quantify the damages of unauthorized

\footnotetext{
"One article states that "the only rational basis for distinguishing between trade secret information and other confidential business information is that the latter does not involve effort, expense, or innovation" [S. J. Davidson and P. L. DeMay, "Application of Trade Secret Law to New Technology-Unwinding the Tangled Web," William Mitchell L. Rev., 12, 579-621 (1986), p. 583].
} 
disclosures of subjective secrets such as the date of release of a new product. Legal systems generally prefer not to get involved in such ill-defined business matters, which may help explain why trade secret law does not protect subjective secrets.

For governments, drastic adverse consequences can arise from the loss of either subjective secrets (invasion dates) or objective secrets (information on new weapons systems). Therefore, governments are very interested in fully protecting both types of secrets. This protection is aided by espionage statutes and other laws.

\section{REFERENCES}

1. L. N. Ridenour, “Military Security \& the Atomic Bomb," Fortune, 32, 170-171, 216, 218, 221, 223 (November 1945), p. 171. Hereafter cited as "Ridenour, 1945."

2. W. Gellhorn, Security, Loyalty, and Science, Cornell University Press, Ithaca, New York, 1950, p. 9. Hereafter cited as "Gellhorn."

3. Ridenour, 1945.

4. Gellhorn, p. 11.

5. Ridenour, 1945, pp. 171, 216.

6. A. DeVolpi, G. E. Marsh, T. A. Postal, and G. S. Stanford, Born Secret: The H-Bomb, The Progressive Case, and National Security, Pergamon Press Inc., Elmsford, New York, 1981, p. 144. Hereafter cited as Born Secret.

7. Born Secret, p. 145.

8. Restatement of the Law of Torts, 4, American Law Institute, St. Paul, Minn., \$757, Comment (b) (1939). 


\section{Chapter 3.} CLASSIFICATION OF INFORMATION-AN OVERVIEW

\section{INTRODUCTION}

This chapter provides an overview of classification of information. The difference between the three categories of classified information-National Security Information, Restricted Data, and Formerly Restricted Data-with respect to "original" classification is discussed in the next section of this chapter. A following section briefly describes the three major actions that are required for the classification of information: (1) determining whether it should be classified, (2) determining its classification level, and (3) determining its duration of classification.

Determining whether information should be classified is the most difficult of the three major actions. Five steps should be completed to determine whether information should be classified. The final section to this chapter outlines those five steps and also describes in more detail the easiest two of those steps. Three subsequent chapters and an appendix are required for a complete discussion of the other three steps of the classification process. The other two major actions that are required when classifying information, determining classification level and determining classification duration, are described in Chapters 7 and 8, respectively.

\section{NSI, RD, FRD, AND ORIGINAL CLASSIFICATION DECISIONS}

Only three categories of classified information are currently used by the U.S. Government-Restricted Data (RD), Formerly Restricted Data (FRD), and National Security Information (NSI)." The authority for classifying information as RD or FRD comes from the Atomic Energy Act of 1954. ${ }^{1}$ The current authority for classifying information as NSI comes from Executive Order (EO) $12356 .^{2}$ RD and FRD are sometimes referred to as "classified atomic energy information" since those two categories deal solely with atomic energy information. Classified atomic energy information can be placed only in the RD or FRD categorics and cannot be placed in the NSI category. ${ }^{+3}$ All other (non-atomic energy) information that is classified by the government must be classified as NSI. The major classifiable areas of NSI are briefly discussed in Appendix B.

Only NSI can be originally classified. RD and FRD are born classified. That is, if information meets the jescription of RD or FRD as defined by the Atomic Energy Act of

\footnotetext{
"Restricted" was a category of classified information until Dec. 15, 1953. It is still used as a classification category by some foreign governments and international organizations. "Official Use Only" was a category of classified information from July 18, 1949, through Oct. 22, 1951.

There is one exception to this statement. Some atomic energy intelligence information concerning foreign countries can be transclassified to NSI [42 U.S.C. \$2162(e)].
} 
$1954^{4}$ and if that information has not been declassified (or transclassified to $\mathrm{NSI}^{5}$ ), then that information is RD or FRD. No classification action is required-only a determination by the Department of Energy (DOE) Director of the Office of Classification (OC) that the information fits within the Atomic Energy Act's definition of RD or FRD. ${ }^{* 6}$ In contrast, an original classifier-a government employee specifically given original classification authority-must make an affirmative decision to classify information as NSI. ${ }^{\dagger}$

Since RD and FRD are born classified, one might ask why a classifier who is mostly concerned with atomic energy information needs to understand classification principles. The response is that all classified information must be periodically reviewed for possible declassification, ${ }^{7}$ and declassification of information, whether NSI, RD, or FRD, involves most of the same principles as classification of information. The DOE OC relies on advice from DOE and DOE-contractor classification officers and their staffs to help decide whether to recommend to the DOE Director of Security Affairs (to whom the Secretary of Energy has delegated the authority to make declassification decisions) that certain atomic energy information should be declassified. Therefore, persons who are primarily concerned with atomic energy information will sometimes provide declassification advice to the $O C$ and should be aware of classification and declassification principles. For "newly developed" atomic energy information, those declassification recommendations might be requested shortly after the information is discovered, to help the classifier decide whether to immediately declassify this information and thereby eliminate, as soon as possible, the costs of unnecessary classification of information.

One might also ask why classification management personnel employed by contractors who do classified work for other government agencies need to be concerned with original classification decisions since only government employees have original classification authority. The answer is the same as that given above for DOE-contractor classification personnel. Other government agencies, such as the Department of Defense (DoD), when preparing classification guidance frequently request advice from their contractor classification personnel on this guidance..$^{\ddagger}$

\footnotetext{
"There appears to be one anomaly to the "born classified" concept. That anomaly is for those methods of isotope separation that can be used to produce special nuclear materials (e.g., to enrich uranium in the U-235 isotope, an isotope useful in nuclear weapons). According to current DOE procedures, research and development on methods of isotope separation other than gaseous diffusion or gas centrifuge can be carried out on an unclassified basis until that research and development shows a "reasonable potential for the separation of practical quantities of special nuclear material." At that point, classification restrictions must be applied [Fed. Reg., 37,15393 (Aug. 1, 1972); Fed. Reg., 32, 20869 (Dec. 28, 1967)]. Thus, this area of atomic energy information is not "born classified" but is classified only when it reaches "adolescence."

${ }^{\dagger}$ Government-contractor classification personnel do not have original classification authority. DOE-contractor classification officers had original classification authority for many years. This authority was withdrawn in 1991, partly as a result of a General Accounting Office study [Nuclear Security: DOE Original Classification Authority Has Been Improperly Delegated, GAO/RCED-91-183, U.S. General Accounting Office, Washington, D.C., July 1991].

†See, for example, D. F. Rankin, "Panel-Classification in the Department of Defense Today, J. Natl. Class. Mgmt. Soc., 3(2), 80-83 (1967), p. 82; G. A. Zacharias, "Remarks," J. Natl. Class. Mgmt. Soc., 7, 14-16 (1971) p. 15; D. L. Edwards, "The Air Force Classification Process," J. Natl. Class. Mgmt. Soc., 22, 109-117 (1986), pp. 114-115; but see M. C. Anderson, "Department of Defense Overview-Information Security Program," J. Natl. Class. Mgmt. Soc., 21, 20-24 (1985), p. 23, who indicated that contractor participation in preparing classification guidance for DoD was limited because the responsibility for that guidance was the government's.
} 


\section{MAJOR DECISIONS IN CLASSIFYING INFORMATION}

The original classification of NSI requires three major decisions: (1) Should the information be classified? (2) What level of classification does it require? (3) What should be the duration of its classification?" Only the second of those decisions is strictly applicable to the classification of RD and FRD. Atomic energy information is classified by the Atomic Energy Act ("born classified"), and a classification determination by an original classifier is not required. The comparable first step for information that may be classified atomic energy information is to determine whether it falls within the Atomic Energy Act definition of RD (or FRD) ${ }^{8}$ and has not been previously declassified (or transclassified to $\mathrm{NSI}^{9}$ ). The second step, determining the classification level of the classified information, is applicable to RD and FRD as well as to NSI. The third step, determining the classification duration, is not applicable to classified atomic energy information. For both RD and FRD, the classification duration is indefinite.

Classification principles useful in making the first decision are discussed in the next section of this chapter and in Chapters 4, 5, and 6. Principles for determining classification level are discussed in Chapter 7, and principles for determining classification duration are discussed in Chapter 8.

\section{DETERMINING WHETHER INFORMATION SHOULD BE CLASSIFIED}

Determining whether information not covered by existing classification guidance should be classified as NSI generally involves five major steps:

1. Precisely defining the information to be classified (optional but recommended).

2. Determining whether the information falls within one of the areas permitted to be classified by EO 12356. ${ }^{\dagger, 10}$

3. Determining whether the information is under the control of the government. ${ }^{\ddagger 11}$

4. Determining whether disclosure of the information reasonably could be expected to cause damage to the national security. ${ }^{*},++, 12$

\footnotetext{
A derivative classifier makes three similar decisions with respect to documents or materials. (1) Should the document or material be classified because of the information that it contains or reveals? (2) What level of classification does the document or material require? (3) What should be the duration of classification of the document or material? Those decisions are all based on existing, relatively detailed (ideally), written classification guidance.

tFor atomic energy information, a comparable step is determining whether the information falls within the definition of RD or FRD and has not been declassified or transclassified to NSI.

For atomic energy information, the government does not have to control it at the time the information is discovered, developed, or created, in order to classify that information. The Atomic Energy Act gives the government the authority to classify and control that information, no matter who discovers, develops, or creates that information. Of course, the person has to be subject to U.S. law before that control can be exerted.

** Actually, the first step in a classification determination may be an order-of-magnitude estimate as to whether the information is important to national security. Only if the information seems to be important to national security would an original classifier expend the effort to go through these steps in the order given. See also Chapter 6 and the proposed de minimis classification principle.
} 
5. Precisely specifying why the information is classified (optional but recommended).

As noted above, Steps 1 and 5 are optional. Step 1 is necessary to ensure that the scope of a classification determination is well defined and that its boundaries are well established. Step 5 is necessary to ensure that the rationale of the classification decision can be readily understood by the derivative classifiers who will subsequently apply this classification guidance to a wide variety of fac. situations. Knowledge of that rationale will assist those derivative classifiers in reaching correct classification decisions. Knowledge of that rationale will also help ensure that different derivative classifiers reach consistent derivative classification decisions. Therefore, Steps 1 and 5 are strongly recommended. ${ }^{\circ}+, 13,14$

Since Steps 1 and 5 are optional and since they require less discussion that the other three steps, for convenience they will be discussed in the following subsections of this chapter. The determination required by Step 2 (whether the information falls within a classifiable NSI area as defined by EO 12356) is relatively straightforward and will not be further discussed. For convenience, the ten classifiable areas of NSI and a brief description of each are given in Appendix B. Steps 3 and 4 are the subjects of Chapters 4, 5, and 6.

\section{Precisely Defining the Information to be Classified}

The information requiring protection should be described in clear, precise language. This classification guidance should leave no doubt about exactly what information is classified and what information is unclassified. ${ }^{15}$ "All written guidance must communicate the same ideas to all users. ${ }^{n, 16}$ Ambiguities in classification guidance will subsequently cause difficulties for derivative classifiers when they try to reach derivative classification decisions based on that guidance. The value of this step is supported by trade secret law, wherein trade secrets are said to be more likely to be given the protection of trade secret law if they are well defined (see Appendix A).

The importance of specifically indicating the information that is unclassified as well as specifying the information that is classified was recognized during the early days of the Atomic Energy Commission (AEC). Because all atomic energy information is "born classified," and because few declassification actions were implemented in the first years of the AEC, it was difficult for scientists working in atomic energy fields to be certain about what information in their fields was not classified. Therefore, it was recommended that the AEC "publish explicit and detailed catalogues of types of data not included in the restricted category," thereby relieving those scientists "of the intolerable fear that publication of every research finding is a violation of the [Atomic Energy Act of 1946]. ${ }^{.17}$

\footnotetext{
HSuch a determination is not required for RD or FRD. The Atomic Energy Act presumes that the unauthorized disclosure of atomic energy information that has not been declassified will cause undue risk to the common defense and security.

Steps 1 and 5 are also applicable to the classification (identification) of RD and FRD.

TMaking original classification decisions is analogous to establishing legal precedents. Therefore, most of the reasons for including Steps 1 and 5 in the classification decision process, as given above and in the following subsections of this chapter, are very similar to the reasons why appellate courts of our legal system provide written decisions for most cases brought to them for resolution.

₹As stated by Mr. Marsh in the same article from which this quotation was taken, "Any rules or guidance that can be misunderstood will be misunderstood." This might be considered one of Murphy's Laws of Classification.
} 
A goal sometimes urged by managers of a classified program or project is that the classification guidance for the project be prepared as unclassified so that it can be easily and widely distributed. However, unclassified classification guidance is usually too generalized. ${ }^{18}$ For example, a guide may state that the operating speed of an aircraft is classified but does not indicate the value for that speed. Even worse is when a guide states that significant advances in technology are classified and does not indicate what constitutes a significant advance in that technology. ${ }^{19}$ Generalization in classification guidance usually leads to many problems. Generalized guidance is ambiguous, requires additional interpretation, and causes mistakes in applying that guidance (either underclassification or overclassification). Precisely defining the information to be classified usually requires, at least with respect to scientific and technical areas, that the classification guidance be classified.

\section{Precisely Specifying Why the Information is Classified}

There should be a definite, identifiable reason or rationale for classifying information or materials. ${ }^{20,21}$ If a reason is definite, then it should be expressible. If a reason cannot be expressed or can only be given in vague terms, then the information or material probably should not be classified. "Precise classification guidance is prerequisite to effective and efficient information security. ..." ${ }^{22}$ In 1970, DoD listed "lack of specific rationale as to what information should be classified" as one of three major factors in the overclassification of information. ${ }^{23}$

In the late 1970s, DOE began a program to prepare better classification guides for its nuclear weapon activities. That effort was started because numerous declassification errors occurred in the early and middle 1970s during a large-scale declassification review of several million classified DOE documents." Also, other information indicated that the then-existing classification guides for nuclear weapon activities were not adequate. ${ }^{24}$ The new guides for the DOE nuclear weapon programs attempt to specifically explain why the classified information was classified. ${ }^{\dagger}$

If specific reasons for classification actions are required, then the classifier will be required to be well informed on what he or she is doing and to carefully think through the classification decision; ${ }^{21,25}$ this will lead to a better classification decision. ${ }^{\ddagger}$ When a reason that can be examined by others is provided, erroneous reasons (bad classification decisions) are more easily identified. Indicating why specific information is classified enables others to better understand the rationale behind the classification decision. Derivative classifiers are better able to make their decisions if they know the rationale for the original classification

\footnotetext{
About 2,440,000 documents were reviewed between July 1971 and June 1975 under this Comprehensive Classification Review Program. About 1,244,000 of those documents were declassified [J. A. Griffin, “ERDA-A New Structure," J. Natl. Class. Mgmt. Soc., 11, 14-29 (1975), p. 27]. Most of those document declassification decisions were subsequently declared to be of no effect, and an additional classification review was required for those documents before they could be considered as declassified.

tConsistent with the previously mentioned first step in determining whether information is classified, the new DOE guidelines provide better definitions of the classified information and also indicate related information that is not classified.

Fne of the major reasons for DoD's 1964 decision to emphasize paragraph marking, both within DoD and DoD's civilian contractors, was a belief that such marking would require disciplined analysis and evaluation and would lead to better classification decisions [W. Skallerup, "Panel-The Executive Views Classification Management," J. Natl. Class. Mgmt. Soc., 1(2, 3, 4), 68-72 (1965) p. 71].
} 
decisions. ${ }^{26}$ Additionally, people are generally more willing to follow guidance if they know the reasons for the guidance. ${ }^{27}$ "Classification is demotivating and of questionable value when people do not understand its purpose. ${ }^{28}$ Finally, as mentioned earlier, if the classification rationale is known by derivative classifiers, there will be more consistency in subsequent derivative classification decisions that are made by different derivative classifiers.

Providing specific reasons for classification will also assist a subsequent declassification or downgrading process. ${ }^{21,29}$ Declassification or downgrading decisions are easier to make if the reason for the original classification decision is known. Those reasons should be recorded so they will not be lost when the person(s) who made the original classification decision leaves the organization. ${ }^{28}$

\section{REFERENCES}

1. Atomic Energy Act of 1954, 68 Stat. 919; 42 U.S.C. $\$ \$ 2011-2296$.

2. Executive Order 12356, Fed. Reg., 47, 14874 (Apr. 6, 1982). Hereafter cited as EO 12356.

3. 42 U.S.C. $\$ 2166$.

4. 42 U.S.C. $\$ 2014(y)$.

5. 42 U.S.C. $\$ 2162(\mathrm{e})$.

6. U.S. Department of Energy, DOE Order 5650.2B, "Identification of Classified Information," Chap. II, Part A, 84(a)(5), Dec. 31, 1991.

7. Atomic Energy Act of 1954, $\$ 142$ (a), 142(b); 32 CFR Part 2001.21(b); U.S. Department of Energy, DOE Order 5650.2B, "Identification of Classified Information," Chap. II, Part A, \$4.a(6)(d), Dec. 31, 1991.

8. 42 U.S.C. $\$ \S 2014(y), 2162(d)$.

9. 42 U.S.C. $\$ 2162(\mathrm{e})$.

10. EO 12356, $\$ 1.3(\mathrm{a})$.

11. EO 12356, §6.1(b).

12. EO 12356, §1.3(b).

13. G. MacLain, "The Road Ahead," J. Natl. Class. Mgmt. Soc., 1(1), 6-9 (1965), p. 7.

14. W. Skallerup, "Panel-The Executive Views Classification Management," J. Natl. Class. Mgmt. Soc., 1(2, 3, 4), 68-72 (1965), p. 71.

15. J. C. Cotton, "Panel-Preparation of Classification Guidance," J. Natl. Class. Mgmt. Soc., 4(2), 107-110 (1968), p. 107.

16. J. Marsh, "Workshop on Training of Classification Managers," J. Natl. Class. Mgmt. Soc., 8, 43-47 (1972), p. 47. 
17. J. R. Newman and B. S. Miller, The Control of Atomic Energy, McGraw-Hill Book Company, Inc., New York, 1948, p. 220.

18. G. M. Stephan, "Military Operational Secrecy and Classification," J. Natl. Class. Mgmt. Soc., 24, 196-199 (i988), p. 199.

19. J. W. Leonard, “Classification Management Panel,” J. Natl. Class. Mgmt. Soc., 23, 21-38 (1987), p. 35.

20. F. W. May, "Classification Futures," J. Natl. Class. Mgmt. Soc., 6, 94-100 (1970), p. 95. Hereafter cited as "May."

21. S. J. Lukasik, "Remarks, Workshop A-Lifetime Cycles for Security Classification," J. Nath. Class. Mgmt. Soc., 7, 56-58 (1971), p. 58. Hereafter cited as "Lukasik."

22. U.S. Department of Defense, Department of Defense Handbook for Writing Security Classification Guidance, DoD 5200.1-H, March 1986, p. 1-1.

23. D. O. Cooke, Department of Defense, in U.S. Government Information Policies and PracticesThe Pentagon Papers (Part 2), Hearings Before a Subcommittee of the Committee on Government Operations, House of Representatives, 92nd Congress, 1st Session, June 28 and 29, 1971, U.S. Govt. Printing Office, 1971, p. 660.

24. R. R. Fredlund, "Developments in Classification in DOE," J. Natl. Class. Mgmt. Soc., 17, 42-44 (198i).

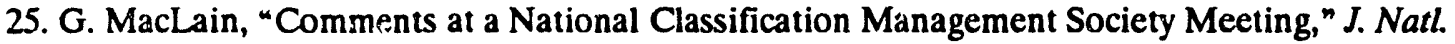
Class. Mgmt. Soc., 1(2, 3, 4), 43-44 (1965).

26. F. J. Thomas, “Remarks, Workshop A-Lifetime Cycles for Security Classification," J. Natl. Class. Mgmt. Soc., 7, 58-62 (1971), p. 61.

27. May, p. 96.

28. J. S. Foster, in Government Secrecy, Hearings Before the Subcommittee on Intergovernmental Relations of the Cormmittee on Government Operations, U.S. Senate, 93rd Congress, 2nd Session, May 22, 23, 29, 30, and 31 and June 10, 1974, U.S. Govt. Printing Office, 1974, p. 268.

29. R. C. Arnold, "Panel-Classification in the Department of Defense Today," J. Natl. Class. Mgmt. Soc., 3(2), 83-87 (1967), p. 85. 


\section{Chapter 4. \\ CAN THE INFORMATION BE CONTROLLED BY THE GOVERAYMENT?}

\section{INTRODUCTION}

Information must be under U.S. Government control before classification of that information by that government is anything other than a relatively ineffective action. Government control is the second major requirement that must be met before information can he classified (see Chapter 3 for identification of the other major requirements).

Determining whether information is under governmental control requires that three major questions be answered. First, is the information subject to governmental control when that information is within the United States? Does the government have the power to control the information, either through governmental ownership, contractual relations, or by a statute? If the government cannot control information that is under consideration for classification, then it is generally futile to classify that information. Second, do the government's adversaries already have the information? Protecting information already known to adversaries is a wasted effort. "Third, can the government's adversaries readily obtain the information by their own, independent, nonespionage efforts? If adversaries can easily obtain the information, then it is usually not cost effective to classify it. Considerations in determining the answers to these three major questions are described in the following subsections of this chapter.

In the first section, factors that determine whether information can be controlled by the government are discussed. Some of those factors are similar to those discussed in Appendix A concerning the general availability of information alleged to be a trade secret.

In the last two sections of this chapter are discussions of whether adversaries already know or can readily obtain the information under consideration for classification. Determining whether adversaries already know or can readily obtain the information that a government desires to protect is an especially troublesome problem in determining whether to classify scientific or technical information of national security significance. The last two sections of this chapter will therefore focus mainly on scientific or technical information.

\footnotetext{
"Under certain circumstances, even if the information is known to some of our adversaries, it may still be advantageous to our national security to keep the information from our other adversaries.
} 


\section{DOES THE GOVERNMENT HAVE THE POWER TO CONTROL THE INFORMATION?}

EO 12356 states that only information that is "owned by, produced by or for, or is under the control of the United States Government" can be classified." 1 If information cannot be controlled by the government, classifying that information will not stop its dissemination. For example, published information cannot be controlled by the government. Outside views of a facility (views from a vantage point accessible to the public) cannot be classified.

Information can be controlled by the government if the government owns it or can exert some legal control over it or its owner (e.g., through a contractual relationship or by a statute such as the Invention Secrecy Act of $1951^{2}$ ). Most information potentially classifiable as NSI is generated by or for the government and is therefore under governmental control when originated (e.g., military and diplomatic information). ${ }^{\dagger}$ DoD provided the following guidance with respect to classification of nongovernment research and development information:

A product of nongovernment research and development that does not incorporate or reveal classified information to which the producer or developer was given prior access may not be classified until and unless the government acquires a proprietary interest in the product. This prohibition does not affect the provisions of the Patent Secrecy Act of $1952 .^{3}$

In any event, it should be relatively straightforward to determine whether information within the United States is or can be placed under governmental control.

Some information that the government classifies is not totally under governmental control. That information may be under governmental control inside the United States but not under governmental control outside the country. Examples include foreign government information (also controlled by the providing government) and information about foreign relations activities (to the extent that it is known by other nations participating in those activities). Another example of information not subject to total control by the government is scientific or technical information. Scientific "secrets" can be discovered independently by others. Even though the government may control this scientific or technical information when it is discovered or created within the United States, other countries may independently discover the same or similar information by their own scientific and technical efforts. ${ }^{\ddagger}$

Some information not totally under government control may be controlled outside the United States by agreements with other nations. For example, shortly after World War II,

\footnotetext{
"Note that the Atomic Ener oy Act gives the government the power to control atomic energy information that is within the United States, even if someone else owns that information. Atomic energy information is "born classified" [Atomic Energy Act of 1954, 68 Stat. 919; 42 U.S.C. $\$ \$ 2011-2296$ ].

This was also true of atomic energy information (Restricted Data) during the Manhattan Project and the early years of the Atomic Energy Commission. Most of that information was generated in government facilities or under contract to the government and therefore was under governmental control when it was generated. The "born classified" concept did not cause major problems at that time.

FThis situation, where the government does not totally control certain information but nevertheless classifies that information, has its analogy in trade secret law (discussed in Appendix A). The same or similar trade secrets may be independently discovered or held by more than one company and each will be entitled to protection of their respective trade secrets. All of those companies use their best efforts to keep those trade secrets from each other and from those who do not possess the trade secrets.
} 
the United States, Great Britain, and Canada agreed to similarly classify the atomic energy information produced by their joint wartime efforts. Subsequently, those countries have generally maintained mutually consistent atomic energy classification guidance on those matters. Another example of this type of classification agreement was instituted in 1960 when the United States, Great Britain, the Netherlands, and West Germany informally agreed to control information on isotope separation by the gas centrifuge process. Agreements were even reached with the Union of Soviet Socialist Republics (U.S.S.R.) (and presumably will be reached with its successors) and other nations to control certain information and materials relative to uranium isotope enrichment technologies and other technologies used to develop nuclear weapons. The objective of those agreements is to prevent countries that do not now have nuclear weapons from developing those weapons, or at least to delay the development of such weapons in those countries. Therefore, even information not totally under government control may be effectively kept from third parties by explicit or implicit agreements between the United States and other countries. ${ }^{4}$

\title{
DO ADVERSARIES ALREADY KNOW THE INFORMATION?
}

Classifying and subsequently protecting information that is already known to adversaries is usually a waste of time and money. DOE considers the "extent to which the information has been published, publicized, or otherwise disseminated" as a major factor when evaluating atomic energy information for declassification. ${ }^{\dagger}, 5$ With respect to declassifying information on nuclear reactors, the Atomic Energy Commission's Director of Classification, J. G. Beckerley, stated in 1953 that:

As other nations develop nuclear reactors and publish data thereon, it is pointless to withhold from publication similar data developed in this country. ${ }^{6}$

DoD classification guidance also requires that the extent of an adversary's knowledge be considered:

\begin{abstract}
Classification requires consideration of the information available from intelligence sources concerning the extent to which the same or similar information is known or is available to others. . . . The state-of-the-art in other natlons may often be a vital consideration?
\end{abstract}

Therefore, in making classification decisions, the classifier must determine whether the information under consideration for classification is already available to an adversary.

\footnotetext{
"In certain circumstances it might be desirable to not publish our information, even if the adversary has published comparable information, and thereby not confirm the accuracy of the adversary's information. There might be an advantage to having the adversary be uncertain about the accuracy of his information (see infra in the next subsection). In other situations, even though an adversary may know certain information, we should not publish the information if its association with a program could reveal a use for the information that has not yet been discovered by the adversary.

This was one of the classification guidelines for preparation of the Manhattan Project's Smyth Report, where one requirement for release of information was "that it is already known generally by competent scientists. ...." [V. C. Jones, "Manhattan: The Army and the Atomic Bomb," United States Army in World War II, Special Studies, Center of Military History, United States Army, Washington, D.C., 1985, pp. 558-559, quoting from a May 21, 1945, letter from General L. R. Groves to H. D. Smyth].
} 
Determining whether an adversary already knows the information requires (1) a knowledge of the published information available to an adversary, (2) a knowledge of the unpublished and unclassified information to which the adversary might have access, and (3) intelligence information concerning information discovered and classified by an adversary.

Published information includes information that is generally available, whether or not it has actually been published in a document." Outside views of a facility are "published" and therefore cannot be classified. Destinations of shipments from a facility can be observed by the public and therefore cannot be classified. When a weapons system is deployed in the field, or tested in the open, its visible features should no longer be classified. ${ }^{\dagger}$ Classification principles in this area are very similar to trade secret law rules (see Appendix A). To paraphrase a court's statement in a trade secret case, that which is readily visible and ascertainable cannot be classified [constitute a trade secret]. ${ }^{8}$

Determining whether scientific or technical information is publicly available requires advice from an expert who has state-of-the-art knowledge in the area of interest. ${ }^{\ddagger}$ That expert should know all pertinent published information about the matter considered for classification. The expert should also know about the as-yet-unpublished information that is disseminated through personal communications between those who are at the forefront of their fields. This is particularly important with respect to scientific and technical information because there is usually a delay of many months between the time that research results are obtained and communicated informally and the time that they are published in the literature. Many more months usually elapse before those results are summarized or otherwise identified in abstracting services' publications or in computer-searchable data bases. This unpublished information is generally just as available to an adversary's experts as to our experts, since scientific and technical information is communicated by many informal methods. Consequently, an expert's advice should be sought to help determine whether certain unpublished information is either widely known or is not widely known but soon will be published or otherwise widely disseminated.

Another factor with respect to the availability of the information under consideration for classification is that this information could already be known to an adversary through his own unpublished efforts which have been kept out of normal communications channels. As mentioned above, a U.S. expert in the technical field may know, through informal communications, about recent unpublished results discovered or developed by an adversary. However, if the information concerns an area of recognized importance to a nation's security, then an adversary's recent results will probably be classified by that country and will not be

\footnotetext{
"Publish" means to declare publicly, make generally known, disclose, circulate, to impart or acknowledge to one or more persons, to proclaim officially [Webster's Third New International Dictionary of the English Language, Unabridged, Merriam.Webster, Inc., Springfield, Mass., 1986].

${ }^{\dagger}$ An example of what should not occur involved the classified external configuration of a nuclear weapon. When deployed, the weapon was externally carried on an airplane. In the field, after attaching the weapon to an airplane behind a security screen, the screen would be removed and the airplane would taxi away, thereby revealing the "classified" external configuration of the weapon. Eventually, of course, the external configuration of that weapon was declassified [J. A. Griffin, “ERDA-A New Structure," J. Natl. Class. Mgmt. Soc., 11, 14-29 (1975), pp. 14-15].

*Reasonable classification determinations cannot be made in the scientific and technical field without analysis of what has been accomplished, and what is being attempted and by whom" [U.S. Department of Defense, Department of Defense Handbook for Writing Security Classification Guidance, DoD 5200.1-1I, Sect. 3.2, p. 3-1, March 1986]. See also DoD 5120.34-11, Writing and Applying Classification Guidance, U.S. Department of Defense, Enclosure 1, Step 2, July 1968.
} 
known to a U.S. expert. Therefore, assistance from intelligence agencies must be obtained to try to determine whether the adversary may know, but has not yet disseminated, the information. $" 9$

Some scientific or technical information of national security significance may be publicly available through its use in commercial products ("dual use" technology). In recent years some advanced microelectronics technologies were used in commercial products before the government selected them for military applications. ${ }^{10}$ In those instances, by the time the advanced technology was selected for military application, it was too late for classification to be of much help in preventing the dissemination of that technology. (However, the specific application of the technology to a weapon system could be classified.)

A complication with respect to determining whether adversaries already know certain information arises when that information has been compromised by an unauthorized disclosure. ${ }^{\dagger \neq}$ A question to be answered is whether the unauthorized disclosure actually resulted in the information getting to the adversary. Information may remain classified even when there has been an unauthorized disclosure if the disclosure was only an isolated instance that did not receive widespread dissemination and therefore probably did not reach the adversary." It may even be possible to recall all documents containing the unauthorized disclosure to eliminate the possibility of further transfer of the information via those documents. ${ }^{\dagger \dagger}$ Related to this matter is the DOE policy not to comment on (i.e., neither confirm, deny, nor expand upon) statements in the open literature on classified subjects. Such comments could add credibility to speculative information. It is also DOE policy not to permit use of obscurely published or not fully documented publications as a basis for releasing confirmatory data in otherwise classified areas of research and development.

A similar situation occurs when unclassified information has been disseminated, by proper authority, within the United States (but not published) but then, later, it appears desirable

\footnotetext{
"Classification requires consideration of the information available from intelligence sources concerning the extent to which the same or similar information is known or is available to others" [U.S. Department of Defense, Information Security Program Regulation, DoD 5200.1-R, Chap. II, \$2-208, June 1986].

This is a consideration in DOE declassification decisions.

FOne of the goals of the DoD classification management program, established in 1963, was to decide what to do about the classification of information when that classified information became "a part of the public domain, either through authorized official action or through disclosures not bearing the stamp of official approval" [W. Skallerup, "Panel-The Executive Views Classification Management," J. Natl. Class. Mgmt. Soc., 1(2, 3, 4), 68-72 (1965), pp. 69-70].

** The Chicago Tribune's 1942 account of the Battle of Midway in the Pacific Ocean in World War II contained classified information that indirectly revealed that the United States had brok it the Japanese naval code. U.S. authorities were very worried that the Japanese would read this account, deduce that the United States had broken their naval code, and change that code, thereby eliminating a U.S. advantage. Fortunately, the Japanese did not become aware of this isolated unauthorized disclosure, and the United States continued to be able to read the Japanese code [D. Kahn, The Codebreakers/The Story of Secret Writing, MacMillan Publishing Co., Inc., New York, 1967, pp. 602-604)].

HExecutive Order 12356 authorizes, under certain circumstances, reclassification of previously declassified information [\$1.6(c)]. The Information Security Oversight Office procedures for implementing EO 12356 state that before reclassifying information, the following factors should be considered: the elapsed time :ullowing disclosure, the nature and extent of disclosure, the ability to bring the fact of reclassification to the atiention of persons to whom the information was disclosed, the ability to prevent further disclosure, and the ability to retrieve the information voluntarily from persons not authorized access to that information in its reclassified state [ 32 CFR Part 2001.6].
} 
to classify that information. Expert advice should be obtained concerning the extent of possible foreign knowledge of that unpublished information before the classification decision is made.

Table 4.1 summarizes what classifiers need to know about the dissemination of knowledge in a scientific or technical field before they can make good classification decisions concerning information in that field.

Table 4.1. Information needed by classifiers about dissemination of knowledge in a scientific or technical field

\begin{tabular}{|c|c|c|}
\hline $\begin{array}{l}\text { Information needed } \\
\text { by classifiers }\end{array}$ & $\begin{array}{l}\text { Source of } \\
\text { information }\end{array}$ & $\begin{array}{c}\text { Probable comprehensive } \\
\text { knowledge and accuracy } \\
\text { of this source }\end{array}$ \\
\hline $\begin{array}{l}\text { Published state-of-the-art } \\
\text { information }\end{array}$ & Experts & Very high \\
\hline $\begin{array}{l}\text { Known, but unpublished, unclass- } \\
\text { ified state-of-the-art information in } \\
\text { - the United States } \\
\text { - friendly countries } \\
\text { - unfriendly countries }\end{array}$ & $\begin{array}{l}\text { Experts } \\
\text { Experts } \\
\text { Experts and } \\
\text { intelligence agencies }\end{array}$ & $\begin{array}{l}\text { High } \\
\text { Medium } \\
\text { Low }\end{array}$ \\
\hline $\begin{array}{l}\text { Extent of foreign knowledge of the } \\
\text { unpublished unclassified state-of- } \\
\text { the-art information in the United } \\
\text { States in }\end{array}$ & & \\
\hline - friendly countries & $\begin{array}{l}\text { Experts and } \\
\text { intelligence agencies }\end{array}$ & Medium \\
\hline - unfriendly countries & $\begin{array}{l}\text { Experts and } \\
\text { intelligence agencies }\end{array}$ & Very low \\
\hline $\begin{array}{l}\text { Known, but classified, state-of-the- } \\
\text { art information in } \\
\text { - the United States } \\
\text { - friendly countries } \\
\text { - unfriendly countries }\end{array}$ & $\begin{array}{l}\text { Cleared experts } \\
\text { Intelligence agencies } \\
\text { Intelligence agencies }\end{array}$ & $\begin{array}{l}\text { High }^{a} \\
\text { Low }^{b} \\
\text { Very low }\end{array}$ \\
\hline
\end{tabular}

\footnotetext{
${ }^{a}$ Need-to-know considerations keep this from being "very high."

${ }^{b}$ Intelligence agencies generally do not "snoop" on their friends. Possibly this should be "very low."
} 


\section{CAN ADVERSARIES READILY OBTAIN THE INFORMATION?}

Classifiers must consider whether specific information under consideration for classification can readily be deduced from theory, minor experimentation, or from fragmentary information already publicly available. ${ }^{\dagger}$ "There is no point in classifying information easily deducible from the laws of physics . . ." If adversaries can readily obtain the specific information through their own straightforward, nonespionage efforts, then it may not be cost effective to classify that information. In those situations, the adverse effects that classification will have in slowing our development of a new technology may outweigh the benefits of imposing slight delays on our adversaries.

Readily obtainable information includes information that can be deduced or derived from known physical principles and information already in the public domain. It is information that follows logically from known principles and available information. Assistance from experts in the technology is needed to determine if the information can readily be deduced or estimated. If estimates can readily be made, then a further consideration is whether it is important to the adversary that these estimates are confirmed. ${ }^{\ddagger}$ Readily obtainable information also includes scientific or technical information that can be obtained with minor experimental effort. The "extent to which the information can be duplicated through simple calculations and experiments" has been used by DOE when evaluating atomic energy information for declassification. ${ }^{12}$

Reverse engineering is another procedure that can be used to deduce or estimate scientific or technical information. Reverse engineering, the process of examining a product to determine how it was made, is mentioned in the appendix on trade secrets (Appendix A). If the information under consideration for classification is embodied in a product that is available to an adversary, then expert advice is needed as to whether that information can be reverse-engineered from that product.

It may not be cost effective, in certain fields, to classify scientific or technical information even if that information is somewhat more than a normal evolutionary advance or more than a straightforward accumulation of experimental data. In some fields, certain innovations become somewhat inevitable as knowledge is accumulated and specific national needs direct attention to the solution of particular problems. ${ }^{13}$ Thus, certain scientific or technical innovations may seem classifiable but they may shortly be discovered in other countries.

\footnotetext{
" "Readily," as used here, means that the information could be obtained with relatively little effort (e.g., about a person-year or less). Considerations with respect to major expenditures of effort to get the information are discussed in the next chapter.

The ease or difficulty with which information could properly be acquired by others is a factor in determining whether that information is a trade secret (see Appendix A).

FThere may be advantages to having an adversary be uncertain about the accuracy of his or her information. Those advantages were recognized by a U.S. Circuit Court in deciding whether the government (i.e., the Central Intelligence Agency) should be compelled to reveal information about an intelligence activity under a Freedom of Information Act request. That court stated that "there may be some advantage in leaving the Soviet intelligence agencies some lingering doubts whether some other purpose motivated the project " [Military Audit Project $v$. Casey, 6.56 F.2d 724, pp. 744-74.5 (D.C. Cir. 1981)].
} 
Table 4.2 summarizes the information control criteria that must be evaluated before it can be determined whether the information under consideration for classification can be controlled to the extent required for meaningful classification of information.

Table 4.2. Information control criteria to use when determining whether information under consideration for classification can be controlled by the government

\begin{tabular}{ll}
\hline $\begin{array}{l}\text { Criterion } \\
\text { Number }\end{array}$ Information control criteria (descriptive questions) \\
\hline
\end{tabular}

Does the government have the power to control the information?

ICC1 Has the information been published? What is the published state of the art for the information in the United States and in other countries?

ICC2 Is the information obtainable by viewing from a vantage point accessible to the public?

ICC.3 Does the U.S. Government have the power to control the information within the United States by governmental ownership, by contractual relations, or by statute?

ICC4 If the information is also known to some other nations, will those other nations control that information?

Do adversaries already know the information?

ICC1 Has the information been published? What is the published state of the art for the information in the United States and in other countries?

ICC5 What is the unpublished, unclassified state of the art for the information in the United States and in other countries.

ICC6 What is the extent of foreign knowledge of the unpublished, unclassified state of the art in the United States?

ICC7 What is the classified state of the art in the United States and in other countries?

ICC8 To what extent has the information been revealed by its use in commercially available products ("dual use" information)?

ICC9 To what extent has the information been compromised by unauthorized disclosure?

Can adversaries readily obtain the information?

ICC10 To what extent can the information be obtained by other nations through simple theoretical calculations or minor experimentation?

ICC11 To what extent can the information be revealed by reverse engineering of unclassified materials?

\section{Miscellaneous}

ICC12 If the information is a scientific or technical "innovation, ${ }^{n}$ is it expected that others will shortly make the same discovery? 


\section{REFERENCES}

1. Executive Order 12356, Fed. Reg., 47, 14874 (Apr. 6, 1982), Preamble, \$1.1, \$6.1(b), §6.1(c).

2. Invention Secrecy Act of 1951, 66 Stat. 3 (Feb. 1, 1952).

3. U.S. Department of Defense, Information Security Program Regulation, DoD 5200.1-R, Chap. II, 82-204.c, June 1986. Hereafter cited as "DoD 5200.1-R." (See also DoD 5200.1-R, Chap. II, 87.)

4. A. S. Fisher, "International Aspects of Classification Management," J. Natl. Class. Mgmt. Soc., $1(2,3,4), 84-98$ (1965).

5. U.S. Department of Energy, Washington, D.C., internal document, 1987.

6. J. G. Beckerley, Director of Classification, Atomic Energy Commission, in Atomic Power Development and Private Enterprise, Hearings Before the Joint Committee on Atomic Energy, Congress of the United States, 83rd Cong., 1st Sess., on Atomic Power Development and Private Enterprise, June and July 1953, U.S. Govt. Printing Office, June 24, 25, and 29; July 1, 6, 9, 13, 15, 16, 20, 22, 23, 27 , and 31,1953, p. 36.

\section{DoD 5200.1-R, 82-208.}

8. Paraphrased from Interox America v. PPG Industries, Inc., 736 F.2d 194, 201 (5th Cir., 1984).

9. G. MacLain, "Panel-Government Classification Management Policies and Programs," J. Natl. Class. Mgmt. Soc., 2, 69-75 (1966), p. 71.

10. Panel on the Impact of National Security Controls on International Technology Transfer, Balancing the National Interest: U.S. National Security Export Controls and Global Economic Competition, National Academy Press, Washington, D.C., 1987, p. 56.

11. A. P. Stringer, "Classification Management in the United Kingdom," J. Natl. Class. Mgmt. Soc., 23, 38-43 (1987), p. 40.

12. (a) Smyth Report guidelines, 1945. See A. S. Quist, "Declassification of Atomic Energy Information," p. 64 in Security Classification of Information, Volume 1. Introduction, History, and Adverse Impacts, K/CG-1077/V1, Martin Marietta Energy Systems, Inc., Oak Ridge, Tenn., Chap. 5. (b) Tolman Committee criterion, 1945. See A. S. Quist, pp. 65-67. (c) U.S. Department of Energy, Washington, D.C., internal document, 1987.

13. R. K. Merton, The Sociology of Science, Univ. of Chicago Press, Chicago, 1973, p. 213, citing the following study, which reported on independently duplicated scientific discoverics and technological innovations: W. F. Ogburn and D. Thomas, "Are Inventions Inevitable? A Note on Social Evolution," Political Science Quarterly, 37, 83-98 (1922). 
Chapter 5.

INFORMATION-DISCLOSURE RISKS AND BENEFITS

\section{INTRODUCTION}

If information under consideration for classification is in a classifiable area and if the government can control that information, then two of the three major requirements for determining whether information should be classified have been met (see Chapter 3). The third and final requirement is met when the following question is answered affirmatively: "Should this information be classified because its unauthorized disclosure reasonably could be expected to cause damage to the national security?" This final requirement, based on Sect. 1.1(a)(3) of EO $12356,{ }^{1}$ is the most difficult to establish of the three major requirements.

The answer to the question of whether unauthorized disclosure of information reasonably could be expected to cause damage to national security is at least a two-step process. The first step is to determine whether an unauthorized disclosure could damage the national security. That step presumably also requires that the specific damage to the national security be identified. The second step is to determine whether it is reasonable to expect such damage. However, even when unauthorized disclosure of information reasonably could be expected to cause damage to the national security, it does not necessarily follow that the information should be classified. There is in practice a third step to this process-a step not mentioned in EO 12356 but a step that is generally followed by those who determine whether information should be classified. That third step balances the damage to national security which reasonably could be expected to be caused by an unauthorized disclosure against the benefit to the nation of having the information unclassified. That third and final step determines whether information-disclosure damages exceed information-disclosure benefits and thereby determines whether the information should be classified.

Balancing information-disclosure risks and benefits (classification benefits and costs) is not required by EO 12356 . That EO requires only a finding that disclosure of information reasonably could be expected to cause damage to national security before the information can be classified. EO 12356 requirements imply that if any damage to national security reasonably could be expected by disclosing information, then that information should be classified to prevent that damage from occurring. However, there are many adverse impacts to the nation that can result when information is classified. ${ }^{2}$ Information should not be classified if the costs of classification (the benefits of having the information unclassified) exceed the benefits of classification (avoiding the damages caused by disclosing the information). Therefore, in practice, both classification costs and classification benefits are usually considered when determinations are made to classify information.

\footnotetext{
"For the declassification of Restricted Data or Formerly Restricted Data, a comparable requirement is "can this information be published without undue risk to the common defense and security?" [42 U.S.C. \$2162(a)].
} 
Although EO 12356 does not require that classification benefits (preventing damage to national security) exceed classification costs (the benefits to the nation of information disclosure) before information can be classified, such a balancing procedure is a sound approach to making classification decisions. Therefore, the remainder of this document assumes that such a balancing process will be carried out when those decisions are made.

Most of the rest of this chapter is concerned with developing criteria for determining the risks and benefits to the national security of disclosing information under consideration for classification and describing factors that can be used to evaluate those criteria. Principles to use when balancing those risks and benefits will be considered in the next hapter. However, before those criteria and factors are discussed, it is important to consider the meaning of the term "national security." Focusing on what is truly meant by national security will help ensure that only damage to national security is included as an information-disclosure risk when classification decisions are made. Damages that do not directly injure the national security (e.g., damages to the general welfare of the nation) should not be considered as informationdisclosure risks. Therefore, in the following section of this chapter the meaning of the terms national security and national defense are discussed with respect to classification of information.

\title{
THE MEANING OF NATIONAL SECURITY AND NATIONAL DEFENSE
}

\section{The Meaning of National Security}

The fundamental meaning of national security is protection from physical attack by foreign nations or from the reasonable apprehension of such attack. ${ }^{3}$ In a very broad sense, national security could encompass many other factors, ${ }^{4}$ including the following:

\begin{abstract}
Current assets and national interests, as well as the sources of strength upon which our future as a nation depends . . . [These] range widely from political assets such as the Bill of Rights, our political institutions and international friendships, to many economic assets which radiate worldwide from a highly productive domestic economy supported by rich national resources. It is the urgent need to protect valuables such as these which legitimizes and makes essential the role of national security. ${ }^{5}$
\end{abstract}

However, such a definition is too broad to guide classification decisions, since classification of information should be minimized, ${ }^{6}$ and such a broad definition would result in far too much infurmation being classified.

The Supreme Court indicated, in Cole $v$. Young, that the term national security related "only to those activities which are directly connected with the Nation's safety, as distinguished from the general welfare." ${ }^{*, 7}$ National security "was intended to comprehend only those activities of the Government that are direclly concerned with the protection of the Nation from internal subversion or foreign aggression and not those which contribute to the strength

\footnotetext{
'The court's discussion of the meaning of the term national security in Cole v. Young was in connection with a 1950 statute [64 Stat. 476; 5 U.S.C. Sect. 22-1, 22-2; Act of August 26, 1950] and a 1953 Fxecutive Order [EO 10450, Fed. Reg., 18, 2489 (Apr. 29, 1953)] which allowed government employees to be dismissed for national security reasons.
} 
of the Nation only through their impact on the general welfare. ${ }^{n 8}$. Thus, the Supreme Court has adopted a relatively narrow definition of national security.

The EO 12356 definition of national security is also relatively narrow. That EO defines national security as "the national defense or foreign relations of the United States." Congress has tended to limit the meaning of national security even more than has the Executive branch. For example, the Freedom of Information Act (FOIA) exemption for information properly classified pursuant to executive order refers to matters "to be kept secret in the interest of national defense and foreign policy ${ }^{n 10}$ (emphasis added). Foreign policy is presumably a narrower field than foreign relations. Further, the FOIA exemption for confidential sources refers to records of information compiled by an agency conducting a lawful national security intelligence investigation. ${ }^{11}$ The legislative history of that confidential source exemption specifically states that "national security' is to be strictly construed to refer to military security, national defense, or foreign policy."12 However, since either foreign relations or foreign policy information is of relatively minor concern in this document, further examination of the definition of national security will be limited to the meaning of the term national defense.

\section{The Meaning of National Defense}

National defense was said by the Supreme Court in Gorin v. United States to refer to "the military and naval establishments and the related activities of national preparedness. $" \neq, 13$ This definition was given in a case involving espionage activities directed at national defense information (a matter very pertinent to security classification of information). The Court's relatively narrow interpretation of the meaning of the term national defense is consistent with the legislative history of the Espionage Act. A broad definition of national defense proposed by the House of Representatives for that Act was not acceptable to the Senate. ${ }^{14}$

A narrow view of what is encompassed by the term national defense was also adopted in another espionage case, United States $v$. Heine, where a U.S. Circuit Court stated the following:

\footnotetext{
-The National Aeronautics and Space Administration (NASA) was said to take a broad view of what constituted national security. Economic and political factors were said to be relevant to classifying information under EO 10501, a predecessor to EO 123.56 [H. G. Maines, "Panel-Government Classification Management Policies and Programs," J. Natl. Class. Mgmt. Soc., 2, 82-87 (1966), p. 85]. However, NASA's programs were mainly nonmilitary and there was relatively little NASA information that was classified.

The Atomic Energy Act of 1954 uses the term "common defense and security" in discussing the declassification of Restricted Data [42 U.S.C. \$2162(a)]. Congress considered using the term "national security" but decided to use "common defense and security" instead [C. Allardice and E. R. Trapnell, The Atomic Energy Commission, Praeger Publishers, New York, 1974, p. 140].

FThe Court actually said, in agreeing with the government's position in this case, that national defense "is a generic concept of broad connotations, referring to the military and naval establishments and the related activities of national preparedness." However, the Court's use of the words "generic concept of broad connotations" should be viewed with respect to the defendant's proposed interpretation of a section of the Espionage Act [Espionage Act of June 15,1917 , c. $30 ; 40$ Stat. 217, Title I, \$1] that it was a crime to conduct certain activities only as to places and things specifically listed in the act. The Court said that the act should not be read that narrowly. National defense was not limited to matters connected only with the specifics mentioned in the act but had a broader scope.
} 
It seems plain that the section [of the Esplonage Act] cannot cover information about all those activitles which become tributary to "the national defense" in time of war; for in modern war there are none which do not. The amount of Iron smelted, of steel forged, of parts fabricated; the number of arable acres, their average yleld; engineering schools, scientific schools, medical schools, their staffs, their students, their curriculums, their laboratories; metal deposits; technical publications of all kinds; such nontechnical publications as disclose the pacific or belligerent temper of the people, or their discontent with the government; every part in short of the national economy and overything tending to disclose the national mind are important in time of war, and will then "relate to the national defense." . . . Such an assertion of national isolationism is certainly not to be imputed to Congress.

\begin{abstract}
A less impossible interpretation would be to confine the clause to information about things adapted only for the national defense, and things of ambiguous use which have been already collected, or prepared, for the support of the armed services. The first would include airplanes, cannon, small arms and munitions of war, warships, forts, and the like; the second, coal, food, clothing or other supplies accumulated for the army and navy. 15
\end{abstract}

In a more recent espionage case, a Circuit Court cited with approval the following jury instructions on the meaning of national defense:

\begin{abstract}
And that term, the term national defense, includes all matters that directly or may reasonably be connected with the defense of the United States against any of its enemles. It refers to the military and naval establishments and the related activities of national preparedness. ${ }^{16}$
\end{abstract}

In summary, the meaning of the term national defense should be given a relatively narrow construction consistent with the judicial decisions in United States v. Heine and Cole $v$. Young. Therefore, when evaluating damage to the national defense caused by information disclosure, the damage under consideration should be limited to that damage reasonably and directly related ${ }^{17}$ to those national activities concerned with protecting U.S. citizens and U.S. property from physical attack or the reasonable apprehension of such attack.

\title{
RISKS (COSTS) OF INFORMATION DISCLOSURE (CLASSIFICATION BENEFITS)
}

\section{General}

Before information can be classified as NSI, it must be determined that disclosure of that information reasonably could be expected to damage the national security. ${ }^{18}$ In three NSI areas (see Appendix B for a discussion of all ten NSI areas), the unauthorized disclosure of information is presumed to cause damage to the national security. Those three areas are (1) foreign government information (NSI area 3), (2) the identity of a foreign confidential source (included in NSI area 9), and (3) intelligence sources or methods (included in NSI area 4). ${ }^{19}$ Information is automatically classified if it falls within one of those three areas. Balancing the costs and benefits of classifying that information is not necessary. If

\footnotetext{
"For an extensive discussion of the meaning of national defense and of other matters concerned with our espionage statutes, see H. Edgar and B. C. Schmidt, Jr., "The Espionage Statutes and Publication of Defense Information," Columbia L. Rev., 73, 929-1087 (1973).
} 
information falls within one of those three NSI areas, then it is necessary only to determine the classification level and duration of that information.

For the other NSI areas (areas 1, 2, 4 through 8, and 9), the damage to national security by disclosing the information must be determined before a classification decision is made. In those areas. it is frequently obvious that releasing certain information will help an adversary and thereby cause damage to national security. For example, if an adversary knew the details of one of our important new weapons, then that adversary could develop that weapon for its own use or could devise effective countermeasures, thereby negating the weapon's advantage. Knowledge of our battle plans or detailed military strategies would aid our adversaries in planning their military strategies. Similarly, we would obviously be at a disadvantage in our foreign relations with a nation if that nation knew our diplomatic negotiating strategies or the keys to our cryptographic codes. However, there are other circumstances where it is not obvious that releasing certain information will damage our national security and guidance is helpful in evaluating the risks to national security.

The following discussions on evaluating risks to national security caused by disclosure of the information under consideration for classification will focus on scientific or technical information (NSI area 6 and atomic energy information). Risks to the national security of disclosing information concerning NSI areas 1,2, 4, and 5 are discussed in Appendixes C through F. Appendix B includes a brief discussion of such risks in some of the other NSI areas.

It should perhaps be mentioned that EO 12356 specifically identifies circumstances when information shall not be classified (i.e., it describes certain "benefits" of classification that shall not be considered as benefits). EO 12356 states that "in no case shall information be classified in order to conceal violations of law, inefficiency, or administrative error; to prevent embarrassment to a person, organization, or agency; to restrain competition; or to prevent or delay the release of information that does not require protection in the interest of national security. $" 20$

\section{Six Criteria for Evaluating Risks of Information Disclosure}

Six basic criteria for evaluating the risks to the national security of scientific or technical information disclosure have been established by DOE. Although those criteria were developed for evaluating declassification actions (for evaluating the risks of declassifying information), they are also applicable to classification actions (for evaluating the risks of not classifying information). The six DOE criteria, ${ }^{21}$ revised so that they are not specific to atomic energy information, are as follows:

- Assistance to other nations in developing new armaments

- Assistance to other nations in improving their armaments

- Assistance to other nations in producing materials for armaments

\footnotetext{
Note that, according to the Atomic Energy Act, Restricted Data is presumed classified. Information need only meet the definition of Restricted Data and it is classified by the Atomic Energy Act. That act essentially presumes that the unauthorized release of Restricted Data (and Formerly Restricted Data) would cause "undue risk to the common defense and security." See 42 U.S.C. $\$ 2162(a)$.
} 
- Detrimental effects on U.S. foreign relations, arms control negotiations, or treaty obligations

- Any other national security impact or significance

- Detrimental effects on classification program credibility

These criteria seem to encompass all the risks that need to be evaluated when one determines whether to classify scientific or technical information." No other major criteria have so far been identified by the author. The following subsections will discuss using those six major criteria to determine the damage to national security caused by information disclosure.

\section{Assistance to Other Nations in Developing New Armaments}

How adversaries may be assisted. Our adversaries may be helped in several ways if certain scientific or technical informatior important to our national security is not classified. ${ }^{\dagger, f}$ That information may provide the following types of assistance to those adversaries:

1. Indicating technology areas that could provide significant national security advantages. Those are areas where we are the first to recognize a national security application of a technology (e.g., when a significant technological advance-a breakthrough-occurs). By classifying the information, we buy lead time, the time to develop that application before it is developed by an adversary. ${ }^{*}, 22$ Sometimes, even the fact that we are interested in a technology area should be classified so that an adversary is not alerted to a potentially advantageous area of

\footnotetext{
-The Manhattan Project's Tolman Committee, established in 1945 to make recommendations on the declassification of atomic energy information developed in that project, used the following "negative" criteria (risks of declassification) for reviewing information for declassification. Items 1 and 2, below, are essentially the same as the first four DOE criteria:

1. Disclosure would jeopardize U.S. military security.

2. Disclosure would weaken U.S. position in international discussions.

3. Disclosure would jeopardize [the U.S.] patent position.

[R. C. Tolman, R. F. Bacher, A. H. Compton, E. O. Lawrence, J. R. Oppenheimer, F. H. Spedding, and H. C. Urey, "Report of Committee on Declassification," Memorandum to Maj. Gen. L. R. Groves, Nov. 17, 1945, p. 3].

'Generally, "If we have secrecy and they have secrecy, we will be ahead. If we have free and open distribution of every bit of knowledge we have, and they have secrecy, they eventually are going ahead because they will finally find out something that we don't know and we won't find it out " [Gen. L. R. Groves, in Atomic Energy, Hearings Before the Special Committee on Atomic Energy, Pursuant to S. Res. 179, U.S. Senate, 79th Cong., 1st Sess., Nov. 27-30, Dec. 3, 1945, U.S. Govt. Printing Office, 1946, p. 62].

\$ We must bear in mind the fact that if the other side learns all that we know, but we remain ignorant of what they discover, we will find it very hard to stay ahead in the game" [F. Seitz and E. P. Wigner, "On the Geneva Conference: A Dissenting Opinion," Bull. At. Sci, 12, 23-24 (1956), p. 23; Drs. Seitz and Wigner were commenting on the relative exchange of atomic energy information between Russian and U.S. scientists and engineers during the 1955 Geneva Conference on the Peaceful Atom].

"One distinction between the U.S. and Canadian classification systems is (or was) that for certain programs the Canadian policy was to assign higher classification levels to rescarch and development activities than to production activities or field use. This policy was applied to programs where protecting lead time was especially important

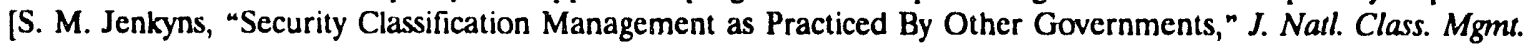
Soc., 7, 18-26 (1971), p. 22].
} 
research and development." Generally, basic scientific research is not classified unless there is a significant breakthrough that has a direct national security application in a new field or unless the new information represents a radical change in an existing field. ${ }^{\dagger}, 23$

2. Indicating what can be achieved (e.g., the fact that an atomic bomb will work) f.24 $^{\ddagger}$ or the existence of a "feasible possibility. ${ }^{25,26}$

3. Indicating the principle by which something can be achieved. ${ }^{*},+\dagger$

4. Indicating technology areas where our knowledge is weak. The fact that certain researches are in progress must sometimes be classified to avoid identifying areas where we are not adequately prepared. $\$$.27 We do not wish an adversary to learn of our vulnerabilities. Therefore, information indicating that we are far behind an adversary should be classified. ${ }^{25}$

5. Indicating technology areas where our knowledge is strong. This may indicate areas that may provide significant national security advantages (see Item 1).

6. Identifying scientific or technical problems that are not readily apparent. This helps an adversary to avoid those problems and thereby saves the adversary time and money.

7. Identifying successful methods of solving the scientific or technical problems (information concerning the methods that will work, the methods that will not work,

\footnotetext{
"It is also important to consider whether it is known, publicly or internationally, that the United States has the information or even is interested in the subject matter " [U.S. Department of Defense, Information Security Program Regulation, Regulation 5200.1-R, 82-208, June 1986].

${ }^{\dagger}$ A danger in classifying this "forefront basic science" is that such classification will likely result in "extraordinarily expensive and extraordinarily wasteful" programs [W. P. Raney, "The Sea Lanes \& Their Challenges," J. Natl. Class. Mgmt. Soc., 13, 17-22 (1977), p. 21].

f" Indeed, the most important fact about a technology is probably its very existence-not its design details. Once feasibility is proved in one country, other governments can confidently launch development efforts of their own " [Scientific Communication and National Security, National Academy of Sciences, National Academy of Engineering, Institute of Medicine, Panel on Scientific Communication and National Security, D. R. Corson, Chairman, National Academy Press, Washington, D.C., 1982, p. 47]. "Remove the uncertainty about whether, and it is much easier to figure out how" [A. DeVolpi, G. E. Marsh, T. A. Postol, and G. S. Stanford, Born Secret-The H-Bomb, The Progressive Case and National Security, Pergamon Press, N.Y., 1981, p. 149].

"* "When the principle of a technological advance is known, then [the advance] will be realized, provided there is a will to do so. The incentive will be there if it is known that the other side is working on it or has achieved it ${ }^{n}$ [L. W. Nordheim, "Fear and Information," Bull. At. Sci, 10, 342-346 (1954), p. 345].

TWarheads used for hard structures have been developed by the United States. The cost to develop such a warhead was said to be about $\$ 10$ million. It has been estimated that if an adversary knew how the United States soived the problems in developing this warhead (i.e., if the adversary knew the successful technical approach taken by the United States), the adversary could develop such a warhead for about $\$ 2$ million, a relatively significant savings [B. A. Kulp, "Air, Space, \& Supcriority," J. Natl. Class. Mgmt. Soc., 13, 22-28 (1977), pp. 24-25].

\# One Navy scientist stated that there are two reasons for security. The first was "to keep the enemy from finding out what you know," and the second was "to keep the enemy from finding out what you don't know" [Ross Gunn, Atomic Energy, Hearings Before the Special Committee on Atomic Energy, U.S. Senate, Pursuant to S. Res. 179, Dec. 13, 14, 19, and 20, 1945, 79th Cong., 1st Sess., U.S. Govt. Printing Office, Part 3, 1946, p. 374]. As a matter of interest, the latter reason is probably seldom important in trade secret protection matters.

"."In trade secret law, when trade secret information saves a competitor time and money, then that competitor is said to have materially benefitted from that information [R. M. Milgrim, Milgrim on Trade Secrets, Matthew Bender \& Co., Inc., New York, 1987, \$2.02[1], p. 2-27].
} 
and the method that is the best). This saves an adversary from wasting time and money on methods that will not work or are not optimum.

8. Identifying key operating parameters for a process. This tells an adversary where to spend major efforts to optimize the process, again saving the adversary time and money.

9. Providing detailed know-how concerning processes or equipment. Classification is particularly useful for controlling design and production information (e.g., detailed drawings and special manufacturing techniques). ${ }^{28}$ A DoD task force on the Export of U.S. technology strongly emphasized the necessity for the United States to control its design and manufacturing know-how (the details of manufacturing) if it was to maintain its technological superiority over other nations. ${ }^{29}$

10. Providing data that will confirm information an adversary already has obtained by its own efforts. This may give an adversary increased confidence in the accuracy of its results, leading to faster progress by the adversary in that field.

Items 1 through 3 indicate the importance of classifying certain research and development work, an action that is consistent with trade secret law which allows this type of information to be a trade secret (see Appendix A). Items 6 through 10 indicate the importance of classifying design details and test results (also important in trade secret matters), information that can be discovered by adversaries but only after expenditure of much effort over a long time period.

Extent of assistance to adversaries. In determining whether to classify certain information, it is not enough to conclude that release of that information could help an adversary. The extent of such help must also be determined for each of the ways by which the adversary may be helped. Expertise in the scientific or technical areas of interest is required for this determination. Intelligence information is also needed because knowledge of the adversary's starting technology base is necessary to quantify the extent to which the new information could help that adversary.

When determining whether release of scientific or technical information could help an adversary, the relative technological position of the United States and an adversary is a major factor to consider. The general opinion is that if the United States is far ahead of an adversary in a technology, then the information should be classified to protect that lead, ${ }^{25}$ especially if the technology is critically important to national security ${ }^{30}$ and if there is a long development time for a weapons system using that technology. ${ }^{\dagger, 31,32}$ This opinion is consistent with the conclusion of the Bucy Report, a DoD analysis of export control of U.S. technology. That report stated that controls should be placed on all key elements of a technology when the United States has a major lead in that technology. ${ }^{33}$ Such controls can

\footnotetext{
"The real secret of how to produce an atomic bomb or an industrial power plant lies in the extensive scientific and industrial know-how which our scientists and engineers possess as part of their heritage and education. The real secret is not how the bomb or power plant operates, but in how to carry these operations out on a large scale so as to make them effective" [F. H. Spedding, "Chemical Aspects of the Atomic Energy Problem," Bull. At. Sci, 5, 48-50 (1949), p. 49]. (See also Chap. 2, p. 8, footnote concerning General Groves' comments on secrecy.)

It should be noted that this opinion is not consistent with the "security by achievement" philosophy mentioned in Chapter 2. A footnote in that chapter indicated that in 1971 a new DoD policy was to not classify technical information in areas where lead time was indispensable and the United States had a worldwide superiority.
} 
help maintain this long lead time, especially when the lead is a result of a "revolutionary" advance in the underlying technology. ${ }^{34}$ Information about a revolutionary advance is less likely to be independently discovered by others than is information about an "evolutionary" advance. When the United States has only a small lead in the technology, which is usually the situation with a mature technology where the lead is a result of evolutionary advances, then controls on dissemination of the technology have only short-term effectiveness (the adversary's technology will also evolve) and it may not be worthwhile to institute such controls. 33

One aspect of determining whether release of information will help an adversary is to consider the time frame during which the information would be helpful to the adversary. Would the information be helpful in the near future (short term) or only in the long term? $?^{35}$

In determining whether to classify scientific or technical information, it must be remembered that our country may have several adversaries who may be at different stages of scientific or technical development. This is a particularly important consideration when the classification decision concerns non-state-of-the-art information. State-of-the-art scientific or technical information related to national security is frequently classified. Sometimes there is a tendency not to classify non-state-of-the-art information in that same area because that information is not important in our national security systems (i.e., not important in our systems that have been designed with respect to "high technology" adversaries). This may not be a wise decision. Although non-state-of-the-art information may not be useful to our adversaries whose level of technological achievement may be only slightly less than our technological level, that information could be very helpful to less-advanced unfriendly nations. ${ }^{36}$ A pertinent example concerns the manufacture of fissile materials for nuclear weapons. A principal adversary, the U.S.S.R. [or its successor(s)], long ago mastered certain technologies for producing uranium enriched in the fissile U-235 isotope. If the United States revealed its classified uranium enrichment technologies, then that information would probably not significantly assist the U.S.S.R. However, such information would be very valuable to certain "Nth-power" countries who have not yet produced nuclear weapons but who are very interested in obtaining that capability. Therefore, for nonproliferation reasons, ${ }^{\dagger}$ the United States continues to classify certain uranium enrichment technical information, information that is probably also possessed by some of our adversaries. ${ }^{\ddagger}$

\footnotetext{
"This rationale has an analogy in export control criteria. "The chief criterion for assessing the impact of a technology transfer is not whether it is obsolete by U.S. standards, but rather the degree to which it would advance an adversary's capabilities" [C. Phipps, "Information Security \& The Export of Technology," J. Natl. Class. Mgmt. Soc., 14, 44-48 (1978), p. 46].

The Nuclear Non-Proliferation Treaty has as an objective the prevention of the spread of nuclear weapons. The United States is a signatory to this treaty, which requires that signatories "not in any way assist" a non-nuclearweapon state to acquire nuclear weapons [Article I, "Treaty on the Non-Proliferation of Nuclear Weapons"]. Consequently, the United States continues to keep classified much information about nuclear weapons, especially information about the design of those weapons and the production of the fissionable materials that are the most important components of those weapons.

${ }^{\ddagger}$ Another example of this type of information, which was the subject of a fairly recent court case, is information on the design of thermonuclear weapons (hydrogen bombs). In United States v. Progressive, Inc., [467 F. Supp. 990 (W.D. Wis.), appeal dismissed, 610 F.2d 819 (7th Cir. 1979)], the government stopped the publication of an article on hydrogen bomb design and manufacture. One basis for the injunction was that although the information was probably known to the U.S.S.R., disclosure might speed hydrogen bomb development by third-world (Nth power) countries.
} 
Extent of effort to obtain data as a measure of assistance. Scientific or technical data are different from much other information that is classified for national security reasons because these data can be independently obtained by adversaries through their own (nonintelligence, nonespionage) efforts (once the adversary realizes that these data may be useful). However, substantial work may be required by an adversary to obtain that data. Classifying the data that we have obtained will then require an adversary to use its own resources (sometimes substantial) to get that information, resources that otherwise could be used by the adversary (e.g., on other weapon systems) ${ }^{37}$ to the adversary's advantage and to our probable detrimer: $i$. That rationale was given by the Atomic Energy Commission (AEC), in 1953, for not declassifying certain atomic energy information:

Relatively little has been released about those nuclear constants which are very difficult to measure and which are essential to the design of advanced reactors. . . . We have released very fow details on [the distortion and corrosion of fuel elements in nuclear reactors, the fabrication of fuel elements, and their performance under irradiation] in the belief that the data are critical to our business and cannot be understood without timeconsuming activities involving unique facilities. ... [A]s long as we feel that we are retarding unfriendly nations in their efforts in this field - by making them perform the work themselves - we can afford to take a measure of slowdown in our own progress. ${ }^{38}$

This "extent of effort" factor was again mentioned by the AEC in 1974 as a factor taken into account when making declassification decisions on atomic energy information. ${ }^{39}$ The amount of time, money, or effort expended to obtain information, particularly information from research and development activities, is also a factor in determining whether that information is a trade secret (see Appendix A).

There is only one instance (known to the author) where quantitative guidance was provided on how much effort an adversary should be required to spend to get information that is relatively straightforward to obtain before that information should be classified by the United States. That instance concerned atomic energy information generated during the Manhattan Project. The Smyth Report ${ }^{40}$ was a general account of all U.S. work during World War II to develop and produce atomic bombs. It was published in August 1945, shortly after two atomic bombs were dropped on Japan. In order to decide which atomic energy information could be released in the Smyth Report, Manhattan Project leaders established several guiding principles. One principle was that information could be made public if "it could be discovered by a small group ( 15 of whom not over 5 would be senior men) of competent scientists working in a well-equipped college lab in a year's time or less. ${ }^{n 1}$ Thus, Manhattan Project management established the principle that if an adversary could obtain scientific or technical information by an effort of less than 15 "scientist-years," then it would not be worthwhile for the United States to classify that information. ${ }^{\dagger}$ This

\footnotetext{
"However, for scientific or technical information to have maximum value to us, it must be used by all of our scientists and engineers. If we keep scientific or technical information, for which we have spent a significant amount of money to develop, from our scientists or engineers who can make use of that information, then classifying that information slows down our progress in addition to slowing down our adversaries' progress.

The following anecdote illustrates a hard-line approach to not giving an adversary any help in the field of atomic energy: "The story is told that in the days of the Manhattan District, a scientist was summoned to Washington and reprimanded for having mentioned in public a physical constant which was still secret. The accused fingered through the Smyth Report and pointed to a number there. 'Yes,' said the security officer, 'but that is in pounds per square inch, while you gave the figure in kilograms per square centimeter. Why make it easier for the Russians?'" ["It's Not What's Said-It's Who Said It," Bull. At. Sci, 6, 130-132 (1950), p. 130].
} 
criterion assumes that the scientific and technical principles are known so that the effort to obtain the information is relatively straightforward (e.g., measurement of neutron capture cross-section of elements). This well-established precedent of a 15 person-year measure of effort seems as appropriate today as it was over 45 years ago. Since it was accepted by the senior officials of the Manhattan Project, a DOE predecessor organization, then it is still appropriate to use that measure of effort for classification decisions within DOE (i.e., the precedent exists and has not yet been overruled).

The effort necessary for an adversary to get certain information can reasonably be estimated from knowing our efforts to get that information. Generally; most advanced nations are at about our level of technology. One of those nations would be expected to expend about the same effort to get the information as we spent. A nation not at our advanced level of technology would be expected to require relatively more effort than we spent to get that information. However, that low-technology nation may be able to buy that expertise from a technologically advanced nation at a cost approximately equal to the development effort. Therefore, estimating the cost to an adversary to get the information under consideration for classification should not be difficult.

The preceding paragraphs considered the effort required to get information as a measure to help decide whether to classify information. The time required to get information is sometimes a more important factor than the effort." Delaying the date by which an adversary acquires a weapon system or countermeasures to a weapon system may determine the outcome of a battle or a war. ${ }^{\dagger}$ Delays in Brazil's and South Africa's uranium enrichment programs (caused by classification and other nonproliferation efforts of the United States and other nations) are said to have given more time for the leaders in those countries who opposed building nuclear weapons a chance to gain political control and terminate those programs. ${ }^{42}$ The time factor will be further considered in a subsequent chapter, where duration of classification is discussed.

\section{Assistance to Other Nations in Improving Their Armaments}

The factors that were discussed in the preceding section on risks of assisting other nations in developing new armaments also apply to the risks of assisting other nations in improving their armaments. However, the risks generally may be less with respect to assisting other nations in improving their armaments (where the improvements are generally by evolutionary advances) than assisting other nations in developing new armaments (which generally result from revolutionary advances).

\section{Assistance to Other Nations in Manufacturing Materials for Armaments}

The factors that were discussed in a preceding section on risks of assisting other nations in developing new armaments also apply to the risks of assisting other nations in manufacturing materials for armaments. As mentioned in the preceding section, the degree of risk may be less for materials that are used to improve armaments (evolutionary advances) than for materials that are used to make new armaments (revolutionary advances). Within DOE, this criterion is of particular importance because it encompasses the production of

\footnotetext{
"Usually a substantial effort requires substantial time.

t"A horse! a horse! my kingdom for a horse!" W. Shakespeare, King Richard III, Act V, Scene 4, Line 7.
} 
special nuclear materials, the materials needed to make nuclear weapons. Production of nuclear weapons was a revolutionary advance in armaments. Therefore, information important to the production of special nuclear materials (e.g., how to produce militarily significant quantities of uranium enriched in the U-235 isotope) should be stringently classified.

\section{Detrimental Effects on U.S. Foreign Relations}

U.S. foreign relations, including arms control negotiations and treaty obligations, could be adversely affected by disclosing (i.e., not classifying) certain information. For example, the U.S. is very interested in preventing other nations from developing nuclear weapons. Major diplomatic initiatives by the United States and other countries (e.g., the Nuclear NonProliferation Treaty) have helped limit the spread of these weapons. Most nuclear weapon countries cooperate with the United States and closely control the materials and technologies of importance in developing and producing these weapons. If the United States released (e.g, did not classify or declassified), for apparent economic reasons, technical information that is perceived to be helpful in producing special nuclear material or otherwise in developing nuclear weapons, then some of these other countries might decide to release similar information, to the major detriment of these international control arrangements and to world political stability.

\section{Any Other National Security Impact or Significance}

The criterion of "any other national security impact or significance" encompasses those national security impacts not included in the other risk criteria. It includes, for example, the extent to which the information would assist other nations (e.g., adversary nations) in assessing or countering U.S. capabilities or determining U.S. limitations or vulnerabilities.

\section{Detrimental Effects on Classification Program Credibility}

For classified projects, if the information disclosed (not classified) is very important to the success of the project and if project personnel believe that reasons for not classifying that information did not adequately consider national security matters (e.g., if short-term cost savings or "political" purposes appear to override important national security factors), then the credibility of the classification program will be diminished by not classifying (or declassifying) that information. Therefore, not classifying (or declassifying) information for unsound reasons (unsound as viewed by rank and file project members) may lead to poor attitudes by some project personnel towards protecting the project's remaining classified information. ${ }^{*}, 43$

The credibility of the classification program may also be affected by the expected breadth of dissemination of the classified information and the planned end use of that information (or a product embodying that information). The extent of dissemination or the planned end use may be such that classification of the information will soon be impractical. "Classification under such circumstances may degrade the classification system by attempting to impose

\footnotetext{
The following quotation, attributed to Ralph Carlisle Smith, provides some indication of the frustration of project personnel in situations like those mentioned: "A break or a relcase of classified information in the field is a breach of security, but in Washington it is a change of policy."
} 
security controls in impractical situations. ${ }^{n 44}$ However, information could be classified until the information was widely distributed or the product that revealed this information was put into use.

\section{BENEFITS OF INFORMATION DISCLOSURE (COSTS OF CLASSIFICATION)}

\section{General}

The benefits of information disclosure (having the information unclassified) are sometimes better understood and evaluated if they are considered as the costs that would accrue if the information was classified. In those instances, determining the costs of classification will establish the benefits of not classifying the information (the benefits of information disclosure).

The benefits of information disclosure are broader in scope than are the risks of information disclosure. Risks of information disclosure pertain only to damages to the national security (see earlier in this chapter). Benefits of information disclosure include benefits to the general welfare of the nation and are therefore much broader in scope.

\section{Eight Criteria for Evaluating Benefits of Information Disclosure}

DOE's current procedure for evaluating a proposed declassification action ${ }^{\dagger}$ includes the consideration of five benefits from having scientific or technical information be unclassified. ${ }^{45}$ Those criteria, revised so that they are not specific to atomic energy information, are as follows:

- The benefit to progress of the U.S. program

- The benefit to the U.S. program by eliminating the costs of classification of the information

- The benefit to the U.S. economy of transferring the technology to U.S. industry for commercialization

- The benefit to U.S. foreign relations, arms control negotiations, or treaty obligations

- The benefit to the credibility of the classification program

The following additional benefit was listed in a 1987 DOE summary of classification policy: ${ }^{46}$

- Importance of the information to public discussion and education

With respect to scientific and technical information, another benefit should be included:

- The benefit to U.S. progress in science and technology, in general

\footnotetext{
Or the benefits of declassifying the information.

tRemember, DOE's classification decisions are mostly concerned with declassifying "born classified" atomic energy information rather than with classifying information as NSI.
} 
This criterion was one of the criteria used by the Tolman Committee in evaluating Manhattan Project atomic energy information for declassification. ${ }^{*}$ "catch-all" benefit criterion should be included, similar to inclusion of the "any other national security impact or significance" criterion that was included as a risk criterion. That final classification benefit criterion is

- Any other significant benefit to the United States

An evaluation of those eight categories of benefits ${ }^{\dagger}$ is presented in the following subsections, usually as costs of classification rather than as direct benefits of having the information unclassified.

\section{Benefits to the Progress of the U.S. Program}

The benefits to the progress of a U.S. program for which scientific or technical information was developed include avoiding the following delays or inefficiencies (which may be translated to costs) to the program if that information is not classified:

- Delays caused by inefficient communication between program personnel (i.e., reduced rate of progress) because of requirements to use secure telephones, to hold discussions and conferences only in secure areas, and to limit information transfer between program staff because of need-to-know requirements

- Delays in program progress while awaiting clearances for newly hired employees or consultants

- Inadequate peer review of the technical work because only a limited number of peers have clearances to review the information

- Diminished motivation of scientists and engineers because of restrictions on discussions with their peers and on the publication of the fruits of their efforts

- Difficulties in recruiting top-notch scientists and engineers to work on classified programs because of information restrictions

*The 1945 Manhattan Project Committee on Declassification (Tolman Committec) used the following positive criteria (benefits of information disclosure) to evaluate atomic energy information for declassification [R. C. Tolman, R. F. Bacher, A. H. Compton, E. O. Lawrence, J. R. Oppenheimer, F. H. Spedding, and H. C. Urey, "Report of Committee on Declassification," Memorandum to Maj. Gen. L. R. Groves, Nov. 17, 1945, p. 3]:

1. Advancement of general science

2. Advancement of non-military aspects of nuclear science

3. Advancement of military aspects of nuclear science

4. Advancement of general technology

5. Advancement of non-military aspects of nuclear technology

6. Advancement of military aspects of nuclear technology

7. Information already substantially known outside the project

8. Information readily obtainable by theory or minor experimentation

Tolman Committee Criteria 1 and 4 correspond to the last criterion mentioned above, and Criteria 2, 3, 5, and 6 correspond to the first and third criteria mentioned above. The equivalents to Criteria 7 and 8 were included in the discussions in Chap. 4 on the power of our government to control the information under consideration for classification.

It is interesting to note that three of these seven categories were especially mentioned in the Atomic Energy Act of 1954 as reasons for disseminating scientific and technical information related to atomic energy. The reasons stated in that act were "to provide that free interchange of ideas and criticisms which is essential to scientific and industrial progress and public understanding and to enlarge the fund of tectinical information " [42 U.S.C. 82161(b)]. 
- Delays caused by increased lead time for classified procurements

As mentioned previously in the section on risks of information disclosure, the relative technological position of the United States and an adversary is a factor to consider when determining whether release of scientific or technical information would help an adversary. When the United States is far ahead in the technology, then the information should probably be classified to protect that lead. In this section on benefits of information disclosure, the question is whether the United States can be helped by an increased rate of progress in the scientific or technical field, if the information is not classified. The general opinion is that if the United States is slightly behind an adversary, then the information that the United States is developing should not be classified. In that situation, because the United States needs to catch up with the adversary as fast as possible, all the work in that area should be unclassified to take advantage of the value of unrestricted communications. ${ }^{25}$ For similar reasons, the technology should be unclassified when the United States is on a par with or only slightly ahead of the adversary and possibly when the United States is far behind an adversary. ${ }^{: 30}$

\section{Benefits to the U.S. Program by Eliminating Classification Costs}

The benefits to a U.S. program of not classifying scientific or technical information include avoiding the following direct costs to the program:

- Costs of fabricating classified hardware using cleared personnel and secure equipment in secure areas. ${ }^{t, 47}$

- Extra costs of classified or "cover" procurements when buying classified hardware or materials (including preparation of security plans and periodic audits of those plans). Sometimes the costs of hardware manufactured in a classified facility are more than double the costs of manufacture in an unclassified facility (e.g., for one procurement the cost was about $\$ 1800$ per unit from a cleared contractor vs. $\$ 854$ or less per unit from an uncleared contractor). ${ }^{48}$

- Extra costs of classified procurements because of limited vendor interest in bidding on classified programs (increased costs because of less competition among vendors).

- Costs of preparing classified documents using "secure" office equipment in secure areas. $^{49}$

- Extra costs to transport or transmit classified hardware, materials, or documents (e.g., special modes of transport; receipting requirements). ${ }^{50,51}$ The experience of one DoD organization was that the cost of shipping classified hardware was ten times the cost of shipping unclassified hardware. ${ }^{52}$

\footnotetext{
"However, when the United States is far behind an adversary, that information should be classified if it reveals a vulnerability [S. J. Lukasik, "Remarks, Workshop A--Lifetime Cycles for Security Classification," J. Natl. Class. Mgmt. Soc., 7, 56-58 (1971), p. 58].

†ncludes extra personnel security costs for classified procurements or classified construction projects because of the high rate of turnover of industry personnel, particularly in the construction industry (more security clearances required).
} 
- Costs of classified document storage, including periodic inventories. ${ }^{53.54}$ A 1967 DoD study found that the direct and indirect annual costs of maintaining Top Secret, Secret, and Confidential documents were \$6.56, \$6.09, and \$2.11 per document, respectively. ${ }^{55}$

- Costs of reviewing classified documents for declassification or downgrading.

- Extra costs for destroying or otherwise disposing of classified documents, materials, or hardware.

- Pro rata share of salaries for classification office and security department staff.

- Physical security costs for protecting facilities, equipment, documents, and products (security fences; surveillance devices, etc.).

- Personnel security costs (security clearances, initial and periodic review).

- Employee time spent in classification and security education and training (initial briefings and periodic refresher briefings).

Although some of those classification costs were discussed in an earlier report, ${ }^{2}$ little information is available to aid in estimating those costs. It would be useful if federal agencies that frequently sponsor major classified technical projects would also sponsor studies on the costs of classification.

Costs of declassifying documents were discussed at a 1971 congressional hearing on U.S. Government information policies and practices. A DoD representative stated that much declassification required document-by-document review. Such review was difficult to accomplish because the experts who must be used to make declassification judgments were fully occupied in other duties. ${ }^{56} \mathrm{He}$ was not able to estimate the costs of declassification. Congressman Horton suggested that it would be a good idea if DoD conducted a study to find out how much it would cost to declassify documents, ${ }^{57}$ but such a study does not appear to have been carried out.

Sometimes the most important benefits to the progress of a program are not due to the reduction of direct costs, but because of the indirect benefits. For example, there will usually be more rapid progress in a scientific or technical field when restrictions on communications between workers in such a field are minimized. This is particularly true when workers on a classified project are able to discuss progress with their peers in academia or those working on unclassified projects. A hindrance to rapid progress in some scientific and technical atomic energy areas is caused by the "born classified" concept. Scientists in unclassified university and other research facilities cannot work in some areas of atomic energy because of classification restrictions. Such restrictions will, of course, hinder the rate of scientific progress in that field. However, such restrictions are sometimes essential for national security reasons. See Security Classification of Information, Volume 1. Introduction, History, and Adverse Impacts, ${ }^{2}$ for further information on indirect benefits of not classifying information.

\footnotetext{
-The experience of England's Ministry of Defence is that classification increases the costs of a contract by $5 \%$ or more [E. Hill, "Defence Procurement and Classification in the U.K., "J. Natl. Class. Mgrnt. Soc., 16, 20-27 (1980), p. 23].
} 


\title{
Benefits to General Scientific and Technological Progress
}

Overall U.S. scientific and technical progress is benefitted by not classifying scientific or technical information because the following costs are avoided:

- Reduced progress in the scientific or technical field because information in that field is classified and not available to all workers in that field

- Reduced progress in related fields because of restrictions on the cross-flow of ideas and information.

An important factor is the short-term and long-term effects of classification on the nation's scientific and technical progress. Generally, short-term (e.g., a year or two) classification of scientific and technical information will not have major impacts on the nation. However, there may be adverse long-range consequences when those constraints are extended. 58

One of the earliest groups to consider the short-term and long-term effects of classifying scientific or technical information was the Tolman Committee, which was concerned with declassifying Manhattan Project scientific and technical information. That committee stated the following about classification of scientific information:

\begin{abstract}
It is not the conviction of the Committee that the concealment of scientific information can in any long term contribute to the national security of the United States. . . If we are looking to the national welfare or national security as they may be two decades from now the Committee has no doubt that the greatest strength in both fields would come from a completely free and open development of science.

Thus the Committee is inclined to the view that there are probably good reasons for keeping close control of much scientific information [related to atomic energy] if it is believed that there is a likelihood of war within the next five or ten years. It is also their view, howevel; that this would weaken us disastrously for the future-perhaps twenty years hence. 59
\end{abstract}

\section{Benefits of Technology Transfer}

Information about certain processes, materials, or devices, which has been developed as part of a classified program, can sometimes be used to develop a new commercial process or to signifi antly improve an existing industrial process. Not classifying that technology and transferring it to private U.S. industry could help U.S. industrial competitiveness in the world marketplace and thereby help the U.S. economy. The expertise necessary to help evaluate the potential benefit to the U.S. economy by transferring technology to private industry can usually be obtained from consultants familiar with that industry.

\section{Benefits to U.S. Foreign Relations}

This category includes benefits to U.S. foreign relations, arms control negotiations, and treaty obligations. Those benefits should be considered in some classification decisions. For example, certain technology might be important to the success of worldwide efforts to detect and deter terrorism involving conventional or chemical weapons or to detect and deter the spread of nuclear, chemical, or biological weapons. Classifying that technology would not benefit those international efforts. 


\section{Importance of the Information to Public Discussion and Education}

The effective governing of our nation is based on input from the governed to the governors (including voting the governors out of office). If citizens do not know what their government is doing, they can hardly have effective input into this governing process. Therefore, when information concerning our government's activities is classified, then there are costs to free and open discussion of our government's activities and consequently there are costs to the processes of "representative" government.

Generally, it is important to have public input into the government's long-term, strategic decisions. Public discussion of short-term, operational information or of detailed technical matters is of lesser importance. Therefore, as a general rule, information pertinent to strategic decisions will have greater public-discussion benefits than will operational information or technical details.

Some factors to be considered when evaluating the importance of information to public disclosure and education include the following:

- Is the information about technical details of military operations or about military contingency plans? $?^{60}$

- Is the information purely scientific or technical information with little importance to public matters? ${ }^{61}$

- Is the information relevant to government officials' performance, integrity, and exercise of power? ${ }^{61}$

- Is the information relevant to spending U.S. tax dollars? ${ }^{61}$

- Is the information important to a current issue of national importance? ${ }^{61}$

- Is the information about cryptographic techniques, with little importance to public matters? $?^{62}$

\section{Any Other Significant Benefit to the United States}

This benefit criterion is meant to encompass any significant benefit to the United States which was not included in the previous seven criteria for determining benefits of not classifying certain information. Note that this is stated as "any other significant benefit." The comparable risk criterion was stated as "any other national security impact or significance."

One benefit of disclosing information about military capabilities, which might otherwise be classified, is to help deter an adversary. For a deterrent effect, one wants an adversary to know of the existence of a force (weapon) and to give credence to that force level (weapon capability). ${ }^{30}$ "A truly secret weapon is valueless for the purpose of deterrence. ${ }^{.63}$ It has

\footnotetext{
In United States v. Progressive, Inc., a Federal District Court granted an injunction to prevent publication of an article about the design of a hydrogen bomb. One of the arguments by the defendants was that publication of this information was necessary to alert U.S. citizens to the false illusion of security that was created by alleged futile government secrecy efforts. The court could "find no plausible reason why the public needs to know the technical details about hydrogen bomb construction to carry on an informed debate on this issue " [United States $v$. Progressive, Inc., 467 F. Supp. 990, 994 (W.D. Wisc., 1979), appeal dismissed, 610 F.2d 819 (7th Cir. 1979)].
} 
been reported that the United States deliberately let the U.S.S.R. know some of the details of our nuclear deterrent force so that this force could be an effective deterrent. ${ }^{64}$

Sometimes, classified information may be deliberately released by the government to "send a message" to an adversary. During the Cuban missile crisis in 1962, President Kennedy released much classified intelligence information about U.S.S.R. missile bases in Cuba. The purpose of this release was to inform the U.S.S.R. that the United States had precise information on the extent of the Soviet threat so that the U.S.S.R. would understand why the United States was taking such strong actions in response to that threat. ${ }^{65}$

\section{Benefits to the Credibility of the Classification Program}

Classification of information must have the enthusiastic support of the persons working in classified programs if that classification is to be effective. For example, if personnel in a classified program believe that certain classified technical information in that program is widely known and used in U.S. or foreign industry (as unclassified information), or that this classified information would be obvious to an expert in the field, then those persons may not enthusiastically support the classification of this information." That attitude may also diminish those persons' respect for information that truly should be classified, information whose unauthorized disclosure would significantly damage the national security. ${ }^{66,67}$ Thus, if information that is common knowledge or of little importance is not classified (or is declassified), then the remaining classified information will probably be better protected by project personnel. $^{\dagger}$

It should also perhaps be noted that consistency in classification matters is important to maintaining credibility in classification. When classification guidance is inconsistent (or illogical), then respect for classification is lost. Also, it is more difficult for persons working on a classified program to remember what is classified if much of the program is classified and if the classification guidance is illogical or inconsistent. ${ }^{68}$

\footnotetext{
"Generally speaking, it is very difficult in this country to enforce compliance with rules if those rules are not widely accepted as both necessary and reasonable [citing the failure of prohibition in the 1920's] ... When much is classified that should not be classified at all, or is assigned an unduly high classification, respect for the system is diminished and the extra effort required to adhere faithfully to the security procedures seems unreasonable " [U.S. Department of Defense, "Report to the Secretary of Defense by the Committee on Classified Information," C. A. Coolidge, Chairman, Nov. 8. 1956, p. 9].

Even the U.S. Supreme Court has recognized the adverse effects of overclassifying information. In New York Times v. United States [403 U.S. 713, 729 (1971)], the Pentagon Papers case, U.S. Supreme Court Justice Stewart, in a concurring opinion, discussed the responsibility of the government's executive branch for protecting information about foreign affairs and the national defense. He stated:
} 
DOE's policy on the credibility of its classification program has been stated as follows:

The effectiveness of Department of Energy (DOE) classification policies depends significantly on the willing cooperation of those who must implement the resulting classification guidance. It is important that they have confidence that the information we are continuing to classify is indeed truly sensitive for national security reasons. This confidence is the manifestation of the DOE classification program's credibility.

Erosion of credibility occurs whenever national security sensitivity is diminished through compromise, technological progress in the public sector, or other valid reasons. If declassification is chosen as an appropriate action to pursue under a given set of circumstances, then, as a policy, credibility of the DOE classification program will be one of the factors considered in the risk-benefit analysis that is performed to support each recommendation for declassification of Restricted Data or Formerly Restricted Data. ${ }^{69}$

A classification program's effectiveness is improved when classification efforts are focused on information that is truly important to national security.

\section{SUMMARY}

The criteria for determining the risks and benefits of disclosing scientific or technical information are summarized in Table 5.1. Factors for evaluating those risks and benefits of information disclosure are summarized in Tables 5.2 and 5.3, respectively. 
Table 5.1. Summary of criteria for determining risks and benefits of disclosure of scientific or technical information for use when considering whether to classify that information

\section{Criterion}

number

Description

\section{Criteria for determining risks}

RC1 The extent to which the information could assist other nations in developing new armaments

RC2 The extent to which the information could assist other nations in improving their armaments

RC3 The extent to which the information could assist other nations in producing materials for armaments

RC4 The detrimental effects that release of the information could have on U.S. foreign relations, arms control negotiations, or treaty obligations

RC5 Any other national security impact or significance (e.g., the extent to which the information would assist other nations in assessing or countering U.S. capabilities and limitations)

RC6 The detrimental effects that release of the information could have on the credibility of the classification program

\section{Criteria for Determining Benefits}

BC1 The benefits to the progress of the U.S. program that could be achieved by release of the information

BC2 The benefits to the U.S. program that could be achieved by eliminating the costs of classifying the information

BC3 The benefits that could be realized by U.S. progress in science and technology, in general, if the information was not classified

BC4 The benefits to the U.S. economy that could be realized by transferring the technology to U.S. industry for commercialization

BC5 The benefits that release of the information could provide to U.S. foreign relations, arms control negotiations, or treaty obligations

BC6 The importance of the information to public discussion or education.

BC7 Any other significant benefit to the U.S.

BC8 The benefits that not classifying the information could have on the credibility of the classification program

${ }^{a} \mathrm{RC}=$ risk criterion; $\mathrm{BC}=$ benefit criterion. 
Table 5.2. Summary of some evaluation factors to use when determining the risks of disclosing scientific or technical information

\section{Factor}

Description of evaluation factors

Factors relevant to assisting other nations with respect to armaments

REF1 Disclosure indicates technology areas that could provide significant national security advantages

REF2 Disclosure indicates what can be achieved in a technology area

REF3 Disclosure indicates the principle by which a technical result can be achieved

REF4 Disclosure indicates technology areas where our knowledge is weak

REF5 Disclosure indicates technology areas where our knowledge is strong

REF6 Disclosure identifies scientific or technical problems that are not readily apparent

REF7 Disclosure identifies successful methods of solving scientific or technical problems

REF8 Disclosure identifies key operating parameters for a process

REF9 Disclosure provides detailed know-how about processes or equipment

REF10 Disclosure could save an adversary a significant effort if otherwise the adversary would have to get the information by its own technological efforts

REF11 Disclosure could significantly reduce the lead time that the United States has over an adversary in that technology

REF12 Disclosure could provide independent confirmation of data already obtained by adversary

\section{Factors relevant to foreign relations}

REF13 Disclosure could lead to a perception that the United States is not totally supporting international arms control efforts

Factors relevant to other national security impacts

REF14 Disclosure could help an adversary in assessing or countering U.S. capabilities or limitations

Factors relevant to classification program credibility

REF15 Disclosure could lead to a perception that program management is releasing, for unsound reasons, information important to the nation's security

REF16 Protection of the information may be impractical and its classification may adversely affect the classification program's credibility by such an attempt to impose security controls in impractical situations

\footnotetext{
${ }^{a} \mathrm{REF}=$ risk evaluation factor.
} 
Table 5.3. Summary of some evaluation factors to use when determining the benefits of not classifying scientific or technical information

Factor

number

Description of evaluation factors

Factors relevant to the specific program

BEF1 Reduced costs of inefficient communications between program personnel

BEF2 Elimination of costs of delays while program personnel await security clearances

BEF3 Elimination of costs of inadequate program management because of inadequate peer review of the scientific or technical efforts

BEF4 Increased productivity because ability to publish results and discuss results with peers will lead to improved motivation of scientists and engineers

BEF5 Improved ability to recruit top-notch scientists and engineers because of fewer restrictions on discussions with peers

BEF6 Reduced delays caused by lengthy times required for classified procurements

BEF7 Reduced costs of hardware because it can be fabricated as unclassified

BEF8 Reduced costs of hardware because it can be procured as unclassified

BEF9 Reduced costs of hardware because of more vendor competition in procurements

BEF10 Reduced costs of document preparation

BEF11 Reduced transportation costs for documents or materials

BEF12 Reduced document storage costs

BEF13 Elimination of costs of reviewing documents for declassification or downgrading.

BEF14 Elimination of costs of destroying or otherwise disposing of classified documents, materials, or hardware

BEF15 Elimination of pro rata share of classification office and security department staff costs

BEF16 Elimination of pro rata share of costs of protecting facilities

BEF17 Elimination of personnel security costs

BEF18 Elimination of employee time spent in classification and security briefings not directly related to production

Factors relevant to general progress in science and technology

BEF19 Improved progress in the scientific or technical field because information is available to all workers in that field

BEF20 Improved progress in related fields because information can contribute to cross-flow of ideas and information to those related fields 
Table 5.3 (continued)

Factor

number
Description of evaluation factors

Factors relevant to technology transfer to industry for commercialization

BEF21 Improved U.S. economy because new and better products are available

BEF22 Improved U.S. economy because improved products are available

$$
\text { Factors relevant to foreign relations }
$$

BEF23 Information could benefit international efforts in control of terrorism or the spread of nuclear, chemical, or biological weapons of war

Factors relevant to public discussion and education

BEF24 Information is relevant to policy, not operational or scientific and technical details

BEF25 Information is relevant to performance or integrity of governmental officials

BEF26 Information is relevant to significant governmental expenditures

BEF27 Information is relevant to a current issue of national importance

$$
\text { Factors relevant to any other significant benefit to the United States }
$$

BEF28 Information provides other significant benefits to the United States which are not included in the previously stated factors for determining benefits of not classifying information

Factors relevant to classification program credibility

BEF29 Improved attitudes of program personnel in protecting classified information

\footnotetext{
${ }^{a} \mathrm{BEF}=$ benefit evaluation factor.
} 


\section{REFERENCES}

1. Executive Order 12356, Fed. Reg., 4714874 (Apr. 6, 1982), Preamble; 81.1(a)(3). Hereafter cited as "EO 12356."

2. A. S. Quist, "Some Adverse Impacts of Classification," Chapter 6 in Security Classification of Information. Volume 1. Introduction, History, and Adverse Impacts, K/CG-1077/V1, Martin Marietta Energy Systems, Inc., Oak Ridge, Tenn., 1989. Hereafter cited as "Quist." p. 1133.

3. "The National Security Interest and Civil Liberties," Harvard L. Rev., 85, 1130-1326 (1972),

4. T. I. Emerson, "National Security and Civil Liberties," Yale J. World Pub. Order, 9, 78-112 (1982), pp. 78-79. Hereafter cited as "Emerson."

5. Gen. Maxwell Taylor, "The Legitimate Claims of National Security," Foreign Affairs, April 1974 , p. 57, as quoted by M. M. Cheh, "Government Control of Private Ideas-Striking a Balance Between Scientific Freedom and National Security," Jurimetrics Journal, 23, 1-32 (1982), p. 16, note 106.

6. New York Times v. United States, 403 U.S. 713, 729 (1971) (J. Stewart, concurring).

7. Cole v. Young, 351 U.S. 536, 543 (1956).

8. Cole v. Young, 351 U.S. 536, 544 (1956).

9. EO $12356,86.1(\mathrm{e})$.

10. 5 U.S.C. $\$ 552(\mathrm{~b})(1)(\mathrm{A})$.

11. 5 U.S.C. $\$ 552(b)(7)(D)$.

12. Conference Report 93-1200, "Joint Explanatory Statement of the Committee of Conference," reprinted in U.S. Code Cong. \& Adm. News, 6285-6293 (1974), p. 6291.

13. Gorin v. United States, 312 U.S. 19, 28 (1940).

14. H. Edgar and B. C. Schmidt, Jr., "The Espionage Statutes and Publication of Defense Information," Columbia Law Rev., 73, 929-1087 (1973), pp. 969-974.

15. United States v. Heine, 151 F. 2d 813, 815-816 (2nd Cir., 1945).

16. United States v. Morrison, 844 F.2d 1057, 1071 (4th Cir., 1988); cert. denied., 108 S. Ct. 1837 (1988).

17. Gorin v. United States, 312 U.S. 19, 31 (1940), citing, with approval, the following jury instructions: "The connection must not be a strained one nor an arbitrary one. The relationship must be reasonable and direct."

18. EO 12356, Preamble; \$1.1(c), \$6.1(c).

19. EO 12356, \$1.3(c). 
20. EO 12356, \$1.6(a).

21. J. C. Tuck, Assistant Secretary for Defense Programs, U.S. Department of Energy, memorandum to Operations Office Managers, "Department of Energy Classification Procedures," Tab 1, May 1, 1990. Hereafter cited as "Tuck Memorandum, Tab 1." A. B. Siebert, Director, Office of Classification, U.S. Department of Energy, Attachment to memorandum to Distribution, "Revised Department of Energy Declassification Procedures," March 12, 1992.

22. W. P. Raney, "The Sea Lanes \& Their Challenges," J. Natl. Class. Mgmt. Soc., 13, 17-22 (1977), p. 21.

23. U.S. Department of Defense, Department of Defense Handbook for Writing Security Classification Guidance, DOD 5200.1-H, March 1986, \$2.2(a)(6).

24. Quist, p. 63, footnote.

25. S. J. Lukasik, "Remarks, Workshop A-Lifetime Cycles for Security Classification," J. Natl. Class. Mgmt. Soc., 7, 56-58 (1971), p. 58. Hereafter cited as "Lukasik."

26. See also T. S. Church, "Panel-Science and Technology, and Classification Management," J. Natl. Class. Mgmt. Soc., 2, 39-43 (1966), p. 43.

27. W. Gelhorn, Security, Loyalty, and Science, Cornell University Press, Ithaca, N.Y., 1950, p. 63. Hereafter cited as "Gelhorn."

28. U.S. Department of Defense, Report of the Defense Science Board Task Force on Secrecy, F. Seitz, Chairman, Office of the Director of Defense Research and Engineering, Washington, D.C., July 1, 1970, pp. iv, v, 1, 2, 10. Hereafter cited as the "Seitz Report."

29. U.S. Department of Defense, An Analysis of Export Control of U.S. Technology-A DoD Perspective, A Report of the Defense Science Board Task Force on Export of U.S. Technology, J. F. Bucy, Chairman, Office of the Director of Defense Research and Engineering, Feb. 4, 1976, pp. iii, v, xiii, 1, 3, 34. Hereafter cited as the "Bucy Report."

30. F. J. Thomas, "Remarks, Workshop A-Lifetime Cycles for Security Classification," J. Natl. Class. Mgmt. Soc., 7, 58-62 (1971), p. 61. Hereafter cited as "Thomas."

31. Seitz Report, p. 2.

32. Lukasik, p. 57.

33. Bucy Report, pp. 9-14.

34. Bucy Report, p. 12.

35. J. H. Kahan, "Remarks, Workshop A-Lifetime Cycles for Security Classification," J. Natl. Class. Mgmt. Soc., 7, 52-56 (1971), p. 55.

36. T. S. Church, "Panel-Science and Technology, and Classification Management," J. Natl. Class. Mgmt. Soc., 2, 39-43 (1966), pp. 42-43.

37. H. G. Maines, "Panel-Government Classification Management Policies and Programs, ${ }^{\text {J. }}$ Natl. Class. Mgmt. Soc., 2, 82-87 (1966), p. 84. 
38. J. G. Beckerley, Director of Classification, Atomic Energy Commission, in Atomic Power Development and Private Enterprise, Hearings before the Joint Committee on Atomic Energy, Congress of the United States, 83rd Cong., 1st Sess., on Atomic Power Development and Private Enterprise, June and July 1953, U.S. Govt. Printing Office, June 24, 25, and 29; July 1, 6, 9, 13, 15, 16, 20, 22, 23, 27 , and 31, 1953, pp. 38-39.

39. U.S. Atomic Energy Commission, Wash., D.C., internal document, 1974.

40. H. D. Smyth, A General Account of the Development of Methods of Using Atomic Energy for Military Purposes Under the Auspices of the United States Government, 1940-1945, U.S. Govt. Printing Office, August 1945.

41. V. C. Jones, Manhattan: The Army and the Atomic Bomb, United States Army in World War II, Special Studies, Center of Military History, U.S. Army, Washington, D.C., 1985, p. 559, referring to a May 21, 1945, letter from Gen. L. R. Groves to H. D. Smyth.

42. D. Charles, "In the Beginning Was Uranium ..., "New Scientist, 136(1844), 30-35 (Oct. 24, 1992), p. 35.

43. S. Fernbach, "Panel-Science and Technology, and Classification Management," J. Natl. Class. Mgmt. Soc., 2, 48-53 (1966), p. 50.

44. U.S. Department of Defense, Security Classification of Official Information, Instruction 5210.47, Chap. VI, Sect. D (Dec. 31, 1964).

45. Tuck Memorandum, Tab 1.

46. U.S. Department of Energy, Washington, D.C., internal document, 1987.

47. J. A. Buckland, "Remarks, Workshop B-Security Costing in Relation to Classification," $J$. Natl. Class. Mgmt. Soc., 7, 77-98 (1971).

48. A. A. Correia, "Panel-Industrial Aspects of Classification Management in West Coast Defense/Aerospace Industry," J. Natl. Class. Mgmt. Soc., 3(2), 134-138 (1967), pp. 137-138.

49. See, for example, E. J. Castro, "Generation of a Classified Document Cost Study," J. Natl. Class. Mgmt. Soc., 8, 111-114 (1972), which describes a methodology for estimating the direct and indirect costs for generating and handling classified documents.

50. E. H. Calvert, "Panel-Realizing Savings From Classification Management," J. Natl. Class. Mgmt. Soc., 1(2, 3, 4), 108-112 (1965).

51. J. F. Pellant, "Remarks, Workshop B-Security Costing in Relation to Classification," J. Natl. Class. Mgmt. Soc., 7, 73-77 (1971).

52. Comments by a U.S. Navy Commander during a panel discussion on costs of classification, as reported in J. Natl. Class. Mgmt. Soc., 1(2, 3, 4), 115 (1965).

53. R. D. Donovan, "Classification Management Cost Study," J. Natl. Class. Mgmt. Soc., 4(2), $72-76(1968)$.

54. See also, for example, A. F. van Cook, "Remarks, Workshop B-Security Costing in Relation to Classification," J. Natl. Class. Mgmt. Soc., 7, 98-102 (1971), p. 99. 
55. M. D. Aitken, "Panel-Classification Management in the Department of Defense Today," J. Natl. Class. Mgmt. Soc., 3(2), 75-80 (1967), p. 78.

56. D. O. Cooke, testifying for the Department of Defense, as reported in U.S. Government Information Policies and Practices-The Pentagon Papers (Part 2), Hearings Before a Subcommittee of the Committee on Government Operations, House of Representatives, 92nd Congress, 1st Session, June 28 and 29, 1971, U.S. Govt. Printing Office, 1971, pp. $601,659$.

57. F. Horton, Congressman from New York, in U.S. Government Information Policies and Practices-The Pentagon Papers (Part 2), Hearings Before a Subcommittee of the Committee on Government Operations, House of Representatives, 92nd Congress, 1st Session, June 28 and 29, 1971, U.S. Govt. Printing Office, 1971, p. 659.

58. Gellhorn, p. 35.

59. R. C. Tolman, R. F. Bacher, A. H. Compton, E. O. Lawrence, J. R. Oppenheimer, F. H. Spedding, and H. C. Urey, Report of Committee on Declassification, Memorandum to Maj. Gen. L. R. Groves, Nov. 17, 1945, p. 3.

60. Adapted from Emerson, pp. 92-93, 97.

61. J. A. Goldston, J. M. Granholm, and R. J. Robinson, "A Nation Less Secure: Diminished Public Access to Information," Harvard Civil Rights-Civil Liberties Law Review, 21(2), 409-491 (1986), p. 458.

62. Emerson, pp. 93, 97.

63. A. H. Katz, "Classification: System or Security Blanket?," J. Natl. Class. Mgmt. Soc., 8, 76-82 (1972), p. 80.

64. W. J. Coughlin, statement to the Foreign Operations and Government Information Subcommittee, as reported in Government Information Plans and Policies, Part 1, Hearings Before a Subcommittee of the Committee on Government Operations, House of Representatives, 88th Congress, 1st Session, March 19, 1963, U.S. Govt. Printing Office, Washington, D.C., 1963, p. 35.

65. U.S. v. Sims, 471 U.S. 159, 180 (note 24) (1985).

66. See, for example, W. J. Howard, "Panel-The Executive Views Classification Management," J. Natl. Class. Mgmt. Soc., 1(2, 3, 4), 73-76 (1965), p. 73; R. C. Arnold, "Panel-Classification in the Department of Defense Today, ${ }^{n}$ J. Natl. Class. Mgmt. Soc., 3(2), 83-87 (1967), p. 85.

67. F. M. Kaiser, "The Impact of Overclassification on Personnel and Information Security," Government Information Quarterly, 3(3), 251-269 (1986), p. 253.

68. R. G. Jordan, Union Carbide Corporation, Nuclear Division, as reported in an internal document of the U.S. Atomic Energy Commission, Washington, D.C., 1965.

69. U.S. Department of Energy, Washington, D.C., internal document, 1985. 


\section{Chapter 6. BALANCING INFORMATION-DISCLOSURE RISKS AND BENEFITS}

\section{INTRODUCTION}

The purpose of this chapter is to describe standards that can be used when the risks of information disclosure are balanced against the benefits. This balancing is the final major step in deciding whether information should be classified.

The following section of this chapter describes the rationale for balancing classification costs against classification benefits when making classification decisions." Such balancing helps ensure that information is not classified unless information-disclosure risks exceed information-disclosure benefits. The next section discusses the need for standards to assist in this balancing process. Subsequent sections of this chapter describe existing standards (rules) that have been used to assist in balancing competing interests and thereby to guide decision-makers to reliable and consistent conclusions. Those rules include long-established rules of persuasion used in our legal system and balancing principles used when atomic energy information is declassified. The final section of this chapter proposes a set of standards to be used when information-disclosure risks and benefits are being balanced.

\section{RATIONALE FOR BALANCING INFORMATION DISCLOSURE RISKS AND BENEFITS}

\section{National Security Information}

NSI, defined by E0 12356, is information whose "unauthorized disclosure, either by itself or in the context of other information, reasonably could be expected to cause damage to the national security. ${ }^{\text {11 }}$ If unauthorized release of information reasonably could be expected to damage our national security, then it seems that EO 12356 requires that the information be classified. Even though classifying information may cause several kinds of adverse national impacts, ${ }^{2}$ EO 12356 does not explicitly require classification benefits (the damages to national security which are prevented by classifying the information) to exceed classification costs (the benefits to the nation of having the information unclassified) before information can be classified. That EO requires only consideration of the damage caused by unauthorized disclosure. However, some balancing of benefits and costs is implicit in many classification decisions. Certainly, information whose unauthorized disclosure would cause only minor damage to the national security should not be classified if major costs to our nation result from that classification.

\footnotetext{
Sometimes the term weighing is used to describe the comparison of risks and benefits. The terms balancing and weighing will generally be used interchangeably in this chapter.
} 
Balancing information disclosure risks against benefits (classification benefits and costs) before reaching a classification decision is not a new idea. Balancing, for some NSI classification situations, was sanctioned by a 1964 DoD directive, as follows:

In certain circumstances, it may be necessary to weigh the benefits which would accrue to the United States generally from the unclassified use by other governmert agencies or commercial interest of information which is classifled or otherwise classifiable under Executhe Order 10501, against the miltary or technological advantage which would be gained or retained by classification or continued classification of the information. Where a net advantage to the United States distinctly can be ascertained beyond a reasonable doubt, that factor should be considered in reaching the classification determination. In such a case, final determination to withhold classification or to declassify shall be made only by the Secretary of Defense ....

A broader scope of the information disclosure benefits to be used in balancing classification costs and benefits was suggested in 1966:

The requirements for national defense in an absolute sense are not ends unto themselves but must be balanced against other necessarily competing requirements such as justice, liberty, and general welfare."

A 1970 DoD report noted that "classification of information has both negative as well as positive aspects" and mentioned some of those negative aspects. ${ }^{5}$ Balancing, for all NSI classification decisions, was mentioned in 1971 as a new DoD classification policy element. $6,7,8$ This was described by a DoD representative in a 1971 hearing before a House of Representatives Subcommittee on Foreign Operations and Government Information as follows:

In October 1970 the Secretary of Defense announced the establishment of a new policy which provides that:

All classification decisions will be reached only after careful consideration of the advantages of open circulation after public release approval of the information against the advantages to a potentlal enemy. Even where security classification is clearly required, it should be retained for the minimum amount of time considering the degree of sensitivity, cost and probability of compromise.

This new policy means that security classification decisions will be reached only after consideration of competing advantages and disadvantages. In the past major emphasis for classification has generally been placed on the possible benefits of the information to potential enemies without consideration of the benefits which could accrue to the U.S. Government, industry and the domestic community, and our allies through open and effective technology dissemination. Now, both reasons must be considered in making the classification decision within that area. ${ }^{6}$

More recently, balancing has been implicitly sanctioned in a 1986 DoD handbook for writing classification guidance. That handbook mentioned the need to consider the "net national advantage" in deciding whether information should be classified as NSI. ${ }^{9}$ Also, DoD's June 1986 Information Security Program Regulation states that "both advantages and disadvantages of classification must be weighed" before making a classification decision. ${ }^{10}$ Thus, there appears to be support within DoD for balancing classification costs and benefits prior to making classification decisions. 
EO 12065 , the predecessor to EO 12356, explicitly directed that a balancing test be used for some declassification decisions:

\begin{abstract}
$I t$ is presumed that information which continues to meet the classification requirements in Section 1-3 requires continued protection. In some cases, however, the need to protect such information may be outweighed by the public interest in disclosure of the information, and in these cases the information should be declassified. When such questions arise, they shall be referred to the agency head, a senior agency official with responsibility for processing Freedom of Information Act requests or Mandatory Review requests under this Order, an official with Top Secret classification authority, or the Archivist of the United States in the case of material covered in Section 3-503. That official will determine whether the public interest in disclosure outweighs the damage to national security that might reasonably be expected from dlsclosure." $" 11$
\end{abstract}

This balancing test caused problems to the government in litigation under FOIA ${ }^{12}$ requests for information. ${ }^{13}$ The major problem was said to be that judges began to be willing to "second guess on the question of whether information would damage the national security, notwithstanding their admitted lack of expertise in the particular subject matter area." 14 Prior to EO 12605, judges were said to be unwilling to engage in such a review. ${ }^{14}$ Therefore, the balancing test was dropped from EO 12356 "not to take away our discretion to consider the competing interest but rather for us to avoid these problems in litigation."

Support for balancing information disclosure risks and benefits has come from the Director of the Information Security Oversight Office (ISOO). This office is responsible for implementing and monitoring the nation's information security program established by EO $12356 .{ }^{16}$ The ISOO director has stated that balancing the competing interests for disclosing and protecting information was inherent in the classification process. ${ }^{14}$

Since balancing classification costs and benefits is inherent in the classification process, then it should explicitly be required in the applicable EO to ensure consistency throughout the government in classifying NSI.

\title{
Atomic Energy Information
}

Strong support for requiring a balancing process in classification decisions is found in U.S. policy for declassifying atomic energy information. RD, a category of classified atomic energy information, is the most stringently protected of our nation's classified information. RD was established by the Atomic Energy Act of $1946,{ }^{17}$ and its protection was entrusted to AEC. ${ }^{18}$ Only an action by the five-member AEC could declassify RD. The AEC very

\footnotetext{
"Additional information on this section of EO 12065 is contained in M. H. Halperin, "The President and National Security Information," Chap. 4 in The Presidency and Information Policy, H. C. Relyea, ed., Center for the Study of the Presidency, Proceedings, 4(1), New York, 1981, pp. 66-78.

tJudicial de novo review of denials of FOIA requests for information is a very important part of the FOIA process. Some commentators believe that federal courts are too reluctant to perform such de novo reviews when agencies deny requested information for national security reasons, even though 1974 amendments to the FOIA specifically authorize judges to determine whether in fact the denied information was properly classified [see, for example, S. A. Faust, "National Security Information Disclosure Under the FOIA: The Need for Effective Judicial Enforcement, " Boston College L. Rev., 25, 611-643 (1984)]. Perhaps the existence of explicitly stated classification principles and balancing standards would better equip judges to inquire further into substantive matters when reviewing agency denials of FOIA-requested information.
} 
early recognized the need to balance competing interests when making declassification decisions. A 1950 AEC report stated the following:

The secrecy classification to be applied to any Hem of information thus depends upon a balance between the value of that information to inimical interests and the value expected to accrue to the United States through its dissemination. ${ }^{19}$

A 1956 AEC report mentioned that, in classification decisions ${ }^{\dagger}$ involving $R D$, “a fine balance must be struck between protecting information which is of national security significance and providing the maximum assistance to peaceful applications [of atomic energy]. ${ }^{20}$ More recently, the DOE policy has been expressed as follows:

\begin{abstract}
The principle underlying classlfication and declassification policy for atomic energy information is to achieve a balance between two alms: (1) assuring the common defense and security by controlling the deciassification of information concerning the military aspects of atomic energy; and (2) promoting the dissemination of scientific and technical information relating to the peaceful applications of atomic energy consistent with the common defense and security. However, the Atomic Energy Act states that the paramount objective of protecting the common defense and security must be observed. A determination on the declassification or downgrading of information can proceed only after a careful balancing of the risk to the common defense and security against the benefit to our own program of the proposed action. ${ }^{21}$ (emphasis added)
\end{abstract}

\title{
Summary
}

Classification decisions are not, in practice, strictly limited to a consideration of only the damage to national security that could reasonably be expected to be caused by disclosure of the information under examination for classification. The costs of classification to the nation (which are the national benefits of information disclosure) are also considered. A balancing of classification's costs and benefits may show greater national costs than benefits. In that case, the net national advantage will favor keeping the information unclassified even though there is a reasonable expectation that some damage could result from disclosure of that information. Information should be classified only when the resulting benefits to national security exceed the accompanying costs to the nation of classifying that information.

\footnotetext{
The need for balancing the competing national interests was recognized even earlier by the first committee established to consider the declassification of atomic energy information generated in the Manhattan Project. That committec, known as the Committee on Declassification or the Tolman Committee, was created in late 1945 by Gen. L. R. Groves, head of that U.S. Army World War II project. The task of the Tolman Committee was to establish guidelines for the declassification of atomic energy information developed during that project. Members were Dr. R. C. Tolman (Chairman), Dr. R. F. Bacher, Dr. A. H. Compton, Dr. E. O. Lawrence, Dr. J. R. Oppenheimer, Dr. F. H. Spedding, and Dr. H. C. Urey. That committee considered the effect of disclosure of atomic energy information (nearly all of which was classified at that time) on both the national security (benefits of classification) and the national welfare (costs of classification). Thus, a balancing process was followed in the earliest decisions on declassification of atomic energy information [R. C. Tolman, R. F. Bacher, A. H. Compton, E. O. Lawrence, J. R. Oppenheimer, F. H. Spedding, and H. C. Urey, "Report of Committee on Declassification," Memorandum to Maj. Gen. L. R. Groves, Nov. 17, 1945, p. 2].

'Presumably, AEC actually meant declassification decisions, since atomic energy information is "born classified."
} 


\section{NEED FOR STANDARDS TO USE IN THE BALANCING PROCESS}

Although information-disclosure risks and benefits must be balanced before a proper classification decision is reached, the classification decision process is generally much less certain than the word balancing implies. Balancing suggests a finely tuned process, where slight differences in the materials being compared will tilt the balance to one side or the other. Salancing suggests the possibility of reaching completely objective classification decisions with scientific precision. Unfortunately, classification decisions frequently are not obvious. Information-disclosure risks and benefits cannot always be reduced completely to uncontroverted, quantified facts. There are always uncertainties, sometimes major, in the estimated risks and benefits.

Because of uncertainties associated with classification costs and benefits, some guidance is needed to assist in the balancing of those costs and benefits. For example, in some situations the balancing guidance should require that there be significant apparent differences between costs and benefits before the information is classified. That is, when damage caused by unauthorized release of information may be severe, a balancing standard might require that the classifier be certain beyond a reasonable doubt that information disclosure benefits outweigh information disclosure risks before determining that the information is not classified. When the consequences of a wrong classification decision are less severe, the balancing rule might require that the classification decision be based on clear and convincing evidence or by the preponderance of the evidence, which are lesser standards of certainty. Use of balancing standards will help ensure that reasonable and consistent classification decisions are made. DoD has suggested a reasoned judgment standard- "Reasoned judgment shall be exercised in making classification decisions. ${ }^{10}$

The balancing rules suggested above for classification decisions are analogous to our legal system's rules for "weighing the evidence" in lawsuits. The following section of this chapter describes rules that are used by judges and juries to balance evidence when they are deciding the outcome of civil or criminal trials.

\section{OUR LEGAL SYSTEM'S RULES FOR WEIGHING EVIDENCE}

Civil and criminal trials represent circumstances where a "trier of fact" (a judge or jury) must weigh (balance) the evidence and decide a lawsuit. Those triers of fact must decide, based on evidence presented to them, the guilt or innocence of persons accused of crimes or the winners and losers in civil lawsuits. The facts (evidence) in those cases are seldom unequivocal. Margins of error in those facts must be anticipated in the search for an accurate decision. Our legal system has developed, over the centuries, balancing rules to help judges and juries reach decisions in lawsuits. Those rules also help ensure that those decisions are consistent." Some of those rules provide guidance with respect to how convinced the trier of fact must be to reach a verdict. Other rules provide guidance on what a judge or jury must

\footnotetext{
"It is important to a stable socicty, as well as to a reliable classification system, that decisions be consistent.
} 
do if they are in doubt about a decision. Those rules are different for civil and criminal lawsuits.

As discussed in Appendix A on trade secrets and classification matters, principles adapted from the legal system are especially reliable for use in classifying information because the legal system's rules have been rigorously debated and have withstood the tests of time. Therefore, it is appropriate to consider our legal system's rules for balancing evidence and perhaps to adapt some of those rules for use in making classification decisions."

For most civil cases, the standard of persuasion is by a preponderance or greater weight of the evidence. 22,23 This standard refers to the "convincing force of the evidence" 24 and means that the "existence of the contested fact is more probable than its nonexistence." 22 There are a few types of civil cases where the standard of persuasion is greater, where clear and convincing evidence is required. That higher standard is applied in those civil cases where there is special danger of deception or where public policy does not favor a particular type of claim. ${ }^{25}$

For trade secret matters, the proper standard of proof, which a trade secret ownerplaintiff must meet, is that "a trade secret must be established by a preponderance of the credible evidence introduced at trial." 26 This is said to be "something more than equivocal balanced evidence" and something less than "clear and convincing evidence." 27 Because it is hard to prove trade secret misappropriation by direct evidence (i.e., direct evidence is generally not available), the plaintiff usually has to rely on circumstantial evidence from which inferences can be drawn. ${ }^{28}$ When no direct evidence is available, some courts have said that the circumstantial evidence must be "clear and convincing." 29

For criminal cases, where a person's liberty is at stake or where other significant penalties may be imposed on a defendant, the standard of persuasion is higher than for civil cases. Our society's policy is to minimize the probability of convicting an innocent person. For criminal cases, the generally accepted standard is "proof beyond a reasonable doubt. ${ }^{n \dagger, 30}$ The more rigorous persuasion standard required for convicting the defendant in criminal cases, as compared with deciding a winner in civil litigation, is also reflected in the degree to which direct and circumstantial evidence is relied on in criminal cases. If the prosecution relies on direct evidence to prove the guilt of the defendant, the standard of persuasion is proof beyond a reasonable doubt. However, if the prosecution has to rely on circumstantial evidence to establish guilt, then the standard of persuasion is sometimes required to be that "the evidence must be so conclusive as to exclude any other reasonable inference inconsistent therewith." ${ }^{31}$

In administrative hearings, the usual burden of persuasion is "a preponderance of the evidence." However, where major issues are at stake, such as in a deportation hearing, the standard is "clear, unequivocal, and convincing evidence." 32

\footnotetext{
A classification determination has been characterized as "a quasi-legal judgment based on the best relevant technical information available, together with the pertinent classification guidance" [J. Marsh, "Workshop on Training of Classification Managers," J. Natl. Class. Mgmt. Soc., 8, 43-47 (1972), p. 44].

${ }^{\dagger}$ "Distinctly can be ascertained beyond a reasonable doubt" was a 1964 DoD standard for certain classification decisions [DoD Directive 5210.4, Dec. 31, 1964, as quoted by J. P. Gillis, "Panel-Classified Research in the University Environment," J. Natl. Class. Mgmt. Soc., 4(2), 80-8.5 (1968), p. 83; the complete quotation is given in the text earlier in this chapter].
} 
A Supreme Court decision of relevance to establishing balancing standards for use in classification matters was rendered in a civil suit against the United States in which the plaintiff wanted the government to produce specific documents. The government asserted that those documents contained military secrets and could not be made public. In deciding whether those documents should be provided to the plaintiff, the Court's standard was whether there was a "reasonable danger" that release of the documents would reveal military secrets that should not be divulged for national security reasons. ${ }^{33}$

Table 6.1 summarizes some of the balancing rules used in our legal system to help decide the outcome of different types of civil and criminal lawsuits.

Table 6.1. A summary of some "balancing" rules used by our legal system in deciding civil or criminal lawsuits

\begin{tabular}{|c|c|}
\hline Circumstance & Applicable balancing rule or standard \\
\hline \multicolumn{2}{|c|}{ Civil Matters } \\
\hline Ordinary civil litigation & Preponderance of the evidence \\
\hline $\begin{array}{l}\text { Litigation where there is a special danger of } \\
\text { deception or where public policy does not favor } \\
\text { a particular type of claim }\end{array}$ & Clear and convincing evidence \\
\hline Trade secret litigation & Preponderance of the evidence \\
\hline $\begin{array}{l}\text { Trade secret litigation where proponent relies } \\
\text { on circumstantial evidence }\end{array}$ & Clear and convincing evidence \\
\hline \multicolumn{2}{|c|}{ Criminal Matters } \\
\hline Ordinary criminal cases & Proof beyond a reasonable doubt \\
\hline $\begin{array}{l}\text { Criminal cases where prosecution relies upon } \\
\text { circumstantial evidence }\end{array}$ & $\begin{array}{l}\text { Proof must be strong enough to exclude any } \\
\text { other reasonable inference inconsistent } \\
\text { therewith }\end{array}$ \\
\hline \multicolumn{2}{|c|}{ Administrative Hearings } \\
\hline Ordinary administrative matters & Preponderance of the evidence \\
\hline $\begin{array}{l}\text { Administrative hearings where major issues are } \\
\text { at stake (e.g., deportation) }\end{array}$ & Clear and convincing evidence \\
\hline
\end{tabular}




\section{BALANCING STANDARDS FOR DECLASSIFYING ATOMIC ENERGY INFORMATION}

Balancing standards have been used when atomic energy information (which is "born classified") is being declassified since the earliest days that declassification of this information was considered. Balancing standards for declassification are, of course, particularly relevant for use in developing balancing standards for classification.

When the Manhattan Project's Tolman Committee developed the first guidelines for declassifying atomic energy information, this information was divided into three classes (areas):

Class I includes basic scientific information which has little direct application to the problems of production or military utilization. Class II includes certain basic scientific information which would be of great value to the development of science but which has a direct bearing on production or military utilization. It also includes technological information which would be of great importance for the peacetime utilization of atomic energy but which also has importance for production or military utilization. Class III includes information which has immediate application to the problems of military utilization but for the most part has little application to the development of science or to peacetime utilization. ${ }^{34}$

"Information recommended for immediate declassification" was contained in Class I (information developed from basic scientific research, little or no national security importance). Class II ("dual-use" scientific or technical information) contained that "information whose declassification would conduce to the national welfare and to long term national security, so that the date of declassification should depend on estimates as to the probability and imminence of war." Class III (information primarily useful only for military applications) contained "information not at present recommended for declassification and whose declassification should await a real reduction in the threat of atomic warfare." ${ }^{*}, 34$ The Tolman Committee's declassification principles (balancing standards) were essentially as follows (arranged from most stringent to least stringent) for the three classes (areas) of information:

T1. Do not declassify because critical national security considerations are much more important than information disclosure benefits. [Risks clearly outweigh benefits]

T2. Do not declassify because national security considerations are more important than information disclosure benefits, even though the risks and benefits are of about equal value. [Benefits and risks about equal; the information remains classified]

T3. Declassify because the information has little national security significance and the benefits from disclosing basic scientific information are important. [Benefits clearly outweigh risks]

Balancing principles are currently used by DOE when declassifying atomic energy information. The basic DOE declassification policy is to achieve a balance between two competing aims:

\footnotetext{
"It may be of interest to DOE classifiers that these three classes of information appear to live on today in research and development activity Categories I, II, and III. See DOE Order 5650.2B, "Identification of Classified Information, ${ }^{n}$ U.S. Department of Energy, Chap. I, \$2.jij (Dec. 31, 1991).
} 
(1) promoting the common defense and security by maintaining at a minimum the declassification of information concerning the milltary aspects of atomic energy, and

(2) promoting the scientific and peaceful applications of atomic energy to the maximum extent possible consistent with the common defense and security. ${ }^{35}$

There are currently several major areas of atomic energy information-weapons design, isotope separation, naval reactors, etc. Each area has its own balancing standard for use when information in that area is considered for declassification. Use of a different balancing standard for each atomic energy information area reflects a conclusion that information in some areas is more important to the national security than information in other areas. Consequently, more-stringent standards should be used when information in those moreimportant areas is being declassified. The balancing standards used when atomic energy information is being declassified are described in more detail in Chapter 11.

A summary of the balancing standards that have been used (some are not now being used) by the AEC and DOE when balancing information disclosure risks and benefits in the different AEI areas (arbitrarily designated as 1 through 8 ) is given below. ${ }^{35,36,37}$ Those paraphrased standards, arranged in order from the most restrictive to the least restrictive, are as follows:

AEI 1. Declassify only when inimical nations will not be helped. (Retarding the progress of inimical nations is more important than advancing our own progress.)

AEI 2. Declassify only when clearly in the national defense interest.

AEI 3. Declassify when the contribution to scientific and peaceful applications of atomic energy clearly outweighs the risk of the disclosure.

AEI 4. Declassify when the contribution to our own progress clearly outweighs the risk to the common defense and security of disclosing the information.

AEI 5. Declassify when the advantage to ourselves clearly outweighs any advantage which may accrue to an inimical nation.

AEI 6. Declassify when advancing our own technology is more important than retarding the progress of inimical nations.

AEI 7. Declassify when advancing our own technology is as important as retarding the progress of inimical nations.

AEI 8. Declassify when the information is not vital (essential) to our defense activities or technologies but is important to basic science or industrial progress (civil nuclear power).

The standard for AEI 1 is clearly the most stringent-declassify only if such declassification would provide no help to inimical nations. The effect on our own progress is not a factor in this area. Use of this standard probably means that declassification should occur only if adversaries already have the information and they know that it is reliable information. This is perhaps the only situation where providing information to someone would not help them.

On first examination, the standard for AEI 2 does not appear to be very helpful. It allows declassification when clearly in the national defense interest but does not indicate what 
constitutes such interest. However, if this standard is interpreted to be "declassify only when the contribution to national defense clearly outweighs the risk of disclosure," then it is more useful. Assuming that this interpretation of the standard for AEI 2 is correct, then the standards for AEI 2, 3, 4, and 5 are quite similar. For each of those areas, the balancing standard is "clearly outweighs." The benefit to be considered becomes broader in going from AEI 2 to AEI 5-from "contribution to national defense," to "contribution to scientific and peaceful applications of atomic energy," to "contribution to our [general] progress" (where "general" is assumed to be part of the AEI 4 benefit description), to "advantage to ourselves." . In all four of those areas, declassification should occur only when such action clearly helps us more than it helps our adversaries.

The standards for declassifying AEI 6 and 7 are similar. The balancing standard in both instances seems to be merely a preponderance of benefits over risks. In both instances it seems acceptable to help the adversary by the declassification. The difference appears to be that in AEI 6 advancing our technology is to be weighted heavier than helping an adversary, while in AEI 7 the two competing interests have equal weights.

AEI 8 seems to be the least stringent criterion. Information can be declassified if it is not vital to our defense activities or technologies but is important to basic science or industrial applications of nuclear power.

\section{STANDARDS FOR BALANCING INFORMATION- DISCLOSURE RISKS AND BENEFITS}

\section{Proposed Standards for Balancing Information-Disclosure Risks and Benefits}

The major risks and benefits of information disclosure are discussed in detail in Chapter 5 and summarized in Table 5.1. Standards for balancing the risks and benefits of declassifying atomic energy information are described in the immediately preceding section of this chapter. An earlier section discusses rules (standards of persuasion) used in our legal system to assist judges and juries in weighing the evidence in civil and criminal cases. Based on those standards of persuasion from our legal system and from atomic energy declassification experience, five general standards (S1 through S5) have been developed for use in making decisions on the classification of information. Those general standards, to use when balancing the risks to national security of disclosing information against the benefits to the nation of having this information unclassified (i.e., balancing the risks and benefits summarized in Table 5.1), are presented and discussed below.

S1. When the information concerns an area that is crucial to our national security, ${ }^{\dagger}$ then the information must be classified unless the classifier is certain beyond a reasonable doubt that release of the information would not help an adversary.

\footnotetext{
Notice that the balancing is stated in terms of risks to national security and benefits to the nation. The benefits are broader in scope than the risks. This approach is consistent with examples cited in an earlier section of this chapter which discussed NSI and with previous discussions in Chap. 5.

tNational security means national defense and foreign relations.
} 
This standard corresponds to a principle for the declassification of certain atomic energy information which stated that retarding the progress of an inimical nation (not providing any assistance to that nation) was more important than assisting our own progress. This standard requires a classifier to be very certain that release of information would not help an adversary before the classifier determines that the information can be unclassified. Informationdisclosure benefits are not considered (i.e., are implicitly assigned zero weight) in classification decisions involving this type of information. There is no balancing of risks and benefits, only a determination that there are no information-disclosure (declassification) risks. This principle is a "presumed classified" principle of classification. There should be very few areas of information that are so important that they would fall in this category. NSI 4 and 9 (see Appendix B) would certainly be considered in this category," as would some AEI areas. Certain information in other NSI areas would also be expected to fall in this category.

S2. When the information concerns an area that is very important to our national security, but not crucial, and if the information-disclosure benefits outweigh the information-disclosure risks beyond a reasonable doubt, then the information should not be classified.

Under this second balancing standard, information-disclosure risks and benefits are balanced prior to reaching a classification decision. When the classifier is certain beyond a reasonable doubt that benefits outweigh risks, then the information can be unclassified. This is another "presumed classified" balancing standard because the information to which it applies is in areas that are very important to our national security.

S3. When the information concerns an area that is very important to our national security, but not crucial, and when the information has major commercial or basic science applications in addition to national defense uses, if the informationdisclosure benefits clearly outweigh the information-disclosure risks, then the information should not be classified.

The information areas covered by this third standard are the same as those covered by the second standard. The difference in the two standards is that the third standard includes situations where the information has known major commercial or basic science applications (it has major dual-use applications). For that situation, the less stringent "clearly outweighs" standard is more appropriate than the "beyond a reasonable doubt" standard. This third standard implicitly assigns more weight to technology transfer benefits than does the second standard.

S4. When the information concerns an area that is important ${ }^{\dagger}$ to our national security and if the information-disclosure risks outweigh the information-disclosure benefits

\footnotetext{
"Information in NSI 3, foreign government information (FGI), is presumed classified (see Chap. 6) and it might be thought that FGI should be governed by this first balancing principle. However, since FGI is either provided to the United States by a foreign government or developed by the United States in cooperation with another country, then the United States presumably cannot even consider not classifying the information without concurrence from the other country. Therefore, these proposed balancing principles are not applicable, at least unilaterally by the United States, to FGI.

This is considered to be the "lowest" area of importance to national security. If the information was in an area that was not important to the national security (i.e., its importance was characterized as lower than "important"), then that information should not be classified.
} 
(a mere preponderance of risks over benefits), then the information should be classified.

This fourth balancing standard applies to information in areas of lesser importance to the national security than encompassed by the first three standards. The majority of information under consideration for classification as NSI is expected to be evaluated under this standard. This is a "presumed unclassified" balancing standard, consistent with a positive action being required to classify information as NSI.

S5. When the information concerns an area that is important to our national security and when the information is of major significance to public debate of important national issues, then the information should be classified only if the risks to national security clearly outweigh the benefits of information disclosure.

This fifth standard is the same as the fourth standard with respect to the national security importance of the information under consideration for classification. The difference is that the fifth standard applies to information that would make a major contribution toward informing the public on an important national issue. In this situation the information should be classified only if information disclosure risks clearly outweigh information-disclosure benefits. This fifth standard represents a policy that a more rigorous standard should be required to classify information that would have a major impact on public debate of important governmental matters (i.e., more weight is assigned to the benefit of public discussions of the information). The presumption for having the information unclassified is higher than for normal circumstances.

These standards might be affected by the international situation existing when the classification decision is made. That is, the balancing standards might become more stringent (tending toward not disclosing information) if we are at war, or if war seems imminent, as contrasted to an existing or expected relatively peaceful international situation." $\uparrow$ Alternatively, more weight might be assigned to national security benefits in time of war or international crises, consistent with a society's different values when at war than in peacetime. $^{38}$

Another factor that might affect the stringency of the balancing standard used in a particular situation is quality of the evidence on which the classifier must base the classification decision. If the evidence is circumstantial (e.g., intelligence information about an adversary's scientific or technical progress, which frequently is not direct evidence), then perhaps a more stringent standard of persuasion should be used as contrasted to a standard that would be used when the evidence is direct (e.g., information in scientific papers published by an adversary as evidence of the adversary's scientific or technical progress). This would be consistent with our legal system's principles. For example, in certain criminal

\footnotetext{
"When a nation is at war many things that might be said in time of peace are such a hindrance to its effort that their utterance will not be endured so long as men fight and that no Court could regard them as protected by any constitutional right" [Schenck v. United States, 249 U.S. 47, 52 (1919) (J. Holmes)].

The Information Security Oversight Office has suggested that the amount of information that is classified during each year depends on the state of world affairs during that year. Increased tensions in international relationships appear to cause an increase in the amount of information that is classified by the U.S. Government [S. Garfinkel, "An Information Security Oversight Office Overview of Executive Order 12356 and Its Implementing Directive," J. Natl. Class. Mgmt. Soc., 18, 17-23 (1982), p. 19].
} 
prosecution situations, the legal system imposes a more stringent balancing standard when circumstantial evidence is presented than when direct evidence is presented. More stringent standards are also imposed on circumstantial evidence than on direct evidence in certain trade secret litigation matters. Those differing standards were discussed previously in this chapter.

For referencing ease, the proposed standards for balancing information-disclosure risks and benefits when classification of that information is being determined are presented in Table 6.2.

Table 6.2. Proposed standards for use in balancing risks and benefits of information disclosure when classification determinations are being made

\begin{tabular}{|c|c|}
\hline $\begin{array}{l}\text { Standard } \\
\text { number }\end{array}$ & Description of standard \\
\hline S1 & $\begin{array}{l}\text { When the information concerns an area that is crucial to our national } \\
\text { security, then the information must be classified unless the classifier is certain } \\
\text { beyond a reasonable doubt that release of the information would not help an } \\
\text { adversary. }\end{array}$ \\
\hline S2 & $\begin{array}{l}\text { When the information concerns an area that is very important to our } \\
\text { national security, but not crucial, and if the information-disclosure benefits } \\
\text { outweigh the information-disclosure risks beyond a reasonable doubt, then } \\
\text { the information should not be classified. }\end{array}$ \\
\hline S3 & $\begin{array}{l}\text { When the information concerns an area that is very important to our } \\
\text { national security, but not crucial, and when the information has major } \\
\text { commercial or basic science applications in addition to national defense uses, } \\
\text { if the information-disclosure benefits clearly outweigh the information- } \\
\text { disclosure risks, then the information should not be classified. }\end{array}$ \\
\hline \$4 & $\begin{array}{l}\text { When the information concerns an area that is important to our national } \\
\text { security and if the information-disclosure risks outweigh the information- } \\
\text { disclosure benefits (a mere preponderance of risks over benefits), then the } \\
\text { information should be classified. }\end{array}$ \\
\hline S5 & $\begin{array}{l}\text { When the information concerns an area that is important to our national } \\
\text { security and when the information is of major significance to public debate of } \\
\text { important national issues, then the information should be classified only if } \\
\text { the risks to national security clearly outweigh the benefits of information } \\
\text { disclosure. }\end{array}$ \\
\hline
\end{tabular}

Table 6.3 summarizes matters of proof in classification decisions (facts to be proven, burden of persuasion, standard of persuasion, and identification of the person who can make the classification decision). This table encompasses all categories of classified information. Further details about RD, FRD, and transclassified NSI are given in Chapter 11. 


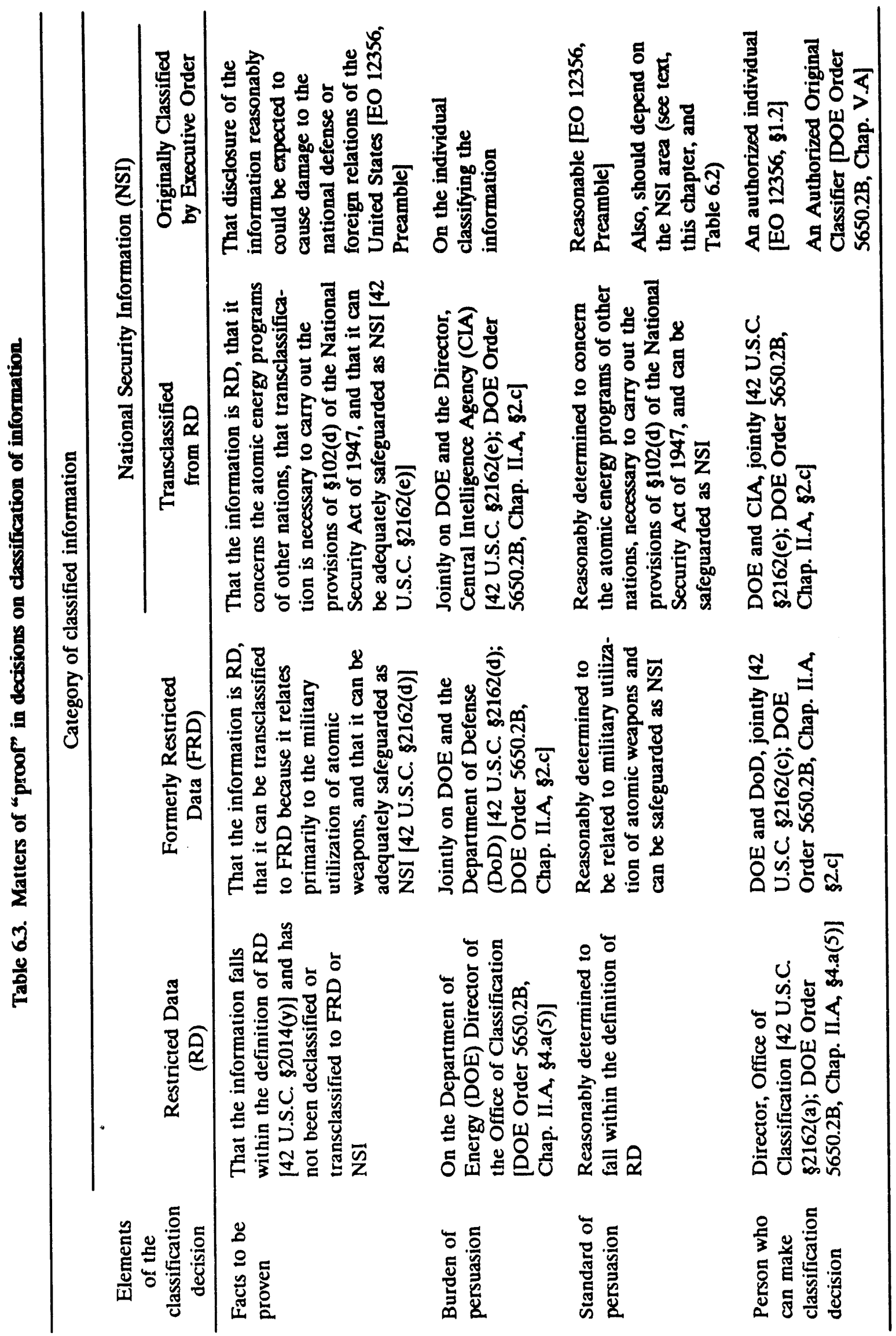




\section{Presumptions in Balancing Information-Disclosure Risks and Benefits}

There are several situations where presumptions need to be established to aid in reaching classification decisions. One such situation is when the uncertainties in the informationdisclosure risks and benefits are so great that there is no evident choice between classifying or not classifying the information. In that case, the presumption should be that the status quo will prevail. For example, information that is under consideration for classification as NSI is initially presumed to be unclassified except for a few NSI areas (see Chapter 5). Therefore, that information should remain unclassified unless the classifier can determine that classification benefits exceed classification costs." Conversely, atomic energy information is "born classified" and should not be declassified unless the benefits of declassification exceed the risks of declassification. This principle is consistent with the rules of our legal system, where the burden of persuasion is on the party that wants "to change the present state of affairs. $^{n 39}$

Another such situation occurs when the classifier has to determine whether adversaries already have the information under consideration for classification. It is usually difficult to prove whether an adversary has the information unless the adversary has published that information. ${ }^{\dagger}$ The classifier usually has to rely on circumstantial evidence such as intelligence information to decide whether the adversary already has the information. ${ }^{\ddagger}$ Who has the burden of proof in this situation? Does the proponent for classification have to prove that the adversary does not have the information, or does the proponent for not classifying the information have to prove that the adversary has the information? Trade secret law is helpful in answering this question.

In trade secret litigation, the trade secret owner does not have to prove that others in the trade do not have the trade secret information which is in dispute. Trade secret information is valuable and closely guarded by its possessors (just as adversaries guard their national security information). Therefore, it is difficult for a trade secret owner to prove that no competitor has the same, or similar, information. ${ }^{40}$ Similarly, it is difficult for a classifier to prove that an adversary does not have the information. Therufore, consistent with trade secret law principles, if there is not adequate proof that an adversary has the information, then the presumption should be that the adversary does not have the information."

\footnotetext{
"EO 12356 states that "if there is reasonable doubt about the need to classify information, it shall be safeguarded as if it were classified pending a determination by an original classification authority " [EO 12356, Fed. Reg., 47, 14874 (Apr. 6, 1982), 81.1(c); sec also Information Security Oversight Office "Directive No. 1, "Fed. Reg., 47, 27836 (June 25, 1982), \$2001.1(b)(1); 32 CFR Part 2001, \$2001.1(b)(1)]. Since the text's discussion is about original classification decisions, it is not clear what the EO requires an original classifier to do when there is reasonable doubt about whether information should be classified. That original classifier is an original classification authority! The author is of the opinion that since non-atomic energy information is presumed to be unclassified, then if there is reasonable doubt about whether information is NSI or not, the information should be presumed to be unclassified (it should remain unclassified).

If the adversary has published the information, then there is generally no reason to classify that information.

FThe intelligence agency may have reasonably direct evidence from its source, but to protect intelligence sources and methods, the agency has to be vague when presenting this information to the classifier. In such situations, the intelligence information should probably be treated more like indirect or circumstantial evidence than as direct evidence.

* This is also consistent with a 1966 (and maybe current) DoD rule which stated that "*if it cannot be determined whether or not a U.S. advancement in the state-of-the-art [of technology] is known by foreign countries,
} 


\section{Weighting Factors for Information-Disclosure Risks and Benefits}

In the discussions on balancing information-disclosure risks and benefits, it was generally assumed that all of those risks and benefi's had equal weight. That is, the discussions assumed (with a few implicit exceptions) that the risks to national security of information disclosure (e.g., assistance to other nations in developing new armaments) carried the same weight as the benefits of information disclosure (e.g., technology transfer benefits). It might be appropriate to assign national security risks more weight than purely economic benefits. Perhaps weighting factors are implicit in the choice of balancing principles. This matter of using different weighting factors for the different types of information-disclosure risks and benefits needs further consideration.

\section{Requirements for De Minimis Damage to National Security}

A principle that might be useful in making classification decisions would be to establish a de minimis amount of damage to the national security, a threshold level somewhere above zero, which must be exceeded before information would be further considered for classification. Whenever expected damage from information disclosure was less than this threshold amount, the information would not be further considered for classification. This de minimis principle is based on the fact that every decision to classify information results in certain minimum classification costs. Not classifying information avoids those classification costs. Consequently, the benefits of not classifying information are at least as large as those de minimis costs. Therefore, the damage to national security from information disclosure should at least be greater than those de minimis costs before information should be classified as NSI. Adopting this principle is essentially establishing a policy that certain "trifling" damages to national security will be accepted, that the United States does not want to expend its resources to avoid such minimal damage. ${ }^{\dagger}$

Such a principle has its analogy in the legal system, where the courts do not want to expend their limited resources on minor matters. The adage "de minimis non curat lex" expresses the legal system's reluctance to use its resources on small or trifling matters. Trade secret law incorporates this principle because information is not protected as a trade secret if it is only a "trivial advance" or its value is "not significant"; an "unusual competitive advantage ${ }^{n}$ is usually required. ${ }^{41,42}$ A de minimis principle has also been suggested as a pragmatic approach with respect to acceptance of de minimis societal risks and focusing limited resources on greater-than-de-minimis risks. ${ }^{43} \mathrm{~A}$ de minimis risk concept has also

\footnotetext{
assume it is not and lean in the direction of security classification" [G. MacLain, "Pane]-Government Classification Management Policies and Programs, ${ }^{n}$ J. Natl. Class. Mgmt. Soc., 2, 69-75 (1966), p. 71].

"National security in a democratic society involves taking some risks and allowing some flexibility" [T. I. Emerson, "National Security and Civil Liberties," Yale J. World Pub. Order, 9, 78-112 (1982), p. 82].

The United States is a very large and powerful nation. Significant events are required to cause consequential damage to our national security. An event that might cause major damage to a small country may not cause significant damage to the United States. Although numerous small events might collectively cause consequential damages to our country, our country is not inert, like a rock, where "chipping away" is irreversible. Our country is like a living organism that can generally repair damages from small events without suffering major adverse effects-unless many small events occur during a short period of time.
} 
been used, or suggested for use, in federal regulatory activities (e.g., in determining permissible exposure levels to carcinogens). ${ }^{44}$

Establishing a principle to accept a certain amount of damage to the national security from disclosure of information, before that information is classified as NSI, is consistent with established U.S. policy for declassifying RD or FRD. RD is our nation's most stringently protected classified information. The Atomic Energy Act of 1954 states that RD can be declassified if it "can be published without undue risk to the common defense and security. ${ }^{n 45}$ Implicit in that declassification policy is the acceptance of some risk when RD is declassified. The statute does not require "no risk" to national security before RD can be declassified. Therefore, our national policy is to accept a level of damage, not to exceed "undue," when RD is declassified.

FRD is the next most stringently protected of our nation's classified information. FRD is not protected as stringently as is RD but is better protected than NSI. FRD can be declassified when it "may be published without constituting an unreasonable risk to the common defense and security. ${ }^{n 46}$ Accepting a less-than-unreasonable risk (i.e., accepting a reasonable risk) presumably means accepting more damage than from an undue risk. Consequently, if a scale of damages to the national security caused by publication of information were established, starting with zero damage and increasing in damage toward the right, then the acceptable damage (the "not undue" damage) caused by publication of RD (it was RD before it was declassified) would be somewhat to the right of zero and the acceptable damage (the "not unreasonable" damage) caused by publication of FRD would be even further to the right (more damage).

EO 12356 states that information can be classified as NSI if its disclosure would cause damage to the national security. Because in practice NSI is less stringently protected than either RD or FRD, and because some damages are acceptable from the disclosure of declassified RD and FRD, then it can be concluded that some damages are acceptable before information should be classified as NSI. The damages acceptable before information is classified as NSI are greater than those acceptable from declassification of FRD. That amount of acceptable damage can be thought of as a de minimis level of damage.

Figure 6.1 illustrates graphically the relative difference in the threshold level of damage (de minimis damage) reasonably expected to be caused by publication of the three different categories of classified information. The threshold level of damage increases from RD to FRD to NSI, consistent with the relative stringency of information security for those three categories. Also shown in Fig. 6.1, as a matter of some interest, is the information that may be disclosed to persons holding " $\mathrm{L}$ " or " $\mathrm{Q}$ " clearances" (assuming that they have a need-toknow). Persons with L clearance may have access only to Confidential RD but may have access to both Confidential and Secret FDR and NSI. Assuming that granting an individual a particular clearance has some relationship to the amount of damage the government is willing to risk by giving that individual some classified information, then this figure tends to indicate that the threshold level of damages for Secret RD is about the same as the threshold level of damages for Top Secret FRD or NSI. Figure 6.1 also tends to indicate that for all categories and levels of classified information, the threshold level of damages for the three

"Clearance levels used by DOE. 
OWa. NO. Wa-00-2002RA

\begin{tabular}{|}
$\begin{array}{c}\text { Information accessible to } \\
\text { persons with " } L \text { " clearances }\end{array}$ & \multicolumn{1}{|c|}{$\begin{array}{c}\text { Information accessible to } \\
\text { persons with "Q" clearances }\end{array}$} \\
$\qquad$\begin{tabular}{|c|c|c|c|}
\hline $\begin{array}{c}\text { Confidential } \\
\text { NSI }\end{array}$ & $\begin{array}{c}\text { Secret } \\
\text { NSI }\end{array}$ & $\begin{array}{c}\text { Top Secret } \\
\text { National Security Information }\end{array}$ \\
\hline $\begin{array}{c}\text { Confidential } \\
\text { FRD }\end{array}$ & $\begin{array}{c}\text { Secret } \\
\text { FRD }\end{array}$ & $\begin{array}{c}\text { Top Secret } \\
\text { Formerly Restricted Data }\end{array}$ \\
\hline Confidential Restricted Data & $\begin{array}{c}\text { Secret } \\
\text { Restricted Data }\end{array}$ & $\begin{array}{c}\text { Top Secret } \\
\text { Restricted Data }\end{array}$ \\
\hline
\end{tabular}
\end{tabular}
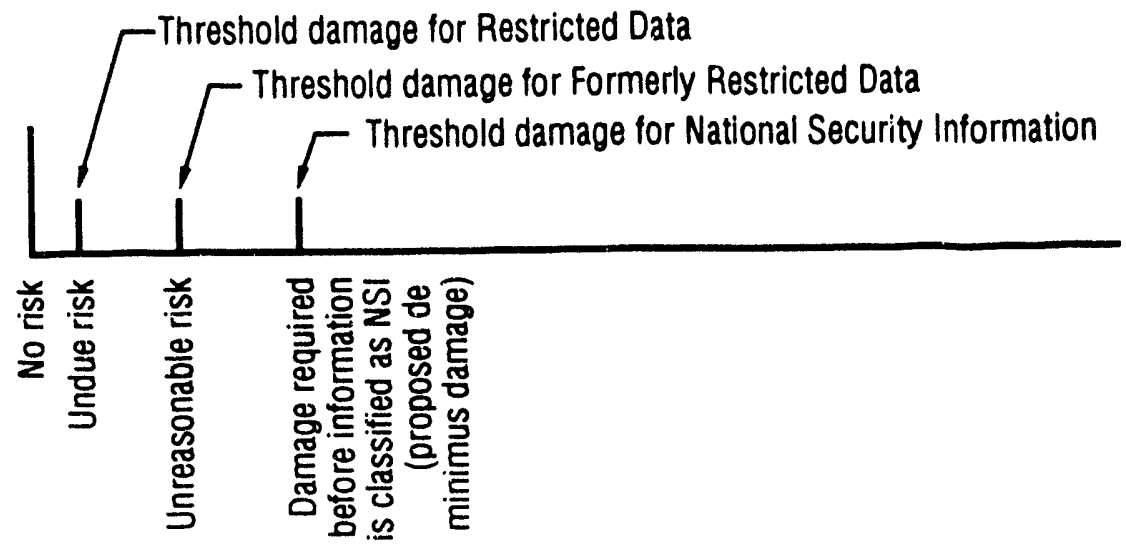

Increasing damage to national security caused by publication of information (nonlinear scale)

Fig. 6.1. Threshold damage required for information classified as Restricted Data, Formerly Restricted Data, or National Security Information, and a comparison of classification levels of the three categories of classified information with the clearances required for access to that information.

categories has the same value for a particular level (c.g., Top Secret) only for Top Secret FRD and Top Secret NSI (although it is possible that the threshold levels could be the same for Secret FRD and Secret NSI). There are other interesting ramifications of Fig. 6.1. One might ask why an L-cleared person should be trusted with Secret NSI, the unauthorized release of which would cause serious damage to the national security, but not with Secret RD, the unauthorized release of which would cause the same amount of damage to national security. It certainly reflects the very high care with which DOE protects $R D$, which is consistent with the national security importance ascribed to RD by congress when the Atomic Energy Acts were enacted. Perhaps it also reflects a major lack of agreement between government agencies in what constitutes damage, serious damage, and exceptionally grave damage to the national security (see Chapter 7 for a discussion of classification levels). 
The de minimis damage to national security could be set equal to estimated minimum costs of classification (minimum benefits of not classifying information). The costs to be included in this de minimis damage would generally be only the direct costs of classification, not the indirect costs (see Chapter 5 for a discussion of those direct and indirect costs). Those direct costs would include record-keeping and storage costs for the classified documents that would be generated by such a classification decision, the eventual declassification (decommissioning) costs, and other costs that are inescapable when information is classified. Costs might reasonably be estimated for parameters such as level of classification, number of copies distributed, extent of distribution of copies, number and level of persornel clearances required, etc. Estimates could also be made for other classification costs, such as costs of classified procurements. The sum of those costs would then be established as the de minimis cost of classifying an item of information.

When following the de minimis damage policy, a classifier would first make a rough estimate of the expected damage to national security caused by disclosure of the information. That information would not be further considered for classification unless that damage estimate exceeded the de minimis cost. That is, a classifier would not go through the complete decision process for classifying information, as described in this and preceding chapters, unless the de minimis damage was expected to be exceeded when the information was disclosed.

\section{Classification of Basic Scientific Research}

EO 12356 states that "basic scientific research information not clearly related to the national security may not be classified. ${ }^{n 7}$ DoD has provided somewhat more extensive guidance in this area:

Ordinarily, except for information that meets the definition of Restricted Data, basic scientific research or its results shall not be classified. However, classification would be appropriate if the information concerns an unusually significant scientific breakthrough and there is sound reason to believe that it is not known or within the state-of-the-art of other nations, and it supplies the United States with an advantage directly related to national security. ${ }^{48}$

Earlier DoD classification guidance contained additional information about classifying basic research:

Classification also would be appropriate if the potential military or industrial application of the information, although not specifically visualized, would afford the United States a significant military or technological advantage in terms $c$ technological lead time. ${ }^{49}$

It is DOE policy to conduct as much atomic energy research and development work as possible on an unclassified basis "so as to promote the free interchange of ideas which is essential to scientific and industrial progress." ${ }^{50}$ Whenever possible, DOE atomic energyrelated research in basic sciences such as chemistry, physics, and the properties of materials is carried out on an unclassified basis. However, in certain areas such as isotcpe separation, nuclear weapons, and naval nuclear propulsion systenis, some basic research is classitied.

Sometimes, it has been proposed that a distinction between basic and applied research be used as a basis ior classification (e.g., classify the applied research and generally leave the basic research unciassified). However, it is frequently difficult to differentiate between basic 
and applied research." Classification guides occasionally specify that only key or breakthrough scientific or technical information should be classified. "Key information" has been defined as follows:

\begin{abstract}
Key information-Information that reveals aspects, features, or attributes of [project] concepts or technologies that: (a) are innovative, not obvious, unexpected, or are difficult or time consuming to duplicate; and (b) permit either a significant technical advancement or resolution to a significant technical problem. A significant technical advance in this definition is an advance of sufficient magnitude to have a potential use in an operational or advanced system and results in a significant developmental or military advantage. A significant technical problem is a problem that cannot be solved by standard engineering techniques, and requires creative approaches for its solution. 51
\end{abstract}

This definition would be more useful if the last part of (a), "or are difficult or time consuming to duplicate," was eliminated. A "difficult or time consuming to duplicate" criterion is out of place with respect to breakthroughs, which usually originate from creative insights or prepared-for serendipity (breakthroughs are "innovative, not obvious, unexpected"). Breakthroughs are not usually directly connected to expenditures of massive amounts of ordinary scientific or technical effort. Scientific or technological breakthroughs are rare. Examples include discovery of nuclear fission, the transistor, and the maser-discoveries for which Nobel prizes are generally awarded. ${ }^{52}$

To go from breakthroughs to hardware that is usable for national security purposes usually requires 5 to 10, ears or more and hundreds of smaller technological steps. ${ }^{3 / 2}$ About 6 years were required to develop the first atomic bomb, even though it was developed under circumstances where the military implications of the discovery of nuclear fission were immediately recognized by scientists and where three of those years involved a massive, welldirected and well-funded U.S. effort (the Manhattan Project). Therefore, generally there is little reason to classify most breakthroughs in pure research.

A 1982 report, Scientific Communication and National Security (also known as the Corson Report), recommended some guidelines with respect to classification of scientific research in universities (generally considered as basic research). Those guidelines may also be applicable to scientific research in other institutions. That report recommended that information from scientific research carried out at universities be controlled only if it involved a technology that met all of the following criteria:

\footnotetext{
The technology is developing rapidly, and the time from basic science to application is short;

The technology has identifiable direct military applications; or it is dual-use and involves process c: : production-related techniques;
}

Transfer of the technology would give the U.S.S.R. a significant near-term military advantage; and

\footnotetext{
The first version of the Senate bill that later became the Atomic Energy Act of 1946 attempted to distinguish between information from basic and applied research. Because it was too difficult to establish a dividing line between those two types of information, that distinction was eliminated from the bill that was passed by Congress [A. S. Quist, Security Classification of Information. Volume 1. Introduction, History, and Adverse Impacts, K/CG-1077/V1, Martin Marietta Energy Systems, Inc., Oak Kidge, Tennessee, September 1989, p. 53].
} 
The United States is the only source of information about the technology, or other friendly nations that could also be the source have control systems as secure as ours. $^{53}$

A classification standard with respect to basic scientific research might be the following:

Only basic scientific research information that is key information clearly related to the national security may be classified.

Only rarely would information from basic scientific research also be key information clearly related to the national security.

Other factors that might lead to classification of basic research include whether the research indicates the direction in which programs are heading, whether it would contribute to feasibility assessments of weapons systems, or whether it reveals specific materials essential to a classified program.

\section{REFERENCES}

1. Executive Order 12356, Fed. Reg., 47, 14874 (Apr. 6, 1982), Preamble, 81.3(b), 86.1(c). Hereafter cited as "EO 12356."

2. A. S. Quist, "Some Adverse Impacts of Classification," Chap. 6 in Security Classification of Information, Volume 1. Introduction, History, and Adverse Impacts, KCG-1077/V1, Martin Marietta Energy Systems, Inc., Oak Ridge, Tenn., 1989, pp. 85-102. See also the previous chapter of this document.

3. U.S. Department of Defense, Security Classification of Official Information, Instruction 5210.47, \$VI.E (Dec. 31, 1964). See also J. P. Gillis, "Panel-Classified Research in the University Environment," J. Natl. Class. Mgmt. Soc., 4(2), 80-85 (1968), p. 83.

4. F. Thomas, "Keynote Address-Classification and Technological Breakthroughs;" J. Natl. Class. Mgmt. Soc., 2, 11-19 (1966), p. 19. Hereafter cited as "Thomas."

5. U.S. Department of Defense, Report of the Defense Science Board Task Force on Secrecy, F. Seitz, Chmn., Office of the Director of Defense Research and Engineering, July 1, 1970, p. 1.

6. D. O. Cooke, U.S. Department of Defense, in U.S. Government Information Policies and Practices-The Pentagon Papers (Part 2), Hearings Before a Subcommittee of the Committee on Government Operations, House of Representatives, 92nd Congress, 1st Session, June 28 and 29, 1971, U.S. Govt. Printing Office, 1971, p. 603.

7. G. MacLain, "Updating Security Classification Management and Its Support by DCAS Organization," J. Natl. Class. Mgmt. Soc., '7, 9-14 (1971), pp. 10-11.

8. See also R. E. Coffin, "Keynote Address," J. Natl. Class. Mgmt. Soc., 7, 5-9 (1971), p. 9; L. C. Myers, "Panel on Implementation of Executive Order 11652," J. Natl. Class. Mgmt. Soc., 8, 33-34 (1972), p. 34.

9. U.S. Department of Defense, Department of Defense Handbook for Writing Security Classification Guidance, DoD 5200.1-H, March 1986, §3-3, p. 3-2. 
10. U.S. Department of Defense, Information Security Program Regulation, DoD 5200.1-R, Chap. II, 82-200, June 1986. Hereafter cited as "DoD 5200.1-R."

11. Executive Order 12065, Fed. Reg., 43, 28949 (July 2, 1978), \$3-303.

12. 5 U.S.C. $\$ 552$, as amended.

13. U.S. Congress, House of Representatives, Committee on Government Operations, Security Classification Policy and Executive Order 12356, 29th Report by the Committee on Government Operations, House Report 97-731, 97th Cong., 2nd Sess., 1982, pp. 25-26.

14. S. Garfinkel, "An Information Security Oversight Office Overview of Executive Order 12356 and Its Implementing Directive," J. Natl. Class. Mgmt. Soc., 18, 17-23 (1982), p. 21. Hereafter cited as "Garfinkel."

15. A. Adler, "ISOO Panel-Why Do We Have So Much Classified Information? How Can We Protect It?," J. Natl. Class. Mgmt. Soc., 22, 43-44 (1986).

16. EO 12356, §5.1(b).

17. Atomic Energy Act of 1946, 60 Stat. 755, 766 (Aug. 1, 1946), \$10(b)(1).

18. Atomic Energy Act of 1946, 60 Stat. 755, 756, 766 (Aug. 1, 1946), \$2(a), \$10(a).

19. U.S. Atomic Energy Commission, Seventh Semiannual Report, January 1950, p. 169.

20. U.S. Atomic Energy Commission, Nineteenth Semiannual Report, January 1956, p. 99.

21. U.S. Department of Energy, Washington, D.C., internal document, 1987.

22. E. W. Cleary, ed., McCormick's Handbook of the Law of Evidence, 2nd Ed., West Publishing Co., St. Paul, Minn., 1972, 8339. Hereafter cited as McCormick's Law of Evidence.

23. F. James, Jr., Civil Procedure, Little, Brown and Company, Boston, 1965, \$7.6. Hereafter cited as "James."

24. James, p. 250, citing Morgan, Some Problems of Proof Under the Anglo-American System of Litigation, 1956, p. 83.

25. McCormick's Law of Evidence, \$340.

26. M. F. Jager, Trade Secret Law, Clark Boardman Co., Ltd, New York, 1988, p. 5-10. Hereafter cited as "Jager."

27. Jager, p. 5-10, citing Monsanto Chemical Co. v. Miller, 118 U.S.P.Q. 74, 78 (D. Utah, 1958).

28. Jager, pp. 5-10, 5-11.

29. Jager, p. 5-12.

30. McCormick's Law of Evidence, §341.

31. McCormick's Law of Evidence, \$338. 
32. McCormick's Law of Evidence, $\$ 355$.

33. United States v. Reynolds, 345 U.S. 1, 10 (1953).

34. R. C. Tolman, R. F. Bacher, A. H. Compton, E. O. Lawrence, J. R. Oppenheimer, F. H. Spedding, and H. C. Urey, Report of Committee on Declassification, Memorandum to Maj. Gen. L. R. Groves, Nov. 17, 1945, p. 4.

35. U.S. Atomic Energy Commission, Washington, D.C., internal document, 1974.

36. U.S. Atomic Energy Commission, Washington, D.C., internal document, 1974.

37. U.S. Atomic Energy Commission, Washington, D.C., internal document, 1962.

38. W. D. Rowe, An Anatomy of Risk, John Wiley \& Sons, New York, \$9.4, 1977.

39. McCormick's Law of Evidence, \$337.

40. Hayes-Albion v. Kuberski, 364 N.W.2d 609, 616 (1984).

41. Jager, p. 5-61.

42. S. J. Davidson and R. L. DeMay, "Application of Trade Secret Law to New TechnologyUnwinding the Tangled Web," Wm. Mitchell L. Rev., 12, 579-621 (1986), p. 607. p. 319.

43. C. L. Comar, “Risk: A Pragmatic De Minimis Approach,” Science, 203(4378) (Jan. 26, 1979),

44. J. Fiksel, "De Minimis Risk-From Concept to Practice," Chapter 1 in De Minimis Risk, C. Whipple, ed., Plenum Press, New York, 1987, pp. 3-7. See also other chapters in that book.

45. 42 U.S.C. $\$ 2162(a)$.

46. 42 U.S.C. $\$ 2162(c)$.

47. EO 12356, \$1.6(b).

48. DoD 5200.1-R, Chap. II, \$2-205.

49. U.S. Department of Defense, Security Classification of Official Information, Instruction 5210.47, Sect. VI.G, Dec. 31, 1964.

50. U.S. Department of Energy, "Guide to the Declassified Areas of Nuclear Energy Research," G-DAR-1, \$1.2, August 1984.

51. U.S. Department of Energy classification guide, 1988.

52. Thomas, p. 14.

53. D. R. Corson, Chairman, Panel on Scientific Communication and National Security, Scientific Communication and National Security, National Academy of Sciences, National Academy of Engineering, Institute of Medicine, National Academy Press, Washington, D.C., 1982, p. 49. 


\section{Chapter 7. CLASSIFICATION LEVELS}

\section{INTRODUCTION}

A classification level must be assigned to information when that information is determined to be classified. A classification level indicates the relative importance of classified information to national security and thereby determines the specific security requirements applicable to that information. Clearly defined classification levels are essential to an effective classification system. ${ }^{1}$

The U.S. classification of information system has three classification levels-Top Secret, Secret, and Confidential-which are defined in EO $12356 .{ }^{2}$ Those levels are used both for NSI and atomic energy information (RD and FRD). Section 1.1(a) of EO 12356 states that:

(a) National Security Information (hereinafter "classified information") shall be classified at one of the following three levels:
(1) "Top Secret" shall be applied to information, the unauthorized disclosure of which reasonably could be expected to cause exceptionally grave damage to the national security.
(2) "Secret" shall be applied to information, the unauthorized disclosure of which reasonably could be expected to cause serious damage to the national security.
(3) "Confidential" shall be applied to information, the unauthorized disclosure of which reasonably could be expected to cause damage to the national security.

Section 1.1(b) of EO 12356 states that "except as otherwise provided by statute, no other terms shall be used to identify classified information."

Previous chapters that discussed classification principles emphasized the need to balance the risks of information disclosure (damage to national security) against the benefits of having the information unclassified. If disclosure of information causes net damage to the nation, then that information should at least be classified at the Confidential level. However, there is very little available guidance to help determine which classification level should be assigned to classified information (i.e., whether it should be classified as Confidential, Secret, or Top Secret).

The appropriate classification level would be expected to usually be determined by the information disclosure risks because those risks largely determine the magnitude of the net damage that could be caused by such disclosure." Generally, the benefits of information

\footnotetext{
"The discussion assumes that the three classification levels-Confidential, Secret, and Top Secret-differ from each other by about an order of magnitude (factor of 10). That is, disclosure of Secret information would cause about ten times as much damage as disciosure of Confidential information, and disclosure of Top Secret information
} 
disclosure are expected to be on the order of magnitude of the Confidential level of damage. Therefore, the difficult balancing situations will usually occur when information disclosure damage is at the Confidential level because then the benefits and risks are expected to be about equal. When information disclosure risks are at the serious or extremely grave levels associated with Secret or Top Secret information, respectively, then the classification levels would usually be expected to be determined solely by those damages. It would be rare that the information disclosure benefits would approximate those significantly higher serious or extremely grave damage levels. The following sections of this chapter provide discussions of the three classification levels, especially with respect to scientific or technical information. Principles are proposed for assigning classification levels.

\section{CLASSIFICATION LEVEL DEFINITIONS AND EXAMPLES}

\section{Top Secret Information}

EO 12356 states that the Top Secret classification level "shall be applied to information, the unauthorized disclosure of which reasonably could be expected to cause exceptionally grave damage to the national security. ${ }^{n 3}$

It is of interest, prior to discussing specific examples of what might be Top Secret information, to examine the definitions of some of the terms used by the EO to describe Top Secret information. The key terms and their definitions are as follows: ${ }^{4}$

$$
\begin{aligned}
& \text { Reasonable-being in agreement with right thinking or right judgment; not conflicting } \\
& \text { with reason; not absurd; not ridiculous; being or remaining within the bounds of } \\
& \text { reason; not extreme; not excessive; moderate; not expensive; having the faculty } \\
& \text { of reason; possessing good sound judgment; well balanced; sensible. } \\
& \text { Could - past tense of can. Can - to be able to do, make, or accomplish. } \\
& \text { Expect-suppose, think, believe; to consider probable or certain; to consider } \\
& \text { reasonable, just, proper, due, or necessary. } \\
& \text { Cause - a person, thing, fact, or condition that brings about an effect or that produces } \\
& \text { or calls forth a resultant action or state; somethir j that occasions or effects a } \\
& \text { result; the necessary antecedent of an effect. } \\
& \text { Exceptional-forming an exception; being out of the ordinary; uncommon, rare. } \\
& \text { Grave-involving or resulting in serious consequences; likely to produce real harm or } \\
& \text { damage; very serious. } \\
& \text { Damage-loss due to injury; injury or harm to person, property, or reputation; hurt; } \\
& \text { harm. }
\end{aligned}
$$

The last EO to provide examples of Top Secret information whose disclosure "could reasonably be expected to cause exceptionally grave damage to the national security" was EO 11652 of March $1972 .^{5}$ Examples of "exceptionally grave damage" included in that EO were "armed hostilities against the United States or its allies; disruption of foreign relations

would cause about ten times as much damage as disclosure of Secret information. This assumption appears to be a realistic approach because of the difficulties in determining information disclosure damages very accurately and the consequent necessity to have significant differences in the assigned Top Secret, Secret, or Confidential damage levels. 
vitally affecting the national security; the compromise of vital defense plans or complex cryptologic and communications intelligence systems; the revelation of sensitive intelligence operations; and the disclosure of scientific or technical developments vital to national security. ${ }^{n 6}$ Subsequent EOs have not provided examples of what constitutes Top Secret information.

Examples of Top Secret information are currently given in National Security Council (NSC) regulations concerning FOIA requests for classified documents. Those examples are "armed hostilities against the United States or its allies," "disruption of foreign relations vitally affecting the national security," "the compromise of vital national defense plans or complex cryptologic and communications intelligence systems," "the revelation of sensitive intelligence operations," and "the disclosure of scientific or technological developments vital to the national security. ${ }^{7}$ Those examples in NSC regulations are the same those used in EO 11652 and are also found in the DoD Information Security Program Regulations. ${ }^{8}$ A 1964 DoD instruction provided more-detailed examples of information that might require Top Secret classification. Some of those examples are as follows:

(1) A strategic plan documenting the overall conduct of a war.

(2) War planning documents which contain worldwide --

(a) Planning data and assumptions,

(b) Wartime planning factors for the use of nuclear weapons,

(c) Intelligence estimates of enemy capabilities,

(d) Force composition and development, and

(e) Real estate requirements and utilization by geographical area which are time-phased for a period of months.

(3) An operations plan either for a single operation or a series of connected operations containing any of the factors in (2) above and with sortie rates or target data.

(5) Intelligence documents that contain completed inteillgence of such scope that it reveals a major intelligence production effort on the part of the United States and which would permit an evaluation by unauthorized recipients of the success attained by, or the capabilitles of, the United States intelligence services. ...

(6) A plan or policy for conducting intelligence or other special operations and information revealing a particular intelligence operation or other special operation, provided that the compromise of such plan, policy, or particular operation could result in exceptionally grave damage to the Nation. Intelligence operations may include certain specifically designated and controlled collection projects.

(7) Vital information concerning radically new and extremely important equipment (munitions of war), such as nuclear weapons, atomic weapons stockpile data, and any other munitions of comparable importance the scientific or technological development aspects of which are vital to national defense. ${ }^{9}$

There is very little classified atomic energy information (RD or FRD) that is assigned a Top Secret classification level by the DOE. Most RD and FRD are classified at either the Confidential or Secret levels. Although some other federal agencies (e.g., DoD) use the Top Secret classification level much more frequently than does DOE, within the entire U.S. 
Government only $4 \%$ of the original classification decisions made in FY 1991 were assigned a Top Secret classification level.

\section{Secret Information}

The Secret classification level "shall be applied to information, the unauthorized disclosure of which reasonably could be expected to cause serious damage to the national security. 10

The definitions of most of the important terms used by EO 12356 to describe the Secret classification level were given earlier. Only the following definition needs to be given here:

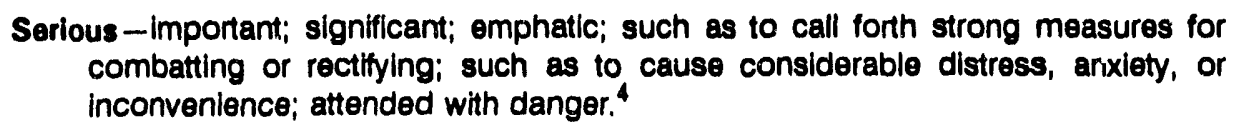

Examples of Secret information were given in EO 11652. Secret information, as defined in that EO, "could reasonably be expected to cause damage to the national security," and examples were stated to include "disruption of foreign relations significantly affecting the national security; significant impairment of a program or policy directly related to the national security; revelation of significant military plans or intelligence operations; and compromise of significant scientific or technological developments relating to national security." 11 Examples of Secret information given in current NSC regulations are "disruption of foreign relations significantly affecting the national security," "significant impairment of a program or policy directly related to the national security," "reveiation of significant military plans or intelligence operations," and "compromise of significant scientific or technological developments relating to national security. ${ }^{12}$ Again, the NSC examples are the same as the EO 11652 examples and the same as in the DoD Information Security Program Regulations. ${ }^{13}$ A 1964 DoD instruction provided more-detailed examples of information that might require Secret classification. Some of those examples are as follows:

(1) A war plan or a complete plan for a future operation of war not included under TOP SECRET, and documents showing the disposition of our forces the unauthorized disclosure of which, standing alone, could result in actual compromise of such SECRET plans.

(2) Defense or other military plans not included under TOP SECRET or (1) above including certain development and procurement plans and programs but not necessarily including all emergency plans.

(3) Specific information which, standing alone, reveals the militany capabilities or state of preparedness of the Armed Forces, but not including information the unauthorized disciosure of which could result in compromise of a TOP SECRET plan.

\footnotetext{
There were an estimated 511,868 original classification decisions by executivi: agencies in FY 1991. Of those decisions, $4 \%$ were Top Secret, $57 \%$ were Secret, and $39 \%$ were Confidential [ ${ }^{4}$ Information Security Oversight Office (ISOO) 1991 Report to the President," Information Security Oversight Cffice, Wash., D.C., March 1992, p. 12]. There were an estimated 6,595,149 derivative classification decisions by executive agencies in FY 1991. Of those decisions, $8 \%$ were Top Secret, $74 \%$ were Secret, and $18 \%$ were Confidential [ibid., p. 15]. The higher percentage of original classification decisions at the Confidential level, as compared with the percentage of derivative classification decisions at that level, is attributed to the fact that the Department of State treats all of its classification decisions as original and classifies most of these (80\%) at the Confidential level [ibid., p. 16].
} 
(4) Information that reveals the strength of our forces engaged in hostilities; quantties or nature of their equipment; or the identity or composition of units in an active theater of operations or other geographic area where our forces are engaged in hostilities, except that mailing addresses may include organization designation. Information which reveals the strength, identity, composition, or location of units normally requires classification as SECRET in time of war. In peacetime SECRET classification of information pertaining to units may be appropriate when related to war plans, estimates or deployments which involve classified information.

(5) Intelligence and other information, the value of which depends upon concealing the fact that the United States possesses it, except when possession of intelligence or other information concomitantly discloses a particular intelligence or other special operation falling within [the TOP SECRET classification level].

(6) Particulars of scientific or research projects which incorporate new technological developments or techniques having direct militany applications of vital importance to the national defense.

(7) Specific details or data relating to new materials or important modifications of materials which reveal significant military advances or new technological developments having direct military application of vital importance to the national defense.

(8) Information of vital importance to the national defense concerning specific quantities of war reserves.

(9) Indications of weakness, e.g., shortages of significant or sensitive items of equipment. ${ }^{14}$

The distinction between Secret and Top Secret information appears to be that Top Secret information is "vital," whereas Secret information is only "significant." See below in this chapter for a further discussion of the difference between Secret and Top Secret information.

Of interest with respect to DOE classification matters are some examples of Secret information given in a 1945 Manhattan Engineering District (MED) Security Manual. ${ }^{15}$ Some of those examples are as follows.

(1) Documents containing specific design details (diagrammatic or descriptive) of complete basic or key equipment, apparatus, instruments, or machinery employed in a critical stage of the processing and production of end products, or the methods of manufacture (where unique to the Manhattan District) of such Items; also, the material itself, as described above.

(2) Documents containing complete uncoded flow sheets, diagrams, or reactions, including specific pressures, temperatures, voltages, rates, formulae, and other operating details not described in the Smyth Report, specifically related to a critical step in the preparation, processing, separation, or purification of basic feed materials, and principal end products.

(3) Documents containing unique nuclear, physical; and chemical characteristics of end products, and critical process materials (including, for example, barrier material and neutron moderators), and also details of the manufacture (where unique to the District) of such materials. Also the products and materials themselves when they disclosed such information.

(4) Documents showing the meaning of a name or symbol used as a code, where the code name or symbol refers to matters classifiable as SECRET.

(5) Documents pointing out the existence of unique operational or production hazards, their nature and solution. 
(6) Detalls pertaining to features of speclal shipping containers, routes and schedules of shipments of Secret materials, except as classified TOP SECRET.

\section{Confidential Information}

The Confidential classification level "shall be applied to information, the unauthorized disclosure of which reasonably could be expected to cause damage to the national security. ${ }^{16}$ All of the important terms used by the EO to describe the Confidential classification level have been defined earlier in this chapter.

EO 11652 provided no examples of Confidential information. The NSC regulations give no examples for the Confidential classification category other than to state that "it must be reasonably expected that unauthorized disclosure of the [Confidential] material would cause damage to the national security. ${ }^{17}$ DoD guidance gives the following examples of Confidential information:

The compromise of information that indicates strength of ground, air, and naval forces in the United States and overseas areas; disclosure of technical information used for training, maintenance, and inspection of classified munitions of war; revelation of performance characteristics, test data, cesign, and production data on munitions of war. 18

Earlier DoD guidance gave the following examples of Confidential information:

(1) Operational and battle reports which contain information of value to the enemy.

(2) Intelligence reports.

(4) Information which indicates strength of our ground, air and naval forces in United States and overseas areas, identity or composition of units, or quantity of specific thems of equipment pertaining thereto. (A defense classification is normally required, if such information reflects the overall strength figures or quantities of weapons whose characteristics are themselves classified, or additional factors necessitate security protection.)

(5) Unless a higher classification is needed to protect information relating to a particular munition:

(a) Documents and manuals containing technical information used for training, maintenance, and inspection of classified munitions of war.

(b) Research, development, production, and procurement of munitions of war.

(c) Performance characteristics, test data, design, and production data on munitions of war.

(6) Operational and tactical doctrine.

(7) Mobilization plans. ${ }^{19}$

The MED Security Manual mentioned above also gave examples of what constituted Confidential information. ${ }^{20}$

(1) Documents containing specific design details (diagrammatic or descriptive) of incomplete components of basic or key equipment, apparatus, instruments, or machinery employed in a critical stage of the processing and production of end 
products, or the methods of manufacture (where unique to the District) of such items. Also, the material liself, as described above.

(2) Documents containing Incomplete uncoded flow sheets, diagrams or reactions; or speclfic pressures, temperatures, voltages, rates, formulae, and other operating detalls related to a non-critical step in the preparation, processing, separation, or purification of basic feed materials, and principal end products where not described in the Smyth Report.

(3) Documents containing unique physical and chemical characteristics of special materials not pertaining to the product material or process but used to overcome operational problems unique to the District. Also critical detalls of the manufacture of such materials and the materials themselves. (Examples: special lubricants, seals, and solvents.)

(4) Documents showing the meaning of code names or symbols used to refer to Confidential information.

(5) Documents relating to special investigations, clearance, or assignment of personnel who will have knowledge of, or access to, classified information wherein adverse information is reflected.

(6) Details pertaining to features of special shipping containers, routes and schedules of shipments of confidential materials.

A major distinction between Secret and Confidential information in the MED appeared to be that Secret documents gave the entire description of a process or of key equipment, etc., whereas Confidential documents revealed only fragmentary information (not the critical information). Also, Secret information pertained to details of critical steps or process parameters, whereas Confidential information pertained to similar parameters for noncritical steps or process parameters.

Table 7.1 contains examples of the effects of disclosure of Confidential, Secret, or Top Secret information for several types of NSI. These examples were summarized from information given previously in this chapter.

\section{PRINCIPLES FOR ASSIGNING CLASSIFICATION LEVELS}

\section{General Principles}

The more important that an item of information is to national security (the more damage that would be caused by its disclosure), the higher should be the classification level of that information. Determining the net damage to the nation caused by disclosure of information was described in Chapter 6. The magnitude of that damage will determine the classification level that should be assigned to the information under consideration for classification.

The amount of damage caused by disclosure of information will be the primary determinant of the classification level to be assigned to that information, but the imminence of that damage might also be a factor in determining its classification level. That is, the shorter the time peric between the time that the information is known to an adversary and the time that the adversary can use that information to our detriment, the higher should be the classification level of that information. 
Table 7.1. Examples of the effects of disclosure of Confidential, Secret, and Top Secret information for several types of NSI information

\begin{tabular}{|c|c|c|c|}
\hline \multirow{2}{*}{$\begin{array}{c}\begin{array}{c}\text { Type of } \\
\text { information }\end{array} \\
\end{array}$} & \multicolumn{3}{|c|}{ Classification level } \\
\hline & Confidential & Secret & Top Secret \\
\hline $\begin{array}{l}\text { Diplomatic } \\
\text { information }\end{array}$ & $\begin{array}{l}\text { Damage to foreign } \\
\text { relations }\end{array}$ & $\begin{array}{l}\text { Disruption of foreign } \\
\text { relations significantly } \\
\text { affecting the national } \\
\text { security }\end{array}$ & $\begin{array}{l}\text { Disruption of foreign } \\
\text { relations vitally } \\
\text { affecting national } \\
\text { security }\end{array}$ \\
\hline $\begin{array}{l}\text { Military or } \\
\text { defense plans }\end{array}$ & $\begin{array}{l}\text { Revelation of strength of } \\
\text { military forces in the U.S. } \\
\text { and overseas; technical } \\
\text { information used for } \\
\text { training, maintenance, and } \\
\text { inspection of classified } \\
\text { munitions of war; or per- } \\
\text { formance characteristics, } \\
\text { test data, design, and } \\
\text { production data on } \\
\text { munitions of var }\end{array}$ & $\begin{array}{l}\text { Revelation of } \\
\text { significant military } \\
\text { plans }\end{array}$ & $\begin{array}{l}\text { Compromise of vital } \\
\text { national defense plans }\end{array}$ \\
\hline \multirow[t]{2}{*}{$\begin{array}{l}\text { Intelligence } \\
\text { information }\end{array}$} & & $\begin{array}{l}\text { Revelation of } \\
\text { significant intelligence } \\
\text { operations }\end{array}$ & $\begin{array}{l}\text { Compromise of com- } \\
\text { plex cryptologic and } \\
\text { communications intelli- } \\
\text { gence systems }\end{array}$ \\
\hline & & & $\begin{array}{l}\text { Revelation of sensitive } \\
\text { intelligence operations. }\end{array}$ \\
\hline $\begin{array}{l}\text { Scientific or } \\
\text { technical } \\
\text { information }\end{array}$ & & $\begin{array}{l}\text { Compromise of signif- } \\
\text { icant scientific or } \\
\text { technological devel- } \\
\text { opments relating to } \\
\text { national security }\end{array}$ & $\begin{array}{l}\text { Disclosure of scientific } \\
\text { or technological } \\
\text { developments vital to } \\
\text { national security }\end{array}$ \\
\hline Miscellaneous & & $\begin{array}{l}\text { Significant impair- } \\
\text { ment of a program or } \\
\text { policy directly related } \\
\text { to the national } \\
\text { security }\end{array}$ & \\
\hline
\end{tabular}

The extent of dissemination of classified information might also be a factor in determining that information's classification level. The probability of unauthorized disclosure of classified information increases with an increase in the number of persons who know that information (see Appendix G). Consequently, it might not be reasonable to assign a Top Secret classification level to information that, for example, is expected to be given to 10,000 persons. Such extensive dissemiration would proportionately increase the probability of unauthorized disclosure of that information. Therefore, the expected extent of 
dissemination of classified information should probably be a factor in determining the classification level to be assigned to that information.

\section{Classification Because of Effort Required to Get the Information}

Sometimes, as was discussed in earlier chapters, information such as scientific or technical information is classified even though an adversary could reasonably be expected to get that same information through its own, straightforward, independent efforts. This information is classified to make an adversary use its resources to get this information, resources that it might otherwise use to our detriment. This type of information does not represent any scientific or technological breakthrough. This type of information can be acquired by competent technical persons using equipment that is readily available or easily constructed. Since such information is relatively easily available and since there is very little, if anything, that can be done to prevent an adversary from obtaining this information through its own efforts, the consequences of an adversary's getting this information can hardly be termed serious enough to warrant a classification level of Secret or higher. Therefore, this type of information should generally not be classified higher than Confidential.

\section{Reasonable Doubt About Classification Level}

When there is reasonable doubt about the appropriate classification level for NSI, EO 12356 requires that the information be safeguarded at the higher level pending a determination by an original classification authority. ${ }^{21}$ However, since the current discussion is about original classification authorities determining classification levels, it is not clear what an original classifier should do if there is uncertainty about the classification level. The strong implication is that the information should be classified at the higher level until more details are obtained on the damage that could be caused by disclosure of the information. Since there are no other presumptions favoring a lower classification level, this would seem to be a reasonable principle.

\section{CLASSIFICATION LEVELS FOR SCIENTIFIC OR TECHNICAL INFORMATION}

\section{Top Secret Scientific or Technical Information}

According to examples provided by current NSC regulations (see above), only scientific or technological developments vital to the national security should be assigned the Top Secret classification level. Disclosure of this information "reasonably could be expected to cause exceptionally grave damage to the national security. ${ }^{n 3}$ Vital is defined as follows:

Vital-of the utmost importance; essential to the continued nxistence, vigor, efficiency, independence, or value of something expressed or implied; taking priority in consideration over other factors or elements. ${ }^{4}$

\footnotetext{
In Chapter 6, reasons were given for presuming that non-atomic energy information should remain unclassified if there was reasonable doubt about whether it should be classified as NSI.
} 
The other key words used to describe the Top Secret classification level were defined earlier.

The 1964 DoD classification instructions referred to earlier in this chapter contained an example for Top Secret scientific or technical information, which was as follows:

Vital information concerning radically new and extremely important equipment (munitions of war), such as nuclear weapons, atomic weapons stockpile data, and any other munitions of comparable importance the scientffic or technological development aspects of which are vital to national defense.2

It would be expected that only rarely would classified scientific or technological information be place in the Top Secret level.

\section{Secret Scientific or Technical Information}

According to examples provided by current NSC regulations (see above), only "significant scientific or technological developments relating to national security" should be classified at the Secret level. "Significant" has the following definition:4

Significant - having meaning; full of import; having or likely to have influence or effect; deserving to be considered; important; weighty; notable.

The previously cited 1964 DoD instructions on information to be classified at the Secret level indicated that the following scientific and technical information should be classified at the Secret level:

\footnotetext{
Particulars of scientific or research projects which incorporate new technological developments or techniques having direct military applications of vital importance to the national defense.

Specific details or data relating to new materials or important modifications of materials which reveal significant military advances or new technological developments having direct military application of vital importance to the national defense. ${ }^{23}$
}

Comparing this description with the previously given DoD description for Top Secret scientific or technical information indicates that both levels are concerned with developments vital to national defense. One difference between the two descriptions is that Secret information includes new technological developments, materials, etc., whereas to be Top Secret the information has to concern radically new and extremely important munitions of war such at atomic weapons.

\section{Confidential Scientific or Technical Information}

Neither EO 11652 nor the NSC regulations mentioned earlier provide specific guidance with respect to classifying scientific or technical information at the Confidential level. The only guidance provided by EO 12356 is that which is used to define the Confidential level - that unauthorized disclosure of Confidential information reasonably could be expected to cause damage to the national security. The previously mentioned 1964 DoD instruction seems to consider that if scientific and technical information related to research and development of munitions of war is not classified at the Top Secret or Secret level, then it should be classified at the Confidential level. That instruction included the following guidance regarding what should be classified at the Confidential level. 
Unless a higher classification is needed to protect information relating to a particular munition:

(a) Documents and manuals containing technical information used for training, maintenance, and inspection of classified munitions of war.

(b) Research, development, production, and procurement of munitions of war.

(c) Performance characteristics, test data, design, and production data on munitions of war. $^{24}$

That guidance is rather broad and encompasses a lot of information.

A 1970 DoD report on the effects of classification on scientific and technical information on research, development, production, and deployment of weapon systems stated the following with respect to the use of the Confidential classification level:

The Task Force was inclined to the view that the classification category [sic] of
"Confidential," as applied at present to research and development not bearing
immediately on field problems of military interest, is probably useless, or even
detrimental, for it prevents normal diffusion of information without providing a really
effective barrier to leaks. It probably would be much more realistic to confine this
category of classification to matters bearing on military plans and readiness.

The comment that the Confidential category did not provide a "really effective barrier to leaks" is rather puzzling with respect to classification matters. If the Confidential category was not effective, then that ineffectiveness may have been caused by inadequate enforcement by security of improper handling of documents or materials in that category, rather than due to improper placement of information in that category.

A similar comment about the ineffectiveness of the Confidential classification category would definitely not be applicable to classified scientific or technical atomic energy information (RD and FRD) classified at the Confidential level by DOE. In practice, DOE uses essentially only the Confidential and Secret classification levels for RD and FRD. DOE very rarely assigns a Top Secret classification level to scientific or technical RD or FRD. The protection of Confidential Restricted Data (CRD) and Confidential Formerly Restricted Data (CFRD) is taken very seriously within DOE, and information is not assigned the Confidential classification level unless it truly warrants classification.

If the balancing process described in Chapter 6 results in a conclusion that disclosure of the information will cause net damage to the nation, and the reasonably expected damage is not great enough to warrant a Top Secret or Secret classification level under the criteria given above, then the Confidential level should be assigned to the classified information.

\section{REFERENCES}

1. Executive Classification of Information-Security Classification Problems Involving Exemption (b)(1) of the Freedom of Information Act (5 U.S.C. 8552), Committee on Government Operations, H.R. 93-221, 93rd Cong., 1st Sess., U.S. Govt. Printing Office, 1973, p. 100.

2. Executive Order 12356, Fed. Reg., 47, 14874 (Apr. 6, 1982). Hereafter cited as "EO 12356."

3. EO $12356, \$ 1.1(a)(1)$. 
4. Webster's Third New International Dictionary of the English Language, Unabridged, MerriamWebster, Inc., Springfield, Mass., 1986.

5. EO 11652, Fed. Reg., 37, 5209 (Mar. 10, 1972). Hereafter cited as "EO 11652."

6. EO 11652, \$1(A).

7. 32 CFR Part 2101.53(b).

8. U.S. Department of Defense, Information Security Program Regulation, DoD 5200.1-R, Chap. I, \$1-501, June 1986. Hereafter cited as "DoD 5200.1-R."

9. U.S. Department of Defense, Security Classification of Official Information, Instruction 5210.47, Appendix A, Part I, Dec. 31, 1964. Hereafter cited as "DoD 5210.47."

10. EO 12356, \$1.1(a)(2).

11. EO 11652, \$1(B).

12. 32 CFR Part 2101.53 (c).

13. DoD 5200.1-R, Chap. I, \$1-502.

14. DoD 5210.47, Appendix A, Part II.

15. U.S. Engineer Office, Manhattan District, Security Manual, Nov. 26, 1945, pp. 20-21. Hereafter cited as "MED Security Manual."

16. EO 12356, §1.1(a)(3).

17. 32 CFR Part 2101.53(d).

18. DoD 5200.1-R, Chap. I, §1-503.

19. DoD 5210.47, Appendix A, Part III.

20. MED Security Manual, pp. 21-22.

21. EO 12356, $\$ 1.1(\mathrm{c})$. See also the Information Security Oversight Office "Directive No. 1," Fed. Reg., 47, 27836 (June 25, 1982), §2001.1(b)(2); 32 CFR 2001.1(b)(2).

22. DoD 5210.47, Appendix A, Part I, Item 7.

23. DoD 5210.47, Appendix A, Part II, Items 6 and 7.

24. DoD 5210.47, Appendix A, Part III, Item 5.

25. U.S. Department of Defense, Report of the Defense Science Task Board on Secrecy, F. Seitz, Chmn., Office of the Director of Defense Research and Engineering, July 1, 1970, pp. 10-11. 


\section{Chapter 8. CLASSIFICATION DURATION}

\section{INTRODUCTION}

Our government classifies information and subsequently applies security procedures to documents and materials containing or revealing that information to prevent adversaries from obtaining that information and using it to our detriment. Unfortunately, classifying information does not absolutely prevent an adversary from obtaining that information. The only way to keep information absolutely secret is either to tell no one about that information ${ }^{*}$ or to use the Captain Kidd method. ${ }^{\dagger, 1}$ However, for information to be of value to our government, that information usually has to be known to more than one person. Therefore, the "tell no one approach" to keeping secrets is generally not a feasible solution. The Captain Kidd method for keeping secrets is not acceptable. Consequently, our government uses the classification-of-information method to help keep secrets. Classification of information and subsequent application of security procedures delay the disclosure of that information ("buys time"). ${ }^{\ddagger}$

Generally, information cannot be kept from an adversary for an unlimited period of time. Sometimes an adversary will obtain classified information through espionage activities. At other times classified information will be inadvertently disclosed and thereby revealed to an adversary. For scientific and technical information, an adversary can possibly obtain the same information through its own efforts.

Even if classified information could be kept from an adversary for many years, it is usually not necessary to keep that information from the adversary for such a long period of time. For classified operational information, the conduct of that operation will reveal much of the classified information to the adversary. For operations that were never carried out, the mere passage of tinie will render the information of little value to anyone except historians.

\footnotetext{
"Three may keep a secret if two of them are dead." Ben Franklin's Wit and Wisdom, Peter Pauper Press, Mt. Vernon, N.Y., p. 46. See also Poor Richard: The Almanacks for the Years 1733-1758, Van Wyck Brooks, ed., New York, Heritage Press, 1964, July 1735, p. 30, as reported by S. Bok, Secrets, Pantheon Books, New York, 1978, p. 108.

tCaptain Kidd was a pirate who was said to bury his treasure for safekeeping and later recovery. He is alleged to have usually killed the persons who helped him bury this treasure to keep them from revealing its location to others or from returning on their own to dig it up. The "Captain Kidd Method" is to "terminate" the persons to whom a secret has been told after their usefulness to the discloser has ended and before they can tell this secret to someone else.

General L. R. Groves, head of the Manhattan Project, succinctly expressed that [Captain Kidd] option in a 1945 Congressional hearing on the control of atomic energy, as follows: "I would like to say that the only thing that would preserve security would be to lock everybody up, and when they decided to leave to shoot them and be done with it. That is the only way you could have perfect security" [U.S. Congress, House of Representatives, Committee on Military Affairs, "Atomic Energy," Hearings on H.R. 4280, "An Act for the Development and Control of Atornic Energy, ${ }^{n}$ October 9 and 18, 1945, 79th Congress, 1st Sess., 1945, Testimony of Gen. L. R. Groves at p. 20.].

\#"There are times in the course of human history when time itself may be very important" [United States $v$. Progressive, 467 F. Supp. 990, 994 (W.D. Wisc., 1979), appeal dismissed, 610 F.2d 819 (7th Cir., 1979)].
} 
For a new weapon system, an adversary may learn its classified aspects when that system is deployed. Therefore, for much classified information there is only a relatively short period of time when it is important to keep that information classified. However, certain types of information such as scientific or technical information, information on intelligence sources and methods, and cryptographic information may need to remain classified for relatively long periods of time.

A classifier should, when classifying information, determine whether or not it is feasible at that time to specify a classification duration (i.e., to specify automatic declassification). The duration of information classification should be kept as short as feasible to avoid unnecessary classification costs. However, establishing too short a classification duration may result in an adversary getting the information more quickly than desired and therefore will prematurely negate the classification benefits (e.g., an adversary may quickly develop effective countermeasures to a weapons system). Therefore, a classifier must be very careful when establishing a classification duration.

A determination of duration of classification is pertinent only to the classification of NSI. Documents that contain RD or FRD, regardless of whether they contain NSI, are not to be marked in advance for declassification. The policy of the Atomic Energy Commission was that no practical time limit could be placed on the life of classified information." Thus, RD and FRD are unique not only because they are "born classified" but also because they can "live forever."

EO 12356 states that NSI should be classified "as long as required by national security considerations." 2 "When it can be determined, a specific date or event for declassification shall be set by the original classification authority at the time the information is originally classified. ${ }^{2}$ Some prior EOs established time limits for declassification. The first such EO was issued by President Kennedy on September 20,1961. ${ }^{3}$ It established four groups of information with respect to automatic downgrading and declassification. Classified information in Group 1 was exempt from automatic downgrading or declassification. It included foreign government information, information from international organizations, RD and FRD, and information requiring special handling such as intelligence and cryptology information. ${ }^{\dagger}$ Group 2 information included extremely sensitive information or material which was exempted, on an individual basis, from automatic downgrading or declassification. Information in Group 3 was automatically downgraded at 12-year intervals until the lowest classification level was reached. It was not automatically declassified. Group 4 information was automatically downgraded at 3-year intervals and automatically declassified 12 years after date of issuance.

EO 12065 stated that, as a general rule, information should be declassified within 6 years of its classification. ${ }^{4}$ Exceptions were provided, but they were to be used sparingly. Information classified longer than 6 years was to be reviewed at a date established at the time

\footnotetext{
This view is more likely to be correct with respect to classified scientific or technical information than with respect to operational information. Most of the Atomic Energy Commission's classified information was scientific and technical information.

Note that Group 1 seems to have included those areas of NSI whose unauthorized disclosure is presumed to cause damage to the national security [see EO 12356, $81.3(\mathrm{c})$ ], plus cryptographic and classified atomic energy information.
} 
of classification but no later than 20 years after its original classification ( 30 years for foreign government information).

Automatic downgrading and declassification did not achieve all expected objectives. It was said that automatic declassification did not result "in a reduction in storage and handling costs nor does such action contribute materially to informing the public on govirnment activities. ${ }^{n 5}$ From a practical standpoint, automatic declassification was said at most to make certain information accessible to historical researchers. ${ }^{5}$ One reason why time-phased downgrading or declassification was said not to work was that program managers excluded classified material from automatic downgrading or declassification because of a lack of "sufficient competent personnel to make the value judgments needed to determine what should be classified and what should not, or what need be no longer classified."

EO 12356 was said to eliminate those "artificial 6- and 20-year limitations [present in prior EOs] that substituted for judgment of original classification authorities."7

\title{
PRINCIPLES FOR DETERMINING THE DURATION OF INFORMATION CLASSIFICATION
}

\section{General}

As might be expected, there is a divergence of opinion on how long information can be kept classified before an adversary becomes aware of that information. A 1970 Feport of the Defense Science Board Task Force on Secrecy expressed the following opinion:

\begin{abstract}
It is unlikely that classified information will remain secure for periods as long as five years, and it is more reasonable to assume that it will become known by others in periods as short as one year through independent discovery, clandestine disclosure or other means. ${ }^{8}$
\end{abstract}

Hanson Baldwin stated that "the experience of history has been that no military secrets can long be kept; in any case, there is nearly always a definite time limit on their importance." 9 Vanevar Bush had a different opinion:

Sometimes . . you will hear it argued that no secret can be kept very long anyhow. This argument flies in the face of the facts [citing the years of effort the U.S. put into "pulse detection of submarines," how well that secret was kept, and how fortunate it was for the U.S. in World War II that the secret had been kept]. ${ }^{10}$

With respect to military equipment, it has been stated that its classification "does not diminish in fixed proportion to elapsed time, but in relation to events, the timing of which usually cannot be predicted." 11 John Foster, former Director of Defense Research and Engineering, DoD, stated the following in 1974:

The time span of sensitivity [of classified information] can be affected by any number of factors: the state-of-the-art of technology, the success of our or the enemies intelligence activities, political, military, and technical developments, and many more. The point is that there can be no magic formula or standard for determining the number of years to retain classification on any particular piece of equipment or item of information. $^{12}$ 
The length of the delay on information disclosure that is possible by classifying information usually depends on the type of information being protected (e.g., subjective or objective; operational or scientific), the number of persons knowing the information, the kind of security procedures used to protect this information, and the diligence in classification and security matters of those possessing and protecting the information. ${ }^{13}$ In favorable situations, the "leaks" of classified information will be in small, fragmentary increments that are widely spaced in time, geographically scattered, and hopefully not completely accurate.

The period of time during which classified information about a military weapon system is kept from an adversary is frequently termed "lead time." Technological lead time is essential if a nation wants to depend on the quality of its weapon systems rather than the quantity. The baseline for lead time determination is the normal time required to transmit information in the absence of a classification system. By classifying information, lead time may exceed this baseline by (1) the time required for independent discovery by an adversary, (2) the time elapsed before an inadvertent unauthorized disclosure, (3) the time elapsed before a deliberate unauthorized disclosure (espionage or deliberate leak), or (4) the time elapsed before authorized disclosure (declassification). Assuming that the classification and security systems work as planned, then the time required for independent discovery (or until authorized disclosure) is the lead time.

Classification duration may be defined (1) in terms of a time period measured from the origination date of a document (i.e., at a future date) or (2) in terms of a future event which must occur prior to declassification. ${ }^{2}$ If a date or event cannot be specified, then a classified document containing NSI will be marked to indicate that the originating agency's determination is required for declassification. "14 The specified marking is "Originating Agency's Determination Required" or "OADR." This indicates that the agency that originally classified the information (or originated the document) has the sole authority to determine when the information (or document) can be declassified. Therefore, for classification decisions, the question is whether a duration of classification can be specified for classified information or whether no duration can be specified so that declassification must await the actual disclosure event.

DoD regulations allow, under certain conditions, a subsequent extension of a classification duration that was specified by the original classifier of the information:

The duration of classification specified at the time of original classification may be extended only by officials with requisite original classification authority and only if all known holders of the information can be notified of such action before the date or event previously set for declassification. 15

The next two sections discuss classification duration described by a time period or an event, respectively. A following section suggests that it may be possible to estimate a classification duration based on the probability of its unauthorized disclosure, which in turn depends to a great extent on the number of persons who have been given the information. The final section of this chapter bricfly mentions some aspects of classification duration applicable to scientific or technical information.

\footnotetext{
- Of the $-512,000$ original classification decisions by executive agencies in FY $1991,5 \%$ were assigned a date or an event for declassification and 95\% were marked OADR ["Information Security Oversight Office (ISOO) 1991 Report to the President," Information Security Oversight Office, Wash., D.C., March 1992, pp. 12-15].
} 


\section{Classification Duration Defined by a Time Period}

A specific classification duration time period is frequently used within DOE and its contractors for classified notices that direct the recipient to classify a specific document that was previously mistakenly issued to that recipient as unclassified. Some of those notices are classified only because they indicate that a certain document, currently not marked as classified, contains classified information. The classification of those notices is usually Confidential-NSI, and they are usually marked to be declassified 2 years from their issue. This is based on the assumption that within 2 years all copies of the document to be upgraded will have been properly marked or destroyed. Of course, if there is doubt about accomplishing shis within 2 years, then the notice should be marked OADR.

Executive Orders preceding EO 12356 established time limits for classification of certain types of NSI. As mentioned earlier in this chapter, those classification duration requirements were not included in EO 12356.

\section{Classification Duration Defined by an Event}

An example of declassification triggered by an event might be the classification of informaition related to military operations. This information is fluid or transient and needs to be classified for only a relatively short period of time. Plans for an operation may be highly classified before and during the operation. ${ }^{\dagger}$ After the operation is over, the plans (especially information about the time and place the operation is to begin) will not be of much value to an adversary and therefore can probably be declassified. Declassification of the plans at that time will not affect the outcome of the operation (although those plans might provide insights into the philosophy of the planners and could remain classified for that reason). Therefore, classified operations plans could be designated to be declassified when a specified time period has elapsed after the operation has started or after the operation has been completed. $\ddagger$ Some classified information about an operation, such as the start date, can of course be declassified immediately after that start date.

Certain classified information about nuclear material shipments is generally declassified after the happening of an event (completion of the shipment). Prior to and during the shipment, information such as time of shipment and specific route taken is classified for reasons of security. After the shipment is over, there is usually no need to keep that

\footnotetext{
"If the notice described Secret Restricted Data (SRD) that was in the document that was issued as unclassified, then the notice itself would also be classified SRD.

tOperation Overlord was the code name for the Allied invasion of Nazi-held France during World War II. When planning started for that operation there were only 32 persons who were cleared and knowledgeable about that operation. Two days before D-day, the invasion of Normandy, about five or six thousand persons were knowledgeable about everything except the exact destination [G. C. Jacobus, "Panel-Research in Automated Classification Management," J. Natl. Class. Mgmt. Soc., 3(2), 49-68 (1967) p. 55]. Several hours after that invasion began, millions of persons knew about the operation.

FThe DoD security classification guidance for Operation Desert Storm, the 1991 military operation by the United Nations against Iraq, suggested that classifiers should consider marking information with "Declassification Upon Termination of Hostilities" to avoid declassification problems at the end of that operation [as reported in "DOD Keeps Tight I.id on Desert Storm Data, Sites National Security Reasons," Inside the Pentagon, Wash., D.C., 7(15), 1 and 12-14 (Apr. 11, 1991) p. 13].
} 
information classified (unless it would reveal patterns in shipments, etc.). That information can therefore be declassified when the shipment has been received by the consignee.

If the purpose of classification is to buy lead time while developing a weapon system, then generally much of the information concerning that system may be declassified when the system is deployed. At deployment, the adversary usually has an opportunity to observe the hardware and its operations, so the operational capability will be known and other associated classified information may be inferred. Consequently, certain information may be marked as "declassify after deployment."

\section{Classification Duration Based on Probability of Unauthorized Disclosures}

General. The preceding sections provided guidance for establishing a classification duration as a function of elapsed time (e.g., declassifying on a certain date) or on the happening of an event. In those situations, the classifier has determined that national security considerations no longer require that the information be classified after a certain date or event. The classification of the information "perishes" at that date or on that event because the information is then no longer valuable to us or to an adversary. The government (the classifier) directly controls the perishability of the classification because the government controls whether or not an event happens.

There is another type of perishability of classification which should be considered when estimating the duration of classification or when predicting how long classified information can realistically be expected to be kept from an adversary. Classification of information perishes, or at least the need for or major benefit of classification perishes, when an adversary obtains the classified information through unauthorized disclosures (via either espionage by the adversary or mistakes by the possessor of the information). ${ }^{* t}$ This other type of perishability is not controlled directly by a government but is somewhat under government control.

Perishability of classified information through unauthorized disclosure of that information to an adversary depends on several factors, a major one of which is the number of persons to whom the classified information has been given. ${ }^{\ddagger}$ A government can control (e.g., through clearances and need-to-know requirements) the number of persons who have access to that information. Therefore, perishability through unauthorized disclosure may be somewhat controllable as well as somewhat predictable.

Some relationships that may be used to estimate the probability of unauthorized disclosure of classified information, based on the number of persons who know that information and on other factors, are given in Appendix $\mathrm{G}$ for different types of unauthorized

\footnotetext{
"However, if there is more than one adversary from whom the information is being kept, then just because one adversary obtains that information is not a reason for declassifying that information and making it available to all adversaries.

tClassification of certain objective information, such as scientific or technical information, also perishes when an adversary obtains that information through its own, nonespionage, efforts. This type of perishability will not be discussed in this section.

†Note that a characteristic of a "protectable" trade secret is that it is known only to a few people [M. F. Jager, Trade Secret Law, Clark Boardman Co., Ltd., New York, 1988, §2.02, p. 2-14].
} 
disclosures. That appendix provides the details of those probability relationships and gives the rationale for their development. Those probability relationships are summarized in the following paragraphs.

Types of Unauthorized Disclosures. Unauthorized disclosures of classified information occur when that information is obtained by someone not authorized to receive such information. An unauthorized disclosure occurs when classified information is received by an individual who does not have a security clearance." Unauthorized disclosures can be either deliberate or inadvertent, direct or indirect, oral or written.

Deliberate unauthorized disclosures include transmittals from a U.S. citizen with a security clearance to a foreign government (from a spy to an adversary). They also include leaks to the press (i.e., essentially public releases) by a member of the government (e.g., for political reasons). Deliberate unauthorized disclosures are direct disclosures. The classified information goes directly to someone not authorized to receive that information. Whether or not deliberate disclosures are oral or written is not important-direct disclosures are meant to get directly to an adversary or to be released to the public such that subsequent transmittal to an adversary is a foregone conclusion.

Inadvertent unauthorized disclosures may be oral or written, direct or indirect. An inadvertent direct unauthorized disclosure is an oral or written communication received directly by an unauthorized person when the transmitter made a mistake and the intended unclassified communication actually contained classified information. An inadvertent indirect unauthorized disclosure occurs, for example, when a person working on a classified project communicates (orally or in writing) with a colleague on that project, when the communication is intended to contain no classified information, when the communication actually contains classified information, and when the communication is overheard by or read by an unauthorized person.

Probability of Unauthorized Disclosures of Classified Information Reaching an Adversary. The probability of an unauthorized disclosure of classified information reaching an adversary is a linear function of the number of persons who know that classified information and on several other factors. The generalized equation for this probability is as follows, for a disclosure scenario $S$ :

$$
\text { Probability }(S)=\mathrm{k}_{\mathrm{s}} \times N P_{s} \times N C O M_{s} \times \mathrm{CREV}_{s} \times C O P_{s} \times U A R_{s} \times R T A_{s},
$$

where $\mathrm{k}_{\mathrm{s}}$ is a constant that depends on the general scenario, NP is the number of persons who know the classified information, NCOM is the average number of communications by each of those persons during a time period, CREV is a classification review factor that is approximately a constant for each general scenario, COP is the average number of copies of each communication, $U A R$ is the number of unauthorized recipients of each communication,

\footnotetext{
"An unauthorized disclosure might also occur when an individual with a security clearance but without a need to know receives classified information that he or she does not need to know. That type of unauthorized disclosure was not considered in Appendix G, since the major unauthorized disclosure risk occurs when the classified information is disclosed to an uncleared person.
} 
and $R T A$ is the probability that one of those unauthorized recipients will send the classified information to an adversary. The numerical value of some of those factors may be estimated for general unauthorized disclosure scenarios, while some may be estimated only for specific scenarios.

As mentioned above, in all scenarios the probability that an unauthorized disclosure of classified information will reach an adversary is a linear function of the number of persons who know the classified information, NP. However, in one scenario, that probability also seems to be a function of the square of NP. That situation is the inadvertent indirect unauthorized oral disclosure scenario, where the total number of communications, $N C O M$ (total), is a function of the number of interactions of classified project participants and is therefore a function of the square of $N P$. In the other scenarios, the total number of communications is a product of NP and NCOMY.

The baseline probability of classified information reaching an adversary through an unauthorized disclosure is the deliberate disclosure scenario, the espionage situation. That probability is solely a function of NP. The constant in the equation, or at least its lower limit, can be estimated with reasonable certainty based on the number of U.S. citizens with security clearances who have sent classified information to adversaries (the number of "spies") in recent years. The probabilities for other scenarios are more complex to estimate. Those probabilities are described in Appendix $\mathrm{G}$, where the approximations and estimates used to derive those probabilities are also discussed.

The generalized equation for the probability of unauthorized disclosures provides a simple, direct way to describe the factors important to protecting classified information. The equation shows, in a straightforward manner, that classified information about a project can best be protected by limiting the number of persons to whom that information is given (stringently enforcing need-to-know requiremerts), by minimizing the number of "unclassified" communications related to that project and generated by such persons, by minimizing the number of copies of such communications, and by requiring classification review of all jobrelated communications originated by project personnel. Some of those methods to protect classified information will be difficult to achieve. However, the equation can be used, for a specific classified project, to help determine the weak links with respect to unauthorized release of classified information concerning that project. This helps classification management programs and security programs in ensuring that available classification and security resources are spent to correct those weak links. It is interesting that evaluation of the probability equation for several scenarios appears to indicate that a major source of unauthorized disclosures is conversations about a classified project which take place between project workers in nonsecure locations. This conclusion is supported by observations previously reported with respect to industrial espionage (see Appendix G). It is hoped that further evaluation of the probability equation and its paraineters and constants will lead to additional results useful in protecting classified information.

\footnotetext{
"Baseline means that all the other probabilities of unauthorized disclosure should be less than this since those other probabilities can be under greater control by us.
} 


\section{Classification Duration of Scientific or Technical Information}

Technical information will generally need to be classified for longer periods of time than either military operational information or information that is classified to protect lead time. However, even the national security value of scientific and technical information is transient. This is because the steady, worldwide advance of science and technology along broad fronts (the general progress of knowledge) may lead others to discover that same information. Also, other nations are usually expending efforts in research and development in the same general technology (if that technology shows great promise of providing national security benefits), and they may make similar discoveries at about the same time as our discoveries.

The rate at which scientific and technical information loses its value (how quickly it can be declassified) depends on the particular field of knowledge (whether it is new and rapidly developing or an old, well-established field that is progressing relatively slowly), the relative research and development efforts of the competing nations, and on other factors. Much $R D$ is very technical in nature (e.g., uranium isotope separation information; nuclear weapon design data) and some RD has been classified for a relatively long period of time (over 40 years). In other national defense areas, such as some conventional weapon technologies, technological advances may quickly occur and obsolescence may be rapid-estimated at about 5 years in certain areas. ${ }^{16}$

It is very difficult to estimate the rate of progress of science or technology or the date by which an adversary will have obtained the classified scientific and technical information by its independent efforts. Therefore, this type of information is usually not marked in advance for declassification. Classified scientific or technical information is usually evaluated periodically to determine whether it may be declassified. That evaluation process is described in a subsequent chapter on declassifying information.

\section{REFERENCES} (1972), p. 81.

2. Executive Order 12356, Fed. Reg., 47, 14874 (Apr. 6, 1982), §1.4(a).

3. Executive Order 10964, "Amendment of Executive Order No. 10501, Entitled 'Safeguarding Official Information in the Interests of the Defense of the United States," Fed. Reg., 26, 8932 (Sept. 22, 1961).

4. Executive Order 12065, Fed. Reg., 43, 28949 (June 28, 1978), \$1-4.

\footnotetext{
"Now, I think that really when it comes to military security and the relative advantages of giving out information and not giving it out, what we are interested in from the military standpoint is the relative movement, you might say, of ourselves and other nations. It isn't so much how fast we progress; it is the relative motion of the two" [Gen. L. R. Groves in Atomic Energy Act of 1946, Hearings before the Special Subcommittee on Atomic Energy, U.S. Senate, on S. 1717, "A Bill for the Development and Control of Atomic Energy," February 18, 19, and 27, 1946, 79th Cong., 2nd Sess., U.S. Govt. Printing Office, 1946, p. 495].
} 
5. D. O. Cooke, testifying for the Department of Defense, as reported in U.S. Government Information Folicies and Practices-The Pentagon Papers (Part 2), Hearings Before a Subcommittee of the Committee on Government Operations, House of Representatives, 92nd Congress, 1st Session, June 28 and 29, 1971, U.S. Govt. Printing Office, p. 601.

6. J. S. Foster, in Government Secrecy, Hearings Before the Subcommittee on Intergovernmental Relations of the Committee on Government Operations, U.S. Senate, 93rd Congress, 2nd Session, May 22, 23, 29, 30, 31 and June 10, 1974, U.S. Govt. Printing Office, p. 269. Hereafter cited as "J. S. Foster, "Govermment Secrecy."

7. A. F. Van Cook, "Information Security and Technology Transfer (An OUSD Overview of Executive Order 12356 and DoD's Vicw Concerning Implementation)," J. Natl. Class. Mgmt. Soc., 18, 1-7 (1982), p. 3.

8. U.S. Department of Defense, Report of the Defense Science Board Task Force on Secrecy, F. Seitz, Chairman, Office of the Director of Defense Research and Engineering, July 1, 1970, p. 1.

9. H. Baldwin, quoted in Bull. At. Sci, 1(9), (Apr. 15, 1946) p. 6.

10. V. Bush, in an address before the American Society of Newspaper Editors, April 16, 1948, as reported in Tab E, pp. 3-4, in Report to the Secretary of Defense by the Committee on Classified Information, C. A. Coolidge, Chairman, U.S. Department of Defense, Nov. 8, 1956.

11. E. Hill, "Defence Procurement and Classification in the U.K., J. Natl. Class. Mgmt. Soc., 16, 20-27 (1980), p. 25.

12. J. S. Foster, Government Secrecy, p. 268.

13. See, for example, C. L. Marshall, Director of Classification, Atomic Energy Commission, in Government Secrecy, Hearings Before the Subcommittee on Intergovernmental Relations of the Committee on Government Operations, U.S. Senate, 93rd Congress, 2nd Session, May 22, 23, 29, 30, and 31 and June 10, 1974, U.S. Govt. Printing Office, 1974, p. 278.

14. Information Security Oversight Office, "Directive No. 1," Fed. Reg., 47, 27836 (June 25, 1982), \$2001.5(d)(3); 32 CFR Part 2001.5(d)(3).

15. U.S. Department of Defense, Information Security Program Regulation, DnD 5200.1-R, Chap. II, \$2-302, June 1986.

16. A. F. Van Cook, "Downgrading and Declassification-Some Observations," J. Natl. Class. Mgmt. Soc., 3(1), 11-18 (1967), p. 12. 


\title{
Chapter 9. CLASSIFICATION OF ASSOCIATIONS OF INFORMATION
}

Information that is not per se classified is sometimes classified because its association with other information implicitly or explicitly reveals additional information that is classified. ${ }^{1,2,3}$ Classification of associations is sometimes referred to as "classification in context." Classification in context is specifically authorized by EO $12356 .{ }^{1}$ It should not be confused with classification of compilations of information, which is a topic discussed extensively in the next chapter.

Classification of information because of its association with other information frequently occurs with respect to items of hardware or materials used to fabricate classified hardware. The Department of Defense Handbook for Writing Security Classification Guidance contains the following:

\begin{abstract}
Unclassified off-the-shelf items, unless modified in some particular way to make them perform differently, can never be classified even though they constitute a critical element, become an integral part of a classified end product, or produce a properly classified effect. However, the association of otherwise unclassified hardware with a particular effort or product may reveal something classified about that effort or product. ${ }^{4}$
\end{abstract}

Thus, a commercially available item of hardware by itself can never be classified, but its association with a classified project may cause that hardware to be classified when it is associated with that project. ${ }^{5}$ For example, shipment of a hardware item to a defense contractor whose only product is one classified hardware subsystem may cause the fact of shipment to be classified if the item would reveal classified information about the subsystem. ${ }^{6}$ However, if the facility has many activities and products, materials may be procured by the plant on an unclassified basis if there is otherwise no link to a classified use.

A chemical or other material may be unclassified per se but when it is associated with a classified process or project such that the association indicates a classified use of that chemical or material, then the association is classified.

In some instances, the presence of a certain individual's name on the distribution list of an otherwise unclassified document may cause that document to be classified. For example, if the name of the manager of a classified project appears on a report's distribution list and if the association of the subject-matter of the report with the classified project is classified, then the report should be classified if the appearance of the manager's name on the distribution list indicates that the subject of the report is of interest to the classified project. As another example, the association of a person with a classified contract (e.g., as a consultant) may reveal the classified subject of that contract if that person's scientific career has been focused on a narrow specialty that is classified with respect to that contract. ${ }^{7}$ Similarly, if an expert in a particular technological area visits a classified facility, and the classified facility's interest in that particular technological area is classified, then the fact that the expert visited that facility (e.g., as revealed by travel records and visitor logs) should be classified. When such classification is required, the individual usually travels under an 
assumed name. This was frequently done in the Manhattan Project and led to many interesting stories about how slips-of-the-tongue were covered up when the visitor was referred to by his real name rather than his assumed name.

Classification by association is sometimes a reason why the United States does not declassify information that has been published in another nation. For example, the information may have a national security use which the adversaries have not yet discovered. If the originating U.S. program published that information, then the information would be linked to that program and could reveal the information's national security use. This problem could be avoided if the U.S. information were published by someone not connected with the program that developed the information. An example has been cited whereby a document was written by one person and published, unclassified, under the name of another person because the document would have been classified if issued by the true author. ${ }^{8}$ However, when the national security use of an item of information is reasonably obvious, then the information should not be disclosed even when disassociated from the originating program. ${ }^{9}$ For example, structural materials that are suitable for containing liquid uranium in foundry work are also suitable for containing liquid uranium in other applications. If the use in other applications is classified, then the use in foundry work should be classified.

In recent years, sites on which classified federal facilities are located have been subject to increased oversight of current activities and extensive review of past activities, especially with respect to releases of chemicals to the environment. Such reviews have been, and are being, carried out by other federal agencies, by state regulatory agencies, and by special investigating teams. Frequently the reviewing groups request "raw" data which identify all chemicals (and perhaps their concentrations) detected in atmospheric releases, liquid effluent, groundwater samples, and soil samples with respect to specific facilities or locations within a site, a: the site boundary, or in the vicinity of a site. Some site activities may have involved, or currently involve, the use of materials that are per se unclassified but are classified when associated with a site or a specific facility at that site (e.g., a classified burial ground or a building housing a classified manufacturing process). Therefore, such raw monitoring data must be carefully examined before it is released as unclassified to determine whether the data reveal patterns or trends that could link a specific chemical to a classified use.

\section{REFERENCES}

1. Executive Order 12356, Fed. Reg., 47, 14874 (Apr. 6, 1982), 81.3(b).

2. U.S. Department of Energy, "Identification of Classified Information," Office of Classification, December 1991, Chap. IV, Part B, §3.

3. U.S. Department of Defense, Information Security Program Regulation, DoD 5200.1-R, June 1986, §2-211.

4. U.S. Department of Defense, Department of Defense Handbook for Writing Security Classification Guidance, DoD 5200.1-H, March 1986, \$4.2(b).

5. C. D. Garrett, “Classifying Hardware,” J. Natl. Class. Mgmt. Soc., 4(1), 15-20 (1968), p. 15. Hereafter cited as "Garrett." 
6. Garrett, p. 18.

7. P. Stagner, "Classification Management Panel," J. Natl. Class. Mgmt. Soc., 23, 25-29 (1987), p. 28.

8. T. S. Church, "Panel-Science \& Technology and Classification Management," comments during the discussion period, J. Natl. Class. Mgmt. Soc., 2, 57-58 (1966).

9. U.S. Atomic Energy Commission, Guidebook for the Authorized Classifier, Division of Classification, p. 6 (approx. 1973). 
Chapter 10.

CLASSIFICATION OF COMPILATIONS OF INFORMATION

\section{INTRODUCTION}

Information is given a security classification when its unauthorized disclosure reasonably could be expected to cause damage to the national security. The classification of information results in unavoidable costs. Because of those classification costs, it is important to classify only information that truly warrants protection and information that can be kept from an adversary.

It might seem obvious that compilations of unclassified items of information should not be classified. When an individual item of information is unclassified, then a decision has been made that this item of information does not need the special kind of protection prescribed for classified information and that the information does not need to be kept from an adversary for national security reasons. If individual items of information are not protected from an adversary, then an adversary can obtain and compile them. Consequently, it would seem that a compilation of items of unclassified information should not be classified when an adversary can independently prepare the same compilation. However, there are many' instances where compilations of previously unclassified information have been classified. ${ }^{\dagger}$

It is important, for two major reasons, not to classify compilations of unclassified information. The first reason is to avoid classification costs when the classified information cannot be protected-when an adversary can obtain that information by independent, nonespionage efforts. The second reason is to maintain the credibility of the classification program, an important aspect of successful classification policy. It is difficult to maintain classification credibility or to ensure that information that truly warrants protection for national security reasons is protected when information that obviously cannot be protected is nevertheless assigned a classification category and level.

Classification specialists do not agree that compilations of unclassified information should be unclassified in all circumstances. This chapter provides a comprehensive discussion of the classification of compilations of unclassified information. It also examines whether a compilation of any items of information classified at one level (e.g., Confidential) can sometimes be classified at a higher level (e.g., Secret). Finally, this chapter proposes certain rules for use when the classification of compilations of information is being considered.

\footnotetext{
"This chapter is essentially the same as an article by the author that appeared in Viewpoints, 2, 7-16 (1992), a periodical of the National Classification Management Society, Rockville, Md.

For example, compilations of unclassified titles or unclassified summaries of classified DoD projects have sometimes been determined to be classified because trends of classified DoD research and development are thereby revealed. If trends of classified research warrant classification and those trends are revealed by compiling unclassified titles or abstracts of the classified projects, then the titles or abstracts of individual projects should be classified so that the trends are not revealed. Otherwise, there is no way to ensure that an adversary could not obtain the unclassified titles or abstracts and thereby detect those trends.
} 
It should be noted that the classification of information because of its association with other information is a subject different than the classification of compilations of information. Information that is unclassified per se can be classified when it is associated with certain other information (e.g., materials or components that are unclassified per se may be classified when associated with a classified project or hardware item). This chapter's discussion about classification of compiled information assumes that there is no association of information within the compilations that would make the compilations classified. Classification of associations is discussed in Chapter 9.

\section{DEFINITION OF THE TERM COMPILATION}

Many of the differences of opinion about the classification of compilations of unclassified information probably are a result of ambiguities from the meaning of "compilation." Some of those differences can therefore be eliminated by defining compilation. In this report, a compilation is defined as an orderly arrangement of preexisting materials (facts, statistics, etc.) gathered from many sources into one document.

To further aid in the discussion of classification of compilations, it is useful to establish two major types of compilations: (1) compilations that have had no substantive value (information) added by the compiler (true compilations), and (2) compilations to which substantive value has been added by the compiler. The first type of compilations contains only information present in the individual items of information that constitute the compilation. The second type of compilations contains substantive information added by the compiler [e.g., the compiler used expert judgment to select certain information for the compilation, or the compiler added new substantive information (e.g., critical comments) to available information]. The same classification rule does not apply to both types of compilations. The following two sections consider these two kinds of compilations.

\section{COMPILATIONS OF UNCLASSIFIED INFORMATION WITH NO SUBSTANTIVE VALUE ADDED}

\section{Description of Compilations with No Substantive Value Added}

Compilations of information to which no substantive value (information) has been added by the compiler merely contain existing information arranged in an orderly fashion (i.e., they are true compilations). The compiler has not used judgment to select or discard items of information and has not otherwise added information based on subject-matter expertise-the compiler has not added any substantive value to the information selected for the compilation. Also, the compiler has not added any information that was not present in the individual items that constitute the compilation. The compiler has not increased the total store of knowledge concerning the subject of the compilation.

These kinds of compilations may be prepared by someone without expertise in the subject matter of the compilation. One example of such a compilation is a township map that shows the location, size, and ownership of parcels of land as obtained from public records. Another example is data on the highway mileage between all the cities in a state, prepared from city, county, or state highway maps available to the public. A third example is a 
directory of names in alphabetical order and addresses of residents of a city produced from an unordered file containing those names and addresses. A final example is a list of all of the report titles prepared for a specific governmental agency during a fiscal year and sent to the National Technical Information Service (NTIS), where the individual report titles were obtained from NTIS publications or the NTIS data base. The compilations could be prepared by clerical personnel, in contrast to surveyors, tax assessors, or technical experts. These compilations are useful because a compiler has gathered all of the pertinent information on a subject and arranged it in a form that enables the convenient use of that information.

\section{Classification of Compilations with No Substantive Value Added}

Proposed Classification Rule and Its Rationale. Compilations of unclassified information to which the compiler has added no substantive value (i.e., no substantive information) should not be classified. This conclusion is based on a fundamental principle of classification-that classified information cannot be completely subdivided into separate, unclassified components. DOE has stated this principle as follows:

Information that is classified under the Atomic Energy Act must not be so subdivided that all its components (including contextual information) are unclassified."

This is sometimes called the keystone principle of classification. This keystone principle may be visualized by considering a classified photograph or drawing that has been subdivided into many components (e.g., pieces of a puzzle), each of which reveals an item of information. According to the keystone principle of classification, not all of the components can be unclassified if the entire entity is classified. One or more key pieces must be classified so that the entire "picture" cannot be obtained when all of the unclassified pieces are assembled. Thus, if individual items of information are truly unclassified (i.e., if no classification error has been made), then assembling (compiling) the items cannot reveal classified information.

A proposed rule for classifying compilations of unclassified information when no substantive value has been added by the compiler is as follows. This is a corollary to the basic DOE classification principle.

If all components (including contextual information) of a compilation are unclassified, and no substantive information (value) has been added by the compiler, then the compilation should not be classified.

The essence of this rule was set forth over 30 years ago by the AEC in a 1958 AEC Monthly Classification Bulletin:

A compilation of unclassified information is unclassified. Therefore, if an area of information has an overall classification some, if not all, of the data which makes up this area must be classified. ${ }^{\dagger}$

\footnotetext{
"This rule is stated in several DOE classification guides.

${ }^{\dagger} \mathrm{A} 1959$ AEC Monthly Classification Bulletin contained the following statements that are of interest with respect to classification of compilations and are consistent with the proposed rule:
}

Attention is called to the fact that a collection of apparently individually unclassified data may reveal classified information, for example, (1) through association or (2) by revealing a significant quantity or rate. In the first case, certain technical data might be quite properly unclassified but would reveal classified information 
The Nuclear Regulatory Commission has published similar guidance for the classification of compilations:

Compliations of unclassified information are generally considered to be unclassified unlass some additional factor is added in the process of compilation. For example: (a) The fact that the information is complete for its intended purposes may be classified; or (b) the fact that compiled information represents an official evaluation may be classified. $^{1}$

This proposed rule for the classification of compilations of unclassified information is consistent with a requirement of EO 12356 for the classification of information. EO 12356 indicates that only inforriation that is "owned by, produced by or for, or is under the control of the United States Government" can be classified as National Security Information. "2 If individual items of information that constitute a compilation are unclassified, then they are not under the control of the government to the extent required by security procedures for protecting classified information (e.g., the documents containing the items of information are not kept in secure repositories while they are unattended, and they are not marked to be kept from unauthorized persons). According to EO 12356, if none of the items of information in a compilation is controlled by the government to the extent required for classified information, then the compilation should not be classified as NSI.

Another EO 12356 requirement supports the conclusion that compilations of unclassified information with no substantive value added by the compiler should not be classified. EO 12356 states that information may be classified only if its unauthorized disclosure reasonably could be expected to cause damage to the national security. ${ }^{3}$ That order defines three levels of classification-Confidential, Secret, and Top Secret-that correspond to three levels of damage-damage, serious damage, and extremely grave damage. ${ }^{4}$ Providing three different damage levels indicates that damage quantification is expected. If the unauthorized release of an item of information reasonably could be expected to cause damage, then the information is considered Confidential. ${ }^{5}$ Let us assume that the damage caused by the release of an item of Confidential information would be 1 on an arbitrary scale of damage. (For Secrei and Top Secret information, the damage value would be greater.) The release of an unclassified item of information would cause no damage (0) to the national security (by definition of what constitutes classified information). Therefore, no matter how many items of unclassified information are compiled, the sum of the damages caused by their release would still be zero and the compilation should not be classified. ${ }^{\dagger}$

\footnotetext{
concerning a particular program if related to it. Any data indicating this association should be classified to avoid this. In the second case, certain production, processing, or shipping records reveal, individually, such a minor quantity of work or material or cover such a minor period of time that they are handled as unclassified or of relatively low classification. A sufficient number of such records taken together, however, can reveal totale which are significant enough to the program to carry a higher classification. Therefore, enough of the individual records must carry the higher classification 80 that the sufficient number referred to cannot be assembled at the lower classification. Note that these particular records will not be overclassified, because the basic rule is that classification should not be by content alone but by what is revealed in conjunction with other classified information.
}

"Restricted Data or Formerly Restricted Data do not have this explicit control requirement. However, it would generally be futile to classify such information if the dissemination of the information could not be controlled by the government.

Note that this rationale might not always lead to this conclusion if classification's risks and benefits are required to be balanced before a classification decision is made. This is because when considering a number of items of information, the risks might be independent and completely additive whereas some of the benefits might be identical 
EO 12065, the immediate predecessor to EO 12356, included a statement that "references to classified documents that do not disclose classified information may not be classified or used as a basis for classification. ${ }^{n 6}$ This seems to indicate that a compilation of unclassified titles of classified documents would not have been considered classified under EO 12065 ."

Trade Secret Law and the Proposed Classification Rule. There are many similarities between the classification and protection of $n$. conal defense and foreign relations information (state secrets) and the identification and protection of trade secrets (see Appendix A). Therefore, it is useful to examine the extent to which compilations of information important to businesses are protected under trade secret law to help determine whether similar compilations of government information should be classified.

A compilation of unclassified technical information is analogous to a combination of a series of widely known industrial processes such as common shop practices. A combination of common shop practices will not be considered a trade secret unless the combination is unique (i.e., unless something substantive or some special insight was added when that combination was developed). ${ }^{7}$ "A trade secret can exist in a combination of characteristics and components, each of which, by itself, is in the public domain, but the unified process, design and operation of which is in unique combination, affords a competitive advantage, and is a protectable secret ${ }^{m 8}$ (emphasis added). The rule that a compilation of unclassified information should not be classified if it has had no substantive value added by the compiler is therefore consistent with trade secret law, which requires that a combination of publicly available information have substantive value added before that combination (compilation) is a trade secret.

Copyright Law and the Proposed Classification Rule. Classification and copyright protection are also somewhat analogous to common shop practices since classification protects information from unauthorized disclosure to adversaries and copyright protects materials from unauthorized use by a competitor.

Copyright protection is provided by a U.S. statute to "original works of authorship," including compilations. ${ }^{10}$ Under copyright law, a compilation is defined as "a work formed by the collection and assembling of preexisting materials or data that are selected, coordinated, or arranged in such a way that the resulting work as a whole constitutes an original work of authorship. ${ }^{n 11}$ An important question concerning the copyrightability of compilations of information available to the public (i.e., unclassified) is what constitutes an "original work of authorship." Originality, with respect to compilations and copyright law, may be achieved by arranging facts in a systematic fashion ${ }^{12.13}$ or by adding material to facts ${ }^{\dagger, 14}$ (e.g., adding substantive value). It is the selection (e.g., names in a social register, stocks in the Dow Jones listings ${ }^{15}$ ) or arrangement of facts that is copyrightable, not the facts

and therefore should not be counted more than once. Therefore, when balancing the risks and benefits of classification of certain individual items of information, a result might be that the benefits would always exceed the risks, but when considered as a whole, the sum of the risks might exceed the sum of the benefits. The other reasons for not classifying compilations of unclassified information, given above, are not affected if risks and benefits are balanced when making classification decisions.

There have been instances where compilations of unclassified titles to classified documents were assigned a classification. See a following section for such an example.

If material is added to existing facts, then the result would not seem to be a mere compilation but would include added information, added value, and would be copyrightable for that reason. 
themselves. ${ }^{16,17,18}$ Copyrighting a compilation does not affect the status of the materials that are in the public domain and from which the compilation was made. ${ }^{19,20}$

Copyright law requires that a compiler of information available to the public use subjective judgment before a compilation can be copyrighted. Therefore, the rule that compilations of unclassified information cannot be classified unless substantive value is added by the compiler is consistent with copyright law, which protects only compilations that derive their value from the compiler's expert judgment or originality used in preparing the compilation.

Judicial Decisions Supporting the Proposed Classification Rule. A 1976 Federal District Court case involved a compilation of unclassified titles of technical reports on research projects under way for DoD. Some of the technical reports were classified, but their titles were unclassified. Compilations of those unclassified report titles (Technical Abstract Bulletin Indexes) had been issued as unclassified for several years until DoD began classifying them because the compilations were believed to reveal research directions and trends of national defense importance. A FOIA request was made for the classified document (the compilation of unclassified titles), the request was refused by DoD, and the matter was litigated. A Federal District Court ordered DoD to release all of the unclassified entries in the document. ${ }^{21}$ Since that meant that all of the report titles in the compilation would have to be released, DoD released the entire document as an unclassified document. ${ }^{22}$ Although the court did not address the question of whether the compilation was improperly classified, the practical effect of its decision was that the compilation itself was an unclassified document. This result is consistent with the proposed classification rule.

Views Not Supporting the Proposed Classification Rule. The proposed rule that compilations of unclassified information should not be classified unless substantive value is added by the compiler is not unanimously accepted. Those opposing this rule believe that compiled items of unclassified information should sometimes be classified. Sometimes a compilation is said to be classified when it contains a nearly complete list of certain items of information that are unclassified when they are isolated items of information. For example, classification guides dealing with communications security (COMSEC) matters have included guidance to the effect that individual inventory reports of certain COMSEC materials are unclassified, but reports that contain a "substantially complete" listing of those materials at a facility are classified. As discussed earlier, it does not seem effective to classify such a listing because an adversary could obtain the same information from the unclassified individual reports."

\footnotetext{
"In addition to not being a sound classification guide, such guidance cannot be applied consistently because of differing interpretations by classifiers as to what quantitatively constitutes a "substantially complete" listing. Is it 75\% of the total? 85\%? 95\%? 99\%? See also E. Smith, "Applying Derivative Classification, " J. Natl. Class. Mgmt. Soc., 18, 106-115 (1982), p. 114, which discussed a hypothetical situation where information giving the location of one U.S. missile silo was unclassified but the locations of all (e.g., 500) silos were classified. Some unanswered questions were: What was the classification of the location of 23 missile silos? Of 499 missile silos? Of 498 missile silos?

Another problem with such vague classification guidance is that when a derivative classifier, the intended user of the guide, determines the specific number of inventory items that constitutes a substantially complete list of those items, which he or she must do to determine whether a list of those items is classified, then that derivative classifier is making an original classification decision. The derivative classifier is defining what is meant by "substantially complete." Derivative classifiers are not authorized to make original classification decisions. Therefore, it seems that such classification guidance (the "substantially complete" guidance) can be used only by original classifiers. That result certainly was not intended by the agency that issued the classification guide.
} 
Sometimes a compilation is said to provide information not present without the compilation. That is, it is said the compilation itself makes evident some classified information not revealed by individual items of information when they are isolated from each other. This new information is perceptible because of the compilation. ${ }^{22,23,24}$ Under that situation, some classifiers believe that the compilation should be classified. This view receives some support from DoD. DoD stated that normally a compilation of unclassified items should not be classified, but that "in unusual circumstances, classification may be required if the combination of unclassified items of information provides an added factor that warrants classification .... ${ }^{n+, 25}$ Individually unclassified items that become classified when associated with one another have been cited as an example of this added factor. $\$ .26$ However, as mentioned earlier, classification because of associations is a separate topic from classification of compilations.

In situations such as those described in the preceding paragraph when classified information is alleged to have been obtained via compilations of unclassified information, it is likely that a classification error was made. That is, the classification guidance applicable to the situation was not comprehensive. The guidance did not include all of the inferences that an expert could draw from the information under consideration for classification. The inferences should include the associations that could be made when combining the

\footnotetext{
'However, DoD's Coolidge Conmittee cited DoD's classification of compilations of unclassified data as an example of DoD's "attempt to do the impossible-to keep as classified [that] information which can no longer be withheld" [Report to the Secretary of Defense by the Committee on Classified Information, C. A. Coolidge, Chairman, Department of Defense, Nov. 8, 1956, p. 8]. The Coolidge Committee was a special committee established by the Secretary of Defense to investigate the classification of information within DoD. The Committee Chairman was C. A. Coolidge, a former Assistant Secretary of Defense. The other members of the committee were four senior retired officers from the Air Force, Army, Marine Corps, and Navy. The report's conclusion on the inappropriateness of classifying compilations of unclassified information is especially notable because of the high quality of the members of the Coolidge Committee and their considerable experience in dealing with classified information. Others have also remarked on a DoD tendency to inappropriately classify compilations of unclassified information [W. G. Florence in "Executive Classification of Information-Security Classification Problems Involving Exemption (b)(1) of the Freedom of Information Act (5 U.S.C. 552)," HR 93-221, Third Report by the Committee on Government Operations; U.S. House of Representatives, 93d Cong., 1st Sess., Supt. of Documents, 1973, p. 46ff].

The author wonders whether DoD's views on classification of compilations might not be strongly influenced by, or a consequence of, DoD's policy on classification paragraph marking (i.e., specifically designating the classification of each paragraph in a document). Paragraph marking has long been practiced in DoD for National Security Information. [See, for example, G. MacLain, "Panel-Government Classification Management Policies and Programs," J. Natl. Class. Mgmt. Soc., 2, 69-75 (1966), p. 74.] Portion marking, essentially the same as paragraph marking, is now required by Executive Order [EO 12356, Fed. Reg., 47, 14874 (Apr. 6, 1982), 81.5(b); Information Security Oversight Office, "Directive No. 1," 32 CFR 2001.5(a)(3)]. DOE does not paragraph mark Restricted Data or Formerly Restricted Data. One of the reasons for not paragraph marking is that within a document, the classification of a paragraph has to be evaluated in the context of the information contained in the other paragraphs of the document [R. R. Fredlund and D. E. Whitman, "The Great Debate ... Continues," J. Natl. Class. Mgmt. Soc., 22, 152-192 (1986), pp. 156-157, 163]. Therefore, when following DoD rules for paragraph marking, the importance of connections or associations of information in the paragraph with other information in the document may be overlooked. [See, for example, K. Wilson, comments at a National Classificat.on Management Society meeting as reported in J. Natl. Class. Mgmt. Soc., 3(2), 91 (1967).] It is only when the isolated paragraphs are closely connected (e.g., as part of a compilation) that the correct classification, which includes the effects of associations, becomes more apparent Therefore, if a document has been paragraph marked, then one may have to invoke the "compilation theory" to correct the classification errors caused by portion marking. (This is, admittedly, an oversimplification of the situation, but it does help to explain why DoD sometimes finds it necessary to invoke the compilation theory.)

${ }^{\ddagger}$ As stated earlier in this paper, such an example should be classified because of associations, not because it is a compilation.
} 
information under consideration for classification with all of the existing unclassified information. A classification determination must always be based on the assumption that any person who receives the information under consideration for classification is (1) highly qualified in that particular field of technology and (2) thoroughly familiar with all related information that has already been issued as unclassified. "t Thus, when a compilation of unclassified information is said to reveal new, classified information, it is probable that the existing classification guidance should be revised to classify one or more of the individual items of information that lead to the revelation of this new information.

EO 12356 is said by some to provide a basis for classification of a compilation of unclassified bits of information. Section 1.3(b) states that before information can be classified, an original classifier must determine "that its unauthorized disclosure, either by itself or in the context of other information, reasonably could be expected to cause damage to the national security" ${ }^{27}$ (emphasis added). The phrase "either by itself or in the context of other information," which was not present in the immediately preceding EO, is said to be recognition of the "compilation theory" of classification. ${ }^{28}$ A better interpretation of Sect. 1.3(b) would be that "in the context of other information" refers to associations of information, rather than compilations. As stated previously, it is a long-standing classification principle that allows associations of information to be classified when the association reveals classified information.

Judicial Decisions not Supporting the Proposed Classification Rule. In a 1982 case [Taylor v. Department of The Army, 684 F.2d 99 (D.C. Cir., 1982)], a newspaper reporter had requested, under FOIA, the U.S. Army's numerical ratings for the four measured resource area ratings (MRARs) for all of its 168 major combat units. At the time of the request, an Army regulation unequivocally stated that the MRARs for single units were unclassified. However, the Army interpreted its regulation to mean that the raw data were unclassified, not the MRARs, and refused to provide the MRARs because they were considered by the Army to be classified. Subsequently, a Federal District Court directed the Army to release the information.

The District Court held that the requested MRARs should be released because an Army regulation concerning the MRARs specifically stated that the MRARs for a single unit were unclassified. Although the Army argued that the information should be denied because it was a compilation of unclassified information with an added factor and was therefore classified under another Army regulation, the District Court rejected this argument. The District Court said that requesters could avoid the compilation problem by having different individuals submit FOIA requests, one-by-one, for the ratings of the different units. The District Court was not convinced otherwise by an Army affidavit that stated that an attempt to get the MRARs one by one "would have been uncovered at a very early stage" and that those individual MRARs would not have been provided by the Army. ${ }^{29}$

\footnotetext{
"The significance of one item of information may frequently depend upon knowledge of many other items of information. What may seem trivial to the uninformed, may appear of great moment to one who has a broad view of the scene and may put the questioned item of information in its proper context " [United States $v$. Marchetti, 466 F.2d 1309, 1318 (4th Cir.), cert. denied, 409 U.S. 1063 (1972)].

${ }^{+\infty}$ The business of coreign intelligence gathering in this age of computer technology is more akin to the construction of a mosaic than it is to the management of a cloak and dagger affair. Thousands of bits and pieces of seemingly innocuous information can be analyzed and fitted into place to reveal with startling clarity how the unseen whole must operate" [Halkin v. Helms, 598 F.2d 1, 8 (U.S. App. D.C., 1978)].
} 
The Army appealed that decision to a Circuit Court, which reversed the District Court decision. The Circuit Court accepted the argument that the information was classified, relying on affidavits from three Army generals which stated that this information had always been considered classified by the Army (the applicable Army regulation had been promulgated about 18 years earlier). The court stated that the Army should be accorded great deference in construing its own regulation. ${ }^{\circ 2}$ The Circuit Court also may have been influenced by the Army's action, taken immediately after they first denied the request for the MRARs, to change its regulation to specifically classify the MRARs for a single unit as Confidential. ${ }^{\dagger}$ The court also accepted the Army's argument (supported by the affidavits of two generals) that the requested information was a compilation of unclassified information with an added factor of sensitivity and was classifiable under another Army regulation. ${ }^{\ddagger}$

Although the Court in Taylor v. Department of the Army accepted the argument that compilations of unclassified information could be classified, the Court's decision appears to rely mostly on the Army's affidavits that the Army had always considered the requested information to be classified and on the fact that the Army had immediately revised its regulations to explicitly declare that information to be classified. Also, the court stated that the requested compilation had an "added factor." ${ }^{30}$ An added factor such as substantive information provides a basis other thal, the compilation theory by which a compilation can be classified (see the following section). Therefore, upon detailed analysis, Taylor $v$. Department of the Army does not appear to be inconsistent with the proposed rule which forbids the classification of compilations of unclassified information without substantive information (value) being added.

A 1987 U.S. Circuit Court decision also appears to lack support for the proposed rule. This decision, American Friends Service Committee v. Department of Defense, ${ }^{31}$ concerned DoD's Technical Abstract Bulletins (TABs). DoD used the "compilation" theory to classify those TABs. A U.S. District Court decided, via summary judgment, that the TABs were properly classified. The Circuit Court to which the District Court's decision was appealed also accepted the compilation theory. However, the Circuit Court's discussion of the compilation theory described it as classification in context, ${ }^{32}$ which as mentioned earlier has long been accepted as a legitimate reason for classification. Although the DoD compilation theory was accepted, the Circuit Court vacated the District Court decision and remanded the case for several findings of fact. One question to be answered on remand was whether a significant number of the TAB entries were also published in the NTIS catalog, which is available at public libraries. ${ }^{33}$ By the time the case was considered again by the District Court, DoD was no longer publishing the TABs but was publishing another document that

\footnotetext{
"It is the general rule that courts extend great deference to an agency's interpretation of its own regulations, especially when those regulations concern information of national security significance (i.e., classified information).

$H_{t}$ is also of interest to note that one of the reasons why "vulnerabilities or capabilities" was included in the list of classifiable areas of NSI in EO 12356 was DoD's request to add this area so that there would be an additional, specific basis for classifying information on the readiness of Army units [S. Garfinkel, "An Information Security Oversight Office Overview of Executive Order 123.56 and Its Implementing Directive, ${ }^{n} \mathrm{~J}$. Nall. Class. Mgmt. Soc., 18, 17-23 (1982), pp. 20-21].

FThe portions of the affidavits cited in the court's opinion are not convincing with respect to the "added factor" argument. The affidavits seem to state that one could determine the Army's combat potential from the compilation and that the compilation was therefore "clearly classifiable information" [Taylor v. Department of the Army, $684 \mathrm{~F} .2 \mathrm{~d}$ 99, 103 (D.C. Cir., 1982)]. The Army's combat potential is not an added factor to the compilation but is an accurate indication of the information that can be deduced from the individual items of information contained in the compilation.
} 
omitied certain information contained in the TABs. Therefore, future information of the type requested by the plaintiff, American Friends Service Committce, was available. Since this action by DoD appeared to demonstrate that the information contained in the previous TABs was segregable, the plaintiff asked that DoD provide the requested information from those TABs. However, the District Court denied that request."

\section{COMPILATIONS OF UNCLASSIFIED INFORMATION WITH SUBSTANTIVE VALUE ADDED}

\section{Description of Compilations with Substantive Value Added}

A compilation of information with substantive value (information) added by the compiler is a compilation prepared by a compiler whose expertise in the subject of the compilation was necessary to prepare that compilation. This type of compilation is significantly different from a mere compilation of information. The compiler's expert judgment may have been used to select specific, pertinent information (e.g., the "reliable" information) from a broader array of available information. Technical handbooks (e.g., the Handbook of Chemistry and Physics $^{34}$ ) are examples of such compilations. Substantive value is also added when a compiler includes all relevant information and then provides critical comments (expert evaluations) on the accuracy or reliability of that information. Scientific and technical review articles are examples of this type of evaluation. The latter "substantive value added" compilation is frequently designated a review, a critique, an analysis, an evaluation, or some other similar term.

\section{Classification of Compilations with Substantive Value Added}

If a compiler has added some information of substantive value to a compilation of unclassified information, then the resulting compilation should be classified (1) if the added information is considered to be classified per se, (2) if the added information is classified because of association with the preexisting information, or (3) if the preexisting information is classified when associated with the added information. This is not a new rule proposed for the classification of compilations of unclassified information with substantive value added. Rather, it is a principle by which all documents are evaluated to determine the security classification of the information contained therein.

\section{Judicial Decisions on Classification of Compilations with Value Added}

A 1978 Federal District Court case involved a request for the release of a compilation of the number and exact titles of National Security Study Memoranda and National Security Divisional Memoranda issued between January 20,1969, and the date of the request. ${ }^{35}$ The National Security Council (NSC) compiled that information but then refused to release this compilation because it contained classified information (i.e., the compilation included classified and unclassified titles and also gave the chronological sequence in which the

\footnotetext{
"The information concerning the action of the District Court on remand was provided to the author by Ms. Julie Shapiro, Philadelphia, Penn., attorney for American Friends Service Committee. A written opinion has not been filed by the District Court.
} 
individual reports were produced). The requester then asked for a compilation of the unclassified titles, and the NSC again refused to release the requested information. The staff secretary of the NSC submitted an affidavit stating that "access to the unclassified titles in their totality would ... enable a foreign intelligence analyst to identify the kinds of issues of grave concern to the United States and the way in which this government reacts to world events, and also to gain unique insights into the method by which issues of this kind are identified, studied and resolved by the President." ${ }^{36}$ Government affidavits also stated that the compilation would provide other nations "with valuable information and insight pertaining to the focus and timing of key U.S. foreign policy concerns. ${ }^{n 7}$ The court determined that the list was "reasonably classified in full, unclassified titles included," ${ }^{38}$ and exempted the list from release. The sequential nature of the titles on the lists may have been a major factor in the decision, since the court said that "this decision is, however, without prejudice to any future claim by plaintiff for access to any unclassified documents now in existence, or any unclassified documents that may come into existence, which list the unclassified titles ... in 'scrambled' sequence and in edited form . . . ."

Although the titles to the reports in the compilation were unclassified, the compiler had listed those titles in chronological order and had included the dates when the reports were prepared. The court was of the opinion that those dates added substantive information (value) to the compilation, particularly with respect to intelligence considerations. The court therefore upheld the agency's determination that the compilation should be a classified document. This outcome is consistent with the general rule that compilations of unclassified information should be clasisified if no substantive value is added by the compiler."

\section{COMPILATIONS OF UNCLASSIFIED INFORMATION REQUIRING SUBSTANTIAL EFFORT TO COMPILE}

One reason for classifying information is to make an adversary expend its own resources to get thai information. A typical example of this situation is the classification of scientific or technical data that would be useful to an adversary and that the adversary could obtain by the straightforward application of its available scientific or technical resources and by other well-known methods. If the data are classified, then the adversary must expend its resources to get the data, resources that might otherwise be used to harm our nation. However, because of the inherent costs associated with classifying information, normally such scientific or technical data are not classified unless substantial resources would be required to obtain the data. That is, the information is not classified unless publishing it would save an adversary a substantial amount of effort in acquiring that information by the adversary's own efforts.

A potential rule (and an exception to the previously proposed rule) for the classification of compilations of information that have required substantial efforts to produce is as follows:

If a substantial effort was required to produce a compilation of unclassified information and if an adversary would expend about the same effort to independently get that information, then that compilation should be classified.

\footnotetext{
"This outcome is also very consistent with the general rule that courts should extend the utmost deference to opinions of an agency's experts concerning the classification of documents generated by that agency.
} 
There is even reasonable quantitative guidance available as to what constitutes substantial effort."

However, the "substantial effort" principle, with respect to classifying scientific or technical data, is limited to data obtained by using scientific or technical expertise. Even though the effort to obiain scientific or technical data is a straightforward application of known principles, scientific or technical expertise is necessary to apply the principles and obtain the data. The compilations to which the above-mentioned potential rule would apply are those which require no subject-matter expertise to produce. ${ }^{\dagger}$ The two situations are not comparable. The accepted classification principle that allows classification of scientific or technical data when substantial scientific or technical effort was required to produce that data is analogous to the classification of compilations that require expertise for their production (compilations with substantive value added during their production). Thus, there appears to be no basis to classify a compilation simply because substantial effort was required to produce that compilation.

This conclusion is consistent with copyright and trade secret law. The majority view in copyright law holds that the effort required to obtain information for a compilation is not a

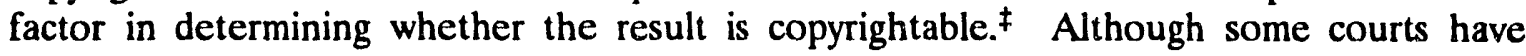
extended copyright protection to certain types of compilations to protect "the product of the compiler's industry," 40 or "the compiler's effort in collecting the data," minority view. The policy of that minority line of decisions seems to be to prevent unfair use of an author's efforts, that is, to require others to do independent research to get the benefits therefrom. ${ }^{*, 42}$ Trade secret law is consistent with copyright law on this matter. The effort required to develop a new arrangement of preexisting, publicly available information is not a factor in deciding whether that arrangement is a trade secret. ${ }^{\dagger+}$. "substantial effort exception" to the proposed rule on classification of compilations of unclassified information is not supported by the majority views in copyright or trade secret law.

\footnotetext{
See Chap. 5, which mentions a 15 person-year effort established as a guideline when considering the declassification of information during the Manhattan Project.

If expertise in the subject matter of the compilation was required for production of the compilation, then the compilation could be classified because of the substantive value added by the expert(s) (see previous discussion).

\$Most U.S. Circuit Courts hold that the labor required to produce a compilation is not a factor in determining whether the product can be copyrighted. [See D. E. Shipley and J. S. Hay, "Protecting Research: Copyright, Common-Law Alternatives, and Federal Preemption," N. Car. L. Rev., 63, 125--181 (1984).]

"Those cases seem to hold that when significant labor is expended to produce a compilation, even though the compiler has not created a unique arrangement of pre-existing data, then someone else should not be able to use those fruits of the compiler's labor without the authorization of the compiler. However, the majority view seems to be that "protection of original research of information in the public domain [e.g., compilations of publicly available information] is better afforded under an unfair competition [legal] theory" [Southern Bell Telephone and Telegraph Company v. Associated Telephone Directory Publishers, 756 F.2d 801, 809-810 (11th Cir., 1985), note 9].

\#I has been implied that if substantial effort is required to develop a series of common shop practices into a process, that the combination will be considered a trade secret [D. C. Maizel, "Trade Secrets and Technical Data Rights in Government Contracts," Military L. Rev., 114, 227-298 (1986), p. 233, citing Comp. Gen. Dec. B-187051 (Apr. 15, 1977), 71-1 CPD para. 262]. However, there is little case authority to support this result [R. M. Milgrim, Milgrim on Trade Secrets, Matthew Bender \& Co., Inc., New York, 1987, \$2.02[2], p. 2-33].

\# However, the extent of effort (e.g., research and deveiopment effort) required to develop information is a factor in determining whether information is a trade secret. The distinction is between creative efforts and efforts dealing with pre-existing public domain information.
} 


\section{CLASSIFICATION LEVEL OF COMPILATIONS OF CLASSIFIED INFORMATIION}

The accepted rule concerning the classification of compilations of classified information is that the compilation is classified at the same level as the highest classification level of any item of information contained therein. However, consistent with sound classification principles, under certain conditions a compilation of many items of information, all of which are classified at one level (e.g., Confidential), can be classified at a higher level (e.g., Secret). This conclusion is based on certain classification of information requirements contained in EO 12356 as described in the following paragraph.

EO 12356 states that information may be classified only if its unauthorized disclosure reasonably could be expected to cause damage to the national security. ${ }^{3}$ The three levels of classification defined by this order-Confidential, Secret, and Top Secret-correspond to three levels of damage-damage, serious damage, and extremely grave damage. ${ }^{4}$ Providing for three levels of damage indicates quantification of that damage by a classifier. If the unauthorized release of an item of information reasonably could be expected to cause damage, then it is considered Confidential information ${ }^{5}$ (assume 1 on an arbitrary damage scale). Release of an item of Secret information could cause serious damage (assume 100 on the damage scale). Release of an item of Top Secret information could cause extremely grave damage (assume 10,000 on the scale). On that basis, the release of a compilation of 100 different items of Confidential information, with each item causing a damage of 1 if released, could cause an aggregate damage of 100 . Therefore, a compilation of 100 or more different items of Confidential information should be classified Secret since its release could cause damage of 100 or more. The same rationale would apply to classifying as Top Secret a compilation of 100 or more different Secret items of infurmation.

On the basis of the foregoing discussion, a potential rule for the classification level of compilations of classified information is as follows:

A compilation of many different items of information classified at one level (e.g., Confidential) should be classified at a higher level (e.g., Secret) if the total damage caused by the unauthorized release of all of these items of information would equal or exceed the damage caused by the release of one item of information classified at that higher level.

This is, in theory, a potentially useful principle to help determine classification levels of documents. Although it is difficult to quantify damages for the unauthorized disclosure of each item of information to the extent required to apply this rule, that difficulty is not different from the problems already frequently encountered by original classifiers when determining whether information should be classified and, if so, at what level. Unfortunately, there appear to be some security-related obstacles to implementing such a rule. Consider Confidential Restricted Data (CRD), which is available (within DOE on a need-to-know

\footnotetext{
The requirement that the items of information be different is meant to preclude classifying at a higher level a compilation of items of information, each item of which carries a lower classification level, where each item reveals essentially the same information. Thus, a list of 100 different codes, each classified as Confidential, where each code provides access to the same classified computer system, would not be classified Secret because the release of all of the codes would probably not cause much more damage than release of one code.
} 
basis) to L-cleared personnel, and Secret Restricted Data (SRD), which is available to Q-cleared personnel but not to L-cleared personnel. Consider also the previously mentioned values for individual different items of Confidential information (1) and Secret information (100). Presumably, an L-cleared person could acquire, on a need-to-know basis, over 100 different CRD items of information. By the previously shown rule for classification level of compilations, that L-cleared person then would have knowledge of SRD information, which would not be in accord with DOE's security regulations. What would the Security Department do in such a situation-request a Q-clearance for that employee or give someone a security infraction for providing SRD to an L-cleared person? Consider also two reports containing only CRD information. One contains $60 \mathrm{CRD}$ items and the other contains 50 CRD items, for a total of 110 different CRD items of information. An L-cleared person would need only acquire those two reports to obtain information classified as SRD by the rule shown above. These types of situations would occur frequently if the above-montioned rule was implemented. Obstacles cited above would cause significant problems in applying this rule.

\section{CONCLUSIONS}

The general rule proposed for the classification of compilations of unclassified information is as follows:

If all components (including contextual information) of a compilation are unclassified and no substantive information (value) has been added by the compiler, then the compilation should not be classified.

A "substantial effort" exception to this rule was considered and rejected as inconsistent with other classification principles and with trade secret and copyright law.

The following rule was considered for establishing the classification level of compilations of classified information:

A compilation of many different items of information classified at one level (e.g., Confidential) should be classified at a higher level (e.g., Secret) if the total damage caused by the unauthorized release of all of these items of information would equal or exceed the damage caused by the release of one item of information classified at that higher level.

This latter rule appears sound in theory, but security-related difficulties associated with applying it to real-world situations may preclude its general use. 


\section{REFERENCES}

1. 10 CFR Part 75, App. A, Introduction, §D.6.

2. Executive Order 12356, Fed. Reg., 47, 14874 (Apr. 6, 1982), \$6.1(b) and \$6.1(c). Hereafter cited as "EO 12356."

3. EO 12356, Preamble.

4. EO 12356, 81.1(a).

5. EO 12356, \$1.1(a)(3).

6. Executive Order 12065, 43 Fed. Reg. 28949 (July 3, 1978), \$1-604.

7. Imperial Chemical Industries v. National Distillers and Chemical Corp., 342 F.2d 737 (2nd Cir., 1965); M. F. Jager, Trade Secret Law, Clark Boardman Co., Ltd., New York, 1988, pp. 5-53, 5-54, and citations therein. Cir., 1965).

8. Imperial Chemical Industries v. National Distillers and Chemical Corp., 342 F.2d 737, 742 (2nd

9. 17 U.S.C. $\$ 102(a)(1982)$.

10. 17 U.S.C. $\$ 103$ (1982).

11. 17 U.S.C. $\$ 101$ (1982).

12. T. M. Gerritzen, "Copyrighting the Book of Numbers-Protecting the Compiler: West Publishing Co. v. Mead Data Central, Inc.," Creighton Univ. L. Rev., 20, 1133-1166 (1987), p. 1163, n. 353. Hereafter cited as "Gerritzen."

13. Gerritzen, p. 1163.

14. Gerritzen, p. 1163 , n. 349.

15. D. E. Shipley and J. S. Hay, "Protecting Research: Copyright, Common-Law Alternatives, and Federal Preemption," N. Car. L. Rev., 63, 125-181 (1984), pp. 141-142. Hereafter cited as "Shipley and Hay."

16. Rockford Map Publishers, Inc. v. Directory Service Co., 768 F.2d 145, 149 (7th Cir.), reh'g denied, 768 F.2d 145 (7th Cir. 1985).

17. Shipley and Hay, p. $125 \mathrm{ff}$.

18. Shipley and Hay, p. 138 (citations omitted). See also p. $141 \mathrm{ff}$.

19. 17 U.S.C. $\$ 103(1982)$.

20. Gerritzen, p. 1146, n. 142.

21. Florence v. Department of Defense, 415 F. Supp. 156 (D.D.C. 1976). 
22. A Van Cook, "Department of Defense Panel," J. Natl. Class. Mgmt. Soc., 12(2), 29-42 (1977), pp. 39-40.

23. F. W. May, "Panel-Government Classification Management Policies and Programs," J. Natl. Class. Mgmt. Soc., 2, 76-80 (1966), p. 78.

24. G. MacClain, "Special Remarks," J. Natl. Class. Mgmt. Soc., 6, 105-110 (1970), p. 106.

25. U.S. Department of Defense, Information Security Program Regulation, DoD 5200.1-R, August $1982, \$ 2-211$.

26. A. L. Thomas, "Application of Security Classification Guides," J. Natl. Class. Mgmt. Soc., 25, 139-158 (1989), p. 145.

27. EO $12356, \S 1.3(\mathrm{~b})$.

28. A. F. Van Cook, "Information Security and Technology Transfer, An OUSD Overview of Executive Order 12356 and DoD's View Concerning Implementation," J. Natl. Class. Mgmt. Soc, 18, 1-7 (1982), p. 3.

29. Taylor v. Department of the Army, 684 F.2d 99, 104 (D.C. Cir., 1982).

30. Taylor v. Department of the Army, 684 F.2d 99, 103-104 (D.C. Cir., 1982).

31. American Friends Service Committee v. Department of Defense, 831 F.2d 441 (3rd Cir. 1987).

32. American Friends Service Committee v. Department of Defense, 831 F.2d 441, 445 (3rd Cir. 1987).

33. American Friends Service Committee v. Department of Defense, 831 F.2d 441, 446 (3rd Cir. 1987).

34. Handbook of Chernistry and Physics, 09th Edition, R. C. Weast (ed.), CRC Press, Inc., Boca Raton, Fla., 1988.

35. Halperin v. National Security Council, 452 F. Supp. 47 (D.D.C. 1978).

36. Halperin v. National Security Council, 452 F. Supp. 47, 50 (D.D.C. 1978).

37. Halperin v. National Security Council, 452 F. Supp. 47, 50 (D.D.C. 1978), affidavit of Z. Brzezinski, Assistant to the President for National Security Affairs.

38. Halperin v. National Security Council, 452 F. Supp. 47, 52 (D.D.C. 1978).

39. Halperin v. National Security Council, 452 F. Supp. 47, 52, n. 6 (D.D.C. 1978).

40. Schroeder v. William Morrow \& Co., 566 F.2d. 3 (7th Cir. 1977), p. 5. p. 941.

41. Rand McNally \& Co. v. Fleet Management Systems, Inc., 600 F. Supp. 933 (N.D. III. 1984),

42. Shipley and Hay, p. 135, citing Toksvig v. B. uce Publishing Co., 181 F.2d 664 (7th Cir. 1950), and Holdredge v. Knight Publishing Corp., 214 F. Supp. 921 (S.D. Cal. 1963). 


\section{Chapter 11. DECLASSIFYING CLASSIFIED INFORMATION}

\section{GENERAL}

Certain requirements must be met before information can be classified. Those requirements were discussed in earlier chapters. When circumstances change, the classified information may no longer meet all of those requirements, and it should be considered for declassification or downgrading. This chapter describes declassification of information principles. In the following chapter, downgrading classified information is discussed.

Information may be declassified only by certain government employees who have been granted declassification authority. ${ }^{\circ}$ However, government employees who are responsible for declassification matters frequently ask government-contractor classification personnel to make recommendations as to which classified information should be considered for possible declassification. Therefore, both government classification personnel and governmentcontractor classification personnel need to be aware of declassification of information principles.

Declassification principles are similar to the previously discussed principles for the original classification of NSI. However, there are some substantive differences with respect to declassifying RD and FRD as compared with the declassification of NSI. Therefore, deciassification of atomic energy information (RD and FRD) will be discussed separately from NSI declassification. The declassification of RD and FRD is described in the next section. A later section describes the declassification of NSI.

\section{DECLASSIFICATION OF RESTRICTED DATA AND FORMERLY RESTRICTED DATA}

\section{General}

Declassification of classified atomic energy information (RD and FRD) is of particular interest because it is usually scientific or technical information (the major classification interest in this document) and because of the unique policies and procedures that the United States has directed toward the control of that information. ${ }^{\dagger}$ The reasons for the stringent

\footnotetext{
Note that there are distinctions between declassifying information and declassifying documents or materials. Only government employees can declassify information. Documents or materials, which are classified because of the information that they contain or reveal, may be declassified by certain specifically designated governmentcontractor employees as well as by certain government employees. The decisions made by government-contractor employees with respect to declassification of documents or materials must be based on classification (declassification) guidance provided by the government.

tSee A. S. Quist, Security Classification of Information. Volume 1. Introducticn, History, and Adverse Impacts, K/CG-1077/V1, Martin Marietta Energy Systems, Inc., Oak Ridge, Tennessee, September 1989, Chaps. 4 and 5,
} 
statutory control of atomic energy information are difficult to understand without some knowledge of the circumstances under which those controls were first instituted. To facilitate that understanding and because the background information is not readily available elsewhere, this section on the declassification of RD and FRD contains a greater than normal amount of background information.

Control of atomic energy information began in early 1939, when some U.S. physicists first realized that it might be possible to build an atomic bomb. These scientists tonk an unprecedented (for university scientists) step by voluntarily withholding certain basic scientific information on nuclear fission from publication. Although the first attempt at obtaining wide acceptance of this atomic energy information-control policy was not successful, another effort was initiated in late 1939 and was successfully achieved by mid-1940. This purely voluntary effort to control basic scientific atomic energy information was initiated and implemented by the U.S. scientific community-the U.S. military disclaimed any interest in controlling this information.

From about midyear 1940 until midyear 1942, civilian organizations of the U.S. Government managed the atomic energy program and instituted rigorous controls on atornic energy information. In June 1942, the U.S. Army assumed responsibility for the atomic bomb project (the Manhattan Project) and established additional rigid controls on atomic energy information. The importance of controlling information about atomic bomb development was especially emphasized in a June 29, 1943, letter from President Roosevelt to Dr. J. Robert Oppenheimer, Director of the Los Alamos Laboratories of the Manhattan Project:

\begin{abstract}
The fact that the outcome of your labors is of such great significance to the Nation requires that this program be even more drastically guarded than other highly secret war developments. I have therefore given directions that every precaution be taken to insure the security of your project and feel sure that those in charge will see that these orders are carried out. ${ }^{1}$
\end{abstract}

The use of atomic bombs produced by the Manhattan Project was a major factor in ending World War II. The awesome power of those weapons, their sudden and dramatic appearance as weapons of war, the extreme secrecy of the Manhattan Project, and the swift surrender of Japan after their first use made a very strong impression on the U.S. public and Congress. The desire of the public and Congress to maintain a U.S. nonopoly on atomic bombs led to the very strict controls on atomic energy information that were included in the Atomic Energy Act of 1946. That act and its successor Atomic Energy Act of 1954 are the only U.S. statutes ever enacted that classify information." The provisions of these two atomic energy acts and their legislative history show that U.S. policy is very strongly directed at stringently controlling atomic energy information that can be used for military purposes.

Before discussing declassification of RD and FRD under the currently applicable Atomic Energy Act of 1954, earlier actions declassifying atomic energy information during the Manhattan Project and declassifying RD under the Atomic Energy Act of 1946 will be described. Such descriptions will provide a perspective on the policy for the control of atomic

\footnotetext{
for more details on the history of classification and declassification of atomic energy information.

Although these acts do not actually state that RD or FRD are classified information, the consequences of the information control provisions in these acts are that RD and FRD are classified information.
} 
energy information in the United States. Additional historical aspects of the declassification of atomic energy information have been discussed elsewhere in some detail. ${ }^{2}$

\section{Declassification of Atomic Energy Information Under the Manhattan Project}

The terms RD and FRD were not used to identify the Manhattan Project's classified atomic energy information. The term RD was first defined by the Atomic Energy Act of 1946. The term FRD was not invented until some time after the Atomic Energy Act of 1954 was enacted. "Classified atomic energy information" is used in this section and throughout this document to denote information that could meet the definition of RD or FRD pursuant to the Atomic Energy Act of 1954.

The first major declassification of U.S. atomic energy information occurred when an atomic bomb was dropped on Hiroshima, Japan, on August 6, 1945. This explosion revealed that a weapon based on nuclear fission could be produced." When the fact that something can be done is made public, then other countries can proceed with confidence towards the same goal, knowing that it can be achieved. Thus, a major secret was disclosed when the first atomic bomb was used in warfare.

The second major declassification of atomic energy information occurred when the Smyth Report $^{3}$ was released to the public on August 11,1945. This report gave a general account of all U.S. work leading to the production of nuclear weapons. Included in that general account was information that would be very helpful to other nations that wanted to develop nuclear weapons. However, Manhattan Project leaders concluded that the adverse impact of releasing that information was outweighed by several information release benefits. The declassification principles used for that decision are given below. However, two additional reasons for issuing the Smyth Report are of particular interest. ${ }^{4,5,6}$ First, the Smyth Report identified the information that could be discussed as unclassified and thereby helped preserve secrecy on the remaining classified information. ${ }^{\dagger}$ Second, the Smyth Report provided general information about atomic energy to U.S. citizens to help them reach informed decisions about U.S. atomic energy policy matters.

Several declassification principles guided the preparation of the Smyth Report. For atomic energy information to be included in the Smyth Report, it had to satisfy at least one requirement in each of the following three categories.

\footnotetext{
"The declassification action can be represented as follows: The fact that a nuclear fission bomb can be produced using enriched uranium is unclassified. This declassification action was inherent in the decision to drop an atomic bomb on Hiroshima. Similarly, another declassification occurred when the second atomic bomb was dropped on Nagasaki. That declassification action can be represented as follows: The fact that a nuclear fission bomb can be produced using plutonium is unclassified.

Since the development of an atomic bomb was such a remarkable achievement, the Manhattan Project leaders recognized that there would be pressure from the press, politicians, public, and peers for more information from project personnel. Those leaders also realized that Manhattan Project personnel would be eager to discuss their achievements. Publishing the Smyth Report established boundaries for releasing such information and for unclassified discussions of those achievements.
} 
I. (A) That th is important to a reasonable understanding of what had been done on the project as a whole or (B) That $i$ is of true scientficic interest and likely to be truly helpful to scientific workers in this country and

II. (A) That it is already known generally by competent scientists or (B) That it can be deduced or guessed by competent scientists from what is already known, combined whth the knowledge that the project was in the overall successful or

III. (A) That th has no real bearing on the production of atomic bombs or (B) That it could be discovered by a small group (15 of whom not over 5 would be senior men) of competent scientists working in a well-equipped college lab in a year's time or less.?

After the end of World War II, there was much interest within the Manhattan Project in making available, for general scientific and technical use, more of the Manhattan Project atomic energy information. In November 1945 a Committee on Declassification was established by Gen. L. R. Groves, head of the Manhattan Project, to develop guidelines for declassifying additional atomic energy information. This committee is usually known as the Tolman Committee because physical chemist R. C. Tolman was its chairman. The Committee's first report stated the following as its general philosophy:

In accordance with your [Gen. Groves'] directive the Committee has considered the effect of release of information both on the national welfare and on the national security. In the interest of national welfare it might seem that nearly all information should be released at once. In the interest of national security a supericial consideration of the problem might lead to the conclusion that very little information should be released.

It is not the conviction of the Committee that concealment of scientific information can in any long term contribute to the national security of the United States. It is recognized that at the present time it may be inevitable that the policy of the Government will be to conceal certain information in the interest of national security. Even within this limitation there are many matters whose declassitication would greatly help the progress of science without violating that policy. If we are looking to the national welfare or national security as they may be two decades from now the Committee has no doubt that the greatest strength in both fields would come from a completely free and open development of science.

Thus, the Committee is inclined to the view that there are probably good reasons for keeping close control of much scientific information if it is believed that there is a likelihood of war within the next five or ten years. It is also their view, however, that this would weaken us disastrously for the future-perhaps twenty years hence. ${ }^{8}$

The Tolman Committee used the following positive and negative criteria to guide the declassification of atomic energy information:

\section{Positive Criteria}

1. Advancement of general science.

2. Advancement of non-military aspects of nuclear science.

3. Advancement of military aspects of nuclear science.

4. Advancement of general technology.

5. Advancement of non-military aspects of nuclear technology.

6. Advancement of military aspects of nuclear technology.

7. Information already substantially known outside project.

8. Information readily obtainable by theory or minor experimentation. 


\title{
Negative Criteria
}

1. Disclosure would jeopardize U.S. military security.

2. Disclosure would weaken U.S. postition in international discussions.

3. Disclosure would jeopardize patent position. ${ }^{9}$

The Tolman Committee recognized that the need for classification of an item of information would change with time. The following were some reasons for such change:

1. As experience is gained in declassification.

2. As the state of general knowledge in the field changes.

3. As the state of the ant changes.

4. As the imternational sttuation changes and as the formulation of policy by the government progresses. ${ }^{10}$

Three classes (declassification categories) for atomic energy information were established by the Committee: ${ }^{11}$

\begin{abstract}
Class I. Information recommended for immediate declassification. [This class] includes basic scientific information which has little direct application to the problems of production or military utillzation.
\end{abstract}

Class II. Information whose declassification would conduce to the national welfare and to long term national security, so that the date of declassification should depend on estimates as to the probability and imminence of war. This class] includes certain basic scienific information which would be of great value to the development of science but which has a direct bearing on production or milltary utilization. It also includes technological information which would be of great importance for the peacetime utilization of atomic energy but which also has importance for production or military utilization.

Class III. Information not at present recommended for declassification, and whose declassification should await a real reduction in the threat of atomic warfare. [This class] includes information which has immediate application to the problems of miltary utilization but for the most part has little application to the development of science or to peacetime utilization. Included in this class are statements with regard to production capacities, amounts of active material on hand, present output of bombs, stock pile of bombs, otc.

For classification guidance purposes, the activities of the Manhattan Project were grouped into six major research and production areas (general, electromagnetic process to enrich uranium, diffusion processes to enrich uranium, plutonium production, nuclear weapon production, and medical information). Project information in each of these six areas was assigned to one of the three declassification categories.

The Tolman Committee's declassification standards for the three classes of atomic energy information can be summarized as follows, arranged from the most stringent to least stringent declassification standard:

TC1. Do not declassify this information because critical national security considerations are much more important than information disclosure benefits.

TC2. Do not declassify this information because national security considerations are more important than information disclosure benefits, even though the risks and bencfits are of about equal valuc. 
TC3. Declassify this information because it has little national security significance and its publication would provide important benefits to general scientific and technical progress.

The Tolman Committee Report provided the general policies, principles, and detailed guidance for the Manhattan Project's first declassification guide, which was dated March 30, 1946. President Truman made the final decision approving that declassification guide. ${ }^{12}$

\section{Declassification Under the Atomic Energy Act of 1946}

The Atomic Energy Act of 1946 became effective on January 1, 1947. That act stated the U.S. atomic energy policy to be that the "common defense and security" of the United States was the paramount factor in atomic energy matters." This was also mentioned in the act's policy statements to control RD and to declassify RD:

It shall be the policy of the [Atomic Energy] Commission to control the dissemination of restricted data in such a manner as to assure the common defense and security (emphasis added). ${ }^{13}$

The term "restricted data" . . shall not include any data which the Commission from time to time determines may be published without adversely affecting the common defense and security (emphasis added). ${ }^{14}$

The declassification standard, publication "without adversely affecting the common defense and security," was very rigorous. Further, declassification of RD required the approval of the five AEC Commissioners and therefore such declassification was not procedurally easily accomplished. It is not surprising that relatively little RD was declassified under the 1946 act.

During 1947 the AEC stated that it supported the Manhattan Project's declassification policy as established by the Tolman Committee. ${ }^{15,16}$ The AEC's policy on information control was summarized in 1950 as follows: ${ }^{\dagger}$

\section{CONTROL OF INFORMATION}

The Commission has continued to give careful consideration to the basic policies underlying the control of information. The Commission, guided by the pertinent provisions of the Atomic Energy Act, has determined that information should be controlled so as to promote the common defense and security by -

a) Withholding from those whose objectives may be inimical to the interests of the United States, information which could be used by them to the detriment of this Nation's security.

b) Providing adiequate information for a vigorous and efficient pursult of the goals of this Nation's atomic energy and related programs, in a rnanner consistent with democratic traditions.

\footnotetext{
"It is hereby declared to be the policy of the people of the United States that, subject at all times to the paramount objective of assuring the common defense and security, the development and utilization of atomic energy shall, so far as practicable, be directed toward improving the public welfare, increasing the standard of living, strengthening free competition in private enterprise, and promoting world peace" (emphasis added) [Atomic Energy Act of 1945, $81(a) ; 60$ Stat. 756].

TI is perhaps worthy of mention that in $19.50 \mathrm{H}$. D. Smyth was one of the five AEC Commissioners. Dr. Smyth seems to have taken a particular interest in information dissemination and control matters.
} 
The secrecy classification to be applied to any Hem of information thus depends upon a balance between the value of that information to inimical interests and the value expected to accrue to the United States through its dissemination.

In ths consideration of policies in such matters, the Commission has recognized that the essential assets of the United States in atomic energy, as in other fields, are the ablilty and experience of industry, the knowledge and enthuslasm of scientists, and the maintenance of momentum in all technical fields. Many of these assets lie outside the Commission's organization and depend to an essential degree upon scientists, technicians, and industrialists having free access to adequate information.

The importance of accountability to the public must be considered, likewise, in determining information-control policy. In a democracy, the people must be able to judge the action of their representatives and officials, and to pass intelligently on policy. The Commission believes that information about a public enterprise of such magnitude as the atomic-energy program should be withheld only for reasons soundly based upon the common defense and securty.

The essential factors in appraising whether particular thems of information must be kept secret depend in part on a technical judgment as to the pertinence of the information to the objectlves of this Nation's over-all program. In forming this judgment, the Commission looks to key technical personnal associated with its activities. It also depends upon many factors of nontechnical nature such as, for example, matters related to military operations, civil defense, plant protection, or imternational relations. In this judgment the Commission must oblain the views of competent authorities in its own organization and in other agencies. The Commission recognizes that control of information requires constant exercise of judgment, in the last analysis, by every individual concerned with classified information. ${ }^{17}$

The AEC's Eighth Semiannual Report stated that the AEC's information control policy was guided by three basic principles:

a) Weapons information, including design, production and stockplies, should be kept secret.

b) Basic science should be free except where it is directly related to weapons.

c) Until international control is attained, there shall be no Information exchanged with other nations on the use of atomic energy for industrial purposes. ${ }^{18}$

The principle for controlling information not falling within one of those three categories was, "Will the release of this information help the United States atomic energy program more than it will help the atomic energy program of a potential enemy? ${ }^{n 19}$

\section{Declassification Under the Atomic Energy Act of 1954}

The Atomic Energy Act of 1954 became effective on August 30, 1954, and is currently in effect. That act's definition of RD' was essentially the same as was in the Atomic Energy Act of 1946, but a new standard for declassifying RD was established by the 1954 Act:

The [Secretary of Energy] shall from time to time determine the data, within the definition of Restricted Data, which can be published without undue risk to the common defense

\footnotetext{
"The term Restricted Data means all data concerning (1) design, manufacture, or utilization of atomic weapons; (2) the production of special nuclear material; or (3) the use of special nuclear material in the production of energy, but shall not include data declassified or removed from the Restricted Data category pursuant to [section 2162 of this title] [42 U.S.C. 2014(y)].
} 
and security and shall thereupon cause such data to be declassified and removed from the category of Restricted Data (emphasis added). ${ }^{20}$

This "without undue risk" standard replaced the "without adversely affecting" standard of the 1946 act and made it easier to declassify RD. One of the major U.S. policy reasons for the change was to make it easier for some atomic energy information to be applied to civilian (peacetime) uses. Another reason was to enable some atomic energy information to be shared with other nations as part of our foreign policy (e.g., to implement the Atoms for Peace Program).

The 1954 act provided for the transclassification of RD to another category of atomic energy information, later designated as FRD:

\begin{abstract}
The [Secretary of Energy] shall remove from the Restricted Data category such data as the [Secretary of Energy] and the Department of Defense jointly determine relates primarily to the military utilization of atomic weapons and which the [Secretary of Energy] and the Department of Defense jointly determine can be adequately safeguarded as defense information: Provided, however, That no such data so removed from the Restricted Daia category shall be transmitted or otherwise made available to any nation or regional defense organization, while such data remains defense information, except pursuant to an agreement for co-operation entered into in accordance with [section $2164(\mathrm{~b})$ of this title]. ${ }^{21}$
\end{abstract}

The 1954 Act also provided for the declassification of FRD:

In the case of Restricted Data which the [Secretary of Energy] and the Department of Defense jointly determine to relate primarily to the military utilization of atomic weapons [FRD], the determination that such data may be published without constituting an unreasonable risk to the common defense and security shall be made by the [Secretary of Energy] and the Department of Defense jointly, and if the [Secretary of Energy] and the Department of Defense do not agree, the determination shall ca made by the President. $22^{2}$

Note that the declassification standard for FRD is publication "without unreasonable risk" as compared to the "without undue risk" standard for declassification of RD. Presumably, an undue risk is not as large as an unreasonable risk since RD is more tightly controlled than FRD. FRD is protected as NSI (except with respect to transmittal to other nations-see above) and therefore declassification standards for FRD would be expected to be similar to those for NSI. However, the declassification standard for FRD, "publication without constituting an unreasonable risk to the common defense and security," is not exactly the same as the NSI declassification standard, which is that disclosures (publication) "reasonably could be expected not to cause damage to the national security" (see below for a discussion of the standard for declassifying NSI).

Much RD and FRD have been declassified under the more liberal declassification standards of the Atomic Energy Act of 1954. However, not much information has been published about the declassification principles and balancing standards used to guide those declassification actions. Some information on those matters is contained in a 1974 AEC

\footnotetext{
-For example, within DOE and its contractors, a person with an L security clearance may have access to Secret information in the FRD and NSI categories but only to Confidential information in the RD category.
} 
report on the AEC classification program. ${ }^{23}$ That report indicated that the AEC had generaliy followed the declassification philosophy of the Tolman Committee. ${ }^{23}$ The report also indicated that the following factors were considered in making recommendations on the declassification of RD and FRD:

(a) The published state of the an both in the United States and elsewhere.

(b) The value of the information to our classified programs.

(c) The value of the information to our unclassified programs.

(d) The effect that the information might have in assisting the development of a nuciear capability in other nations.

(e) The feasibility of providing adequate security protection.

(f) The extent to which classification would interfere with our progress in the field under consideration.

(g) The extent to which classification might adversely affect delivery schedules for items, e.g., weapons to stockpile.

(h) The extent of effort required in developing the information. ${ }^{23}$

Those factors are risks and benefits of information disclosure (see Chapter 6), except for the first factor, which is an information control factor, and the last factor, which is a measure of the extent to which an adversary would be helped by the information disclosure.

The 1974 AEC report also described balancing standards (termed declassification policy statements) to use when declassifying RD and FRD. Five major RD and FRD information areas were listed in that report and a balancing standard (policy statement) was given for each area. $^{23}$ Those five balancing standards are paraphrased and summarized as follows:

S1. Retarding the progress of inimical nations is more important than advancing U.S. progress.

S2. Declassify information only when such an action makes a contribution to U.S. progress which clearly outweighs the risk to the national defense and security of disclosing the information.

S3. Declassify only when the advantage to the U.S. clearly outweighs any advantage to an inimical nation.

S4. Advancing U.S. technology is more important than retarding the progress of inimical nations.

S5. Declassify only when the information disclosed is not vital to nuclear weapons or to military production reactors.

Current DOE policy and standards for declassifying atomic energy information are contained in a 1974 classification policy guide. The basic principle to be used when declassifying atomic energy information was expressed as follows:

\footnotetext{
-This is a somewhat strange declassification standard, since it is difficult to retard the progress of an inimical nation by releasing information. This standard probably should have been stated as "Declassify only when the deciassification wiii not assisi the progress of an inimicai nation.."
} 
The principle undertying declassification policy is to achieve a balance between two aims: (1) promoting the common defense and security by maintaining at a minimum the declassification of information concerning the military aspects of atomic energy, and (2) promoting the scientific and peaceful applications of atomic energy to the maximum extent possible consistent with the common defense and security. ${ }^{24}$

Declassification balancing standards were given for several areas of classified atomic energy information. Those standards are paraphrased and summarized as follows:

SA1. Declassify information only when it makes a contribution to U.S. progress which clearly outweighs the risk to the common defense and security of disclosing the information.

SA2. Declassify information only when the contribution to the scientific and peaceful applications of atomic energy clearly outweighs the risk of the disclosure.

SA3. The information should remain classified if it is essential primarily to military activities.

SA4. Declassify information only when clearly in the national defense interest.

SA5. Only that information essential primarily to defense activities need remain classified.

A 1987 DOE report summarized DOE policy for declassifying atomic energy information. The underlying principle was stated as follows:

\begin{abstract}
The principle underlying classification and declassification policy for atomic energy information is to achieve a balance between two aims: (1) assuring the common defense and security by controlling the declassification of information concerning the military aspects of atomic energy; and (2) promoting the dissemination of scientific and technical information relating to the peaceful applications of atomic energy consistent with the common defense and security. However, the Atomic Energy Act states that the paramount objective of protecting the common defense and security must be observed. A determination on the declassification or downgrading of information can proceed only after a careful balancing of the risk to the common defense and security against the benefit to our own program of the proposed action. In such a risk-benefit analysis, credibility of the DOE classification program is one of the factors considered. It is also particularly important to avoid revealing information that may contribute to horizontal (by a non-weapon state) or vertical (by a weapon state) proliferation. 25
\end{abstract}

That report also stated that when information was considered for possible declassification, the following factors were among those considered:

Impact on U.S. national security by release of the information.

Benefit to the progress in a U.S. program.

Extent to which the information has been published, publicized, or otherwise disseminated.

Whether release of the information would strengthen the credibility of the classification program.

Extent to which technological progress has made the information less sensitive.

Importance of the information to public discussion and education.

Impact on a U.S. negotiation posture. 
Extent to which the information has been compromised through unauthorized disclosure.

Extent to which the information can be duplicated through simple theoretical calculations and experiments. ${ }^{25}$

In 1990 DOE adopted new declassification procedures and stated that proposed declassification actions would be evaluated against the following criteria:

The extent to which the information would assist in the development of a nuclear weapons capability in non-nuclear weapon states or in improvements to the weapons in a nuclear weapon state.

The extent to which the information would assist in the production of special nuclear material.

The benefit to be realized by the U.S. program from the declassification action, including any significant technology commercialization potential.

The cost to the U.S. program by the continued classification of the information.

Any detrimental (or beneficial) effect release of the information might have on U.S. foreign relations, arms control negotiations, or treaty obligations.

Any impact on the credibility of the Department of Energy classification program by the continued classification of the information.

The cost in terms of time and money of acquiring the information.

The published state of the art for the information in both the U.S. and in other countries. $^{26}$

Except for the last two items on this list, the criteria are essentially risks and benefits to be considered when evaluating information for declassification. The last item on the list, which refers to published information, is really an information control matter. The next-tolast item, the cost of developing the information, is a measure of how much the declassification would help an adversary and is therefore not a risk but a factor to be used in evaluating several of the risks. DOE added the following additional criterion to this list in 1992:

Any other national security impact or significance (e.g., the extent to which the information would assist an adversary nation to assess or counter the U.S. capabilities and limitations). ${ }^{27}$

Table 11.1 summarizes the risk and benefit criteria that could be used when deciding whether to declassify RD or FRD. That table includes the 1990 and 1992 DOE criteria (expressed specifically in terms of risks and benefits) plus, as benefits, the importance of the information to public discussion and education (stated in the 1987 DOE report), the benefits to U.S. general progress in science and technology (stated in the Tolman Committee Report), and a catch-all "Any other significant benefit to the United States" that was added to be consistent with a similar criterion for determining risks. This table is essentially the same as Table 5.1, except that Table 11.1 is specific for declassifying RD or FRD. 
Table 11.1. Criteria that could be used to determine the risks and benefits of disclosure of scientific or technical information when considering whether to declassify Restricted Data or Formerly Restricted Data

\section{Criterion}

number

Description

Criteria for Determining Risks

RC1 The extent to which the information could assist a non-nuclear weapon state in developing a nuclear weapon capability

RC2 The extent to which the information could assist a nuclear weapon state in improving its nuclear weapons

RC3 The extent to which the information could assist in the production of special nuclear material

RC4 The detrimental effects that release of the information could have on U.S. foreign relations, arms control negotiations, or treaty obligations

RC5 Any other national security impact or significance (e.g., the extent to which the information would assist other nations in assessing or countering U.S. capabilities and limitations)

RC6 The detrimental effects that declassification of the information could have on the credibility of the Department of Energy classification program

\section{Criteria for Determining Benefits}

$\mathrm{BCl}$ The benefits to the progress of the U.S. program that could be achieved from the declassification action

BC2 The benefits to the U.S. program that could be achieved by eliminating the costs of continued classification of the information

BC3 The benefits to the U.S. economy that could be realized by transferring the technology to U.S. industry for commercialization

BC4 The benefits that could be realized by U.S. progress in science and technology, in general, if the information were declassified

BC5 The benefits that release of the information could provide to U.S. foreign relations, arms control negotiations, or treaty obligations

BC6 The importance of the information to public discussion and education

BC7 Any other significant benefit to the U.S.

BC8 The benefits that declassification of the information could have on the credibility of the Department of Energy classification program 
The complete chronology of the information-control factors, the information-disclosure risks, and the information-disclosure benefits used for declassifying atomic energy information from 1945 to 1992 is summarized in Table 11.2. The last column of that table contains, as proposed comprehensive criteria, the information-control factors discussed in Chapter 4 and the risk and benefit criteria discussed in Chapter 5 and also given in Table 11.1.

The specific standards used by DOE for balancing risks and benefits of declassifying RD and FRD depend upon the area of atomic energy information in which the RD or FRD is included. Those standards were summarized and paraphrased earlier in this chapter. They may be compared with the proposed standards for classifying information that were given in Table 6.2.

RD may be declassified only by the DOE Director of Security Affairs. ${ }^{28}$ FRD may be declassified only by a joint determination of the DOE Director of Security Affairs and DoD. ${ }^{28,29}$

\section{DECLASSIFICATION OF NATIONAL SECURITY INFORMATION}

\section{Declassification Requirements Contained in Executive Orders}

The first two EOs on the classification of information, issued in 1940 and 1950, did not discuss declassifying or downgrading classified information. ${ }^{30}$ EO 10290 , issued in 1951 as the third EO on classification of information, provided for review of classified information (currently termed NSI) for downgrading and declassification and for automatic declassification and downgrading of NSI after a specified event or date. ${ }^{31}$ Essentially the same declassification and downgrading provisions were included in EO 10501, issued in 1953..$^{32}$ In 1961, EO 10501 was amended by EO 10964 to require that certain types of NSI be automatically downgraded or declassified at specified time intervals. ${ }^{33}$ The time intervals were to be measured from the date of issuance of the document containing the classified information. Required automatic downgrading or declassification was specified for some types of NSI in subsequent EOs until EO 12356 was issued in 1982. That EO, which currently governs the classification of NSI, does not require automatic downgrading or declassification of NSI. With respect to declassification and downgrading, EO 12356 states that:

Information shall be classified as long as required by national security considerations. When it can be determined, a specific date or event for declassification shall be set by the original classification authority af the time the information is originally classified. ${ }^{34}$

The elimination of automatic downgrading or declassification requirements is recognition of the fact that the security sensitivity of most NSI does not decrease at a fixed rate with respect to elapsed time but is affected by events that cannot be predicted. ${ }^{35,36}$ "Gone are the artificial 6- and 20-year limitations that substituted for judgment of original classification authorities." 37 The elimination of those requirements is consistent with a 1974 statement by the DoD Director of Research and Engineering: "There can be no magic formula or standard for determining the number of years to retain classification on any particular piece of equipment or item of information. ${ }^{\text {38 }}$ 
Table 11.2. Chronology of the development of criteria for

Generally known by competent scientists

Can be deduced or guessed by competent scientists from what is already known, combined with knowledge that the project was, overall, successful; could be discovered by a small group (15, of whom not over 5 would be senior men) of competent scientists working in a well equipped college lab in a year's time or less
The information is already substantially known outside the project

The published state of the elsewhere
The information is readily obtainable from theory or minor experimentation
Use reveals "breakthrough" scientific and technical information-that a

major new weapon was feasible

\section{Disclosure would jeopardize U.S. military} security

\section{Information discle}

Assistance to the developrt capability in other nations

Could be discovered by a small group (15, of whom not over 5 would be senior men) of competent scientists working in a well equipped college lab in a year's time or less

Extent of effort required in information

Disclosure would weaken U.S. position in international discussions

Disclosure would jeopardize patent position
Value of the information th programs
Use provides a major advantage in winning a war
Advancement of military aspects of nuclear science or technology

Of true scientific interest and likely to be truly helpful to scientific workers in the U.S.

Advancement of science or technology, in general

Advancement of nonmilitary aspects of nuclear science or technology

\section{Information disclo:}

Adverse effects of classifi: field under consideration

The feasibility of providin protection

Value of information to $\mathrm{U}$ :

Adverse effects of classific schedules for items (e.g., w
Importance to a reasonable understanding of what was done on the project as a whole

Disclosure defined what could be revealed-the remaining secrets would be better kept

Has no real bearing on the production of atomic bombs 
DOE-1987 DOE-1990, 1992

ers

U.S. and The extent to which the information has been published, publicized, or otherwise disseminated

The published state of the art in the U.S. and elsewhere

Exteot to which the information can be duplicated through simple theoretical calculations and experiments
Proposed general description criteria (this document, Chaps. 4, 5, and 11 )
Extent to which technological progress has made the information less sensitive

Extent to which the information has been compromised by unauthorized disclosure

\section{inks}

Impact on U.S. national security of release of the information

Detrimental effects on foreign relations

assified iing the
Assiatance to development of nuclear weapons by a non-nuclear country

Assistance to improvements in nuclear weapons of a nuclear weapons state

Assistance in the production of special nuclear material

Cost of acquiring the information
Published state of the art

Extent to which the information can be duplicated by competent scientists through simple theoretical equations or minor experimentation, or by reverse engineering an unclassified product

Known but unpublished classified state of the art (U.S. and abroad)

Extent of foreign knowledge of unpublished, unclassified, state of the art in the U.S.

Known bul classified state of the art (U.S. and abroad)

Extent to which technological progress has made the information less sensitive

Extent to which the information has been compromised through unauthorized disclosure
Assistance to other nations in developing new armaments

Assistance to other nations in improving armaments

Assistance to other nations in producing materials for armaments
Detrimental effects on foreign relations

Any other national security impact or significance

Detrimental effects on classification program credibility

Benefits to the U.S. program

Technology transfer benefits

Benefits to U.S. foreign relations, arms control negotiations, or treaty obligations
Detrimental effects on foreign relations

Any other national security impact or significance

Detrimental effects on classification program credibility
Benefits to U.S. foreign relations

Importance of the information to public discussion and education delivery

to stockpile)
Strengthening the credibility of the classification program
Benefits to classification program credibility
Benefits to the progress of the U.S. program

Benefits to the U.S. program of eliminating classification costs

Benefits to general scientific and technical progress

Technology transfer benefits

Benefits to U.S. foreign relations, arms control negotiations, or treaty obligations

Importance of the information to public discussion and education

Any other significant benefit to the U.S.

Benefits to classification program credibility 
EO 12065 , the immediate predecessor to EO 12356, stated that "declassification of classified information shall be given emphasis comparable to that accorded classified information. $^{\text {n39 }}$ A comparable directive was not included in EO 12356 . EO 12065 also explicitly stated that information which continued to meet all classification requirements might sometimes be declassified when to do so was in the public interest. ${ }^{40}$ That provision was not included in EO 12356."

NSI can be declassified by the person originally classifying that information, that person's successor, supervisors of either, or other persons delegated such authority in writing by an agency head or other designated senior agency official. ${ }^{41}$ Within the DOE and its contractors, NSI can be declassified by the Original Classifier of such information (or successor to that person), the Director of Classification, or the Director of Security Affairs. $^{\dagger, 42}$

\section{Principles for Declassifying NSI Classified by Executive Order}

The basic policy for declassifying NSI, as paraphrased from EO 12356 where the policy is expressed in terms of classifying information, is that NSI can be declassified if its disclosure reasonably could be expected to not cause damage to the national security. $\ddagger$ Table 11.3 compares the declassification policy for NSI with the previously given declassification policies for RD and FRD.

Principles to use when declassifying information are similar to those used for classifying information. Three major steps are involved in classifying information: (1) determining whether the information is under governmental control, (2) evaluating the risks and benefits of information disclosure, and (3) balancing those risks and benefits.

Criteria for determining information-disclosure risks and benefits and the factors for evaluating those criteria were described in Chapter 5 with respect to deciding whether information was classified. Those criteria and factors are also applicable to declassifying information and so they will not be discussed further in this chapter.

\footnotetext{
"Central Intelligence Agency (CIA) information security regulations still include criteria for declassifying properly classified information when public interest in its disclosure outweighs the need to protect that information. Such properly classified information would not be disclosed if disclosure could reasonably be expected to (1) place a person's life in jeopardy, (2) adversely affect the public health and safety, (3) impede legitimate law enforcement functions, (4) impede the investigation of oversight functions of the Congress, (5) obstruct the fair administration of justice, or (6) deprive the public of information indispensable to public discussion on issues of crucial national importance. The balancing of the competing interests for those situations was to be carried out by a CIA official having Top Secret classification authority. The final decision rested with higher CIA authorities [32 CFR Part $1902.13,88(\mathrm{c})$ and $(\mathrm{d})]$.

${ }^{t}$ Documents or materials containing NSI, RD, or FRD can be declassified, within DOE and its contractors, by the Director of Classification, Original Classifiers, or Derivative Declassifiers [DOE Order 5650.2B, "Identification of Classified Information," Dec. 31, 1991, Chap. V, Part A, \$4(g)(2)(b); Chap. VI, Part A, \$82(a) and 2(b)(5)]. Custodians of classified documents or materials may declassify those documents or materials in accordance with a declassification notice from an authorized source [DOE Order 5650.2B, Chap. VI, Part A, 82(a)].

FThis policy for declassifying NSI is a paraphrase of EO 12356, Preamble, which states the government policy for classifying information, and 83.1(a), which authorizes declassification of information.
} 
Table 11.3. A summary of declassification policies for the different categories of classified information

\begin{tabular}{|c|c|c|}
\hline $\begin{array}{l}\text { Category of } \\
\text { classified } \\
\text { information }\end{array}$ & Declassification policy & Source for policy \\
\hline $\begin{array}{l}\text { Restricted Data } \\
\text { (1946 Atomic } \\
\text { Energy Act) }\end{array}$ & $\begin{array}{l}\text { "Can be published without adversely affecting } \\
\text { the common defense and security" }\end{array}$ & $\begin{array}{l}\text { Atomic Energy Act of } \\
1946 \text {, P.L. 585, } \\
\$ 10(b)(1)\end{array}$ \\
\hline $\begin{array}{l}\text { Restricted Data } \\
\text { (1954 Atomic } \\
\text { Energy Act) }\end{array}$ & $\begin{array}{l}\text { "Can be published without undue risk to the } \\
\text { common defense and security" }\end{array}$ & $\begin{array}{l}\text { Atomic Energy Act of } \\
1954,68 \text { Stat. } 941 ; \\
42 \text { U.S.C. } \$ 2162(\mathrm{a})\end{array}$ \\
\hline $\begin{array}{l}\text { Formerly } \\
\text { Restricted Data }\end{array}$ & $\begin{array}{l}\text { "May be published without constituting an } \\
\text { unreasonable risk to the common defense and } \\
\text { security" }\end{array}$ & $\begin{array}{l}\text { Atomic Energy Act of } \\
1954,68 \text { Stat. } 941 ; \\
42 \text { U.S.C. } \$ 2162 \text { (c) }\end{array}$ \\
\hline $\begin{array}{l}\text { National } \\
\text { Security } \\
\text { Information }\end{array}$ & $\begin{array}{l}\text { Disclosure reasonably could be expected to not } \\
\text { cause damage to the national security }\end{array}$ & $\begin{array}{l}\text { Executive Order } 12356, \\
\text { Preamble and } \$ 3.1(\mathrm{a})\end{array}$ \\
\hline
\end{tabular}

The Atomic Energy Act of 1946 was superseded by the Atomic Energy Act of 1954 . Therefore, this declassification standard is no longer valid. It is included for comparison purposes only.

Principles and standards to use when balancing information-disclosure risks and benefits were described in Chapter 6 with respect to classification of information decisions. Those principles and standards are also applicable to declassification actions and so they will not be discussed further in this chapter. The standards in Chapter 6 are consistent with the declassification policy given in EO 12356 (see above) when that policy is expressed in terms of net damage to the national security. That is, the classification (declassification) standards of Chapter 6 are consistent with EO 12356 policy when that policy is paraphrased to state that NSI can be declassified when its disclosure reasonably could be expected to not cause net damage to the national security.

The first major step in classifying information (i.e., determining whether the information is under governmental control) has not yet been mentioned in connection with declassification. That is because if the information is currently classified, then it is presumably also currently under governmental control. However, loss of governmental control may provide a reason for declassifying information.

Sometimes classified information that has not yet been declassified will appear in unclassified publications because of unauthorized disclosure, either deliberate or unintentional. In those situations that classified information is no longer totally under government control. A subsection of EO 12356 deals specifically with the publication of classified information." It states that classified information "shall not be declassified automatically as

\footnotetext{
"DOE has a "no comment" policy that forbids knowledgeable employees from making any comments concerning the appearance of classified information in an unclassified publication.
} 
a result of any unofficial publication or inadvertent or unauthorized disclosure in the United States or abroad of identical or similar information. ${ }^{n 43}$ DoD guidance specifically mentions the effect of open publication of classified information on declassification considerations:

\begin{abstract}
Classified information shall not be declassified automatically as a result of any unofficlal publication or Inadvertent or unauthorized disclosure in the United States or abroad of identical or similar information. Appearance in the public domain of information currently classified or being considered for classification does not preclude intial or continued classification. However, such disclosures require immediate determination or the degree of damage to the national security and reevaluation of the information to determine whether the publication has so compromised the information that downgrading or declassification is warranted. 4
\end{abstract}

Courts have held that information in the public domain that is similar to classified information does not warrant the disclosure of the classified information. One court emphasized that the least "bit" of classified information requires protection. ${ }^{45}$ Another court held that classified information is not to be considered as declassified unless it has been officially disclosed. ${ }^{46}$ Thus, the appearance of classified information in an unclassified publication does not mean that the information has been declassified. In some situations "the effect of its classification has been lost, but in fact the information is still classified. ${ }^{*}, 47$

\title{
Principles for Declassifying NSI Transclassified from RD
}

There is reason to believe that the declassification principles mentioned above should not apply to all NSI. There are two kinds of NSI: NSI classified under EO 12356 and NSI transclassified from RD. The Atomic Energy Act of 1954 authorizes the transclassification of certain RD to NSI:

The [Secretary of Energy] shall remove from the Restricted Data category such information concerning the atomic energy programs of other nations as the [Secretary of Energy] and the Director of Central Intelligence jointly determine to be necessary to carry out the provisions of section [102(d) of the National Security Act of 1947, as amended,] and can be adequately safeguarded as defense information. ${ }^{48}$

A similar section of the 1954 act authorized the transclassification of certain RD to FRD (discussed previously in this chapter).

Although FRD is treated like NSI in most respects, the 1954 act specifically requires that FRD be declassified by a joint determination of DOE and DoD, the two entities that also decide if RD can be transclassified to FRD (previously discussed in this chapter). The declassification standard for FRD was also established by the 1954 act (previously discussed in this chapter). That standard (publication without unreasonable risk to the common defense and security) is different than either the standard for RD (publication without undue risk to

\footnotetext{
"With respect to the unauthorized release of classified information, it is said to be sometimes difficult to obtain official recognition of the fact that the effect of classification has been lost and that the rational course of action is to declassify the information. One author has stated that "one of the most costly and hardest to justify decisions is to classify a program, or certain information related to a program, after the information has been rather widely disseminated as unclassified. All classification management can do here is to present the best case possible that this is an unreasonable decision and will accomplish nothing" [W. N. Thompson, "Security Classification ManagementCoordination Between Industry and DOD," J. Natl. Class. Mgmt. Soc., 4(2), 121-128 (1968), p. 126).
} 
the common defense and security) or NSI (disclosure reasonably could be expected not to cause damage to the national security).

The unique requirements for declassifying FRD, even though FRD is generally protected like NSI, are consistent with the special concern that Congress has always had for atomic energy information. It is curious that the Atomic Energy Act does not also specify declassification procedures for the RD that has been transclassified to NSI. One might have expected a requirement that the declassification decision be made jointly by DOE and the Director of the Central Intelligence Agency (CLA). One might also expect that the declassification standard for this NSI should be based on the area of atomic energy information from which this NSI was transclassified, since there are different standards for the declassification of RD for the different areas of atomic energy information. Another consideration arises from the probability that the RD transclassified to NSI was probably obtained from intelligence sources and methods. The Director of the CIA is responsible for protecting intelligence sources and methods from unauthorized disclosure. ${ }^{49}$ Does the CIA have a veto power for any decision to declassify NSI that was transclassified to NSI from RD?

There is another unusual aspect to the declassification of transclassified NSI (NSI that was created by transclassifying RD). RD and FRD, once declassified, cannot be reclassified. "50 However, under certain circumstances EO 12356 permits declassified NSI to be reclassified. $^{51}$ Therefore, if the same classification and declassification rules are applicable both to NSI classified under EO 12356 and to NSI transclassified from RD, then NSI transclassified from RD may be declassified and subsequently reclassified. Such an action would be inconsistent with the Atomic Energy Act's provision that forbids the reclassification of information that was once RD..$^{50}$

\section{SUMMARY OF DECLASSIFICATION PRINCIPLES}

The criteria for determining the risks and benefits of information disclosure, for use in classification of information decisions, were summarized in Table 5.1 of Chapter 5. The same criteria should be used for determining the risks and benefits of declassifying information. Each risk and benefit must be evaluated to determine its magnitude so that risks can be balanced against benefits. For each risk and benefit there may be several evaluation factors that should be considered. The evaluation factors to use when determining whether information should be classified were summarized in Tables 5.2 and 5.3 of Chapter 5. Those same evaluation factors should be used in determining whether information should be declassified.

Standards to use to balance information-disclosure risks against information-disclosure benefits when making classification decisions were summarized in Table 6.2 of Chapter 6 . Those same balancing standards should be used when determining whether information should be declassified.

Matters of proof in declassification decisions are summarized in Table 11.4 for each category of classified information, including the two subcategories of NSI (see above). See Table 6.3 for comparable matters of proof for classification decisions.

\footnotetext{
'Although the Atomic Energy Act of 19.54 does not explicitly state this prohibition, the act has consistently been interpreted by DOF and its predecessor agencies as forbidding the reclassification of declassified RD.
} 


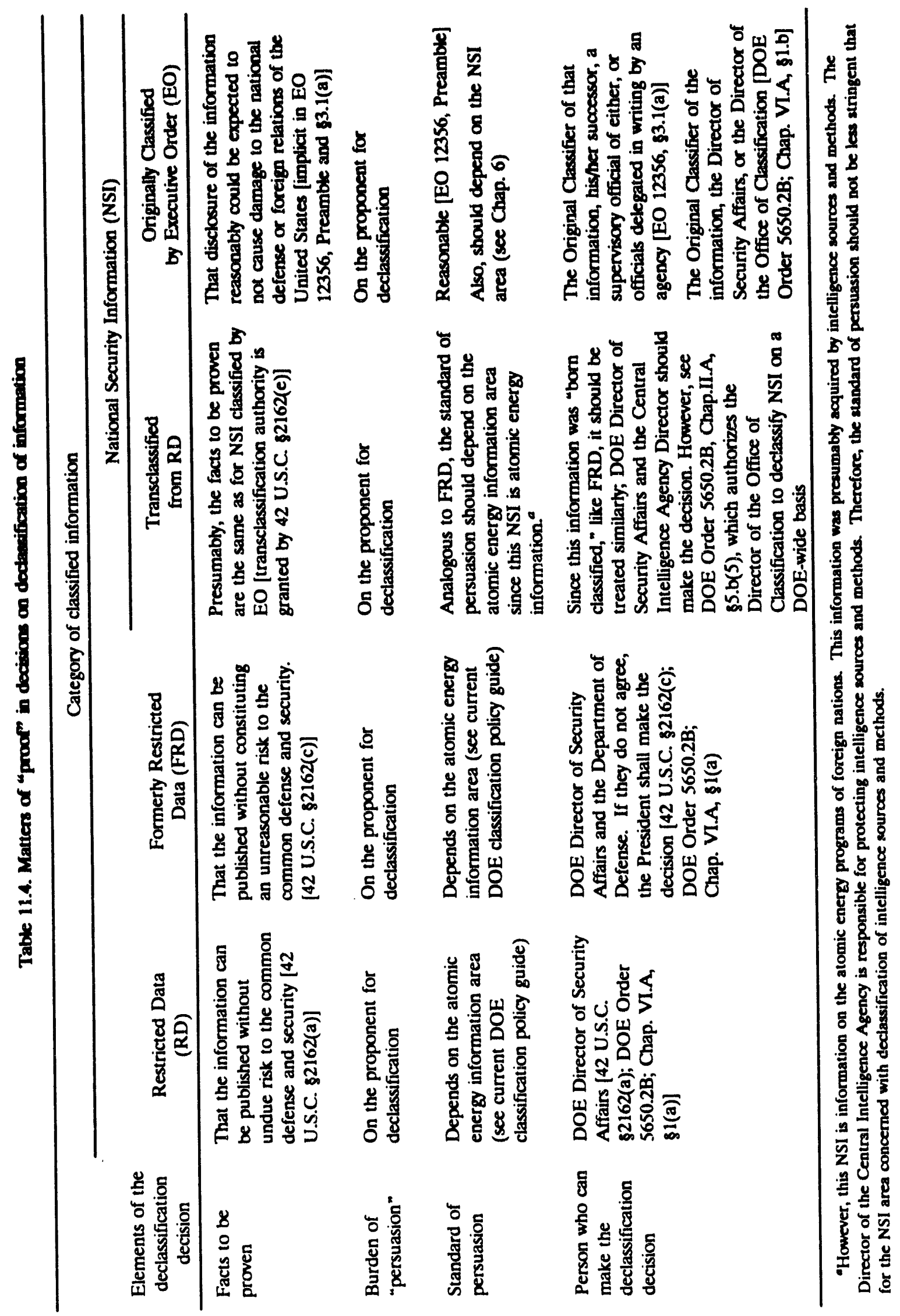




\section{REFERENCES}

1. U.S. Atomic Energy Commission, "In the Matter of J. Robert Oppenheimer," Transcript of Hearing Before Personnel Security Board, Washington, D.C., April 12, 1954, through May 6, 1954, U.S. Govt. Printing Office, 1954, p. 30.

2. A. S. Quist, Security Classification of Information. Volume 1. Introduction, History, and Adverse Impacts, K/CG-1077/V1, Martin Marietta Energy Systems, Inc., Oak Ridge, Tennessee, September 1989, Chap. 5. Hereafter cited as "Quist."

3. H. D. Smyth, A General Account of the Development of Methods of Using Atomic Energy for Military Purposes Under the Auspices of the United States Government, 1940-1945, U.S. Govt. Printing Office, August 1945.

4. R. G. Hewlett and O. E. Anderson, Jr., The New World, 1939/1946, The Pennsylvania State University Press, University Park, Pa., 1962, pp. 400, 407. Hereafter cited as "Hewlett and Anderson."

5. L. R. Groves, Now It Can Be Told, Harper \& Brothers, New York, 1962, pp. 348-352.

6. V. C. Jones, Manhattan: The Army and the Atomic Bomb, United States Army in World War II, Special Studies, Center of Military History, United States Army, Washington, D.C., 1985, pp. 556-562. Hercafter cited as "Jones." Smyth.

7. Jones, pp. 558-559, quoting from a May 21, 1945, letter from General L. R. Groves to H. D.

8. R. C. Tolman, R. F. Bacher, A. H. Compton, E. O. Lawrence, J. R. Oppenheimer, F. H. Spedding, and H. C. Urey, Report of Committee on Declassification, Memorandum to Maj. Gen. L. R. Groves, Nov. 17, 1945, pp. 2-3. Hereafter cited as "Tolman Report."

9. Tolman Report, p. 3.

10. Tolman Report, p. 4.

11. Tolman Report, pp. 4-5.

12. Hewlett and Anderson, p. 647.

13. Atomic Energy Act of 1946, \$10(a); 60 Stat. 766.

14. Atomic Energy Act of 1946, $\$ 10(b)(1) ; 60$ Stat. 766.

15. B. J. Bok, F. Friedman, and V. Weisskopf, "Security Regulations in the Field of Nuclear Research," Bull. At. Sci, 3, 321-324, 344 (November 1947), p. 321. This article included the contents of a letter dated Aug. 27, 1947, from C. L. Wilson, General Manager of the Atomic Energy Commission, to B. J. Bok, which described the Commission's policy on atomic energy information security.

16. U.S. Atomic Energy Commission, Second Semiannual Report, July 1947, p. 15.

17. U.S. Atomic Energy Commission, Seventh Semiannual Report, January 1950, pp. 169-170. 
18. U.S. Atomic Energy Commission, Eighth Semiannual Report, July 1950, pp. 227-228. Hereafter cited as "Eighth Semiannual Report."

19. Eighth Semiannual Report, p. 228.

20. 42 U.S.C. $\$ 2162(a)$.

21. 42 U.S.C. $\$ 2162(d)$.

22. 42 U.S.C. $\$ 2162(c)$.

23. U.S. Atomic Energy Commission, Washington, D.C., internal document, 1974.

24. U.S. Atomic Energy Commission, Washington, D.C., internal document, 1974.

25. U.S. Department of Energy, Washington, D.C., internal document, 1987.

26. Memorandum from J. C. Tuck, DOE Under Secretary of Energy, to DOE Operations Office Managers, "Department of Energy Declassification Procedures," Tab 1, May 1, 1990.

27. Letter from A. B. Siebert, Director, DOE Office of Classification, to Distribution, Revised Evaluation Criteria for Proposed Declassification Actions, Attachment 2 to "Revised Department of Energy Declassification Procedures, ${ }^{n}$ March 12, 1992.

28. U.S. Department of Energy, DOE Order 5650.2B, "Identification of Classified Information," Chap. VI, Part A, \$1.a, Dec. 31, 1991. Hereafter cited as “DOE Order 5650.2B.”

29. 42 U.S.C. $\$ 2162(c)$.

30. See Quist, Chap. 3, for a more detailed discussion of EOs governing the classification of information.

31. Executive Order 10290, Fed. Reg. 16, 9795 (Sept. 27, 1951), \$28.

32. Executive Order 10501, Fed. Reg., 18, 7049 (Nov. 10, 1953), \$4.

33. Executive Order 10964, Fed. Reg., 26, 8932 (Sept. 22, 1961).

34. Executive Order 12356, Fed. Reg., 47, 14874 (Apr. 6, 1982), \$1.4(a). Hereafter cited as EO 12356.

35. E. Hill, "Defence Procurement and Classification in the U.K.," J. Natl. Class. Mgmt. Soc., 16, 20-27 (1980), p. 25.

36. A. P. Stringer, "Classification Management in the United Kingdom," J. Natl. Class. Mgmt. Soc., 23, 38-43 (1987), p. 43.

37. A. F. Van Cook, "Information Security and Technology Transfer (An OUSD Overview of Executive Order 12356 and DoD's View Concerning Implementation), ${ }^{n}$ J. Natl. Class. Mgmt. Soc., 18, 1-7 (1982), p. 3.

38. J. S. Foster, Jr., in Government Secrecy, Hearings Before the Subcommittee on Intergovernmental Relations of the Committee on Government Operations, U.S. Senate, 93rd 
Congress, 2nd Session, May 22, 23, 29, 30, 31 and June 10, 1974, U.S. Govt. Printing Office, 1974, p. 268.

39. Executive Order 12065, Fed. Reg., 43, 28949 (July 3, 1978), §3-301. Hereafter cited as "EO 12065."

40. EO 12065, \$3-303.

41. EO 12356, \$3.1(b).

42. DOE Order 5650.2B, Chap. VI, Part A, 81(b).

43. EO 12356, \$1.3(d).

44. U.S. Department of Defense, Information Security Program Regulation, DoD 5200.1-R, Chap. II, 82-209, June 1986.

45. Abbotts v. NRD, 766 F.2d 604, $607-608$ (D.C. Cir. 1985).

46. Simmons v. United States Department of Justice, 796 F.2d 709 (4th Cir., July 31, 1986).

47. J. F. Doherty, "Classification in the Federal Government," J. Natl. Class. Mgmt. Soc., 3(2), 97-105 (1967), p. 104.

48. 42 U.S.C. $\$ 2162(e)$.

49. 50 U.S.C. $\$ 403(d)(3)$; National Security Act of $1947, \$ 102(d)(3)$.

50. 42 U.S.C. $\$ 2166$.

51. EO 12356, §1.6(c). 


\section{Chapter 12. DOWNGRADING CLASSIFIED INFORMATION}

To downgrade classified information is to reduce its classification level. Thus, Top Secret information can be downgraded to the Secret or Confidential classification levels. Secret information can be downgraded to the Confidential level. Confidential information cannot be downgraded-it can only be declassified (or upgraded, if circumstances require such an action).

NSI can be downgraded, within federal agencies, by the person originally classifying that information, that person's successor, supervisors of either, or other officials delegated such authority in writing by the agency head or other designated senior agency official. ${ }^{1}$ Within DOE and its contractors, authority to downgrade NSI is limited to the Original Classifier of such information (or the successor to that person), the Director of the Office of Classification, or the Director of Security Affairs.

As mentioned in Chapter 8, some executive orders prior to EO 12356 required that certain types of NSI be downgraded at specified times after the date of issuance of that NSI. Such requirements for automatic downgrading were not included in EO 12356.

RD or FRD may be downgraded only by the DOE Director of Security Affairs or the Director of the Office of Classification. ${ }^{\dagger, 3}$

The principles discussed in Chapter 7 with respect to initially determining the specific level of classified information also apply to downgrading decisions. Consequently, there is no need to further discuss these same principles with respect to downgrading classified information.

\footnotetext{
"The term "downgrade" probably originated in the British classification of information system. The British use a "grading guide" to. "grade" information, rather than using a classification guide to classify information [E. Hill, "Defence Procurement and Classification in the U.K.," J. Natl. Class. Mgmt. Soc., 16, 20-27, (1980) p. 22]. The term "downgrading" was probably adopted by the United States during World War I, when the U.S. Army established a classification system largely based on the classification systems of the British and French armies [See A. S. Quist, Security Classification of Information, Volume 1., Introduction, History, and Adverse Impacts, K/CG1077/V1, Martin Marietta Energy Systems, Inc., Oak Ridge, Tennessee, September 1989].

tWithin DOE or its contractors, documents or materials containing NSI, RD, or FRD may be downgraded by the Director of the Office of Classification, Original Classifiers, and Derivative Declassifiers (not the same as Derivative Classifiers) [U.S. Department of Energy, DOE Order 5650.2B, "Identification of Classified Information," Chap. V, Part A, 84(g)(2)(b); Chap. VI, Part A, \$\$2(a) and 2(b)(5); Chap. VI, Part C, 83 (Dec. 31, 1991 )].
} 


\section{REFERENCES}

1. Executive Order 12356, Fed. Reg., 4714874 (Apr. 6, 1982), 83.1(b).

2. U.S. Department of Energy, DOE Order 5650.2B, "Identification of Classified Information," Chap. VI, Part A, \$1(b), Dec. 31, 1991. Hereafter cited as “DOE Order 5650.2B.”

3. DOE Order 5650.2B, Chap. VI, Part A, §1(a). 


\section{APPENDIXES}




\section{Appendix A. CLASSIFICATION OF INFORMATION PRINCIPLES AND TRADE SECRET LAW}

\section{INTRODUCTION}

This appendix describes similarities between the field of knowledge designated as security classification of information and the field of knowledge designated as trade secret law. Those similarities can be used to provide support to some existing classification principles and to develop new classification principles. That trade secret/classification analogy is particularly appropriate with respect to principles for classifying scientific and technical information, which is of major interest in this document.

Our legal system's roots go back millennia, thereby giving that system a solid foundation. Trade secret law is a part of that legal system. Trade secret law has developed over hundreds of years and has been a distinct area of the legal system for over a century---principles of trade secret law are widely accepted. Because trade secret law evolved as part of the "common law," it has a firm basis in our culture. Our extensive body of trade secret law has been developed by a very open process; the workings of our legal system are essentially completely open to the public, and the judicial decisions on trade secrets have been extensively published and discussed. Thus, trade secret law rests on a solid foundation, is consistent with our culture, and is known, understood, and accepted by our citizens.

Although the right of a government to classify information has been accepted for thousands of years, ${ }^{1}$ extensive classification of information by the U.S. Government began only relatively recently at the start of World War II. During the $\sim 50$ years that the government has been extensively classifying information, there has been little development of classification principles. Also, details of the rationale for specific classification decisions usually have not been discussed openly-only by personnel with the requisite security clearance and a need to know the information. Therefore, the few classification principles that have been developed have not been subject to nearly as much thought and discussion as have trade secret law principles.

We (the security classification of information community) should take advantage of trade secret law and related knowledge to help establish an extensive system of classification principles. ${ }^{\dagger}$ To the extent that existing classification principles are consistent with accepted principles from another, well established field of knowledge (trade secret law), increased

\footnotetext{
"Common law" is that part of our law based on custom and precedents of court cases, as contrasted to statutory law, which is based on enactments of legislatures.

${ }^{4}$ "A dwarf standing on the shoulders of a giant can see farther than the giant himself." [Quoted, but with no citation, by Z. Chaffee, Jr., in "Reflections on the Law of Copyright: I," Col. L. Rev., 45, 503 (1945), p. 511. Substantially the same quotation has been attributed to Bernard of Chartres (circa 1100) by J. Hunter, "Giants and Dwarfs," in "Letters," New Scientist, 137(1864), 55 (Mar. 13, 1993), citing M. A. Edey and D. C. Johnson, Blueprints: Solving the mystery of evolution.]
} 
confidence can be placed in those classification principles. To the extent that new classification principles can be derived from accepted principles from that other field of knowledge, those new classification principles should be relatively reliable. Additionally, the time and effort required to independently develop new classification principles can be significantly reduced if those new principles can be derived from analogous principles from that other field of knowledge.

The next section of this appendix describes the many similarities between trade secret law and classification of information. A following section discusses the important elements of a trade secret with particular emphasis on those that are related to matters of classification of information, especially to the classification of scientific or technical information. The final section of this appendix briefly mentions a part of trade secret law that may be helpful when determining the extent to which expertise that an individual acquires by working on a classified program can (or cannot) legitimately be applied by that individual to unclassified programs.

Although the similarities between classification of information and trade secret law are useful in helping to develop a system of classification principles, it should perhaps be emphasized that those analogies do not provide all the bases for such a system. Additional insights are needed, and much additional thought needs to be brought to bear on classification matters. Some of that material is provided in the main body of this document.

\section{SIMILARITIES BETWEEN TRADE SECRET LAW AND CLASSIFICATION OF INFORMATION}

Businesses protect information that gives them an advantage over competitors just as governments protect information that gives them an advantage over adversaries. One of today's best-kept secrets is a trade secret, the recipe for Coca-Cola Classic $"$ " "State secrets" probably accompanied the formation of the first "state." "Trade secrets" (proprietary information) may have been important assets of the first business. State secrets and trade secrets occasionally were identical. For about 3000 years the Chinese royal family closely guarded, as a state secret, the source of and production methods for silk, an important export item in China's trade with other countries. ${ }^{2}$ It was not until the 6th century A.D. that a silk industry was established in western countries when two Persian monks clandestinely removed silkworm eggs and mulberry tree seeds from China. ${ }^{3}$ The Chinese were even said to have used a "cover story" to confuse those who tried to learn the secrets of silk manufacture. The cover story was that the process of making silk involved putting wool in the sun, sprinkling it with water, and then combing it to produce silk. ${ }^{4}$

\footnotetext{
"The recipe for Coca-Cola Classic has been kept a secret for over one hundred years. It is said that only two Coca-Cola ${ }^{\circ}$ company executives know that recipe [M. Schiffres and G. Bronson, "Business Struggle to Keep Their Secrets," U.S. News and World Report, Sept. 23, 1985, p. 59]. The recipe's only written formula is in a safe deposit box in Atlanta, which may be opened only by a vote of the company's board of directors [Coca-Cola Bottling Co. of Shreveport v. Coca-Cola Company, 227 USPQ 18 (D. Del. 1985); see also Coca-Cola Bottling Co. of Shreveport v. Coca-Cola Company, 230 USPQ 1 (D. Del. 1986)]. Few national security secrets are as well-kept as the secret of Coca-Cola ${ }^{\circ}$ (although we probably would not know if a national security secret was as well-kept as the secret of Coca-Cola ${ }^{\circ}$ ).
} 
There are many similarities between the classification and protection of national defense and foreign relations information by governments and the identification and protection of trade secrets by businesses. ${ }^{5,6,7}$ In both circumstances the information being protected is so important that its loss to an adversary (enemy/competitor) could have very bad effects on key interests (national security/profits) of the protector. Both trade secrets and classified information require continuing vigilance to protect against their unauthorized disclosure. Both may lose their status as secrets with the passage of time (e.g., because of technological advances, state-of-the-art technology may become commonplace). A rule in trade secret law- "that which has become public property cannot be recalled to privacy" ${ }^{8}$-has its classification counterpart in the rule that information declassified or officially disclosed cannot be reclassified."

Some trade secrets such as chemical formulas or knowledge of certain manufacturing processes are comparable to classified scientific and technical information. Other trade secrets such as lists of customers are analogous to classified intelligence information (e.g., confidential sources). A proprietary code for determining discounts from a catalog price list is not unlike classified cryptographic codes.

Information about a new commercial product is kept secret by a business to give that business a head start ${ }^{\dagger}$ and, therefore, a market advantage (greater profits) over its competitors. Information about the design and manufacture of a new weapons system is kept secret by a nation to give that nation a lead time and, therefore, a military advantage (greater security) over its adversaries.

Classified information is more likely to be protected if it is precisely defined. Trade secrets are more likely to be protected if they are "delineated with some particularity." 9 The need to know has relevance in trade secret law; if a business does not limit knowledge of a trade secret only to those who need this knowledge to benefit the business, then a court may decide that this knowledge was not a trade secret. ${ }^{10}$ The need to know is also a well known principle in the protection of classified information.

Espionage, long practiced by governments, has its counterpart in business as industrial espionage, ${ }^{\ddagger 1}$ which significantly affected technology transfer during the industrial

\footnotetext{
"This rule is absolute with respect to atomic energy information that has been declassified. [42 U.S.C. 82166] National Security Information may be reclassified if "the information requires protection in the interest of national security" and if "the information may reasonably be recovered" [Executive Order 12356, Fed. Reg., 47, 14874 (Apr. 6, 1982), $\$ 1.6(\mathrm{c})$ ]. This authority to reclassify National Security Information is a new feature of Executive Orders on the classification of information. It was added to make possible the reclassification of information where a mistake has been made in its declassification and only a few unauthorized persons have received that information. The Information Security Oversight Office is very much concerned about the potential for abuse of this authority to reclassify information [S. Garfinkel, "An Information Security Oversight Office Overview of Executive Order 12356 and Its Implementing Directive," J. Nat. Class. Mgmt. Soc., 18, 17-23 (1982), p. 22].

The term "lead time" has also been used with respect to trade secrets. Injunctions have been issued against those who misappropriated trade secrets to negate the lead time they have gained through that misappropriation ["Uniform Laws Annotated," 14, 1988 Cumulative Annual Pocket Part, West Publishing Co., St. Paul, Minn., 1988, pp. 336-337; M. F. Jager, Trade Secrets Law, Clark Boardman Co., Ltd., New York, 1988, p. 3-27].

${ }^{\ddagger}$ Authors R. Eells and P. Nehemkis (Corporate Intelligence and Espionage, Macmillan Publishing Co., New York, 1984, pp. 108-110) cite (at p. 108) J. Bergier, Secret Armies-The Growth of Corporate and Industrial Espionage, Bobbs-Merrill, New York, 1975, to the effect that industrial espionage is older than military espionage. However, that concept is difficult to accept because physical survival is generally more important to an individual than
} 
revolution. $^{12}$ A Society of Competitor Intelligence has even been established. ${ }^{13,14}$ With the apparent end of the "cold war," the U.S. Central Intelligence Agency appears to be interested in putting its espionage expertise to use in industrial espionage for the benefit of the nation. ${ }^{15}$

The legal protection afforded both to trade secrets and state secrets have their roots in the common law. Some of our states now provide statutory protection for trade secrets in addition to or in place of the common-law protection afforded trade secrets. The government now uses statutes and Executive Orders as authority to classify and protect our national secrets.

The government specifies three levels of classification-Confidential, Secret, and Top Secret. It has been suggested that businesses with trade secrets should perhaps establish two or three grades (levels) of importance for those secrets. ${ }^{* 16}$

Neither trade secrets nor classified information need to be the sole knowledge of one entity (e.g., business entities for trade secrets; national entities for state secrets) to warrant protection. Just as several countries independently have and protect the secrets for enriching uranium by gas centrifuge technology, so may a specific trade secret be known to more than one company in a field and still be protected by each company as a trade secret. ${ }^{17}$

Trade secret law protects the holder of a trade secret "against the disclosure or unauthorized use of the trade secret by those to whom the secret has been confided ... or when the knowledge [of the trade secret] is gained, not by the owner's volition, but by some 'improper means'."18 Trade secret law does not protect a trade secret holder against discovery of that trade secret by "fair and honest means, such as by independent invention, accidental disclosure, or by so-called reverse engineering.",+ 19 In that respect, trade secret law is identical to classification policy, because the objective of classification is not to prevent an adversary from obtaining the information by independent efforts or by reverse engineering but rather to avoid assisting the adversary in acquiring that information. ${ }^{\ddagger}$

Because of the above-mentioned similarities between trade secrets and classified information, the rationale for some of the principles used in deciding whether certain information is a trade secret can also be used as a rationale for some of the principles for classifying information, thereby providing added support to those classification principles. The

economic survival and it would seem that desperate measures (espionage) would have been more likely to have occurred first with respect to matters of survival (self-defense, warfare, etc.) than with respect to making profits from a business.

"One author has suggested the following designations for information that should be protected by a business: critical trade secrets (CTS), important trade secrets (ITS), trade secrets (TS), and know-how (K-H). Know-how is valuable information but probably does not warrant trade secret protection [D. Unkovic, The Trade Secrets Handbook: Strategies and Techniques for Safeguarding Corporate Information, Prentice-Hall, Inc., Englewood Cliffs, N.J., 1985, pp. 54-55].

twReverse engineering" is a process that starts with a product and works backward to discover how the product was made.

FThere is also somewhat of a similarity between the ways that trade secret law and classification treat accidental disclosures. Classification policy requires "no comment" about classified information that has been accidentally disclosed but which the government has not officially declassified. Nothing, of course, can be done to prevent others from using that information. Trade secret law will not prevent a competitor from using trade secrets that the trade secret owner has accidentally disciosed. 
next section of this chapter very briefly summarizes the principles of trade secret law that appear to be applicable to security classification of information.

\title{
TRADE SECRET LAW
}

\section{Definitions of a Trade Secret}

A trade secret consists of secret knowledge used in a business, not previously available, and not known to a business's competitors. It is difficult to precisely define a trade secret (just as it is difficult to precisely define classified information). One widely accepted definition, from the Restatement of the Law of Torts, is as follows:

\begin{abstract}
A trade secret may consist of any formula, pattern, device or compilation of information which is used in one's business, and which gives him an opportunity to obtain an advantage over competitors who do not know or use it. It may be a formula for a chemical compound, a process of manufacturing, treating or preserving materials, a pattern for a machine or other device, or a list of customers. It differs from other secret information in a business (see $\mathbf{8 7 5 9}$ ) in that it is not simply information as to single or ephemeral events in the conduct of the business, as, for example, the amount or other terms of a secret bid for a contract or the salary of certain employees, or the security investments made or contemplated, or the date fixed for the announcement of a new policy or for bringing out a new model or the like. A trade secret is a process or device for continuous use in the operation of the business. Generally it relates to the production of goods, as, for example, a machine or formula for the production of an article. It may, however, relate to the sale of goods or to other operations in the business, such as a code for determining discounts, rebates or other concessions in a price list or catalogue, or a list of specialized customers, or a method of bookkeeping or other office management. ${ }^{20}$
\end{abstract}

Another definition of trade secrets is contained in the Uniform Trade Secrets Act:

"Trade secret" means information, including a formula, pattern, compllation, program, device, method, technique, or process that:

(i) derives independent economic value, actual or potential, from not being generally known to, and not being readily ascertainable by proper means by, other persons who can obtain economic value from its disclosure or use, and

(ii) is the subject of efforts that are reasonable under the circumstances to maintain its secrecy. ${ }^{21}$

In the definition of trade secret contained in the Uniform Trade Secrets Act, the words "method, technique" are intended to include know-how. 22 It is evident that many types of information can be trade secrets, just as many types of information can be classified.

The Uniform Trade Secrets Act allows information to be protected as a trade secret even though that information has not yet been put to use ${ }^{22}$ (i.e., it protects research and development information that may lead to commercial products in addition to protecting information

\footnotetext{
"One court has stated that "The concept of 'know-how' is also a very fuzzily defined area, used primarily as a short-hand device for stating the conclusion that a process is protectable [as a trade secret]" [Van Products Co. $v$. General Welding \& Fabricating Co., 213 A. 2d 769, 777 (Рa. 1965)].
} 
on existing commercial products). However, the Restatement of the Law of Torts definition requires that a trade secret be used in a business before the business can receive protection under trade secret law. The broader definition in the Uniform Trade Secrets Act recognizes the value of research and development information or other information that gives a business a head start over its competitors ${ }^{23}$ and is, therefore, cioser to the definition of classified information than is the Restatement of the Law of Torts definition.

A trade secret represents objective knowledge, such as a manufacturing process and not subjective knowledge, such as the date for the announcement of a new product. In that regard, trade secrets differ from classified information because subjective national defense or foreign relations information is frequently classified (e.g., a time or location for a military invasion of another nation). ${ }^{\dagger}$ Trade secret information particularly resembles classified scientific or technical information, which is always objective information.

Not all commercial secrets are trade secrets. Many business matters are confidential (e.g., for a business's internal use only) but "only secrets affording a demonstrable competitive advantage may be properly considered as trade secrets. ${ }^{24}$ Perhaps most of the confidential business matters that are not trade secrets represent subjective information that, as mentioned above, is not generally given trade secret protection.

Determining whether information meets the requirements of a trade secret is to some extent a subjective process. ${ }^{\ddagger}$ The elements of a trade secret described below are widely accepted as factors to be used when making such a determination. However, the weight assigned to each factor will vary depending on the facts of a particular situation (e.g., the nature of the information and the conduct of the parties involved). ${ }^{25}$

\section{Specific Elements of a Trade Secret}

The characteristics of information that is protectable as a trade secret are similar to the characteristics of information that is protectable as classified information. Because of those similarities, it is especially pertinent to examine that part of trade secret law which characterizes trade secrets.

Six elements or factors have been proposed for use in determining whether information is a trade secret: " "(1) the extent to which the information is known outside of his business; (2) the extent to which it is known by employees and others involved in his business; (3) the extent of measures taken by him to guard the secrecy of the information; (4) the value of the information to him and to his competitors; (5) the amount of effort or money expended by him in developing the information; (6) the ease or difficulty with which the information could

\footnotetext{
"Trade secret information differs from other secret information used in a business "in that it is not simply information as to single or ephemeral events in the conduct of a business" [Restatement of the Law of Torts, 4, American Law Institute, St. Paul, Minn., 87.57, Comment (b), 1939, p. 5].

tSee Chapter 2 in this document for a discussion of objective and subjective secrets.

¥Somewhat like deciding whether information should be classified!

"There may also be other major elements of trade secrets of which the author is not aware.
} 
be properly acquired or duplicated by others. ${ }^{\bullet .26}$ These specific elements of a trade secret are discussed in the following subsections.

It should be noted, with respect to similarities between trade secret law and classification principles, that the second and third elements of a trade secret (given above) are mostly security-of-information matters, not classification-of-information concerns. Those two elements indicate whether the possessor of an alleged trade secret truly acted as if that information was valuable to the business. They are not elements to be considered when objectively evaluating whether the information is a trade secret.

General Availability of Information. For information to be a trade secret, that information must in fact be secret. ${ }^{\dagger}$ The Restatement of the Law of Torts is unequivocal on this point:

The subject matter of a trade secret must be secret. Matters of public knowledge or of general knowledge in an industry cannot be appropriated by one as his secret. Matters which are completely disclosed by the goods which one markets cannot be his secret. 27

A substantlal element of secrecy must exist, so that, except by the use of improper means, there would be difficulty in acquiring the information. ${ }^{26}$

Absolute secrecy, in the sense that only the trade secret owner's employees or business associates know the trade secret, is not required. Some trade secrets may be known, via independent discovery, by several businesses in a trade. Each discoverer may have a trade secret in his information. ${ }^{28}$ However, as more entities obtain the information through legitimate means, "the protectable interest erodes-at some point there will be a sufficient number of independent users to render the matter no longer secret." 29

Easily obtainable information, or information generally known, is not a trade secret. ${ }^{30}$ "Information is readily ascertainable if it is available in trade journals, reference books, or published materials ${ }^{\mathbf{2 2}}$ or is otherwise in the public domain. This includes information that is a matter of general knowledge within a trade or business. ${ }^{\ddagger}$

Outside views of a facility are not trade secrets. ${ }^{31}$ "That which is readily visible and ascertainable cannot constitute a trade secret. ${ }^{32}$

Some customer lists are considered trade secrets; others are not. Generally, if the customer list could be developed from public sources without extraordinary efforts, it is not a trade secret. ${ }^{33}$ For example, a customer list that is obtainable from the yellow pages of a telephone directory is not a trade secret. ${ }^{34}$ Customer routes that can be obtained by

\footnotetext{
"See also A. V. Gross, p. 652 of What is "Trade Secret" So As to Render Actionable Under State Law Its Use or Disclosure by Former Employee, 59 ALR 4th, 641, 652 (1988), who describes three major factors considered when determining whether information is a trade secret. Those factors combined Elements 1 and 6 as one factor, Elements 2 and 3 as another, and Elemerts 4 and 5 as the third major factor. Thus, Gross's three major factors include all six elements proposed by the Resiatement of the Law of Torts.

tOne author has stated that "Courts have never upheld the existence of a trade secret absent the element of secrecy" [M. A. Epstein, "Modern Intellectual Property," Law \& Business, Inc./Harcourt Brace Jovanovich, Publishers, Clifton, N.J., 1984, p. 2].

It is not always easy to determine whether information is generally known. In classification matters, the advice of experts in a field is necessary to establish whether an item of information in that field is generally known. Input from intelligence agencies is sometimes necessary to establish whether adversaries know that item of information.
} 
observation are not trade secrets. ${ }^{35}$ Customer lists that have been developed over a number of years and that cannot easily be obtained from public sources will be afforded trade secret protection.

Common "shop practices" are widely known, are not novel, and thus do not qualify as trade secrets. A combination of common shop practices generally will not be considered to be a trade secret unless the combination is unique." A machine was considered to be a trade secret, even though all its components were known in the industry, because the combination was unique. ${ }^{36}$ High-technology products are said to "often consist largely of novel applications of 'know-how' common to the industry" and "the trade secret status of such products depends not on the component parts but on the arrangements of such parts into new designs. $^{\text {n37 }}$ By requiring at least some uniqueness, originality, or novelty, courts ensure that information in the public domain is not withdrawn from that common knowledge and designated a trade secret. ${ }^{38}$

The Extent to Which the Information is Known by Employees and Business Associates. To be of value, information must be used. Trade secret information usually has to be disclosed to some employees or agents of a business so that they may use this information to further the purposes of the business. This principle was stated in one of the first trade secret cases in this country:

\section{A secret of trade or manufacture does not lose ths character by being confidentially disclosed to agents or servants, without whose assistance it could not be made of any value. ${ }^{39}$}

Under the doctrine of "relative secrecy," trade secret owners do not abandon their claim of secrecy by limited disclosure of the secret for a restricted purpose (i.e., to further their business). ${ }^{40}$ However, a "substantial element of secrecy must exist." 41

Trade secrets should be disclosed to employees or business associates only on a need-toknow basis. Trade secrets should be given only to those employees who need the information to do their jobs. Trade secrets should be given to nonemployees only if they need that information to further the trade secret owner's interests. ${ }^{40}$ Trade secret information can be given, in confidence and for valid business reasons, to joint venturers, materials suppliers, and others without losing its status as a trade secret. ${ }^{42}$ However, if trade secret information is not closely controlled-is given to employees or business associates even though the recipients do not need that information to further the trade secret owner's interests-then courts may determine that the information no longer deserves protection as a trade secret because the information was not rigorously protected by its owner. As mentioned earlier, this need-toknow element is mainly a protection-of-information consideration (a security matter) and not important to classification-of-information principles.

The Extent of Measures to Protect the Information. When determining whether information deserves protection as a trade secret, courts consider the extent to which the information's owner took measures to protect the information. To prove the existence of a

\footnotetext{
"A trade secret can exist in a combination of characteristics and components, each of which, by itself, is in the public domain, but the unified process, design and operation of which is in unique combination, affords a competitive advantage and is a protectable secret " [Imperial Chemical Industries v. National Distillers and Chemical Corp., 342 F.2d 737, 742 (2nd Cir., 1965)].
} 
trade secret, one must show that the possessor of the alleged trade secret considered it to be a secret and protected it accordingly. "Security costs money, and presumably an employer would not incur such costs if it believed that the competitors already knew the information. ${ }^{\text {"43 }}$ Conversely, if the owner did not take special measures to protect the information, then one could infer that the owner did not consider the information to be valuable and, therefore, the law should not consider it a secret. ${ }^{44}$ The "secrecy must be real and not merely formalistic. ${ }^{45}$

Although this element of a trade secret is not exactly relevant to classification principles (protection of classified information is the responsibility of the security organization, not the classification organization), the similarities between classification and trade secrets make it of interest to describe security measures considered reasonable in protecting trade secrets. Heroic protective measures are not required-only reasonable security precautions. ${ }^{46}$ Security measures used by industry to protect trade secrets include the following:

1. Facilities are surrounded by fences.

2. Access to facilities is by a limited number of gates.

3. "No Trespassing" or similar signs are used.

4. Security guards are present.

5. Employees are required to sign confidentiality agreements or restrictive covenants.

6. Employees are briefed on the confidential aspects of their work (initially and periodically).

7. Employees are required to wear identification badges on the premises.

8. Need-to-know procedures with respect to access to the trade secrets by employees and others have been established and are followed.

9. Permission is required to remove company property.

10. Nonemployee access is regulated (e.g., nonemployees are required to sign in and out; escorts are required for nonemployees).

11. Suppliers are advised that information (concerning trade secrets) provided to them is confidential.

12. Distribution of operating manuals for trade secret equipment or processes is limited.

13. Engineering drawings and other documents that reveal trade secrets are kept in locked cabinets or rooms when not in use.

14. Engineering drawings and documents that contain trade secrets bear "confidential" markings or cautionary labels or legends, including perhaps two or three "levels" of secrecy markings. Those markings are used selectively, so that the credibility of such markings is maintained.

15. Professional employees' technical presentations (oral or written) are screened before release.

16. When employees leave the company, they receive exit briefings on their continuing trade secret protection responsibilities. 
In Eastman Co. v. Reichenbach, the court noted with approval that a secret formula "was kept under lock and key, and, lest it should be discovered by other manufacturers, the different ingredients composing it were purchased in the name of a third party. ${ }^{\circ}, 47$ In another case involving secret machinery, the court noted that when new machinery was built, different components were obtained from different suppliers so that no "outside" person would see a completed machine in operation. ${ }^{+, 48}$

The "extent of measures to protect the information" element of trade secret law has an analogy in prosecutions under the U.S. espionage statutes. In United States $v$. Heine, ${ }^{49}$ the defendant Heine was convicted in a U.S. District Court of violating an espionage statute that forbade the communication of information relating to the national defense to a foreign nation. Heine had gathered information on the U.S. aviation industry and sent it to a foreign country (the United States was not at war with this country). The information that he gathered was "lawfully accessible to anyone who was willing to take the pains to find, sift, and collate it. ${ }^{\text {n0 }}$ A Circuit Court overturned the conviction, stating that Heine could not be guilty of violating the espionage statute for such activities because the government had not objected to the dissemination of the information (that Heine had gathered) within the United States." Thus, the court held that if the government did not protect the information within the United States, then it cannot be espionage to send that information outside the United States. The Executive Branch must try to protect information that it considers to be secret before the Judicial Branch will apply the sanctions of espionage statutes to such information. ${ }^{\dagger \dagger}$

The Value of the Information to the Business and to its Competitors. Trade secret information must have economic value (competitive advantage), actual or potential, in not being known to others. ${ }^{\ddagger .51}$ The requirement that a trade secret provide a competitive advantage has been characterized as "minimal," and "deemed to exist almost by virtue of a corporation taking steps to meet the secrecy element requirement for information to be a trade secret." 52 "In essence . . . it [the trade secret] must reasonably be believed to provide the trade secret owner with some not too speculative value and benefit. ${ }^{53}$

-Analogous to "cover" or "classified" procurements in certain classified U.S. Government programs.

tSimilar principles were applied during the U.S. Army's World War II Manhattan Project that developed the first atomic bombs. Security considerations resulted in the requirement that certain equipment be assembled at a location different from that of its manufacture and that certain raw materials be procured from a number of suppliers so that the end use could better be concealed [V. C. Jones, Manhattan: The Army and the Atomic Bomb, United States Army in World War II, Special Studies, Center of Military History, United States Army, Washington, D.C., 1985, p. 269].

¥Currently codified at 18 U.S.C. 794(a).

* "It is obviously lawful to transmit any information about weapons and munitions of war which the services [U.S. Army and Navy] had themselves made public; and if that be true, we can see no warrant for making a distinction between such information, and information which the services have never thought it necessary to withhold at all. ... The services must be trusted to determine what information may be broadcast without prejudice to the 'national defense,' and their consent to its dissemination is as much evidenced by what they do not seek to suppress, as by what they utter" [United States v. Heine, 151 F.2d 813, 816 (2nd Cir., 1945)].

HuApart from the traditional areas of libel, obscenity, and incitement to violence, the Supreme Court has never sanctioned a restriction upon the circulation of information in the public domain" [T. I. Emerson, "National Security and Civil Liberties," Yale J. World Pub. Order, 9, 78-112 (1982), p. 89].

\#The value of classified information is in avoiding damage to national security caused by unauthorized disclosure of the information. 
Negative information, such as results that show a process will not work, has economic value and frequently may be a trade secret. ${ }^{22,54}$ However, some courts have held that knowledige about a mistake to be avoided is not a trade secret. ${ }^{55}$

Ir formation is not protected as a trade secret if it is only a "trivial advance" or its value is "not significant"; an "unusual competitive advantage" is usually required. ${ }^{56,57}$ However, slight advantages in technical know-how have sometimes been considered trade secrets because they help control production costs and thereby provide a competitive edge. ${ }^{58}$

\begin{abstract}
The history of human progress is rarely characterized by the giant advances achieved by isolated geniuses whose presence towers above entire civilizations. Rather Man's progress occurs through gradual accretion to the established mode of thought and behavior. To the ideas of our forefather's we add small, perhaps infinitesimal, new matter.
\end{abstract}

This tendency has relevance to the protection which may be accorded improvements to otherwise well-known processes, formulas or machines. The courts are prepared to recognize that a small improvement may lend a distinct advantage to an old process. ${ }^{59}$

The value of information to a competitor is also an important consideration in determining whether that information is a trade secret. If the information saves a competitor time and money, then that competitor has materially benefitted from the information. ${ }^{60}$ With respect to business matters such as secret bid information, a suggested threshold test is whether a competitor could use the information to change the competitive balance in favor of the competitor. ${ }^{61}$

Amount of Effort or Money Expended to Develop the Information. One of the purposes of trade secret law is to protect "the substantial investment of employers in their proprietary information [trade secrets] ${ }^{n 62}$ so as to encourage invention and promote research and development. ${ }^{63}$ Trade secret determinations are based in part on "the investment of time, money, or effort expended to research and develop or otherwise acquire the information..$^{*, 64}$ In cases where the existence of a trade secret was upheld because of the time, money, or effort required to develop that trade secret, the amounts of time, money, or effort have varied widely. ${ }^{\dagger, 65}$ Thus, there are no established minimum values for these parameters that can be used as guidance in determining whether information qualifies as a trade secret-the outcome of each case depends upon the facts and equities in that case.

The amount of effort expended to develop information is never the sole factor in determining whether that information is a trade secret. ${ }^{66}$ Other trade secret elements, especially the secrecy element, must be present. Because trade secrets can arise from inexpensive development efforts or fortuitous discoveries, ${ }^{67,68}$ it would be inconsistent if the effort required to develop information was the determinative element of a trade secret. ${ }^{69}$

\footnotetext{
The amount of time and effort required to develop scientific or technical information is a factor in determining whether to classify that information.

In an earlier section of this appendix it was stated that a combination of common shop practices will not be considered a trade secret unless the combination is unique. It has been implied that if substantial effort was required to develop a combination of common shop practices, then that combination can be a trade secret [D. C. Maizel, "Trade Secrets and Technical Data Rights in Government Contracts, "Military L. Rev., 114, 227-298 (1986), p. 233, citing Comp. Gen. Dec. B-187051 (15 Apr. 1977), 71-1 CPD para. 262]. However, there is said to be little case authority to support this result [R. M. Milgrim, Milgrim on Trade Secrets, Matthew Bender \& Co., Inc., New York, 1987, 82.02[2], p. 2-33].
} 
The Ease or Difficulty with Which the Information Could be Properly Acquired by Others. The first element of a trade secret given above was that the information is not generally known or available. Thus, information easily obtainable is not a trade secret. However, information that is publiciy available but not easily ascertainable can be a trade secret. Therefore, the ease with which others may obtain the same information is a factor in determining whether that information is a trade secret.

A trade secret may be embodied in a product available to the public. Sometimes this trade secret may be discovered by reverse engineering a product purchased on the open market. If so, the information discovered is no longer a trade secret. However, it is not a defense to a charge of trade secret theft that the information could have been obtained by legitimate means (e.g., reverse engineering) but in fact was not obtained in that manner. ${ }^{10}$ "A valuable ingredient [in a hair care formula] that was not discovered by others for twenty years could not be 'readily ascertainable." 71 "Any finding of easy discoverability must be reconciled with the fact of non-discovery. ${ }^{71}$ The time required for reverse engineering is a factor in determining whether the information was readily obtainable. ${ }^{72}$ "If reverse engineering is lengthy and expensive, a person who discovers a trade secret through reverse engineering can have a trade secret in the information obtained from reverse engineering. ${ }^{\circ}, 22$

The policy of the law of trade secrets is that a competitor should not be given an advantage by obtaining a trade secret without incurring the usual costs of invention or duplication $^{\dagger}$ or without payment to the owner of the trade secret. In DuPont de Nemours v. Rolfe Christopher (1973), the court said: "To obtain knowledge of a process without spending the time and money to discover it independently is improper unless the holder voluntarily discloses it or fails to take reasonable precautions to ensure its secrecy. ${ }^{-73}$ Another court said that a person should not be able to get a trade secret by unfair means and use it to advantage "Without himself paying the price in labor, money or machines expended by the discoverer." 74

\section{FORMER EMPLOYEES AND TRADE SECRETS}

Trade secret litigation frequently occurs when a skilled employee quits a job to work for a competitor or to start a new business. The former employer is very suspicious that the employee was hired by his new employer because of the employee's knowledge of the former employer's trade secrets or that the employee will use those trade secrets in the employee's new business. Courts are then asked to determine whether a scientific or technical employee who knows his employer's trade secrets and who is a very competent scientist or engineer may (or may not) use certain specific information after leaving that employer. The employee's

\footnotetext{
"One author has characterized a trade secret as "that which cannot be discovered by any process of reverse engineering within a limited period of time" [G. R. Bell, "Protecting and licensing trade secrets and know-how under Canadian law," Int. J. Technology Management, 3(1/2), 105-121 (1988), p. 111].

This is consistent with a classification principle which states that if information is useful to an adversary, then the adversary should be required to expend its resources to get that information. The classification rationale is that generally one does not want to give an adversary information of significant value for nothing. One wants to make an adversary spend its resources to get that information instead of being able to use those resources in other ways to the detriment of the "donor."
} 
know-how (scientific and technical skills) includes publicly known information as well as the former employer's trade secrets.

Similar problems sometimes arise in classified research, development, or production activities." The questions with respect to classified activities include: (1) What aspects of the technology may be applied to other unclassified programs? and (2) What restrictions may be placed on a scientific or technical person who leaves a classified program to work on an unclassified program (either within the same company or for a new employer)? ${ }^{t, \ddagger}$ In the latter case, the employee's knowledge includes unclassified informaiion as well as classified information. The answers to those questions may be found in the guidance supplied by court decisions concerning former employees and trade secrets.

When working for a new employer or in his or her own business, an employee can make use of his or her general skills, knowledge, memory," and experience, some of which may have been acquired while working for the former employer, so long as those skills do not include trade secret knowledge--that "special confidentia! knowledge obtained from the employer which belongs to the employer." 75 An employee "is entitled to take with him to his new employment his native skills as enhanced by his employment experiences." 76 However, specialized knowledge (know-how) obtained on the job is more than experience and may be protectable trade secrets of the former employer. ${ }^{17}$ An employee's ability and experience do not belong to an employer; only "The compiled products of that ability and experience that had been recorded for repetitive use" are entitled to trade secret protection (emphasis added). ${ }^{78}$ The decision as to what knowledge an employee may use in a new job involves a balancing process between the employee's individual freedoms and the employer's right to protection of his business assets (trade secrets). ${ }^{79,80}$

'See, for example, discussions in J. Natl. Class. Mgmt. Soc., 2, 22-24 (1966).

This problem was mentioned by General L. R. Groves when appearing before a congressional committee in 1945. General Groves was discussing the types of secrets of the Manhattan Project and stated: "Another class of secrets falls in the industrial sphere. This contains many industrial applications which, in the course of time, will be made known in this country. A man who has worked on this project and who is confronted with a similar problem in industrial life cannot forget the solution that was used on this project, and he is going to use that information no matter how honorable he is, and he cannot be prevented from doing it " [Atomic Energy, Hearings on H.R. 4280, An Act For the Development and Control of Atomic Energy, U.S. Congress, House of Representatives, Committee on Military Affairs, 79th Congress, 1st Session, Oct. 9 and 18, 1945, U.S. Govt. Printing Office, 1945 , p. 13]. General Groves later made a similar comment regarding scientific knowledge: "And it is the same in the scientific field. If, as the result of his [the scientist's] experimental work [on the Manhattan Project], he sees a machine or an instrument used to make a certain measurement, and he is faced in his own laboratory later, 2 or 3 years later, with that same problem in front of him, he is going to use that knowledge, and you cannot strike it out of his brain" [Ibid., p. 24].

${ }^{\ddagger}$ A Department of Defense official has suggested that the high mobility of U.S. scientific and technical personnel contributes significantly to the dissemination of knowledge from classified programs, to the overall benefit of the United States. When major new technical programs are established by the government, technical personnel from previous large programs will join the new program and bring to it their knowledge which was acquired on a previous job. Classified information developed in one program can thereby be transferred to a new classified program [F. Thomas, "Keynote Address-Classification and Technological Breakthroughs," J. Natl. Class. Mgmt. Soc., 2 11-19 (1966), p. 16].

"However, an employee cannot memorize the employer's trade secrets and subsequently lawfully use what he memorized for the benefit of himself or a new employer [G. Sobel, "Preserving Trade Secret Protection," Chap. 12 in Protecting Trade Secrets 1986, M. F. Jager, Chmn., Practising Law Institute, New York, 1984, p. 598. 
Reasoning similar to that contained in the previous paragraph can be used to evaluate classification aspects of situations that arise when a scientific or technical employee working on a classified program applies professional expertise to an unclassified program.

\section{REFERENCES}

1. A. S. Quist, "Introduction to Classification," Chap. 1 in Security Classification of Information, Volume 1. Introduction, History, and Adverse Impacts, K/CG-1077/V1, Martin Marietta Energy Systems, Inc., Oak Ridge, Tennessee, 1989.

2. The New Encyclopedia Britannica, Macropaedia, Encyclopedia Britannica, Inc., Chicago, 15th ed., 1982, 7, p. 287; 9, p. 183. The Encyclopedia Americana, International ed., Grolier, Inc., Danbury, Conn., 24, 1985, pp. 816-819. The World Book Encyclopedia, World Book-Childcraft International, Inc., Chicago, 17, 1979, pp. 379-382. Compton's Encyclopedia and Fact-Index, The University of Chicago, 21, 1987, pp. 197-202.

3. The New Encyclopedia Britannica, Macropaedia, Encyclopedia Britannica, Inc., Chicago, 15th ed., 7, 1982, p. 287.

4. R. J. Healy, "Panel: Protection of Company Proprietary Information," J. Natl. Class. Mgmt. Soc., 10, 84-88 (1974), p. 85.

5. T. S. Church, "Panel-Science and Technology, and Classification Management," J. Natl. Class. Mgmt. Soc., 2, 39-43 (1966), p. 40.

6. R. L. Taylor, "A Study of the Effects of Security Classification Restrictions on Technical Communication, ${ }^{n}$ J. Natl. Class. Mgmt. Soc., 9, 47-53 (1973), p. 48.

7. W. P. Ranney, "The Sea Lanes \& Their Challenges," J. Natl. Class. Mgmt. Soc., 13, 17-22 (1977), p. 21.

8. Smith v. Dravo Corp., 203 F.2d 369, 373 (7th Cir., 1953).

9. Jostens, Inc. v. National Computer Systems, 318 N.W.2d 691, 699 (Minn. 1982).

10. R. M. Milgrim, Milgrim on Trade Secrets, Matthew Bender \& Co., Inc., New York, 1987, $\$ 2.04$, pp. 2-62 through 2-64. Hereafter cited as "Milgrim."

11. See also S. Ghoshal and S. K. Kim, "Building Effective Intelligence Systems for Competitive Advantage," Sloan Management Review, 28(1), 49-58 (Fall 1986); E. Mount and W. B. Newman, Top Secret/Trade Secret, Neal-Schumam Publishers, Inc., New York, 1985.

12. J. Harris, "Spies Who Sparked the Industrial Revolution," New Scientist, 110(1509), 42-47 (May 22, 1986).

13. E. M. Fowler, "Careers: Intelligence Experts for Corporations," New York Times, 138(47,641), p. D23 (Sept. 27, 1988).

14. D. A. Maxwell, "Keeping the Secret in Trade Secrets," Security Management, 33(1), 38-42 (January 1989), p. 39. 
15. A. Borrus et al., "Should the CIA Start Spying for Corporate America?" Business Week, 3235, 96-100 (Oct. 14, 1991); M. Crawford, "CIA Stakes Out Larger Role in Technology and Trade Policy," Defense Week, 13(17), 17 (Apr. 27, 1992).

16. S. H. Lieberstein, Who Owns What is in Your Head, Hawthorn Books, Inc., New York, 1979, pp. 91-92.

17. Electro-Craft Corporation v. Controlled Motion, Inc., 332 N.W.2d, 890,900 (Minn. 1983).

18. Kewanee Oil Co. v. Bicron Corp., 416 U.S. 470, 475-476 (1974).

19. Kewanee Oil Co. v. Bicron Corp., 416 U.S. 470, 476 (1974).

20. Restatement of the Law of Torts, 4, American Law Institute, St. Paul, Minn., 8757, Comment (b) (1939). Hereafter cited as "4 Restatement of the Law of Torts."

21. "Uniform Trade Secrets Act," in Uniform Laws Annotated, 14, 541-551 (1980), \$1(4), p. 542, West Publishing Co., St. Paul, Minn. Hereafter cited as "Uniform Trade Secrets Act."

22. Uniform Trade Secrets Act, comment to $\$ 1$, p. 543.

23. Milgrim, $\$ 2.02[1]$, p. 2-28.

24. Milgrim, \$2.03, p. 2-40.

25. A. V. Gross, What is "Trade Secret" So As to Render Actionable Under State Law Its Use or Disclosure by Former Employee, 59 ALR 4th, 641, 652 (1988). Hereafter cited as "Gross."

26. 4 Restatement of the Law of Torts, p. 6.

27. 4 Restatement of the Law of Torts, pp. 5-6.

28. J. S. Rakoff and M. A. Glassberg, "Trade Secrets and the Criminal Law," Chap. 5 in Protecting Trade Secrets 1986, M. F. Jager, Chmn., Practising Law Institute, New York, 1986, pp. 167-168, citing E. I. duPont Nemours \& Co. v. United States, 288 F.2d 904, 911 (Ct. Cl. 1961). Hereafter cited as "Rakoff and Glassberg."

29. Rakoff and Glassberg, p. 168, citing Milgrim, \$2.07[2], p. 2-179.

30. Kewanee Oil Co. v. Bicron Corp., 416 U.S. 470, 475, 481 (1974).

31. M. F. Jager, Trade Secrets Law, Clark Boardman Co., Ltd., New York, 1988, p. 5-37. Hereafter cited as "Jager." See also Interox America v. PPG Industries, Inc., 736 F.2d 194 (5th Cir. 1984).

32. Interox America v. PPG Industries, Inc., 736 F.2d 194, 201 (5th. Cir. 1984).

33. G. Sobel, "Preserving Trade Secret Protection," Chap. 12 in Protecting Trade Secrets 1986, M. F. Jager, Chmn., Practising Law Institute, New York, 1986, p. 573.

34. M. A. Epstein, Modern Intellectual Property, Law \& Business, Inc./Harcourt Brace Jovanovich, Publishers, Clifton, N.J., 1984, p. 13 and citations therein. Hereafter cited as "Epstein." 
35. Jager, p. 5-22.5.

36. Jager, pp. 5-52.1 through 5-54, citing By-Buk Co. v. Printed Cellophane Tape Co., 329 P.2d $147,152(1958)$ and other cases.

37. M. K. Readio, 'Balancing Employers' Trade Secret Interests in High-Technology Products Against Employees' Rights and Public Interest in Minnesota," Minn. L. Rev., 68, 984-1006 (1985), p. 995.

38. Jager, p. 5-57.

39. Peabody v. Norfolk, 98 Mass. 452, 461 (1868).

40. Jager, p. 5-32 and citations therein.

41. 4 Restatement of the Law of Torts, p. 6.

42. Jager, pp. 5-32, 5-33, 6-3.

43. Jager, p. 5-48.

44. M. J. Hutter, "Legal Theories and Recent Developments," Chap. 1 in Protecting Trade Secrets 1986, M. F. Jager, Chmn., Practising Law Institute, New York, 1986, p. 18. Hereafter cited as "Hutter."

45. Hutter, p. 19.

46. Jager, p. 5-41.

47. Eastman Co. v. Reichenbach, 20 NYS 110, 113 (1892).

48. O. \& W. Thum Co. v. Tloczynski, 114 Mich. 149, 152 (1897).

49. United States v. Heine, 151 F.2d 813 (2nd Cir., 1945).

50. United States v. Heine, 151 F.2d 813, 815 (2nd Cir., 1945).

51. Uniform Trade Secrets Act, \$1(4)(i).

52. Epstein, p. 3.

53. Epstein, p. 3, citing Syntex Ophthamics, Inc. v. Tsuetaki, 701 F.2d 677, 683 (7th Cir., 1983).

54. Milgrim, \$2.02[1], pp. 2-28 through 2-33.

55. Jager, p. 5-60.

56. Jager, p. 5-61.

57. S. J. Davidson and R. L. DeMay, "Application of Trade Secret Law to New TechnologyUnwinding the Tangled Web," Wm. Mitchell L. Rev., 12, 579-621 (1986), p. 607. Hereafter cited as "Davidson and DeMay." 
58. Jager, p. 5-63, citing Sheridan v. Mallinckrodt, Inc., 568 F. Supp. 1347, 1352, n. 7 (N.D.N.Y. 1983).

59. Milgrim, $\$ 2.07[3]$, p. 2-181.

60. Milgrim, $\$ 2.02[1]$, p. $2-27$.

61. Davidson and DeMay, p. 608. (1988).

62. Valco $v . N \&$ D Machining, 24 Ohio St. 3d, 41 (1986); 492 NE2d 814; 59 ALR 4th 629, 638

63. Kewanee Oil Co. v. Bicron Corp., 416 U.S. 470, 481-482 (1974).

64. Gross, p. 652.

65. Gross, pp. 872-887.

66. Milgrim, \$2.02[2], p. 2-33.

67. Milgrim, \$2.02[2], pp. 2-33 through 2-36.

68. Hutter, p. 20 and citations therein.

69. Milgrim, $\$ 2.02[2]$, p. 2-36.

70. Jager, pp. 3-26, 5-22.8, 5-22.9.

71. Jager, p. 5-22.7, citing Zotos International, Inc. v. Young, 830 F.2d 350, 353 (D.C. Cir. 1987).

72. Electro-Craft Corp. v. Controlled Motion, Inc., 332 N.W.2d, 890, 899 (Minn., 1983).

73. DuPont de Nemours v. Rolfe Christopher, 431 F.2d 1012, 1015-1016 (5th Cir. 1970).

74. Jager, pp. 5-62 and 5-63, citing A. O. Smith Corporation v. Petroleum Iron Works Co., 73 F.2d 531, 538 (6th Cir., 1934).

75. Jager, p. 8-10. See also P. Guthrie, “Employee's Duty, In Absence of Express Contract, Not to Disclose or Use in New Employment Special Skills or Techniques Acquired in Earlier Employment," 30 ALR 3d, 631-669 (1970).

76. W. D. Hawkland, "Some Recent American Developments in the Protection of Know-How," Buffalo L. Rev., 20, 119-145 (1970), p. 137.

77. Jager, p. 5-55.

78. Hutter, p. 15, citing S. I. Handling Systems, Inc., v. Heisley, 753 F.2d 1244 (3rd Cir., 1985).

79. Engineered Mechanical Services, Inc. v. Langlois, La. App. 1 Cir. 1984, 464 So.2d 329, writ denied 467 So.2d 531.

80. T. Robison, "The Confidence Game: An Approach to the Law About Trade Secrets," Ariz. L. Rev., 25, 347-393 (1983). 


\section{Appendix $B$. CLASSIFIABLE AREAS OF NATIONAL SECURITY INFORMATION}

\section{INTRODUCTION}

For information to be classified as National Security Information (NSI), it must fall into at least one of the ten classifiable national security areas that are specified in Sect. 1.3(a) of Executive Order (EO) $123566^{\circ}, 1$ Determining whether information falls into one of those NSI areas is the second of the five major steps in determining whether information should be classified as NSI (see Chapter 3). ${ }^{\dagger}$ Those ten areas are set forth in the subsequent sections of this appendix, along with a brief description of each area.

\section{MILITARY PLANS, WEAPONS, OR OPERATIONS}

Military operations information is "information pertaining to a strategic or tactical military action, including training, movement of troops and equipment, supplies, and other information vital to the success of any battle or campaign." 2 Military weapon information concerns the design, manufacture, and use of military weapons. It also includes information on countermeasures to those weapons. The Department of Defense (DoD) has the primary responsibility for classifying information in this area. ${ }^{\ddagger}$ An exception is for information on nuclear weapons, which is classified by the Atomic Energy Act of 1954, as amended. The classification decisions concerning military plans, weapons, or operations that are made by most other federal agencies generally will be derivative classification decisions based on DoD's original classification determinations. Appendixes $C$ and D discuss specifics of classification of military operations information and military weapons information, respectively.

\footnotetext{
"EO 12065, promulgated by President Carter in 1978, was the first Executive Order to specifically identify classifiable NSI areas. Seven NSI areas were identified [EO 12065, Fed. Reg., 43, 28949 (July 3, 1978), 81-301]. The three NSI areas not included in EO 12065, but included in EO 12356, were vulnerabilities or capabilities, cryptology, and confidential sources.

FFor atomic energy information, the comparable step is to determine whether the information falls within the definition of Restricted Data or Formerly Restricted Data and has not been declassified or transclassified to NSI.

FOf the estimated 511,868 original classification decisions in the United States in FY 1991, about $19 \%$ were by DoD ["Information Security Oversight Office (ISOO) 1991 Report to the President," March 1992, p. 13]. Of the estimated 6,595,149 total derivative classification decisions in the United States in FY 1991, about $64 \%$ were by DoD [Ibid., pp. 15-16].
} 


\section{VULNERABILITIES OR CAPABILITIES OF SYSTEMS, INSTALLATIONS, PROJECTS, OR PLANS RELATING TO NATIONAL SECURITY}

A vulnerability is an exploitable capability or an exploitable security weakness or deficiency. Examples include vulnerabilities in the protection of U.S. facilities against terrorist attacks (e.g., governmental buildings in the United States and embassies in foreign countries) and in the physical protection of the President. ${ }^{3}$ Also included in this NSI area is information concerning the readiness of U.S. Army units. ${ }^{4}$ Statements by government officials "in the known that the United States is significantly behind a major adversary in a certain area and, therefore, possibly vulnerable to attack could be classified.

Information on major weaknesses of operational military weapons systems should be classified, especially before those vulnerabilities have been corrected. ${ }^{5}$ If a system essential to national security is vulnerable (e.g., a design flaw in a deployed missile) and that vulnerability could be exploited by an adversary, then the information about the vulnerability should be classified. ${ }^{6}$ See Appendix D for more details about classification of vulnerabilities of military weapons systems.

\section{FOREIGN GOVERNMENT INFORMATION}

EO 12356 defines foreign government information (FGI) as:

(1) information provided by a foreign government or governments, an international organization of governments, or any element thereof with the expectation, express or implied, that the information, the source of the information, or both, are to be held in confidence; or

(2) information produced by the United States pursuant to or as a result of a joint arrangement with a foreign government or governments or an international organization of governments, or any element thereof, requiring that the information, the arrangement, or both, are to be held in confidence. ${ }^{7}$

FGI either retains the classification assigned to it by the foreign government or is assigned a U.S. classification at least equivalent to the foreign government classification level. ${ }^{8}$ Documents containing FGI "shall include either the marking 'FOREIGN GOVERNMENT INFORMATION,' or a marking that otherwise indicates that the information is foreign government information," except when the fact that the document contains FGI must be concealed. $^{9}$ FGI is not usually declassified by the United States without the express permission of the foreign government that generated the information.

Because FGI is generally identifiable from its source (e.g., a foreign government) and because it is presumed classified (see Chapter 4 ), there will be little further discussion in this document about its classification. 


\section{INTELLIGENCE ACTIVITIES (INCLUDING SPECIAL ACTIVITIES) OR INTELLIGENCE SOURCES OR METHODS}

Intelligence activities also include counterintelligence and foreign intelligence activities. Intelligence sources are the persons or technical means that provide intelligence. Intelligence methods are the means of gathering and analyzing intelligence information. Nearly all of the original classification decisions in this area will be made by the Central Intelligence Agency, the Department of Justice (mostly with respect to the Federal Bureau of Investigation's counterintelligence activities), ${ }^{10}$ or other U.S. intelligence organizations. The classification decisions of all other federal agencies in this area will generally be derivative classification decisions based on the intelligence agencies' original classification determinations. Appendix E discusses classification of intelligence activities, sources, and methods.

\section{FOREIGN RELATIONS OR FOREIGN ACTIVITIES OF THE UNITED STATES}

Foreign relations are the connections between nations, and foreign activities are actions related to those connections. The Department of State determines and implements U.S. foreign policy and has the primary responsibility for classifying information on foreign relations and foreign activities. ${ }^{\dagger}$ In this NSI area, most classification actions of all other federal organizations will be derivative classification decisions based on Department of State classification guidance. See Appendix F for additional information on the classification of foreign relations or foreign activities information.

\section{SCIENTIFIC, TECHNOLOGICAL, OR ECONOMIC MATTERS RELATING TO NATIONAL SECURITY}

This category includes basic and applied research, technological developments, and economic information concerning the United States. EO 12356 prohibits the classification of "basic scientific research information not clearly related to the national security." Classification of scientific and technical information is discussed frequently in the chapters of this document concerning principles of original classification of information. It appears that only rarely do economic matters warrant classification for national security reasons (see the discussion on the meanings of the terms national security and national defense in Chapter 5). Therefore, this document gives little attention to the classification of economic matters.

\footnotetext{
"Twenty-eight percent of the original classification decisions in the United States in FY 1991 were by the Department of Justice (DOJ) and $13 \%$ were by the Central Intelligence Agency (CIA) [Information Security Oversight Office (ISOO) 1991 Report to the President, March 1992, p. 13]. Twenty-seven percent of all derivative classification decisions in the United States in FY 1991 were by the CIA and $8 \%$ were by the DoJ [Information Security Oversight Office (ISOO) 1991 Report to the President, March 1992, pp. 15-16].

Thirty-eight percent of the original classification decisions in the United States in FY 1991 were by the Department of State [Information Security Oversight Office (ISOO) 1991 Report to the President, March 1992, p. 13]. The Department of State treats all of its classification decisions as original classification decisions and, therefore, reported no derivative classification decisions for FY 1991 ["Information Security Oversight Office (ISOO) 1991 Report to the President," March 1992, p. 14].
} 


\section{U.S. GOVERNMENT PROGRAMS FOR SAFEGUARDING NUCLEAR MATERIALS OR FACILITIES}

This is a rather specialized area and will not be discussed further in this document. Department of Energy classification guidance covers this topic rather thoroughly.

\section{CRYPTOLOGY}

Cryptology includes methods to keep messages secret (to construct codes) and methods to intercept and decipher messages from adversaries. The government needs codes to be able to efficiently and in a timely manner communicate sensitive information to units of the military services, to its representatives located in foreign nations, and for other purposes and yet keep the communicated sensitive information from adversaries. Conversely, it is very desirable to be able to understand adversaries' codes so that their plans and capabilities are known to our government. Successes in breaking codes are usually kept secret for a long time so that other nations are not alerted to possible deficiencies in their codes.

The field of cryptology has long been considered to be a very sensitive area of intelligence. It was given special attention by the Espionage Act of $1917 . .^{12}$ A later statute specifically criminalized certain disclosures of classified information related to cryptography. ${ }^{13}$ Another statute criminalized the disclosure of any matter that was obtained from intercepts of coded transmissions between a foreign country and its diplomatic mission in the United States. ${ }^{14}$

Until relatively recently, cryptologic information was mostly of interest only to governments. However, when businesses began to use the telegraph or radio to transmit commercial information, the private sector became more interested in cryptology. This private-sector interest has been particularly keen in recent years as computers have been widely used to store and transmit vital business data. This has led to much private research in cryptology, which in turn has led to National Security Administration concerns about the results of this research helping other nations to our detriment. ${ }^{\circ 15}$ These government concerns have not yet been resolved. The government has no specific authority to classify results of private cryptographic research other than by the Invention Secrecy Act. ${ }^{16}$

Cryptology was specifically identified in EO 12356 as a classifiable NSI area (it was not mentioned in the immediately prior Executive Order on classification, EO 12065) to make clear that communications security information was classifiable. ${ }^{17}$ It is somewhat surprising that unauthorized disclosure of classified cryptologic information is not presumed to cause damage to the national security, because having difficult-to-decipher codes for certain government communications is essential to the national security.

\footnotetext{
"For example, the National Security Administration is concerned that the results of the private research will become available to some of the less technologically advanced nations and could enable those nations to improve their diplomatic codes and make it harder for the United States to break those codes.
} 


\section{CONFIDENTIAL SOURCES}

A confidential source is defined by Sect. 6.1(t) of EO 12356 as "any individual or organization that has provided, or that may reasonably be expected to provide, information to the United States on matters pertaining to the national security with the expectation, express or implied, that the information or relationship, or both, be held in confidence." Information on foreign confidential sources is presumed classified (see Chapter 5).

\section{OTHER CATEGORIES}

The final NSI area specified by EO 12356 is titled "Other categories of information that are related to the national security and that require protection against unauthorized disclosure as determined by the President or by agency heads or other officials who have been delegated original classification authority by the President. ${ }^{n 18}$ Any original classification of information that does not fall under the previously specified nine classifiable areas of NSI must be reported promptly to the Director of the Information Security Oversight Office.

Table B.1 lists the ten areas of national security and indicates the agencies principally responsible for original classification determinations in those areas. It also indicates those areas where unauthorized disclosure of information is presumed to cause damage to national security (see Chapter 5). 
Table B.1. The ten areas of National Security (NSI) Information and related information

\begin{tabular}{|c|c|c|}
\hline NSI area & $\begin{array}{c}\text { Responsible } \\
\text { federal } \\
\text { agency }\end{array}$ & $\begin{array}{l}\text { Is damage presumed to } \\
\text { result from unauthorized } \\
\text { disclosure? } \\
\text { (yes/no) }\end{array}$ \\
\hline 1. Military plans, weapons, or operations & DoD & No \\
\hline $\begin{array}{l}\text { 2. Vulnerabilities or capabilities of systems, } \\
\text { etc. }\end{array}$ & & No \\
\hline 3. Foreign government information & $\begin{array}{l}\text { DoS, CIA, } \\
\text { and DoD }\end{array}$ & Yes \\
\hline $\begin{array}{l}\text { 4. Intelligence activities or intelligence } \\
\text { sources or methods }\end{array}$ & CIA and DoJ & $\begin{array}{l}\text { Yes, for intelligence } \\
\text { sources or methods }\end{array}$ \\
\hline $\begin{array}{l}\text { 5. Foreign relations or foreign activities of } \\
\text { the United States }\end{array}$ & DoS & No \\
\hline $\begin{array}{l}\text { 6. Scientific, technological, or economic } \\
\text { matters relating to national security }\end{array}$ & & No \\
\hline $\begin{array}{l}\text { 7. U.S. Government programs for } \\
\text { safeguarding nuclear materials or facilities }\end{array}$ & $\begin{array}{l}\text { DOE, DoD, } \\
\text { DoS }\end{array}$ & No \\
\hline 8. Cryptology & NSA & No \\
\hline 9. Confidential source & CIA, DoJ & $\begin{array}{l}\text { Yes, for a foreign } \\
\text { confidential source }\end{array}$ \\
\hline 10. Other areas related to national security & & No \\
\hline
\end{tabular}

${ }^{a}$ The agency or agencies listed are principally responsible for classification determinations in the area shown. CIA = Central Intelligence Agency; DOE $=$ Department of Energy; DoD $=$ Department of Defense; $\mathrm{DOJ}=$ Department of Justice; $\mathrm{DOS}=$ Department of State; NSA $=$ National Security Agency.

${ }^{b}$ The full question is, Can damage be presumed to result from an unauthorized disclosure?

\section{REFERENCES}

1. Executive Order 12356, Fed. Reg., 47, 14874 (Apr. 6, 1982). Hereafter cited as "EO 12356."

2. U.S. Department of Defense, Department of Defense Handbook for Writing Security Classification Guidance, DoD 5200.1-H, March 1986, \$5-2, p. 5-1.

3. A. F. Van Cook, "Information Security and Technology Transfer (An OUSD Overview of Executive Order 12356 and DoD's View Concerning Implementation)," J. Natl. Class. Mgmt. Soc., 18, 1-7 (1982), p. 3.

4. S. Garfinkel, "An Information Security Oversight Office Overview of Executive Order 12356 and Its Implementing Directive," J. Natl. Class. Mgmt. Soc., 18, 17-23 (1982), pp. 20-21. See also Chapt. 10, supra, discussing Taylor v. Department of the Army. 
5. F. Seitz, Chairman, Office of the Director of Defense Research and Engineering, Report of the Defense Science Task Board Task Force on Secrecy, U.S. Department of Defense, July 1, 1970, p. 8.

6. F. J. Thomas, "Workshop A-Lifetime Cycles for Security Classification," J. Natl. Class. Mgmt. Soc., 7, 58-62 (1971), p. 61.

7. EO 12356, \$6.1(d).

8. EO 12356, 81.5(d).

9. Information Security Oversight Office, "Directive No. 1," Fed. Reg., 47, 27836 (June 25, 1982), $\$ 2001.5(\mathrm{e})(4)$.

10. Information Security Oversight Office, Information Security Oversight Office (ISOO) 1991 Report to the President, Washington, D.C., March, 1992, p. 14.

11. EO $12356, \S 1.6(\mathrm{~b})$.

12. 40 Stat. 217,218 (1917).

13. 18 U.S.C. $8798(a)$ (1982).

14. 18 U.S.C. $\$ 952$ (1982).

15. M. M. Cheh, "Government Control of Private Ideas-Striking a Balance Between Scientific Freedom and National Security, "Jurimetrics Joumal, 23, 1-32 (1982), p. 11.

16. 35 U.S.C. $\$ 181-188$ (1982).

17. U.S. Congress, House of Representatives, Committee on Government Operations, "Security Classification Policy and Executive Order 12356," Twenty-Ninth Report by the Committee on Government Operations, House Report 97-731, 97th Cong., 2nd Sess., 1982, p. 16.

18. EO 12356, $\$ 1.3(10)$. 


\section{Appendix $C$. CLASSIFICATION OF MILITARY OPERATIONS INFORMATION}

A hasic principle in determining the classification of military operations information is said to be that strategic doctrine and overall deployment plans (defense policy) need not be classified but that specific operational targeting plans and command arrangements (the means and methods to execute the policy) should be classified. ${ }^{1,2}$ Strategic deterrence includes letting an adversary know "in considerable detail" exactly what the opponent can do but not letting the adversary know how it can be done (to prevent the adversary from developing countermeasures). ${ }^{3}$

Some properties of military operations information (operational secrets) are that it is compact, understandable, arbitrary, subject to change, and perishable. ${ }^{4}$ Explanations of those terms are as follows: ${ }^{4}$

Compactness-a few words can reveal a major secret (e.g., the place and time of the World War II invasion of Normandy on June 6, 1944), which makes the secret easy to steal.

Understandable-no special training or ability to understand is required in order to understand, evaluate, and transmit the secret.

Arbitrary-the secret cannot be deduced. It needs to be stolen to be obtained (e.g., the time and place of the Normandy invasion).

Subject to change-since the secret consists of an arbitrary decision, it can be changed up to the time it is put into operation.

Perishable-once an attack has begun, the enemy knows the information. The secret needs to be protected only for a limited time period.

Another characteristic of this type of information is that there is generally no advantage to making the information public-in not keeping it a secret. For example; after it had been determined that a national goal was to liberate continental western Europe, there was no need to have public input on the exact date and time of the invasion of Normandy in World War II. Operational secrets are part of a category of secrets known as subjective secrets (see Chapter 2).

The Department of Defense (DoD) provides guidance in classifying military operations information. The following information is taken from DoD's Department of Defense Handbook for Writing Security Classification Guidance. ${ }^{5}$

While there are no hard and fast rules for classification of military operations information, and while each Military Servico and command may require a unique approach to operations security (OPSEC), there are tasic concepts which can be applied. What must be protected are operational concepts and their applications, and the capabilities, 
vulnerabilities, and weaknesses of the plan. The element of surprise is essential to military effectiveness in both tactical and strategic operations, and requires the continuous concealment of capabilities and intentions. OPSEC is the principal means of achieving that conceaiment. ${ }^{*} 6$

Military operations information is defined for the purpose of this Handbook as information pertaining to a strategic or tactical military action, including training, movement of troops and equipment, supplies, and other information vital to the success of any battle or campaign.

Successful battle operations depend largely upon our ability to assess correctly the capability and intention of enemy forces at each stage of the battle and to communicate an effective battle doctrine throughout our forces. ${ }^{\dagger}$ Classifiable information would include:

a. The number, type, location, and strengths of opposing units.

b. The capabilities and vulnerabilities of weapons in enemy hands, and how he normally applies the weapon.

c. The morale and physical condition of the enemy force. 8

Information related to operational plans (whether executed or not, presented in whole or in part) that if disclosed could be expected to cause damage to the United States, must be protected. ${ }^{8}$

In considering classification guidarice for operations, there may be good reason to classify more information about the operation in the beginning than will be necessary later. Cerisin elements of information such as troop movements may no longer require protection after a certain date or event. When this point is reached, downgrading or even declassification should be considered. ${ }^{8}$

A classification guide should clearly identify the elements of information pertaining to the operational plan for which classification guidance is required. Classification shall continue only so long as unauthorized disciosure would result in damage to the national security, which may be an indefinite period of time in the case of unexecuted long range plans. $^{9}$

Example items to be considered for classification include the following: ${ }^{10}$

- overall operational plans;

- system operational deployment or employment;

- initial operational capability date;

- planned location of operational units;

- equipage dates, readiness dates, and operational employment dates;

- total personnel requirements for total operational foce;

- coordinates of selected operational sites;

- specifit, operational performance data that relate to the effectiveness of the control of forces and data on specific vulnerabilities and weaknesses;

- existing operational security and communications security procedures, projections, and techniques; and

- target characteristics.

\footnotetext{
"Operations security is the "process of denying adversaries information about friendly capabilities and intentions by identifying, controlling, and protecting indicators asscciated with planning and conducting military operations and other activities" [U.S. Department of Defense, Department of Defense Handbook for Writing Security Classification Guidance, DoD 5200.1-H, U.S. 5-3(d), March 1986].

to this might be added "and to keep the enemy from knowing, in advance, our capabilities and intentions during the battle."
} 


\section{REFERENCES}

1. J. H. Kahan, panel member, "Workshop A-Lifetime Cycles for Security Classification," J. Natl. Class. Mgmt. Soc., 7, 52-56 (1971), p. 55.

2. D. J. Murphy, "Some Thoughts on Defense Policy," J. Natl. Class. Mgmt. Soc.. 16, 1-3 (1980), p. 1.

3. W. P. Raney, "The Sea Lanes \& Their Challenges," J. Natl. Class. Mgmt. Soc., 13, 17-22 (1977), p. 18.

4. L. N. Ridenour, "Military Security \& the Atomic Bomb," Fortune, 32, 170-171, 216, 218, 221, 223 (November 1945), p. 171.

5. U.S. Department of Defense, "Classifying Military Operations Information," Chap. 5 in Department of Defense Handbook for Writing Security Classification Guidance, DoD 5200.1-H, March 1986. Hereafter cited as "DoD 5200.1-H."
6. DoD 5200.1-H, 5-1.
7. DoD 5200.1-H, 5-2.
8. DoD 5200.1-H, 5-4.
9. DoD 5200.1-H, 5-5.
10. DoD 5200.1-H, 5-6. 


\section{Appendix D. CLASSIFICATION OF MILITARY WEAPONS INFORMATION}

\section{GENERAL}

Most of the following information on classification of military weapons was taken directly from Chapter 4, "Classifying Hardware Items," of Department of Defense (DoD) 5200.1-H, Department of Defense Handbook for Writing Security Classification Guidance. ${ }^{1}$ As used in this appendix, "hardware" is synonymous with "military weapon." Although the following information was developed for military weapons classification guidance, some of that information should also be useful to Department of Energy and other federal agency classifiers when they are considering whether to classify technical information.

Military weapons or hardware items that comprise military weapons are classified because of the information revealed by or obtained from those weapons or items. A piece of hardware conveys information about itself or the system of which it is a part just as readily as a narrative describing the hardware. The following are some basic considerations for classifying hardware items:

1. An item of hardware does not necessarily need to be classified simply because it is part of a classified product or effort.

2. Unclassified off-the-shelf hardware items, unless modified in some way to make them perform differently, can never be classified even though they constitute a critical element, become an integral part of a classified end product, or produce a classified effect. However, the association of otherwise unclassified hardware with a particular effort or product may reveal something classified about that effort or product. Common integrated circuits that control frequencies are notable examples. In such cases it is the association with the effort or product that reveals the classified information, not the circuits themselves. Decisions regarding what aspect of the system to classify may be difficult, but it is necessary to consider the effect of association and how that association could reveal classified information.

3. Frequently, classified information pertaining to a hardware item can be restricted to the paperwork associated with the item. When this is possible, the hardware itself should be unclassified.

4. Unusual, unique, or peculiar uses or modifications of ordinarily available unclassified materials or hardware items may create a classifiable item of information. In another instance, the mere fact of use of a particular material in a particular effort might reveal a classifiable research or development interest. In such cases, it is especially important to accurately identify the classified information to determine whether the hardware or material itself reveals this information or whether it is merely the association or use of the hardware item with a particular effort that reveals it. In the latter case, classification of the hardware itself would not be proper. 
5. At some stage in a production effort, production and engineering plans are drawn. Usually a family-tree-type diagram is prepared to assist in determining what components, parts, and materials will be required. This diagram supplies a good basis for determining where and when classified information will be involved in the production effort.

6. Another step in production engineering is the development of drawings for all the individual elements that go into the final product. These drawings show design data, functions, and specifications, all of which are closely tied to items of information that may be classified. From these drawings it is possible to determine exactly which elements of the final product will reveal classified information. It is also possible to determine associations between hardware items that reveal classified information. It is necessary, of course, to determine the classifications, if any, to be assigned each drawing. Accordingly, a classification team should take part in the production engineering phase to assist in identifying and isolating classification situations.

\section{DETAILS OF HARDWARE THAT MIGHT BE CLASSIFIED*}

Operational capability, and the efforts to develop operational capability, should be classified. $^{2}$ In the latter case, the goal is to buy lead time. In the former case, classification prevents the adversary from knowing exactly what can be done and how that capability is achieved. Details of these capabilities that could be classified are given in the following subsections.

\section{Performance or Capability}

1. What will the hardware do (actual or planned) that is more, better, faster, or cheaper (in terms of all kinds of resources) than anything like it?

2. How does this degree or kind of performance contribute to or create a national security advantage? How much of an advantage does it create?

3. How long can this information be protected? What is the advantage?

4. How would knowledge of these performance details help an enemy or damage the success of this effort?

5. Would statement of a particular degree of attained performance or capability be of value to hostile intelligence in assessing U.S. capabilities, in spurring a foreign nation to similar effort...or in developing or planning countermeasures or counteraction?

\section{Uniqueness}

1. What information pertaining to this effort is known or believed to be the exclusive knowledge of the United States?

2. Is it known or reasonable to believe that other nations have achieved a comparable degree of success or attainment?

\footnotetext{
"The material in this section was taken from Appendix B of DoD 5200.1-H, Department of Defense Handbook for Writing Security Classification Guidance, March 1986.
} 
3. What information, if disclosed, would result in or assist other nations in developing a similar item or arriving at a similar level of achievement?

4. In what way or ways does the uniqueness of this item contribute to a national security advantage?

5. In what way or ways has the end product of this effort or any of its parts been modified, developed, or applied so as to be unique to this kind of effort? How unique is this?

6. Is the method or adaptation or application of the end product or any of its parts the source of the uniqueness and a national security advantage? In what way or ways? Is it in itself a unique adaptation or application in this kind of effort?

\section{Technological Lead Time}

1. How long did it take to reach this level of performance or achievement?

2. How much time and effort have been expended? Was this a special concerted effort or only a gradual developmental type of activity?

3. If all or some of the details involved in reaching this stage of development or achievement were known, how much sooner could this goal have been reached? Which details would contribute materially to a shortening of the time for reaching this goal? Can these details be protected? How long can these details be protected?

4. Have other nations reached this level of development or achievement?

5. Do other nations know how far we have advanced in this kind of effort?

6. Would knowledge of this degree of development or achievement spur a foreign nation to accelerate its efforts to diminish our lead in this field? What details of knowledge would be likely to cause such acceleration?

7. How important, in terms of anticipated results, is the lead time we think we have gained?

8. What national security advantage actually results from this lead time?

9. How long is it practical to believe that this lead time will represent an actual advantage?

10. How long is it practical to expect to be able to protect this lead time?

\section{Surprise}

1. Do other nations know that we have reached this level of development or achievement?

2. Will operational use of the end item of this effort give us an immediate advantage that would be less or lost if it were known that we have achieved this particular goal?

3. What is the nature of the advantage resulting from surprise use of this end item?

4. When will this element of surprise be lost? 


\section{Vulnerabilities and Weaknesses}

1. What are the weak spots in this effort that make it vulnerable to failure? What is the rate or effect of this failure?

2. How will failure of the effort in whole or in part affect the national security advantage expected upon completion of this effort or use of the resulting end item?

3. What elements of this effort are subject to countermeasures or counteraction?

4. How would knowledge of these vulnerable elements assist in planning or carrying out countermeasures or counteraction?

5. Can information concerning these weak or vulnerable elements be protected from unauthorized disclosure, or are they inherent in the system?

6. Can these weaknesses or vulnerabilities be exploited to reduce or defeat the success of this effort? How could this be done?

7. What measures are planned or have been taken to offset these weaknesses or vulnerabilities?

8. Are the counter-countermeasures obvious, special, unique, or unknown to outsiders or other nations?

9. How would knowledge of these counter-countermeasures assist in carrying out or planning new countering efforts?

10. Would knowledge of specific performance capabilities assist in developing or applying specific countermeasures or counteractions? Hcw? What would be the effect on the expected national security advantage?

\section{Specifications}

1. What details of specifications would reveal:

a. a special or unusual interest that contributes to the resulting or expected national security advantage?

b. special or unique composition that contributes to the resulting or expected national security advantage?

c. special or unique levels of performance that are indicative of a classifiable level of achievement or goal?

d. special or unique use of certair materials that reveals or suggests the source of a national security advantage?

e. special or unique size, weight, or shape that contributes to the resulting or expected national security advanitage?

2. Are any specification details in themselves contributory to the resulting or expected national security advantage? How do they contribute?

3. Can details of specifications be protected? How long can these details be protected? 


\section{Critical Elements}

1. What are the things that really make this effort work?

2. Which of these critical elements contribute to the resulting or expected national security advantage? How do they contribute? To what extent do they contribute?

3. Are these critical elements the source of weakness or vulnerability to countermeasures or counteraction?

4. What details of information pertaining to these critical elements disclose or reveal the national security advantage or weakness or vulnerability to countermeasures or counteraction?

5. Can details of information pertaining to these critical elements be protected by classification? How long can these details be protected?

\section{Manufacturing Technology}

1. What manufacturing methods, techniques, or modes of operation were developed to meet the requirements of this effort or to make the desired end product?

2. Which of these manufacturing innovations are unique to this effort or this product? Are they generally known or suspected?

3. Are these manufacturing innovations essential to successful production of the product?

4. Could the desired result be obtained without these innovations?

5. What kind of lead time results from these innovations?

\section{Associations}

1. Are there any associations between this effort and others which raise classification questions?

2. Are there any associations between information in this effort and already publicly available information (unclassified) which raise classification problems?

3. Is it necessary or possible to classify items of information in this effort because their association with other unclassified or classified information would diminish or lose a national security advantage?

\section{Protectability}

1. Can the information effectively be protected from unauthorized disclosure by classification? How long can the information effectively be protected?

2. If not, what alternative means can be used to ensure protection? 


\section{CHECKLIST OF CLASSIFYING DETAILS FOR HARDWARE}

Appendix C of DoD 5200.1-H lists many items of information for use in determining whether strategic or tactical capabilities and vulnerabilities are disclosed (a comprehensive check list). The listing is not all-inclusive nor completely applicable in every instance. Those items of information are as follows:

\section{Performance and Capabilities}

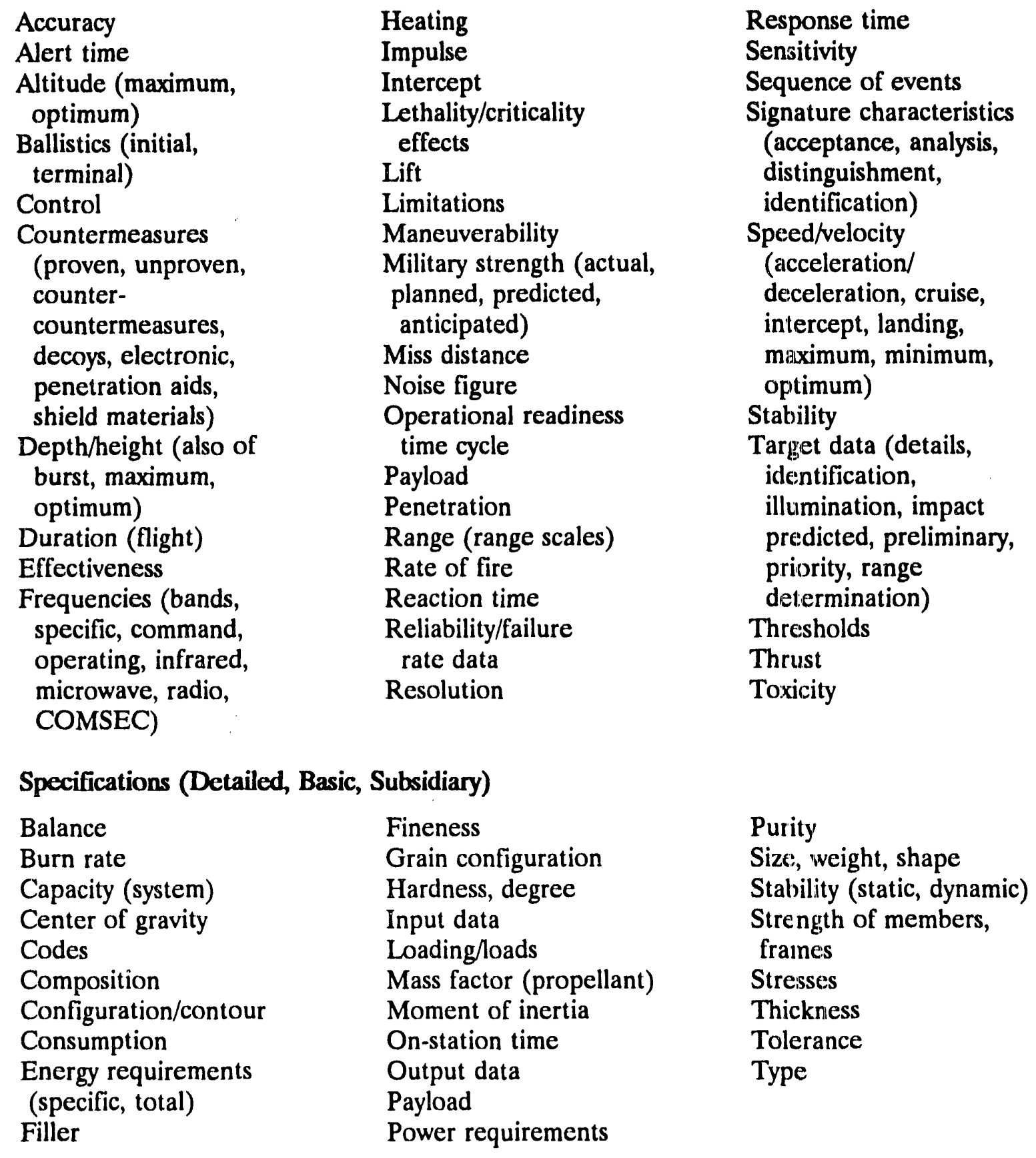




\section{Vulnerability}

Countermeasures/

counter-

countermeasures

Dynamic pressure (supersonic)

Procurement and Production

Completion date or dates

Numbers [dispersion (numbers per unit of force); on hand

\section{Operations}

Countdown time

Deployment data

Environment

Location

Numbers available

Objectives [mission or

program, specific or
Electromagnetic pulse (radiation)

Ground or air shock

Jamming
Signature characteristics (acoustic, electrical, infrared, magnetic, pressure, radar)

Static overpressure (stockpile); planned or programmed (totals scheduled); rate of delivery or production; requirements; spares]
Progress/schedules

(milestones)

Stock density

Supply plans and status

Tactical deployment
Staging techniques Statement/concept Tactical (build-up, units per force, activation dates, personnel)

\section{REFERENCES}

1. U.S. Department of Defense, Department of Defense Handbook for Writing Security Classification Guidance, DoD 5200.1-H, March 1986.

2. W. P. Raney, "The Sea Lanes \& Their Challenges," J. Natl. Class. Mgmt. Soc., 13, 17-22 (1977) p. 21. 


\title{
Appendix $E$. CLASSIFICATION OF INTELLIGENCE INFORMATION
}

\section{BACKGROUND}

The earliest intelligence activities of the United States were carried out by the Committee on Secret Correspondence of the Continental Congress. This committee was created on November 29,1775 , to correspond with "friends" in other parts of the world. ${ }^{1}$ This committee even had authority to keep certain information secret from the Continental Congress. For example, when the Continental Congress requested certain information from the committee on May 10,1776, it authorized the committee to withhold "the names of the persons they have employed, or with whom they have corresponded. ${ }^{*}, 2$

\section{GENERAL INFORMATION}

Intelligence operations generally concern either information gathering or covert operations. Most intelligence information is obtained from open sources, but some is gathered clandestinely. Executive Order (EO) 12356 permits classification of information about intelligence activities or intelligence sources or methods. ${ }^{3}$

Intelligence activities usually are categorized as either counterintelligence or foreign intelligence. The Department of Defense (DoD) has defined counterintelligence and foreign intelligence as follows:

\begin{abstract}
Counterintelligence is information gathered and activities conducted to protect against espionage, other intelligence activities, sabotage, or assassinations conducted for or on behalf of foreign powers, organizations, persons, or international terrorist activities, but not including personnel, physical, document, or communications security programs.

Foreign intelligence is information relating to the capabilities, intentions, and activities of foreign powers, organizations, or persons, but not including counterintelligence except for information on international terrorist activities. ${ }^{\dagger, 4}$
\end{abstract}

Intelligence information could also encompass foreign government information, which may be classified under Sect. 1.3(a)(3) of EO 12356.

Unauthorized disclosure of intelligence sources or methods is presumed to cause damage to the national security. ${ }^{5}$

\footnotetext{
"By this action the Continental Congress essentially classified the "confidential sources" of the Committee on Secret Correspondence. Was this the first classification guidance of the U.S. Government?

${ }^{\dagger} A$ Department of Energy order defines foreign intelligence as "information relating to the capabilities, intentions and activities of foreign powers, organizations or persons" [U.S. Department of Energy, DOE Order 5635.1A, "Control of Classified Documents and Information," Feb. 12, 1988, Attachment 2, Item 42.a, p. 6].
} 
Intelligence sources and methods are "the heart of all intelligence operations. ${ }^{n 6}$ The following definition of a confidential source is given in FO 12356:

\begin{abstract}
"Confidential source" means any individual or organization that has provided, or that may reasonably be expected to provide, information to the United States on matters pertaining to the national securty with the expectation, express or implied, that the information and relationship, or both, be held in confldence. ${ }^{7}$
\end{abstract}

The Supreme Court has defined an intelligence source as follows: "An intelligence source provides, or is engaged to provide, information the [Central Intelligence] Agency needs to fulfill its statutory obligations." ${ }^{n}$ The DoD has defined an intelligence source as "A person or technical means providing intelligence." 4

Important sources of intelligence information must be classified. Disclosure of the identity of a source would essentially prevent the source from being of further use (the adversary would take steps to close that source) and would probably endanger the life of the identified source. The Intelligence Identities Protection Act of $1982^{9}$ provides penalties for unauthorized disclosure of intelligence agents and sources-either directly by someone who has access to classified information about those agents and sources or by someone who is trying to identify and expose covert agents. ${ }^{10}$

DoD has defined an intelligence method as "Any process, mode of analysis, means of gathering data, or processing system or equipment used to produce intelligence." ${ }^{4}$ Disclosure of intelligence methods would allow the target nation to develop countermeasures and stop the flow of intelligence information. With respect to intelligence gathering by technological methods, it costs much less to negate a system then to develop and deploy the system. ${ }^{11}$ Therefore, it is important to classify and protect the specific techniques used to gather intelligence. Classified information on intelligence methods might be disclosed indirectly by intelligence reports, because their content may give clues as to the identity of methods (or agents) used to gather the information. Consequently, the products of intelligence are frequently classified because they contain information that reveals an intelligence source or method. ${ }^{12}$

Section 102(d)(3) of the National Security Act of $1947^{13}$ makes the Director of Central Intelligence responsible for protecting intelligence sources and methods from unauthorized disclosure. The director has "very broad authority to protect all sources of intelligence information from disclosure." 14

50 U.S.C. Sect. 413 concerns congressional oversight of intelligence operations. It requires Congress to establish procedures to protect against unauthorized disclosure of intelligeäce sources and methods.

DoD has developed some basic considerations for classification of intelligence information. Those considerations are essentially as follows: ${ }^{15}$

\footnotetext{
A well-known example of the adverse effects of disclosure occurred after Philip Agee, an ex-Central Intelligence Agency (CIA) agent, publicly identified Richard Weich as the CIA station chief in Athens, Greece. Welch was assassinated shortly thereafter ["Plugging the Leak: The ase for a Legislative Resolution of the Conflict Between the Demands of Secrecy and the Need for an Open Government, " Va. Law Rev., 71, 801-868 (1985), pp. 802-803, note 10, quoting The New York Times, Dec. 24, 1975, p. 1, col. 3, and p. 10, col. 3].
} 
1. In general, resource information should not be classified unless it reveals some aspect of the intelligence mission and its revelation would jeopardize the effectiveness of a particular function. An example of classifiable resource information is the intelligence contingency fund.

2. Intelligence concerning foreign weapons systems may be classified based on what is generally known about a particular system or its components. Normally, the less that is publicly known about a particular system or component, the higher its level of classification.

3. Intelligence identifying a particular source or method is classified as well as the evaluation of the particular source or method.

4. Intelligence that does not identify or reveal a sensitive source or method is usually not classified unless the information contains other classified information such as intelligence plans, policies, or operations.

5. Intelligence that reveals the identity of a conventional source or method normally does not require classification. However, if the information is communicated to the DoD by a foreign government under a government-to-government agreement, it must be protected at the level and for the length of time the transmitting government desires. If the information is obtained from a conventional source or methud, and the information is provided freely without any agreement or othes rest iction, expressed or implied, the classification, if any, should be based solely on the content of the information provided.

6. Intelligence that reveals the identification of all known and possible enemy capabilities to collect and exploit information from a given or similar operation is classified. This threat includes known enemy intelligence collection and analysis capabilities, efforts, and successes. An integral part of these data is an assessment of enemy human intelligence, signals intelligence, and reconnaissance satellite capabilities.

7. An intelligence estimate is normally classified, because it contains sensitive sources, methods, or raw or evaluated intelligence.

8. An intelligence requirement is classified when it reveals what is not known, what is necessary to know, and why. Moreover, the requirement may recommend a sensitive source or method or other military intelligence required or contain technical and operational characteristics of classified weapons systems.

9. The classification of relationships with foreign intelligence organizations is related to the following considerations.

a. Normally, the fact of broad, general intelligence cuoperation with foreign countries or groups of countries with which the United States maintains formal military alliances or agreements (e.g., the North Atlantic Treaty Organization) is not classified.

b. The fact of intelligence cooperation between the United States and a specific governmental component in an allied country or general description of the nature of intelligence cooperation between the United States and any allied country may be classified. The fact of intelligence cooperation between the 
United States and specifically named countries or their governmental components with which the United States is not allied is always classified.

c. Details or specifics concerning any intelligence exchange agreement are classified. In some instances, the mere fact of such an agreemen may be classified.

d. The identities of foreign governmental or military personnel who provide intelligence information under such agreements or liaison relationships may be classified.

10. Information that reveals counterintelligence activities, identities of undercover personnel or units or clandestine human agents, or methods of operations and analytical techniques for the interpretation of intelligence data is classified.

11. Cryptologic information (including cryptologic sources and methods) is classified.

12. Information concerning electronics intelligence, telemetry intelligence, and electronic warfare is usually classified.

13. The intelligence community normally considers the following categories of information to be classified.

a. Cryptologic and cryptographic information signals intelligence, or imagery intelligence

b. Counterintelligence

c. Special access programs

d. Information that identifies clandestine organizations, agents, sources, or methods

e. Information on personnel under official or nonofficial cover, or revelation of a cover arrangement

f. Covertly obtained intelligence reports and the derivative information which would divulge intelligence sources or methods

g. Methods or procedures used to acquire, produce, or support intelligence activities

h. Intelligence organizational structure, size, installations, security, objectives, and budge

i. Information that would divulge intelligence interests, value, or extent of knowledge on a subject

j. Training provided to or by an intelligence organization which would indicate its capability or identify personnel

k. Personnel recruiting, hiring, training, assignment, and evaluation policies

l. Information that could lead to foreign political, economic, or military action against the United States or its allies

m. Events leading to international tension that would affect U.S. foreign policy 
n. Diplomatic or economic activities affecting national security or international security negotiations

o. Information affecting U.S. plans to meet diplomatic contingencies affecting national security

p. Nonattributable activities conducted abroad in support of U.S. foreign policy

q. U.S. surreptitious collection [of information] in a foreign nation which would affect relations with the country

r. Covert relationships with international organizations or foreign governments

s. Information related to political or economic instabilities in a foreign country threatening U.S. lives and installations there

t. Information divulging U.S. intelligence and assessment capabilities

u. U.S. and allies' defense plans and capabilities that enable a foreign entity to develop countermeasures

v. Information disclosing U.S. systems and weapons capabilities or deployment

w. Information on research, development, and engineering that enables the United States to maintain an advantage of value to national security

x. Information on technical systems for collecting and producing intelligence

y. U.S. nuclear programs and facilities

z. Foreign nuclear programs, facilities, and intentions

aa. Contractual relationships that reveal the specific interest and expertise of an intelligence organization

bb. Information that could result in action that would place an individual in jeopardy

cc. Information on secret writing when it relates to specific chemicals, reagents, developing [solutions], and microdots

dd. [Information about] U.S. military space programs [related to intelligence gathering]

Normally, intelligence will remain classified for a longer duration than other types of classified information. EO 10964, the first Executive Order to establish automatic dowr. grading and declassification for certain types of classified information, specifically excluded intelligence information from automatic downgrading or declassification. ${ }^{16}$ However, intelligence should only remain classified as long as is necessary to protect a certain source or method. Intelligence that is critical to an understanding of our national policy should be disseminated as soon as national security permits. 


\section{REFERENCES}

1. Journals of the Continental Congress, 1774-1789, Vol. 3 (for the period 1775), U.S. Govt. Printing Office, Washington, D.C., 1905, p. 392; Secret Joumals of the Acts and Proceedings of Congress, Vol. 2, Thomas B. Wait, Boston, 1820, p. 5.

2. Joumals of the Continental Congress, 1774-1789, Vol. 4 (for the period 1776), U.S. Govt. Printing Office, Washington, D.C., 1906, p. 345.

3. Executive Order 12356, Fed. Reg., 47, 14874 (Apr. 6, 1982), 81.3(a)(4). Hereafter cited as "EO 12356."

4. U.S. Department of Defense, Department of Defense Handbook for Writing Security Classification Guidance, DoD 5200.1-H, March 1986, \$6-2, p. 6-1. Hereafter cited as "DoD 5200.1-H."

5. EO $12356, \S 1.3(\mathrm{c})$.

6. Central Intelligence Agency v. Sims, 471 U.S. 159, 167 (1985).

7. EO 12356, §6.1(f).

8. Central Intelligence Agency v. Sims, 471 U.S. 159, 177 (1985).

9. 50 U.S.C. $\$ 421-426(1982)$.

10. 50 U.S.C. $\$ 421(a)-(c)$.

11. J. Vorona, "Sources, Methods \& Technology-A Means to Assess the Threat," J. Natl. Class. Mgmt. Soc., 13, 1-5 (1977), p. 1.

12. A. M. Cox, The Myths of National Security, The Perils of Secret Government, Beacon Press, Boston, 1975, p. 70.

13. 50 U.S.C. $\$ 403(d)(3)$.

14. Central Intelligence Agency v. Sims, 471 U.S. 159, 168-169 (1985).

15. DoD 5200.1-H, \$6.3.

16. Executive Order 10964, "Amendment of Executive Order No. 10501, Entitled 'Safeguarding Official Information in the Interests of the United States,' Fed. Reg., 26, 8932, \$1(B) (Sept. 22, 1961). 


\section{Appendix $F$. CLASSIFICATION OF FOREIGN RELATIONS INFORMATION}

The Department of State (DoS) is the agency primarily responsible for classification of foreign relations information. Other agencies' classification decisions will usually be derivative classification decisions. This appendix presents some guidance for classification of foreign relations information to assist the authorized classifier in recognizing what might be foreign relations information if it is encountered. This guidance is taken essentially verbatim from a Department of Defense handbook for writing security classification guidance. ${ }^{1}$

Foreign relations are the connections between nations. Information that pertains to the political, military, and economic relationships between countries and international organizations is foreign relations information. Foreign affairs refers to matters having to do with foreign relations. The following are some of the types of foreign relations information that warrant classification consideration.

1. All material that reveals or recommends U.S. Government positions or options in a negotiation with a foreign government or group of governments or that comments on the merits of foreign government positions in such negotiations.

2. All material that comments on the quality, character, or attitude of a serving foreign government official, whether elected or appointed, and regardless of whether the comment is favorable or critical. Such information might reveal:

a. a foreign official speaking in a highly critical manner of his or her own government's policy;

b. a foreign official suggesting how pressure might effectively be brought to bear on another part of his or her own government;

c. a foreign official acting in unusually close concert with U.S. officials where public knowledge of this might be harmful to that foreign official; or

d. a foreign official whose professional advancement would be beneficial to U.S. interests, especially if any implication has been made of U.S. efforts to further his or her advancement, or if public knowledge of this might place the person or his or her career in jeopardy.

3. All unpublished, adverse comments by U.S. officials on the competence, character, attitudes, or activities of a serving foreign government official.

4. All material that constitutes or reveals unpublished correspondence between heads of state or heads of government.

5. Statements of U.S. intent to defend or not to defend identifiable areas or along identifiable lines in any foreign country or region. 
6. Statements of U.S. intent to attack militarily, in stated contingencies, identifiable areas in any foreign country or region.

7. Statements of U.S. policies or initiatives within collective security organizations (e.g., the North Atlantic Treaty Organization).

8. Agreements with foreign countries for the use of or access to military or naval facilities.

9. Contingency plans insofar as they involve other countries; thi use of foreign bases, territory, or airspace; or the use of chemical, biological, or nuclear weapons.

10. Defense surveys of foreign territories for purposes of basing [military units] or using [parts of those territories] in contingencies.

11. Statements relating to any use of foreign bases not authorized under bilateral agreements.

A general rule might be that foreign policy objectives and broad diplomatic options should be kept unclassified for purposes of public discussion but that specific information about ongoing negotiations should be classified. ${ }^{2}$

With respect to the duration of classification of foreign relations information, it has been stated that "the need for diplomatic secrecy is usually limited to the period of negotiation, normally of short duration." 3

\section{REFERENCES}

1. Department of Defense Handbook for Writing Security Classification Guidance, DoD 5200.1-H, U.S. Department of Defense, Washington, D.C., March 1986, \$7.

2. J. H. Kahan, "Workshop A-Lifetime Cycles for Security Classification, " J. Natl. Class. Mgmt. Soc., 7, 52-56 (1971), p. 55.

3. J. Zagel, "The State Secrets Privilege," Minn. L. Rev., 50, 875 (1966), p. 877, n. 9. 


\section{Appendix G. CLASSIFICATION DURATION BASED ON THE PROBABILITY OF UNAUTHORIZED DISCLOSURE OF THE CLASSIFIED INFORMATION}

\section{INTRODUCTION}

When a classifier (the government) determines that certain information is National Security Information (NSI), then that classifier also must decide whether that NSI can be assigned a classification duration. ${ }^{1}$ Such a classification duration, when assigned, is usually specified in terms of the happening of an event or with reference to a future date (see Chapter 8). When classification duration is specified, the classifier thereby decides that the information can be automatically declassified. However, even though the declassification is automatic, it is under governmental control because the government controls the happening of the event which declassifies the information or by which the future date is determined.

Unauthorized disclosures of classified information ${ }^{\dagger}$ sometimes also essentially declassify that information, depending on the extent of dissemination of the unauthorized disclosure and the recipients thereof. $¥$ "Declassifications" by such disclosures are not directly controlled by the government even though the government "owns" the information. However, the probability of an unauthorized disclosure of classified information depends on some factors that can be controlled by the government.

The major factor that determines the probability of unauthorized disclosure of classified information is the number of persons to whom the classified information has been given." This probability increases with an increase in the number of persons who know that information. Although it is not possible to specify exactly when an unauthorized disclosure to an adversary will occur, it may be possible to predict when the probability of that unauthorized disclosure will become relatively high (because of the large number of persons

\footnotetext{
"Only 5\% of the government's original classification decisions made in FY 1991 were marked for declassification upon a specific date or event ["Information Security Oversight Office (ISOO) 1991 Report to the President," Information Security Oversight Office, March 1992, pp. 14-15].

tUnauthorized disclosures of classified information occur when classified information is communicated to, or obtained by, someone not authorized to receive that information. An unauthorized disclosure occurs when classificd information is received by an individual who does not have a security clearance. Such a disclosure also occurs when an individual with a security clearance but without a need to know receives that classified information. That latter type of unauthorized disclosure will not be further considered in this appendix, because the major risks from unauthorized disclosures occur when classified information is disclosed to uncleared persons.

FNote that classified information is not "declassified automatically" as a result of any unofficial publication or inadvertent or unauthorized disclosure in the United States or abroad of identical or similar information [Executive Order $12356,81.3(\mathrm{~d})$ ]. However, as a practical matter, the major benefits of classification may have disappeared [see also U.S. Departinent of Defense, Regulation DoD 5200.1-R, Information Security Program Regulation, \$2-209 (June 1986)].

"Note that a characteristic of a "protectable" trade secret is that it is known only to a few people [M. F. Jager, Trade Secrets Law, Clark Boardman Co., Ltd., New York, 1988, \$2.02, p. 2-14].
} 
who know the information) and thereby to estimate an effective classification duration. The government can certainly establish rules concerning who can legitimately have access to classified information (e.g., by security clearances and need-to-know requirements) and can thereby control the number of persons who know the classified information. Therefore, the government can control (to some extent) the probability of unauthorized disclosure of that information and thus the classification duration.

Unauthorized disclosures can be either deliberate or inadvertent, direct or indirect, oral or written. The purpose of this appendix is to describe how unauthorized disclosures of classified information to adversary foreign governments, which thereby lead to possible de facto declassifications, depend on the number of persons who know the classified information, on the number of communications by those persons, on the number of copies of each communication, on classification management practices, and on other factors. The following sections describe some relationships for estimating the probability of unauthorized disclosure of classified information to an adversary for several different unauthorized disclosure scenarios. Those cliscussions may be more applicable to unauthorizerd disclosures of classified scientific or terhnical information concerning major classified projects than to unauthorized disclosures in other situations." However, the basic principles should be applicable to most types of classified information and unauthorized disclosure scenarios. It should be noted that estimates of effective classification duration based on unauthorized disclosures are applicable to Restricted Data and Formerly Restricted Data as well as to NSI.

The material in this appendix is discussed in a very qualitative manner and does not encompass all possible scenarios. The information presented is intended to stimulate further discussions about the possibility of estimating classification duration based on the number of persons who know the classified information and on other factors. This information may be useful in developing guidelines for specific types of classified information that state that this information should be considered for declassification when it becomes known to more than a certain number of authorized persons (cleared persons with a need to know). Similarly, this information may be useful in developing guidelines, based on the number of persons authorized to know the information, for downgrading some types of classified information.

Estimates of the probabilities of unauthorized disclosures by different scenarios may be of significant assistance to classification management and security personnel. Such estimates may identify, for specific classified projects, activities, or technologies, certain scenarios as having unacceptable risks of unauthorized disclosure of classified information. Classification management personnel can then channel their classification education and document review efforts toward reducing those major vulnerabilities. Security personnel can also use those estimates to allocate their resources.

The discussion in this appendix does not include "second order" effects. That is, the discussion has not considered the increased unauthorized disclosure when a recipient of an unauthorized disclosure of classified information includes that information in an original communication prepared and disseminated by that recipient.

\footnotetext{
"The author is more familiar with classification of scientific or technical information than with operational types of information and, having come from the ranks of research scientists, is aware of the propensity of scientific and technical personnel to discuss their work with their colleagues and peers.
} 


\section{PROBABILITY OF DELIBERATE UNAUTHORIZED DISCLOSURE TO AN ADVERSARY}

The probability of a deliberate unauthorized disclosure of classified information to an adversary government $(P D D)$ is a linear function of the number of persons who know that information. That is, if ten persons know the information, then the probability of that information being deliberately disclosed is ten times the probability of that information being deliberately disclosed when only one person knows the information. The mathematical equation for that probability is

$$
P D D=k_{1} \times N P,
$$

where $P D D$ is the probability of deliberate unauthorized disclosure of classified information to an adversary government, NP is the number of persons who know that information, and $k_{1}$ is the probability that one person will deliberately disclose classified inforination to an adversary government (a "disloyalty" constant). The constant $k_{1}$ is assumed to be the same for all persons." Based on the number of U.S. citizens with security clearances who have deliberately revealed classified information to foreign governments in recent decades (as publicly reported), $k_{1}$ might be on the order of $10^{-5}$ (1 spy in 100,000 cleared citizens). ${ }^{\dagger, \pm}, \cdots,+\dagger$

Deliberate unauthorized disclosures are direct disclosures. The classified information goes directly to someone not authorized to receive that information. Whether deliberate disclosures are oral or written is not important-those deliberate disclosures get directly to an adversary foreign government.

\footnotetext{
"This should be a reasonable assumption since each person who is authorized to know the classified information has a security clearance. If there was any reason to suspect that a person might be likely to deliberately reveal classified information, then that person should not be given a security clearance and, therefore, should not have access to that information.

If one considered that every "leak" of classified information in Washington, D.C., was a deliberate unauthorized disclosure of classified information, then this constant might be on the order of $10^{-4}$ or $10^{-3}$. However, perhaps those leaks are really unofficial authorized disclosures or perhaps the leaked information is not truly classified since it seems that few "leakers" are punished via administrative actions by the Executive Branch or by the legal system. Leaks are not considered as unauthorized disclosures in this appendix.

tOne should not assume that there is a great deal of accuracy in this value or in the values for other constants given later in this appendix. Those values are approximate values given to help discuss the principles proposed in this appendix. Those values may perhaps be accurate to within a factor of 10 of the true value.

"The government to some extent controls the value of this constant by controlling the security clearance requirements (e.g., the extent of a background investigation) which must be met before an individual is given access to classified information.

${ }^{+}$For a 10-year period from about 1978 to 1988, the U.S. Department of Defense had on record 93 cases of detected espionage agents [M. C. Anderson, "The Hostile Intelligence Threat," J. Natl. Class. Mgmt. Soc., 25, 8-13, (1989) p. 12].
} 


\section{PROBABILITY OF INADVERTENT UNAUTHORIZED DISCLOSURE TO AN ADVERSARY}

Inadvertent unauthorized disclosures occur by mistake. They occur during communications (either oral or written) between persons. The probability that an inadvertent unauthorized disclosure of classified information will occur and will subsequently reach an adversary government depends on several factors. That probability, PID (probability of inadvertent unauthorized disclosure to an adversary government), depends directly on the number of different "unclassified" communications that inadvertently contain classified information, the number of such communications that reach an unauthorized person, and the probability that such an unauthorized recipient will transmit the classified information to an adversary government. The general outline for determining PID for a classified project will be given in the following paragraphs. Subsequent sections in this appendix will discuss this probability in more detail for some common inadvertent unauthorized disclosure scenarios.

When an unclassified communication is originated and transmitted by a person associated with a classified project and that person knows classified project information, then there is always a probability that such a communication will inadvertently contain classified project information. For a classified project, the total number of different (i.e., separate and distinct) unclassitied communications (i.e., intended to be unclassified but which might contain classified information) issued during the course of a year by persons associated with that project is equal to the number of persons working on that project who know classified project information (NP), multiplied by the average number of different communications per such person per year (NCOM). "This product represents the total number of communications by project personnel in which unauthorized disclosures concerning that project have the opportunity to appear during that year.

Whether or not an unclassified communication actually contains classified information when originated depends on the carelessness of the person who generates that communication. Multiplying the total number of communications per year $(N P \times N C O M)$ by a "carelessness constant," $k_{c}$, which expresses the probability that a project person will inadvertently include classified information in an unclassified communication, gives the number of communications that contain classified information when they are originated (but before they are issued).

The number of unclassified communications that inadvertently contain classified information when issued can be significantly reduced by a review of those communications by classification experts before they are issued. Such classification management procedures are particularly effective for written communications but are less successful for oral communications (see later in this appendix). Therefore, a classification review factor (CREV), should be included which incorporates the effectiveness of classification review procedures in reducing the inadvertent disclosure of classified information. As used in this discussion, $C R E V$ expresses the probability that classification experts will overlook classified information during their classification review of a communication (i.e., this factor represents the probability that the classified information will escape detection and removal by a classification

\footnotetext{
"The deliberate disclosure scenario presumed that NCOM was one. Only one communication is necessary when that communication is directly from a spy to an adversary government.
} 
expert). Effective classification management procedures result in low values for CREV. If there is no review by classification experts, then $C R E V=1$.

The total number of different unclassified communications that are issued during a year by personnel working on a classified project and which actually contain classified information, $N C O M C L$, is represented by the following equation:

$$
N C O M C L=\mathrm{k}_{\mathrm{c}} \times N P \times N C O M \times C R E V .
$$

The number of such communications that will actually reach unauthorized persons depends on the total number of distributed copies of such communications and the probability that one of those distributed communications will be obtained by an unauthorized person. The total number of distributed copies of communications containing classified information is equal to the number of different such communications, NCOMCL, multiplied by COP, the average number of distributed copies of each different communication. ${ }^{\dagger}$ The probability that one of those communications will reach an unauthorized person is expressed by the probability factor $U A R$ (unauthorized recipient). ${ }^{\ddagger}$

Even if an unclassified communication that inadvertently contains classified information reaches an unauthorized recipient, it is not a certainty that this recipient will transmit the classified information to an adversary government. Therefore, the equation for the probability that an inadvertent unauthorized disclosure will occur and will reach an adversary government, $P I D$, must include the probability that an unauthorized recipient will transmit the classified information to an adversary government. This latter probability is expressed by the probability factor RTA (recipient to adversary)." The overall equation for PID can therefore be written as follows:

$$
P I D=\mathrm{k}_{\mathrm{c}} \times N P \times N C O M \times C R E V \times C O P \times U A R \times R T A .
$$

As is evident, $P I D$ is a linear function of $N P$, the number of persons who know the classified project information.

There are two major types of inadvertent unauthorized disclosures, direct and indirect. Within each of those types, there can be either oral or written disclosures. The following sections will discuss values for the terms in the above equation for PID for four different unauthorized disclosure scenarios (direct-oral; direct-written; indirect-oral; indirect-written).

\footnotetext{
The classification review factor is set equal to one for the deliberate disclosure scenario. A spy is not going to have a Classification Office review the communication to an adversary government before the communication is sent to that government.

For the deliberate disclosure scenario, the value tor COP was presumed to be 1 . Only one copy of a communication from a spy to an adversary government is needed to transmit the classificd information.

This factor is presumed to have a value of 1 for the deliberate disclosure scenario.

"The value for RTA was presumed to be 1 for the deliberate disclosure scenario.
} 


\section{Probability of Inadvertent Direct Unauthorized Disclosure to an Adversary}

An inadvertent direct unauthorized disclosure occurs when a person working on a classified project communicates classified information directly (by mistake, in a communication intended to be unclassified) to a person not authorized to receive that information. This unauthorized disclosure can be by an oral or written communication to a colleague not working on the classified project, orally to a friend or neighbor, to many persons via an article in a professional journal, or by other similar means. The probability of inadvertent direct unauthorized disclosure $(P I D D)$ is expressed as follows:

$$
P I D D=\mathrm{k}_{2} \times N P \times N C O M \times C R E V \times C O P \times U A R \times R T A,
$$

where $k_{2}$ is a "carelessness" constant, the probability that a person working on a classified project will inadvertently disclose classified project information by this scenario, and the other terms are as defined earlier. This carelessness constant $k_{2}$ is expected to be greater than the disloyalty constant $k_{1}$ because there seem to be more careless people than espionage agents. That constant is also assumed to be the same for all individuals who have access to classified information (i.e., who have the same clearance levels). ${ }^{\dagger}$ Therefore, if $k_{1}$ is about $10^{-5}$, then $k_{2}$ might be expected to be on the order of $10^{-4}$ or $10^{-3}$. If there are 100 times fewer disloyal persons than careless persons, then $k_{1}$ would be about $10^{-3}$.

The carelessness constant $k_{2}$ is likely to be larger for oral disclosures than for written disclosures. Writers generally review their communications before they are sent and may thereby discover and correct any classification errors. There is no opportunity to review and delete spoken words. ${ }^{\ddagger}$ It might be reasonable to assume that the oral carelessness constant, $k_{2}(o)$, is ten times larger than the written carelessness constant, $k_{2}(w)$ [e.g., $k_{2}(o)=10^{-3} ; k_{2}(w)$ $\left.=10^{-4}\right]$.

Possible values for NCOM, the average number of different communications per project person, must be estimated for each specific classified project. The average number of copies of each communication, COP, also must be estimated for each project. For oral disclosures, $C O P(o)$ could vary from one (a one-to-one communication) to several hundred or more (via a presentation at a large meeting). For written disclosures, $C O P(w)$ could vary from one (a letter to a colleague) to several thousand (an article in a professional journal).

\footnotetext{
As mentioned earlier, for the purposes of this appendix the recipients of an unauthorized disclosure are assumed to not have security clearances.

IIf there was a specific reason why an individual would be expected to be more careless than "normal," then that person should not be given a security clearance.

${ }^{\ddagger}$ However, the written disclosure may cause greater damage to national security. An oral disclosure is transient, and adverse impacts depend mostly on a malefactor overhearing the conversation. A written disclosure is permanent (unless the document is recalled) and is available to anyone who can obtain and study the document. Because the document is not protected as a classified document, the "anyone" can include an uncleared person who is also a spy. The effects of prolonged availability of written communications are included in other factors which will be discussed later in this appendix.
} 
Within the Department of Energy (DOE) and its contractors, the probability of inadvertent direct unauthorized written disclosures, $P I D D(w)$, is significantly reduced by classification management procedures. DOE requires that all written unclassified scientific and technical communications related to a classified project and intended for widespread internal distribution or for public release must be reviewed by a Classification Officer prior to distribution of those communications. ${ }^{\circ 2}$ Sometimes an organization's procedures will also require a review by an Authorized Derivative Classifier (ADC) prior to the Classification Officer review. Presumably those reviews would detect most inadvertent (careless) direct disclosures via writings. Assuming ADCs to be about $99 \%$ accurate in their reviews, that Classification Officers are about $99.9 \%$ accurate in their reviews, and that the classification management system functions as intended (the documents are actually reviewed prior to their release), then the value of the classification review factor, $C R E V$, would be expected to be about $10^{-2}$ (ADC review) or $10^{-5}$ (Classification Officer and $A D C$ review) for the inadvertent direct unauthorized written disclosure scenario.

The DOE classification management program also requires a similar classification review for formal oral presentations. However, this review is usually limited to a review of the view graphs, slides, abstracts, and handouts that are used for these oral presentations. It is difficult to control the impromptu oral statements that are a part of those presentations, especially those made during the question and answer perions after the formal presentations. The classification review factor for oral presentations will be greater than for written presentations [e.g., $C R E V(o)$ may be about $10^{-1}$ to $10^{-2}$ ].

In the inadvertent direct unauthorized disclosure scenario, the recipient of the information disclosed is an uncleared individual (by definition of the scenario). Therefore, $U A R$, the probability that an unauthorized person will receive the communication, is equal to 1 . The "recipient to adversary" factor, $R T A$, which is the probability that the recipient of the unauthorized disclosure will send the classified information to an adversary government, must be estimated. In the ideal situation, the recipient would not recognize that the disclosed information was classified, or would not otherwise recognize its importance, and would not disseminate that information further or use it in any manner adverse to U.S. interests. In the worst case situation, the recipient would be a foreign agent who would recognize the significance of the information and transmit it to an adversary government.

Earlier, for the deliberate disclosure situation, it was assumed that about 1 in every 100,000 persons who had a security clearance would be an espionage agent. For the inadvertent direct disclosure situation, the question is "What is the probability that an uncleared individual who received the classified information would reveal that information to an adversary government (i.e., what is the probability that the uncleared individual is a spy)?" If $80 \%$ of the persons who apply for a security clearance get that clearance (a not unreasonable assumption), then there is only about a $20 \%$ greater probability that an individual member of the general population is an espionage agent, as compared with the probability that a cleared individual is an espionage agent. ${ }^{\dagger}$ For the current probability

\footnotetext{
The author is under the impression that the Department of Defense has similar requirements.

However, that may not be a valid assumption since perhaps a spy would not apply for a job requiring a security clearance because the spy would fear that a background check would reveal some activities that would lead to identification of that person as a spy. On the other hand, it may be valid because in recent years most of the persons who have been identified as spies became spies after they gained access to classified information [M. C.
} 
estimations, a $20 \%$ increase is minor when considering the other uncertainties in these estimates. Therefore, it will be assumed that the probability that a member of the general public is an espionage agent is about 1 in 100,000 . Based on that assumption, the risk that the recipient of an inadvertent direct disclosure would send the classified information to an adversary would be about $10^{-5}\left(R T A=10^{-5}\right)$. However, this view neglects possible real-life situations where persons working on classified projects might be targeted by adversaries. Such a person's national or international colleagues might include individuals who gather intelligence for adversary governments. That circumstance might significantly increase the value of $R T A$ to about $10^{-2}$ or $10^{-3}$. If the written communication was via a professional journal or other widely circulated publication and the author was well known as a participant in classified projects, then the probability that an agent of an adversary government would read the article would be expected to be very nearly 1 . Generally, RTA might range from about $10^{-2}$ to $10^{-5}$ for these scenarios.

The overall probabilities of inadvertent direct unauthorized oral or written disclosures, $P I D D(o)$ and $P I D D(w)$, may be written as follows:

$$
\begin{gathered}
P I D D(0)=\mathrm{k}_{2}(0) \times N P \times N C O M(0) \times \operatorname{CREV}(0) \times \operatorname{COP}(0) \times \operatorname{RTA}(0) ; \\
P I D D(w)=\mathrm{k}_{2}(w) \times N P \times N C O M(w) \times \operatorname{CREV}(w) \times \operatorname{COP}(w) \times R T A(w) .
\end{gathered}
$$

As mentioned previously, $U A R(0)$ and $U A R(w)$ have a value of 1 , by definition of the scenario, and are not included in the above equations.

\section{Probability of Inadvertent Indirect Unauthorized Disclosure to an Adversary}

The indirect type of inadvertent unauthorized disclosure of classified information occurs by scenarios somewhat like the following scenario (all steps in the following scenario must occur for an unauthorized disclosure to occur by that scenario):

1. A person who knows classified information about a classified project communicates with one or more persons who also know the classified information (e.g., with a colleague on the project).

2. The communication is directly related to the classified project but is intended to contain only unclassified information about that classified project.

\footnotetext{
Anderson, "The Hostile Intelligence Threat," J. Natl Class. Mgmt. Soc., 25, 8-13, (1989) p. 12]. Then again, maybe the general populace is much more trustworthy in this regard, because the spies may have been subjected to "recruitment" pressures to which a member of the general public would not be subjected.

"This would mean that in the current U.S. population there would be about 2500 espionage agents. That value seems rather high. However, to assume a lower probability than $10^{-5}$ would mean reaching a conclusion that the probability that a person in the general population is an espionage agent is lower than the probability that a cleared person is an espionage agent. Such a conclusion would not speak very highly of our system for granting security clearances.
} 
3. The mode of communication is unclassified (e.g, via an unclassified writing, by using an unsecure telephone, by an unsecure electronic mail message, or orally in a nonsecure area).

4. The unclassified communication actually contains (by mistake) classified information.

5. The unclassified communication is also received (e.g., overheard) by a person not authorized to receive the classified information contained therein (i.e., by an uncleared person).

In this scenario, the communication (either oral or written) is between individuals with the appropriate security clearance. That communication is intended to be unclassified (the communicator knows that classified information should not be included in that communication since the communication is via a unsecure mode). However, an inadvertent unauthorized disclosure of classified information occurs because some classified information about the classified project is inadvertently included in the intended-to-be-unclassified communication. This disclosure is termed an "inadvertent indirect unauthorized disclosure" because one of the eventual recipients of the communication was not an intended (direct) recipient of the communication (e.g., the indirect recipient overheard a conversation or by chance saw a written communication addressed to another person).

Probability of Inadvertent Indirect Unauthorized Written Disclosure. An inadvertent indirect unauthorized written disclosure of classified information occurs, for example, when a person working on a classified project prepares, for primary distribution to someone else working on this project, an unclassified document concerning the project. The writer intends to convey substantive information about the project but also intends that this information be unclassified. Unfortunately, when a writer tries to "cleverly" convey substantive information about a classified project in an unclassified document, the writer inadvertently may reveal some classified information." Other times, the writer simply makes a mistake (i.e., when not even trying to be clever about conveying information) and inadvertently includes classified information in the document. In either case, because the document is not marked as classified then its subsequent distribution is not necessarily limited to cleared persons. The document is likely to become available to persons not authorized to receive the classified information (e.g., the primary recipient may send the document to nonproject personnel; the document may be put into the company's library and become available to many persons; or the document may subsequently be made available to auditing, regulatory, or similar nonproject personnel). When this happens, an unauthorized indirect disclosure of classified information has occurred.

The probability of inadvertent indirect unauthorized written disclosures $P I I D(w)$ is expressed by the following equation:

\footnotetext{
A 1959 Atomic Energy Commission Classification Bulletin included a discussion of the dangers of the use of code words or pseudocodes by authors trying to convey, in an unclassified document, information absut a classified project. That bulletin contained the foltowing statement: "Perhaps worst of all is the use of codes and/or pseudocodes together with obscure language in an effort to avoid the necessity of classifying a document. It may be easier to mystify the recipient than a clever espionage agent."
} 


$$
P I D D(w)=\mathrm{k}_{3}(w) \times N P \times N C O M(w) \times C R E V(w) \times C O P(w) \times U A R(w) \times R T A(w) .
$$

All the factors have been mentioned previously. The carelessness constant $k_{3}(w)$ in this scenario is expected to be greater than in the direct disclosure sce-surio. In the direct disclosure scenario, the writer was communicating with someone not associated with the classified project and therefore the writer would generally be expected to be quite sensitive to not including classified information in the communication. In the current scenario, the writer is communicating with someone on the classified project about the classified project and, even though the communication is intended to be unclassified, the writer is likely to be more careless about not including classified information. The fact that the subject of the document concerns the classified project is also likely to lead to classification errors. Therefore, whereas $k_{2}(w)$ was estimated to be about $10^{-4}, k_{3}(w)$ is estimated to be about $10^{-3}$.

The classification review factor $C R E V$ will also be greater for the current scenario. For the direct disclosure scenario, the value for $C R E V$ was expected to be between about $10^{-2}$ to $10^{-5}$, depending on whether the written document received one or two classification reviews. In the current scenario, the document would receive, at most, one classification review, and therefore CREV will be about $10^{-2}$ or greater (CREV would have a value of 1 for no classification review)."

It is difficult to estimate a value for the factor $U A R$, the probability that an unauthorized person will read the communication that contains the classified information. In this scenario, the direct recipients of the communication (those on the distribution list) are persons connected with a classified project. If the original distribution is limited to persons closely connected to the project, then the probability that an unauthorized person would read the communication might be quite low (e.g., persons closely connected with the project would be expected to have their offices in secure areas; unauthorized persons would not have access to those areas and therefore would not have the opportunity to see the communication by chance). If the communication is widely distributed and sent to persons only peripherally connected with the project, then $U A R$ might be relatively high (e.g., persons with peripheral connections to the project might be located in areas accessible to uncleared persons, with concurrent increased probability that an uncleareu person would see the communication). The extent to which secondary distributions are made of the communication is also a factor. ${ }^{\dagger}$ A communication that covers a broad topic might receive a relatively large secondary distribution. If the communication became part of a company library (e.g., a "reports" library), then the $U A R$ factor might be relatively large. A value for $U A R$ of $10^{-2}$ to $10^{-3}$ will be assumed for this scenario.

The factor that represents the probability that the recipient of the disclosure will transmit the classified information to an adversary, $R T A$, may be larger for an inadvertent indirect

\footnotetext{
"There could be an "indirect" classification review in this scenario. The primary recipients of the communication are cleared individuals. If classified information appears in the communication, then one of the cleared primary recipients might recognize the classified information and have the document recalled before it reached an unauthorized recipient. The better the classification education in a project, the greater the probability that indirect classification review will detect the classified information.

tSecondary distributions are a much greater problem now than they were several fecades ago, because of the ease of access to copying machines and the ease of forwarding electronic mail messages.
} 
written unauthorized disclosure than was the case for an inadvertent direct written unauthorized disclosure. The reason for that increase is because an adversary may target all available unclassified written communications about a classified project. Written communications, because of their permanence (copies stay in personal files or in libraries for a long time) are especially likely to be accessed by an adversary. Therefore, $R T A(w)$ for this scenario may be as high as about $10^{-1}$ and may be as low as $10^{-5}$.

Probability of Inadvertent Indirect Unauthorized Oral Disclosures. Inadvertent indirect unauthorized oral disclosures of classified information occur when persons working on a classified project discuss this project, in nonsecure locations, with their colleagues who also work on that classified project. Such discussions may occur at nonsecure workplace areas such as while eating in the company cafeteria, walking between secure workplace areas, riding in vehicles between secure workplace areas, or at other nonsecure locations in the workplace. Such discussions may occur during work-related travel (e.g., in airport waiting rooms, on airplanes, in taxis, or in restaurants). Such discussions may occur in carpools traveling to and from the workplace. Such discussions may also occur during social functions in the community where the workplace is located (e.g., when two colleagues on the project meet and one tries to convey, in an unclassified oral communication, recent significant project developments). In each of the above situations, the persons communicating with each other are aware that they should not mention classified information. However, sometimes they simply make a mistake, a "slip of the tongue," and reveal classified information. Other times they try to talk around classified information and inadvertently reveal classified information. ${ }^{3}$ Unfortunately, most persons are not adept at talking around classified information. Therefore, classified information may be revealed during such conversations and that classified information may be overheard by persons not authorized to receive that information.

The equation to estimate the probability of inadvertent indirect unauthorized oral disclosures to adversaries $P I I D(o)$ contains the same factors as did the equation for $P I I D(w)$ :

$$
P I D D(0)=\mathrm{k}_{3}(0) \times N P \times \operatorname{NCOM}(0) \times \operatorname{CREV}(0) \times \operatorname{COP}(0) \times \operatorname{UAR}(0) \times \operatorname{RTA}(0),
$$

where $k_{3}(o)$ is a "talkativeness" constant ${ }^{\dagger}$ that may be significantly higher than $k_{2}(0) .^{\ddagger}$ If $k_{1}$ is approximately equal to $10^{-5}$ and $k_{2}(o)$ is approximately equal to $10^{-3}$, then $k_{3}(0)$ may have a value of about $10^{-2}$.

In the other scenarios, the average number of communications per person per time period NCOM was to be estimated for each case and was assumed to be relatively small since those communications are usually planned and usually, at least for written communications, require more than a little time and effort to prepare. For those scenarios, NCOM does not

\footnotetext{
" "If you were to add up all the information that you get at a cocktail party, you might find that there is an awful lot of classified information there" [S. Fernbach, "Panel-Science and Technology, and Classification Management," J. Natl. Class. Mgmt. Soc., 2, 48-53, 50-51 (1966)].

Designated a "talkativeness" constant, because persons like to discuss their work with colleagues, and these discussions frequently occur when they chance to meet and in places that are not secure.

FPersons are usually more careful with respect to classified information when they are communicating with a person not authorized to receive that classified information than they are when discussing an unclassified aspect of a classified project with colleagues in an unsecure location.
} 
seem to depend on any "general" factor and must be estimated for each casc. The total number of communications NCOM(tot) was equal to NP $\times$ NCOM. However, in the current scenario, the total number of communications depends on the number of interactions (in nonsecure locations) between different persons who know the classified information. These interactions are not generally planned, as was the case with writings, but occur somewhat randomly. At each meeting between project colleagues, there is the opportunity to communicate and, generally, the expectation that there will be some information exchanged (i.e., greetings, small-talk, etc.) which may lead to discussions about the project. The number of theoretically possible interactions, $I$, between different persons in a group of persons who know classified information about a project, is given by the following equation:

$$
I=\frac{N P(N P-1)}{2}
$$

where NP is the number of persons who know the classified information (see Fig. G.1 for help in visualizing the situation). The interactions calculated by this equation are the "instantaneous" number of possible interactions, and an additional parameter must be introduced to estimate the number of interactions in a specified time period. The number of probable interactions during a relatively short time period will be significantly less than the number of possible interactions." Therefore, the parameter $I$ should be multiplied by another parameter, $\mathrm{k}_{\mathrm{l}}$, an interaction constant, to get a realistic estimate for the number of probable interactions (communications). This $\mathrm{k}_{\mathrm{l}}$ should also include time as a variable so that the number of communications can be estimated for any time period (e.g., for 1 year). For this unauthorized disclosure scenario, the total number of communications, NCOM(total), can be expressed by the following equation:

$$
N C O M(\text { total })=\mathbf{k}_{\mathrm{I}} \times I=\mathbf{k}_{\mathrm{I}} \times \frac{N P(N P-1)}{2} .
$$

According to this equation for NCOM(total), if only one person knows the classified information, then the number of inadvertent indirect oral disclosures by this scenario is zero $(N P-1=0)$, an answer consistent with Ben Franklin's adage that "three may keep a secret if two of them are dead." 4 Note that for high values of NP (practically speaking, above about $N P=50$ ) the value of $N C O M($ total) essentially varies with the square of $N P$. Thus $P I I D(O)$ is approximately a function of the square of $N P$, the number of persons who know the classified information. When $N P$ increases by a factor of $10, P I I D(o)$ will increase by a factor of 100 . The probabilities for the other scenarios mentioned above vary only linearly with NP. The significance of this is that even though the number of probable interactions may be only a small fraction of the number of possible interactions (i.e., $\mathrm{k}_{\mathrm{l}}$ may be small), when $N P$ becomes large, the total number of probable interactions may become very large (since it varies with the square of $N P$ ). Consequently, when $N P$ is large, then $P I I D(o)$ may become

\footnotetext{
The number of probable interactions depends on the opportunity for interaction. For large projects, each person does not normally have the opportunity to interact with all of the other persons working on that project.
} 


\section{OWG. NO. K/G-93-2161/RA}

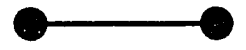

2 persons

1 interaction

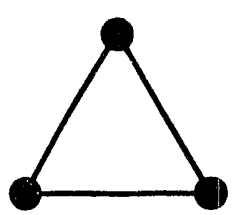

3 persons

3 interactions

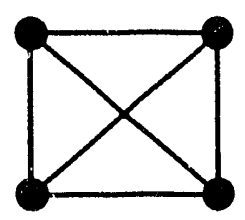

4 persons

6 interactions

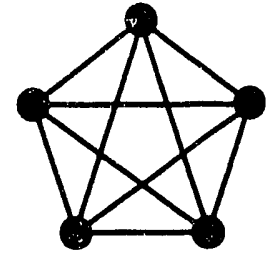

5 persons 10 interactions

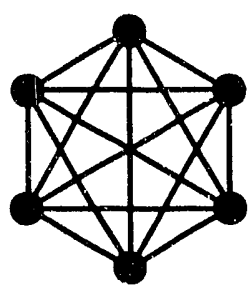

6 persons 13 interactions

\section{0 persons $\rightarrow 45$ interactions \\ 20 persons $\rightarrow 190$ interactions \\ 50 persons $\rightarrow 1225$ interactions \\ 100 persons $\rightarrow 4950$ interactions \\ 1000 persons $\rightarrow$ 499,500 interactions}

Fig. G.1. The possible number of interactions I betwoen NP persons. $I=N P(N P-1) R$

larger than the other probabilities and this scenario may be the major route by which unauthorized disclosure of classified information occurs.

As mentioned ea-lier, the number of probable interactions depends on the opportunities for interaction. For large projects or activities (e.g., 10,000 persons), each person usually neither knows of, nor has the opportunity to interact with, all of the other persons working on that project. Therefore, $\mathbf{k}_{\mathrm{l}}$, the interaction constant, in the above equation for $N C O M$ (total) might be relatively small. For small projects (e.g., 100 persons), each person might know most of the other persons working on that project and might interact relatively frequently in nonsecure locations with many of those persons. Therefore, $k_{1}$ might be significantly higher for small projects than for large projects. Another way of examining the situation would be to assume that there is generally a maximum practical value for $N P$, with 
respect to interactions between persons working on a project. That is, even if NP is equal to 10,000 persons, in practice one person probably does not usually interact with more than, for example, a few hundred persons. Therefore, $\mathrm{k}_{\mathrm{I}}$ could be assumed to be relatively constant, but NP may be assigned a limiting maximum value (c.g., 100) in the equation for $N C O M$ (total) for this scenario." The latter method for evaluating $N C O M$ (total) seems the easicr. A value for $\mathrm{k}_{\mathrm{l}}$ could be obtained by estimating a value for $N C O M($ total) for a case where $N P$ has a value of 100 or less. For example, when $N P=100$, then the number of possible instantaneous interactions is $\mathbf{4 9 5 0}$. One might do a survey (e.g., over a week's period of time) to estimate how many interactions, in nonsecure locations, take place between members of a specific group that includes about 100 persons. This could be then be extrapolated to obtain the number of such interactions for 1 year, and thereby one could estimate an approximate value for $k_{l}$.

In the previous scenarios (except for the deliberate disclosure scenario), the value for the number of copies factor, COP, depended on the specific case. However, in the current inadvertent indirect oral unauthorized disclosure, there is assumed to be only one copy of a communication (i.e., the conversation is assumed to be overheard by an average of only one unauthorized persons). Therefore, $C O P=1$ for this scenario.

In this inadvertent oral disclosure scenario, there is no opportunity for classification review of the conversation before it is overheard-the Classification Officer did not even known that such a conversation would take place. Therefore, similar to the deliberate disclosure scenario, the classification review factor $C R E V=1$.

The probability that an uncleared person will overhear the unauthorized oral disclosure, $U A R$, is difficult to estimate. That probability may be relatively small (e.g., $10^{-4}$ to $10^{-5}$ ) when the disclosure occurs in nonsecure areas of the facility that houses the classified project, since many of the persons in those workplace areas would be expected to have clearances. That probability would be expected to be greater when the disclosure occurs in public locations, such as in public transportation (airplanes) or in community social situations (cocktail parties). Values for $U A R$ might range from $10^{-2}$ to $10^{-1}$ in those latter situations.

The probability that a recipient of an unauthorized oral disclosure will transmit it to an adversary has about the same range of values as mentioned earlier for other scenarios. Thus, $R T A$ might vary from $10^{-5}$ (random probability that the recipient is a spy) to $10^{-2}$ [when a foreign agent targets community gathering plases frequented by project workers (e.g., bars or taverns) or community organizations or social circles to which project workers belong].

\section{COMPARTMENTALIZATION OF CLASSIFIED INFORMATION}

Under the above-mentioned hypothesis for estimating the probability of inadvertent indirect unauthorized oral disclosure of classified information $P I I D(O)$, that probability is

\footnotetext{
"Another way of examining the situation would be to consider an "effective" NP that would vary linearly with the actual $N P$ up to a certain value and then vary nonlinearly above that value. Thus, NP(effective) might equal $N P$ (actual) up to values of $N P$ (actual) $=100$, but then would be less than $N P$ (actual) for larger values such that when $N P($ actual $)=1000, N P($ effective $)$ might be only 300 or less.
} 
proportional to the number of different interactions between persons who know the classified information. The theoretical number of those interactions is approximately proportional to the square of the number of persons who know the classified information. Of course, the actual number of interactions depends on the opportunity to interact. If the persons who know the classified information are not all at one geographic location, but are individually widely dispersed, or are members of small groups that are widely dispersed, then the opportunities to interact are decreased and PIID $(o)$ will also be decreased.

If 1000 persons work on a classified project and those persons are widely dispersed geographically, then there are few opportunities for them to interact under the example situations described above. (If they were completely isolated, then $P I I D(o)$ would be zero.) However, if those 1000 persons were living in a single, relatively small community, there would be very many opportunities for interactions. If there were 10 groups with 100 persons in each group, and each group was isolated geographically from the other groups, the number of interactions would be intermediate between the two previously mentioned extremes. These examples may be summarized as follows:

\begin{tabular}{|c|c|c|}
\hline $\begin{array}{l}\text { Number of } \\
\text { isolated groups }\end{array}$ & $\begin{array}{l}\text { Persons per } \\
\text { group }\end{array}$ & $\begin{array}{l}\text { Total possible different } \\
\text { interactions }\end{array}$ \\
\hline 1000 & 1 & 0 \\
\hline 100 & 10 & 4,500 \\
\hline 10 & 100 & 49,500 \\
\hline 1 & 1000 & 499,500 \\
\hline
\end{tabular}

The above information indicates that there is a "dispersal" or "group size" effect that may significantly affect $P I I D(o)$.

The approximate tenfold reduction in probability in going from one group of 1000 to 10 isolated groups of 100 provides an approximate example of the value of compartmentalization (which was stringently practiced by Gen. L. R. Groves during the Manhattan Project) in greatly reducing the probability of inadvertent unauthorized oral disclosure of information." This dispersal, or compartmentalization, effect can be represented as a function of the number of groups into which NP persons are divided. For equal-sized groups and when NP

\footnotetext{
'However, General Groves' reasons for compartmentalization were not the same as those presented here. He wanted compartmentalization so that each person would not know any more classified information than he or she needed to know to do his or her job. Thus, if one person happened to be a spy, the amount of information at risk would be minimized. The reason given above for compartmentalizing classified projects is to significantly reduce the opportunities for, and, therefore, the probability of, inadvertent oral disclosure of classified information.

The Manhattan Project also provides an example of other benefits of isolating the communities in which many of the classified projects workers reside. As postulated above in this appendix, there is a significant risk that classified information will inadvertently be revealed via oral disclosures at locations or functions where project participants meet or socialize off the job. If entry into the community, which is the site of most of those locations or interactions, is stringently controlled for security reasons, then the probability that one of those unauthorized disclosures would be overheard by someone who would transmit the information to an adversary will be significantly reduced. The Manhattan Project had three such cities-Oak Ridge, Tennessee; Los Alamos, New Mexico; and Richland, Washington.
} 
is large, the maximum possible number of interactions $I$ is a function of $G^{-1}$, where $G$ is the number of equal-size groups onto which NP persons are divided.

$$
I=\frac{N P(N P-1)}{2 G}
$$

For actual situations, $I$ would have to be evaluated for each group and then summed to give an aggregate value for $I$. Note that from earlier discussions of the value of NCOM(total) for this scenario, the relative benefits of compartmentalization may be reduced when NP exceeds a certain value bec ause for large values of $N P$ self-compartmentalization may occur.

\section{GENERALIZED EQUATION FOR PRO:BABILITY OF UNAUTHORIZED DISCLOSURE OF CLASSIFIED INFORMATION TO AN ADVERSARY}

The probability $P$ of unauthorized disclosure of classified information to an adversary, for the scenarios mentioned above, can be represented by the following general equation:

$$
\text { Probability }(S)=\mathbf{k}_{s} \times N P_{s} \times N C O M_{s} \times C R E V_{s} \times C O P_{s} \times U A R_{s} \times R T A_{s},
$$

where $S$ represents the scenario, $\mathrm{k}_{\mathrm{s}}$ is a constant for that scenario, $N P$ is the number of persons who know the classified information, NCOM is the average number of communications per person per year, $C R E V$ is a classification review factor, COP is the average number of copies of a communication, $U A R$ is the probability that an unauthorized person would be the recipient of an unauthorized disclosure, and $R T A$ is the probability that the unauthorized recipient will transmit the information to an adversary government. Estimated values for some of those factors for the different scenarios mentioned previously are shown in Table G.1. Where values for the factors are given in Table G.1, they should be considered only as rough approximations. However, the relative values of those factors might be of more significance.

The generalized equation for the probability of unauthorized disclosures provides a simple, direct way to describe the factors important to protecting classified information. The equation shows, in a straightforward manner, that classified information about a project can best be protected by limiting the number of persons to whom that information is given (stringently enforcing need-to-know requirements), by minimizing the number of "unclassified" communications related to that project and generated by such persons, by minimizing the number of copies of such communications, and by requiring classification review of all job-related communications originated by project personnel. The generalized equation can also be used, as will be described in a subsequent section, to assist security personnel in concentrating their resources on the most vulnerable pathways for unauthorized disclosures of information from specific classified projects. Benefits of compartmentalization and isolated "project communities" are also directly shown by that equation. 


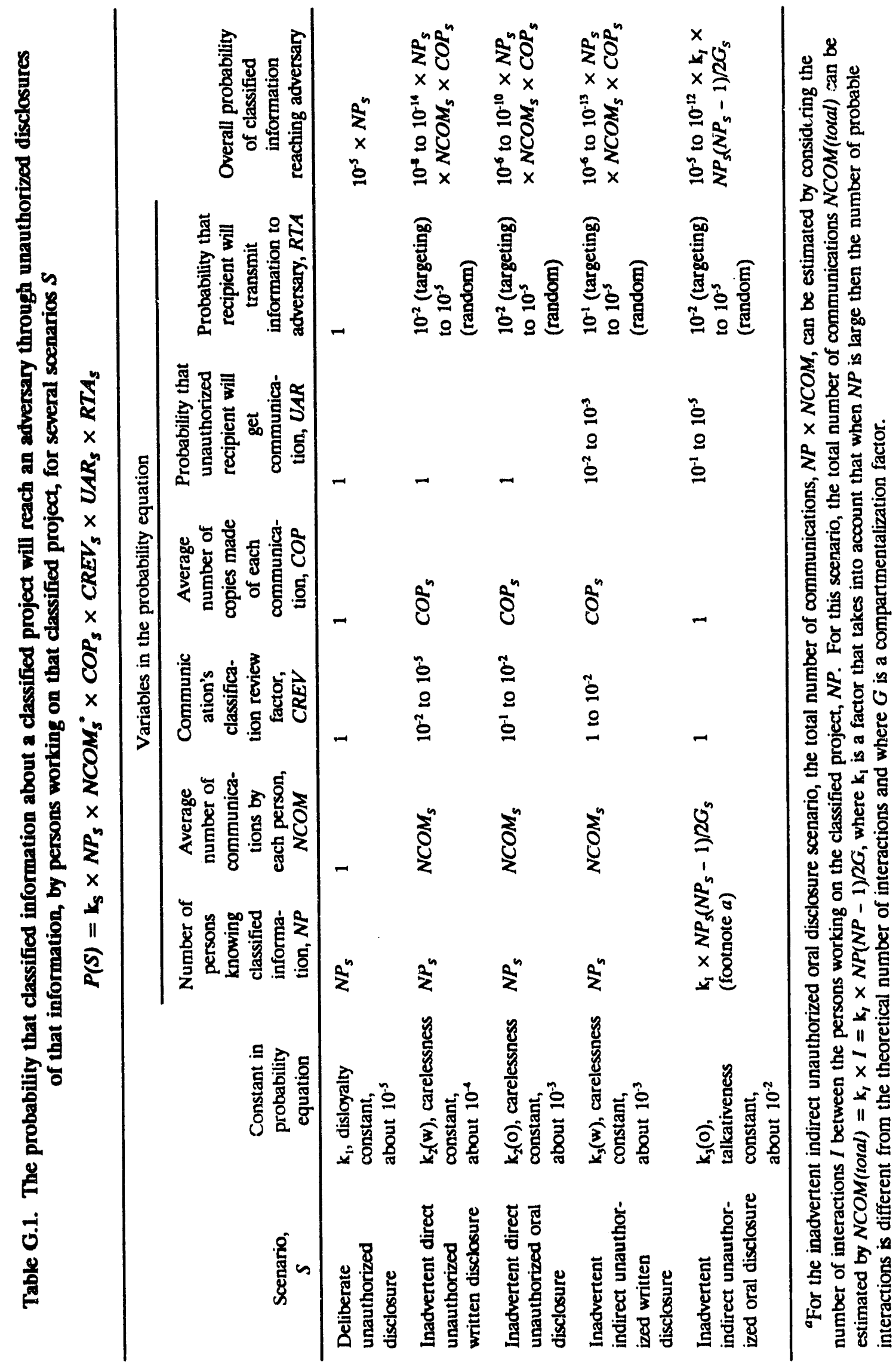




\section{CLASSIFICATION DURATION CONSIDERATIONS}

The above discussions with respect to probabilities of unauthorized disclosures of classified information were initiated for possible use in estimating the duration of classification. That is, when the number of authorized persons who have been given the classified information becomes large enough, the probability of unauthorized disclosure becomes great enough so that de facto declassification becomes likely. One could specify an acceptable value for this probability and concurrently establish a classification rule stating that whenever this probability was exceeded then the information should be declassified. By keeping records of the number of persons who know the classified information, then one could determine when the information should be declassified. Certain declassifications could perhaps be triggered when the cumulative number of persons who know the classified information exceeds a certain value, or when the person-years for knowledge of the classified information exceeds a certain value. It should not be too difficult to keep a record of the number of persons who know certain classified information and thereby to calculate, at any point in time, the number of persons to whom the classified information has been told and the value for the person-years parameter. Such an approach might also serve to emphasize the need-to-know requirement for access to classified information, a requirement which does not seem to have received as much emphasis in recent years as it should receive.

In practice, a classification duration is not likely to be established based only on the considerations presented in this appendix. There are currently too many uncertainties in the various factors to enable someone to responsibly base a classification duration decision on the disclosure probability equations given above. However, further investigations could lead to establishing some reasonably reliable values for those factors. Then, at the least, estimated probabilities of unauthorized disclosures could be used to determine when the information should be evaluated for possible declassification.

On the other hand, in principle there may be more of a basis for establishing a classification duration based on the number of persons who know the classified information than there was a basis for establishing a classification duration based on mere passage of time. Some executive orders on classification of information, prior to the currently applicable Executive Order 12356, established a requirement that certain types of classified information should be designated to be automatically downgraded and, in some instances, declassified after a certain number of years had elapsed from date of issuance. (See Chapter 8 for a brief discussion of automatic declassification and downgrading of NSI as a function of time.)

With respect to downgrading matters, a rationale similar to that given above for declassification might lead to the conclusion that, for example, for Top Secret information, when the number of persons who are authorized to know that information exceeds a certain value (say 1000), then the information should be downgraded to Secret. If the information is so important to national security to warrant a Top Secret classification level, then the number of authorized recipients of that information should be stringently limited to reduce the probability of unauthorized disclosure. Disclosure to a large number of persons indicates that maybe the information is no longer so important to national security and maybe it should be downgraded." In any event, as mentioned above for declassification, a certain value for

\footnotetext{
"It is perhaps interesting to note that when the Department of Justice is asked to investigate an unauthorized leak of classified information, frequently the first question asked is "Ilow many people had access to that
} 
the number of persons who know the classified information might be used to trigger a review of the information for downgrading even if that value was not used to automatically downgrade that information.

\section{CLASSIFICATION MANAGEMENT CONSIDERATIONS}

Classification management procedures can reduce significantly the probability that unauthorized disclosures of classified information will result from the issuance of unclassified documents by project personnel. Classification management procedures that include two independent classification reviews of all unclassified documents generated by personnel working on a classified project can reduce, by a factor of about $10^{-5}$, the probability that such documents will contain classified information. The "two-review" rule is a requirement at some contractor-operated DOE facilities for documents intended for release to the public. It would perhaps be advisable to have at least a "one-review" rule for all documents that touch on or concern classified projects, activities, or technologies. Such classification review procedures are less effective for oral presentations because those presentations are generaliy less structured and because impromptu remarks by the speaker (or startled reactions by a speaker to certain questions) are not subject to prior review by classification experts.

Classification briefings to employees working on classified projects can inform and remind those employees of the information that is classified. Such briefings could also emphasize how bits and pieces of seemingly innocuous project information are actually classified because that information, when combined with the information that has already been released as unclassified, can reveal classified information. Such briefings could sensitize employees to the importance of not revealing any information beyond that which they definitely know to be unclassified. Such briefings could reduce the "carelessness" and "talkativeness" constants and thereby reduce the probability of inadvertent direct and indirect disclosures of classified information.

\section{INFORMATION SECURITY CONSIDERATIONS}

Information security is concerned with protecting classified information. Information security resources should be directed toward reducing the probability of unauthorized disclosures for those disclosure scenarios that have the highest probabilities of unauthorized disclosure of classified information (e.g., toward protecting the most vulnerable routes for the unauthorized disclosure of classified information). The general equation for the probability of unauthorized disclosure of classified information can be used to evaluate probabilities for several disclosure scenarios for specific classified projects or facilities. Those estimated probabilities may reveal the most vulnerable routes for unauthorized disclosures. The resources of the security organization can then be focused on those routes.

information?" When the response indicates that several hundred persons had access to the classified information, then there will probably be no investigation because there are too many persons to investigate thoroughly [S. Garfinkel, "Information Service Oversight Office (ISOO) Panel," J. Natl Class. Mgmt. Soc., 24, 44-65, (1988) p. 52]. 
An evaluation of the probability equation for different disclosure scenarios, and the experience of this author with respect to unauthorized disclosures, suggests that efforts in briefing employees who work on classified projects on the dangers of inadvertent indirect unauthorized oral disclosures might be very productive. A recent article on security of industrial information (e.g., trade secrets) contains three pertinent observations which support this conclusion:

The most vulnerable form of information is still that which is spoken.

Information security managers should not develop controls against technological misuse [e.g., wiretapping] until they have successful baseline controls such as safeguarding paper trash and teaching employees to resist telephone deceptions.

Criminals tell me that there are far better ways to obtain information than electronic eavesdropping, such as finding it printed on paper or overhearing what people say.s

A 1988 article on industrial intelligence activities stated that Japanese companies "station people with tape recorders on commuter trains to pick up careless conversations. ${ }^{\circ 6}$ Knowing the right "social hour" was said to aid espionage agents in seeking England's trade secrets in the 18th century. ${ }^{7}$ "If you were to add up all the information that you get at a cocktail party, you might find that there is an awful lot of classified information there. ${ }^{n 8}$ Enough said.

\section{REFERENCES}

1. Executive Order 12356, Fed. Reg., 47, 14874 (Apr. 6, 1982), \$\$1.4, 1.5(4).

2. U.S. Department of Energy, DOE Order 5650.2B, "Identification of Classified Information," Chap. V, Part G.2.c (Dec. 31, 1991). (1987) p. 3.

3. R. G. Priddy, "Security: The Philosophical Bureaucracy," J. Natl Class. Mgmt. Soc., 23, 1-5,

4. Ben Franklin's Wit and Wisdom, Peter Pauper Press, Mt. Vernon, N.Y., p. 46. See also Poor Richard: The Almanacks for the Years 1733-1758, Van Wyck Brooks, ed., New York, Heritage Press, 1964, July 1735, p. 30, as reported by S. Bok in Secrets, Pantheon Books, New York, 1982, p. 108.

5. D. B. Parker, "Seventeen Information Security Myths Debunked," ISSA Access, Information Systems Security Association, Inc., Newport Beach, Calif., 3(1), (1990) pp. 1, 42-43.

6. E. M. Fowler, "Careers-Intelligence Experts for Corporations," The New York Times, 138(47,641) (Sept. 27, 1988), p. D23.

7. J. Harris, "Spies Who Sparked the Industrial Revolution," New Scientist, 110(1509), 42-47 (May 22, 1986), p. 43.

8. S. Fernbach, "Panel-Science and Technology, and Classification Management," J. Natl. Class. Mgmt. Soc., 2, 48-53 (1966), pp. 50-51. 

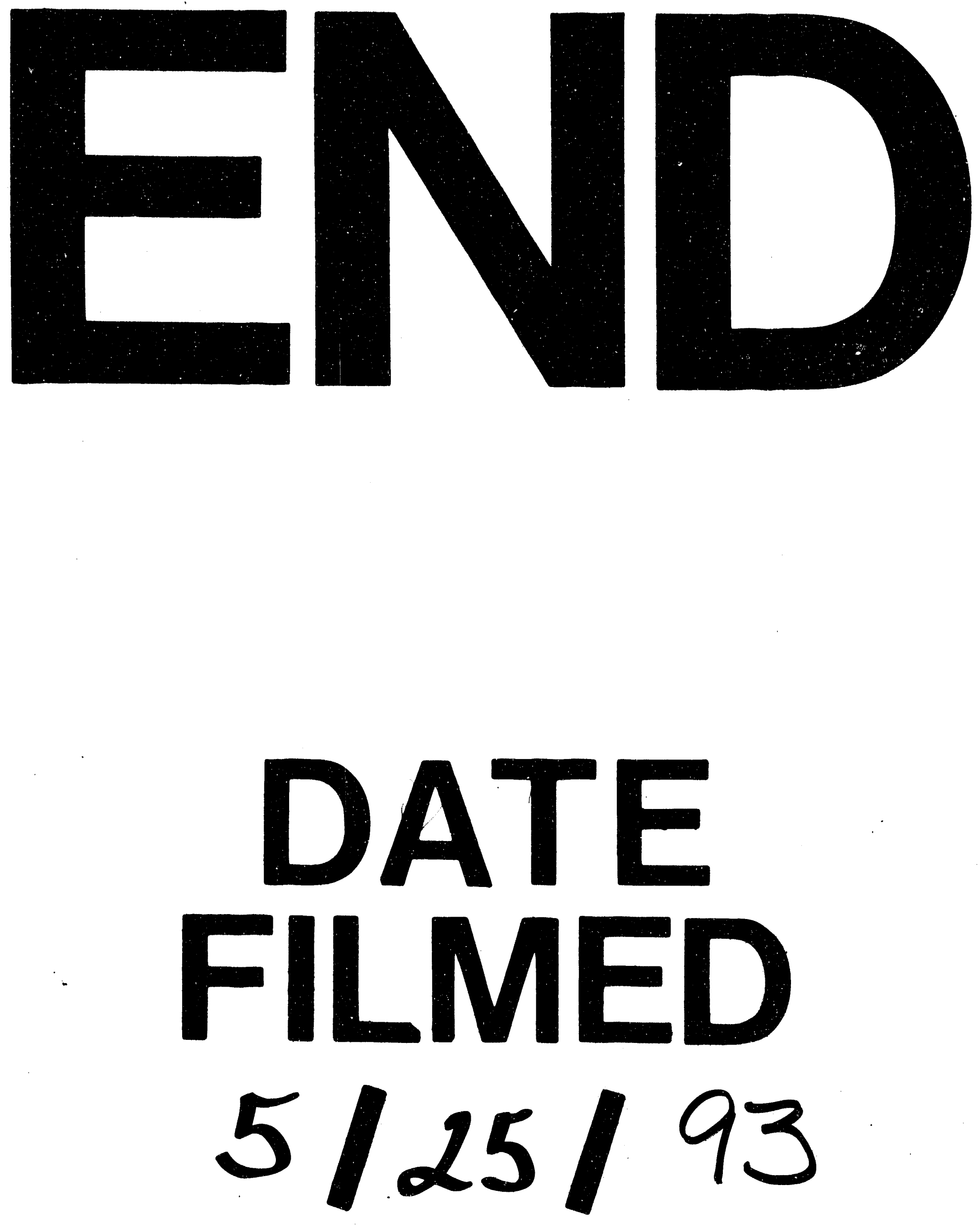
